\title{
INSTITUTIONS AND \\ ECONOMIC DEVELOPMENT
}

by

KWOK YING LAM

\author{
A thesis submitted to \\ The University of Birmingham \\ for the degree of \\ DOCTOR OF PHILOSOPHY
}

Department of Economics

College of Social Sciences

The University of Birmingham

November 2010 


\section{UNIVERSITYOF BIRMINGHAM}

\section{University of Birmingham Research Archive \\ e-theses repository}

This unpublished thesis/dissertation is copyright of the author and/or third parties. The intellectual property rights of the author or third parties in respect of this work are as defined by The Copyright Designs and Patents Act 1988 or as modified by any successor legislation.

Any use made of information contained in this thesis/dissertation must be in accordance with that legislation and must be properly acknowledged. Further distribution or reproduction in any format is prohibited without the permission of the copyright holder. 


\section{Synopsis}

This thesis composes of four empirical studies with an attempt to assess the role of institutions as key determinant of cross-country development. We have unbundled the different facets of institutions, including the security of property rights, democracy, regulation and stability of monetary policy. In Chapter 2, we investigate the direct impact of institutions on economic growth using dynamic panel data estimations. Employing this estimator aims at alleviating the technical problems embedded in the existing literature. Our results suggest that the security of property rights and stability of monetary policy have direct impact on economic growth, whereas democracy and regulation are not directly growth-enhancing. In Chapter 3, we further explore the role of democracy and regulation in the development process. We empirically test whether economic reform is more likely to take place in democratic economies. The answer seems affirmative. More specifically, our empirical results show that democracy causes reforms in redistributive policies, trade liberalisation and credit market deregulation. In the next Chapter, we consider the institutional barriers as compared to natural barrier and at-the-board barriers as determinants of bilateral FDI. The augmented gravity model provides empirical evidences to support that geography, regional integration and domestic regulatory environment of the destination economies all have significant impacts on FDI inflows. In particular, credit market regulation is amongst the most important, which echoes the view that financial development is essential to economic development. In the final empirical work, we hypothesise that institutions matter to cross-country economic performances as economies with better institutions are technically more efficient. We estimate a global stochastic production frontier, where countries lie below the frontier are less efficient. Our empirical results suggest that countries with better security of property rights and fewer regulations allocate their production inputs more efficiently. The effects of democratic regime and stability of monetary policy are also positive to improve inefficiency, if a threshold level of human capital is reached. Other possible factors like openness and human capital, in turn, seem not to play direct role. Our research provides empirical basis to understand how particular aspects of institutions could affect development outcomes. 
To my parents and sister Zoe 


\section{Acknowledgement}

This thesis could have not been completed without the enormous assistance from my supervisory panel, family and colleagues.

I am deeply indebted to my principal supervisor Professor Somnath Sen. He has devoted enormous effort and patience in keeping me on track. His invaluable ideas, assistance and persistent encouragement all contributed to the progress of my research and brought the output into better shape. He has also shared my anxiety and confusion at different stages of my work. I appreciate his kindness and understanding in every circumstance. I would also like to show my gratefulness to Professor Jayasri Dutta. She has always been the source of inspiration, generously offering her rich and deep comments over the course. I owe an everlasting debt to both my supervisors.

My sincere thanks go to Dr. Colin Rowat, being a responsible mentor and showing me the greatest dedication, devotion and diligence the way a researcher should be. I am also most grateful to Professor Jim Ford for sharing his comments and sparing his valuable time on my earlier work. I am also most thankful to the Department of Economics which has provided me the scholarship for my research as well as the excellent study environment for postgraduate students. Especially the administration team, their utmost professional support is undoubtedly the most effective I have ever encountered.

I must also thank all my friends and colleagues in Birmingham, in particular to their strong support, help and companies in both my academic and personal capacity. These wonderful people have brought me so much laughter everyday during my study. I am going to miss the thoughtful and inspiring discussions we had over all these years.

Finally I would like to express my greatest gratitude to my caring parents and sister for their enduring patience and forgiveness, as well as their endless encouragement. Without their support throughout, my study would have been much more difficult. 


\section{TABLE OF CONTENTS}

1.1 Background .2

1.2 What are Institutions and Which Types of Institutions are Important to Economic Development?

1.2.1 North's Definition ............................................................4

1.2.2 Interrelationships between Political Institutions and Economic Institutions ....................................................5 5

1.2.3 Rodrik's Taxonomy of Institutions................................. 7

1.3 Effects of Institutions and their Dynamics..............................9

1.3.1 Institutional Quality and Development Outcomes............. 9

1.3.2 Institutional Changes and Transitions Over the Past Decades .............................................................................. 11

1.3.3 Quantitative Measures of Institutions .............................. 13

1.4 Research Objectives ......................................................................... 16

$1.5 \quad$ Organisation of the Thesis ..........................................................17

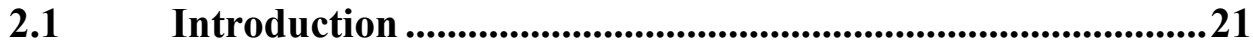

2.2 Literature Survey: Institution and Economic Growth ........23

2.2.1 Endowment View on Economic Growth........................... 23

2.2.1.1 Direct Impact of Geography .......................................24

2.2.1.2 Indirect Impact of Geography via Institutional Choice

2.2.2 Institution View: Economic vs. Political Institutions ...... 29

2.2.2.1 Economic Institutions and Growth ..............................29

2.2.2.2 Political Institution and Growth....................................31

2.2.3 Empirical Results of Testing the Competing Views......... 33

2.2.4 Critics of Existing Institutions and Growth Literature.... 35

2.2.4.1 Data Problem: Availability, Credibility and Comparability ..............................................................35

2.2.4.2 Reverse Causality: Economic Growth causes Institutional Change .......................................................36

2.2.4.3 Endogeneity and Validity of Instrumental Variables

22440.38

2.2.4.5 Omitted Variables: Country- and Time-Specific Effects........................................................................38

2.2.4.6 Specification Problem: Growth Rates vs. Income Level ...............................................................................39

2.3 Empirical Strategy and Data................................................40

2.3.1 Baseline Specification .....................................................40

2.3.2 Estimation Strategy ....................................................... 41

2.3.1.1 Linear GMM Estimator ..........................................42

2.3.1.2 Dynamic Panel Data Models.........................................45

2.3.1.3 Post-estimation Test...................................................48 
2.3.1.4 Advantages of Using Panel GMM Estimators for

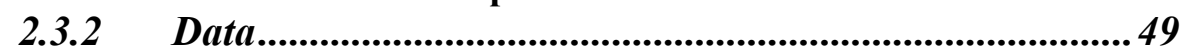

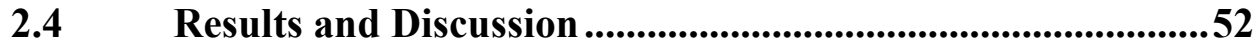

2.4.1 Institution in a Growth Model: Preliminary Test .............52

2.4.2 Direct Partial Impact of Institution on Growth ............... 57

2.4.2.1 Baseline Specification .................................................57

2.4.2.2 Choice of Estimators..................................................60

2.4.2.3 Robustness Tests ...........................................................63 63

$2.5 \quad$ Conclusion ........................................................................ 70

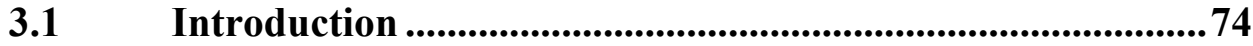

3.2 Literature Survey: Interrelationship between Political Regime and Economic Reform.............................................79

3.2.1 Theoretical arguments ................................................ 79

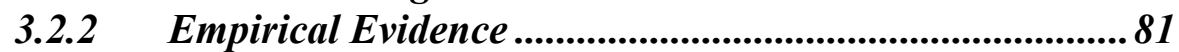

3.2.2.1 Trade Liberalisation ......................................................81

3.2.2.2 Financial Liberalisation ............................................. 83

3.2.2.3 Joint Tests of Multi-Sector Reforms ............................83

3.3 Data and Methodology ................................................................8 87

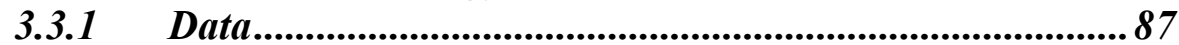

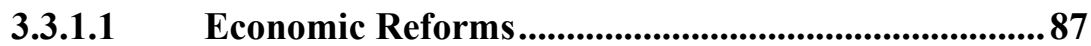

3.3.1.2 Democracy …................................................................99

3.3.1.3 Controlled Variables.........................................................93

3.3.2 Model Specification and Estimation Strategy ................... 94

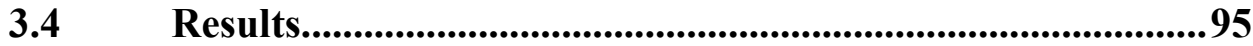

3.4.1 Does Democracy cause Economic Freedom?..................95

3.4.2 Does Democracy cause Economic Reform in Different Sectors?.................................................................................99 97

3.4.3 Robustness Tests.................................................................. 100

3.4.4 Reverse Causality: Economic Reform Causes Democratisation?.......................................................... 108

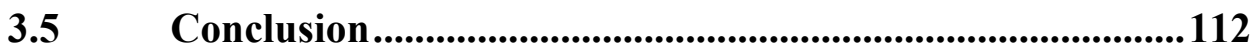

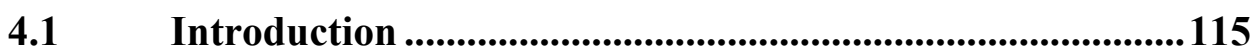

4.2 Literature Survey: Regulations and Regional Integration as

Determinants of FDI .......................................................121

4.2.1 Natural Barriers and FDI................................................ 122

4.2.2 Regulations and FDI................................................. 123

4.2.3 Regional Integration and FDI......................................... 127

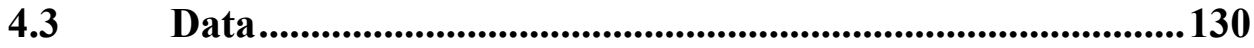

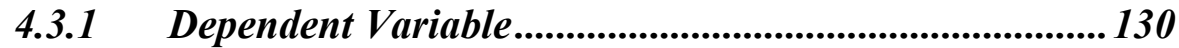

4.3.2 Independent Variables ................................................... 131

4.3.2.1 Gravity Variables..................................................131

4.3.2.2 Regional Integration and Regulatory Variables ..... 132

4.3.2.3 Instrumental Variables...............................................133

4.3.2.4 Data Limitation ........................................................134

4.4 Model and Estimation Strategy ................................................ 134

4.4.1 Augmented Gravity Model ........................................... 134 


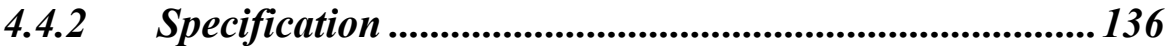

4.4.3 Estimation Strategies....................................................... 136

4.4.3.1 Linear Panel Data Models.........................................137

4.4.3.2 Feasible Generalised Least Squares (FGLS) Estimation........................................................................139

4.4.3.3 Hausman and Taylor Estimator ...................................139

4.4.3.4 Two Stage Least Squares Instrumental Variable (IV) estimation.............................................................................141

4.5 Results......................................................................................... 142

4.5.1 Pooled Regressions...................................................... 142

4.5.2 Linear Panel Data Regressions ....................................... 148

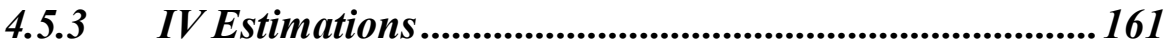

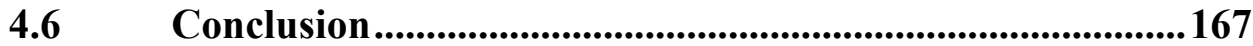

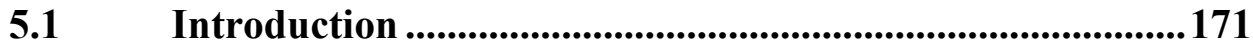

5.2 Literature Survey: Human Capital, Openness and

Institutions as Sources of Efficiency ..................................175

5.2.1 Human Capital .................................................................... 177

5.2.2 Openness: Trade, FDI and Financial Integration ........ 178

5.2.3 Institution and Macroeconomic Policies.......................... 181

5.3 Fundamentals of Stochastic Production Frontier (SPF).... 185

5.3.1 Basic Framework ............................................................ 186

5.3.2 Some Applications of SPF ......................................... 188

5.3.3 General Critics on SPF ............................................ 191

5.4 Model Estimation and Specification ....................................... 192

5.4.1 Battese and Coelli (1993) and (1995) Model.................. 193

5.4.2 Post-estimation Test ........................................................... 199

5.4.3 Model Specification.........................................................200

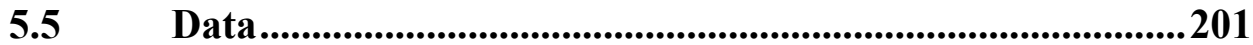

5.5.1 Output and Production Inputs........................................ 202

5.5.2 Explanatory Variables for TE Models........................... 204

$5.6 \quad$ Estimation Results ....................................................................205

5.6.1 Specification of Production Function ..............................2205

5.6.2 Sources of Technical Inefficiency ...................................208

5.6.3 Measures on Technical Efficiency ................................ 215

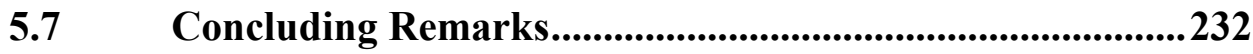

6.1 Summary of Findings and Policy Implications...................235

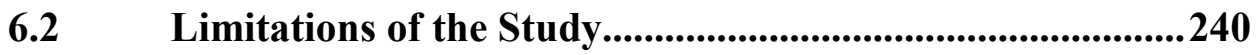

6.3 Further Research................................................................242

A.1 Summary Table of Institution and Growth Literature .....245

A.2 Data Description and Sources ................................................251

i. $\quad$ Variables Used in Chapter 2, 3 and 5..........................251

ii. $\quad$ Variables Used in Chapter 4 ............................................ 254

iii. Components of the Regulation Index (REG) of the Fraser Institute's Economic Freedom of the World Report...... 255 
A.3 Descriptive Statistics and Correlation Matrices..................256

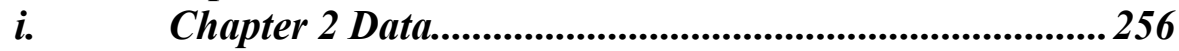

ii. $\quad$ Chapter 3 Data.............................................................. 258

iii. $\quad$ Chapter 4 Data......................................................... 260

iv. $\quad$ Chapter 5 Data........................................................................ 262

A.4 List of Economies......................................................................264

i. Country Coverage of the Fraser Institute's Economic Freedom of the World Report in Chapter 2...................... 264

ii. $\quad$ Country Coverage in Chapter 3 ......................................... 265

iii. $\quad$ Country Coverage in Chapter 4 ..................................... 267

iv. Country Coverage in Chapter 5 ....................................268

A.5 List of Regional Trade Agreements (RTA).........................2271

A.6 Diagnostic Tests for Estimations in Chapter 4 ....................273

i. $\quad F$-test for FE vs. OLS Estimations............................... 273

ii. Breusch and Pagan test for RE vs. OLS Estimations.... 273

iii. Hausman Specification Test ............................................ 274

iv. $\quad$ Test for Autocorrelation ................................................2275

v. Sargan-Hansen Test on Instruments Validity.................. 276

A.7 Summary Table of Time-Varying Technical Efficiency Models...............................................................................2277 


\section{LIST OF FIGURES}

Figure 1.1-1: Average Growth Rates of Real GDP Per Capita during 1961-2008 (\%).

Figure 1.1-2: GDP per capita (2005 constant price, PPP-adjusted) by Regions. 3

Figure 1.3-1: Economic Freedom and PPP-adjusted Real GDP Per Capita (const 2005 dollar) in 2007.

Figure 1.3-2: Economic Freedom and Average Real GDP Per Capita Growth

Rate during 1990-2007

Figure 1.3-3: Economic Freedom and Net Inflows of FDI as \% of GDP during 1990-2007

Figure 1.3-4: Economic Freedom and Gross Capital Formation during 1990 2007

Figure 1.3-5: Economic Institutions (measured by Governance Indicators) by

Regions (1996 - 2004)... .12

Figure 1.3-6: Political Institutions by Regions $(1970$ - 2003)......................... 13

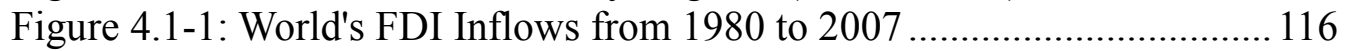

Figure 4.1-2: FDI Inflows as Percentage of World's Total............................. 116

Figure 4.1-3: FDI Inflows as Percentage of World's Total in Developing

Economies

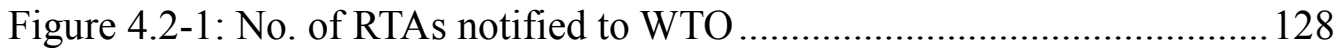

Figure 5.6-1: TE of Brazil, China and India vis-à-vis USA ..........................221

Figure 5.6-2: TE of Hong Kong, Republic of Korea, Singapore and Taiwan vis-à-vis USA.

Figure 5.6-3: TE of Indonesia, Malaysia, Philippines and Thailand vis-à-vis USA.

Figure 5.6-4: TE of Selected Lower Middle Income Countries in Latin America and Caribbean vis-à-vis USA.

Figure 5.6-5: TE of MENA Region vis-à-vis USA

Figure 5.6-6: Ranking s of EC, TC as against TFP of 108 Economies..... 226 


\section{LIST OF TABLES}

Table 1.2.1-1: Income Gap with respect to High-income OECD Countries by

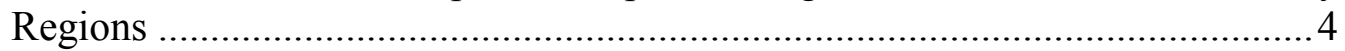

Table 1.2.3-1: A Taxonomy of Market-Sustaining Institutions .......................... 8

Table 1.3.3-1 : Comparison of Selected Institutional Indicators....................... 15

Table 2.4.1-1: Preliminary Tests of Dynamic Growth Models (Two-Step

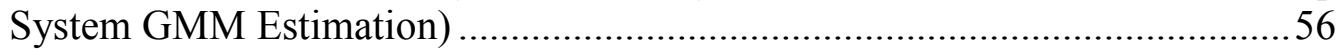

Table 2.4.2-1: Institution and Economic Growth - Baseline Specification (Two-Step System GMM Estimation) ......................................................58

Table 2.4.2-2: Institution and Economic Growth - Baseline Specification Using

Different Estimation Techniques.................................................................62

Table 2.4.2-3: Institution and Economic Growth - Baseline Specification with Additional Covariates (2-Step System GMM Estimations)............................66

Table 2.4.2-4: Institution and Economic Growth - With Alternative Measures of Institutions (2-Step System GMM Estimations) ...........................................6 67

Table 2.4.2-5: Institution and Economic Growth - Sub-Samples Estimations

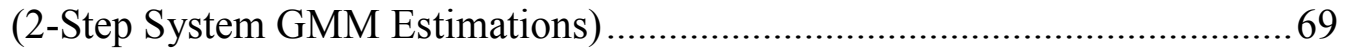

Table 3.1-1: Number of economies under different political regimes .............. 75

Table 3.1-2: Number of economic free economies under democracy and

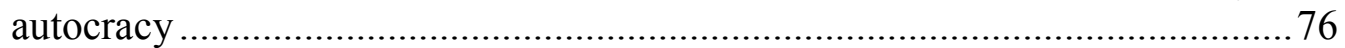

Table 3.1-3: Scores on Democracy (DEMOC) and Economic Freedom $(E F)$ of

Selected Emerging Economies...................................................................... 77

Table 3.2.2-1: Empirical Studies of Measuring the Causality between Economic

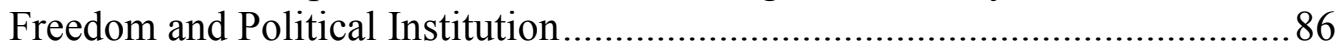

Table 3.3.1-1: Comparison between IMF Economic Reform Index and Fraser Institute's Economic Freedom Index........................................................... 90

Table 3.4.1-1: Does Democracy Cause Economic Freedom? - Different

Estimation Techniques .......................................................................... 97

Table 3.4.2-1: Does Democracy Cause Economic Reform in Different Sectors? -

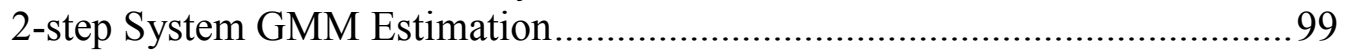

Table 3.4.2-2: Causal Impact of Democracy on Economic Reform ............... 100

Table 3.4.3-1: IPOLITY2 As An Alternative Measure of Democracy............. 101

Table 3.4.3-2: Dichotomous DEMOC1 As An Alternative Measure of

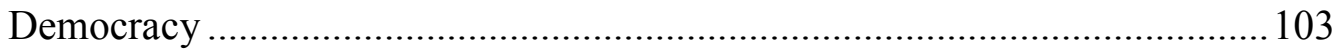

Table 3.4.3-3: Baseline Specification for Non-High income Countries ......... 105

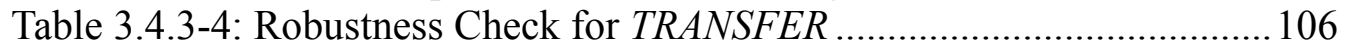

Table 3.4.3-5: Robustness Check for FREE TRADE .................................... 107

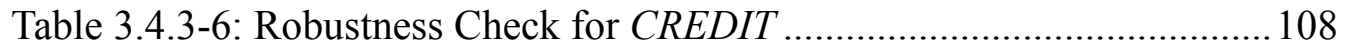

Table 3.4.4-1: Economic Reforms Cause Democracy? .................................. 110

Table 3.4.4-2: Economic Reforms Cause Democracy? - Measured by

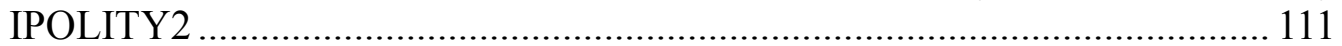

Table 4.1-1: Top FDI Destinations and Hosts in 2007 ................................. 117

Table 4.1-2: FDI Inflows as Percentage of Gross Fixed Capital Formation (\%) 118

Table 4.2.2-1: Selected Recent Empirical Studies Estimating the Impact of

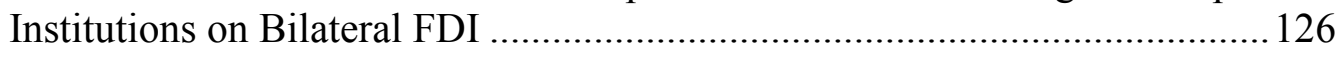

Table 4.5.1-1: Pooled OLS Regression Results: Full Sample......................... 143

Table 4.5.1-2: Pooled OLS Regression Results: Intra-OECD Sample ........... 145 
Table 4.5.1-3: Pooled OLS Regression Results: Inter-OECD Sample ........... 146

Table 4.5.2-1: RE Models for Full Sample .................................................... 149

Table 4.5.2-2: FE Models for Full Sample.................................................. 150

Table 4.5.2-3: RE Estimations by Sub-samples (Key Variables): Intra-OECD

Sample

Table 4.5.2-4: RE Estimations by Sub-samples (Key Variables): Inter-OECD

Sample. 153

Table 4.5.2-5: FGLS Estimation Results by Sub-Smaples (Key Variables) ... 154

Table 4.5.2-6: Hausman and Taylor Estimation Results -- Full Sample......... 157

Table 4.5.2-7: Hausman and Taylor Estimation Results -- Inter-OECD Sample 158

Table 4.5.2-8: Hausman and Taylor Estimation Results -- Intra-OECD Sample 159

Table 4.5.2-9: Effect of RTA on FDI........................................................... 160

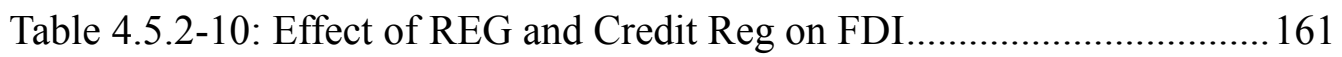

Table 4.5.3-1: IV Estimation Results - Full Sample........................................ 164

Table 4.5.3-2: IV Estimation Results - Inter-OECD Sample .......................... 165

Table 4.5.3-3: IV Estimation Results - Intra-OECD Sample ........................ 166

Table 5.2.3-1: Comparison of Stochastic Production Frontier and Data

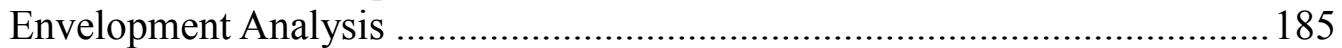

Table 5.6.1-1: Maximum Likelihood Estimation of Stochastic Production

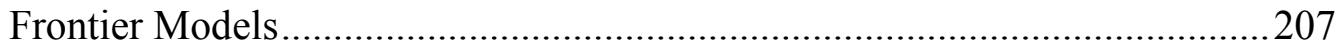

Table 5.6.1-2: Hypothesis Testing for SPF Models (1) - (3)..........................208

Table 5.6.2-1: Maximum Likelihood Estimation of Stochastic Production Frontier Model (TE Model (1))....................................................................209

Table 5.6.2-2: Hypothesis Testing for TE Model (1) ...................................... 211

Table 5.6.2-3: Maximum Likelihood Estimation of Stochastic Production Frontier Model (TE Model (2)) .....................................................................2212

Table 5.6.2-4: Hypothesis Testing for TE Model (2) ..................................... 213

Table 5.6.2-5: Maximum Likelihood Estimation of Stochastic Production Frontier Model (TE Model (3)) - Final Model ............................................2213

Table 5.6.2-6: Hypothesis Testing for TE Model (2) vs. TE Model (3)..........214

Table 5.6.3-1: Average TE by Regions during 1971-2000.............................216

Table 5.6.3-2: Cross-country Technical Efficiency during 1971-2000 ...........217

Table 5.6.3-3: Sources of Economic Growth (rate of change in \%) for the Sample Countries (1971-2000) 227 


\section{LIST OF ABBREAVATIONS}

\begin{tabular}{ll} 
2SLS & 2-Stage Least Square \\
ADB & Asia Development Bank \\
BERI & Business Environmental Risk Intelligence \\
EC & Efficiency Change \\
FDI & Foreign Direct Investment \\
FE & Within Group Fixed Effect Estimation \\
FGLS & Feasible Generalised Least Square \\
GDP & Gross Domestic Product \\
GMM & Generalised Method of Moments \\
ICRG & International Country Risk Guide \\
IH & Identification through Heteroskedasticity \\
ILO & International Labour Organisation \\
IMF & International Monetary Fund \\
IV & Instrumental Variable \\
LR-test & Likelihood-ratio Test \\
ML & Maximum Likelihood \\
OECD & Organisation for Economic Co-operation and Development \\
OLS & Ordinary Least Square \\
PWT & Penn World Table \\
RE & Random Effect Estimation \\
RTA & Regional Trade Agreement \\
SPF & Stochastic Production Frontier \\
TE & Technical Efficiency \\
TFP & Total Factor Productivity \\
UNCAD & United Nations Conference on Trade and Development \\
UNDP & United Nations Development Programme \\
VAR & Vector Autoregressive Regression \\
WDI & World Development Indicators \\
WTO & World Trade Organisation \\
\hline
\end{tabular}


CHAPTER 1 : INTRODUCTION 


\subsection{Background}

Economic growth is perhaps one of the most important subjects in the field of economic development. Sustained high growth rates are usually regarded as the main driver of improving the general welfare and income of a country. Neoclassical growth models, like Solow (1956), have put great emphasis on the role of physical capital accumulation. Modern economic growth theories have been extended to consider innovations, technology, human capital as well as institutions as the fundamental causes of growth.

Reviewing the recent global development, we saw the most rapid growth around the world in the past 30 years. The rate of global integration, via trade and foreign direct investment, is unprecedented. This in turn has facilitated technology flow. Total world trade as a percentage of GDP rose from $26.7 \%$ in 1970 to $54.2 \%$ in 2005 . At the same time nevertheless, the income gaps between the rich and the poor economies are also increasing. The headcount number of poverty has just lately reached a new peak of over 1.3 billion ${ }^{1}$. The development experiences are quite diverse across regions.

Figure 1.1-1 shows that there has been a distinct acceleration of real GDP per capita growth since the $80 \mathrm{~s}$ in most of the developing economies. Continuous economic growth should have naturally helped close the income gaps between the developed and developing economies. However, this seemingly is not the case, especially for countries in the Sub-Saharan Africa (see Figure 1.1-2).

\footnotetext{
${ }^{1}$ Source: Food and Agriculture Organisation of the United Nations (2009) (Retrieved from: http://www.fao.org/hunger/hunger_home/hunger_at_glance/en/)
} 
Figure 1.1-1: Average Growth Rates of Real GDP Per Capita during 1961—2008 (\%)

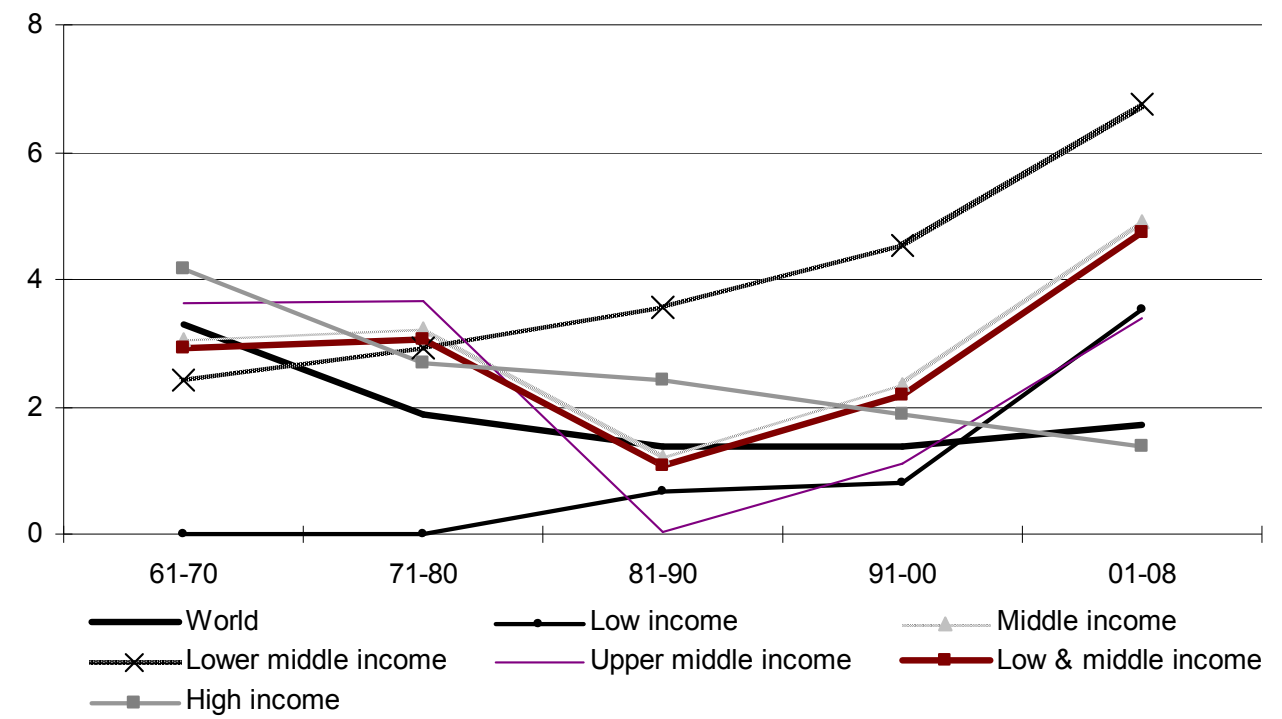

Source: World Development Indicators, World Bank. Growth rates are simple average.

Figure 1.1-2: GDP per capita (2005 constant price, PPP-adjusted) by Regions

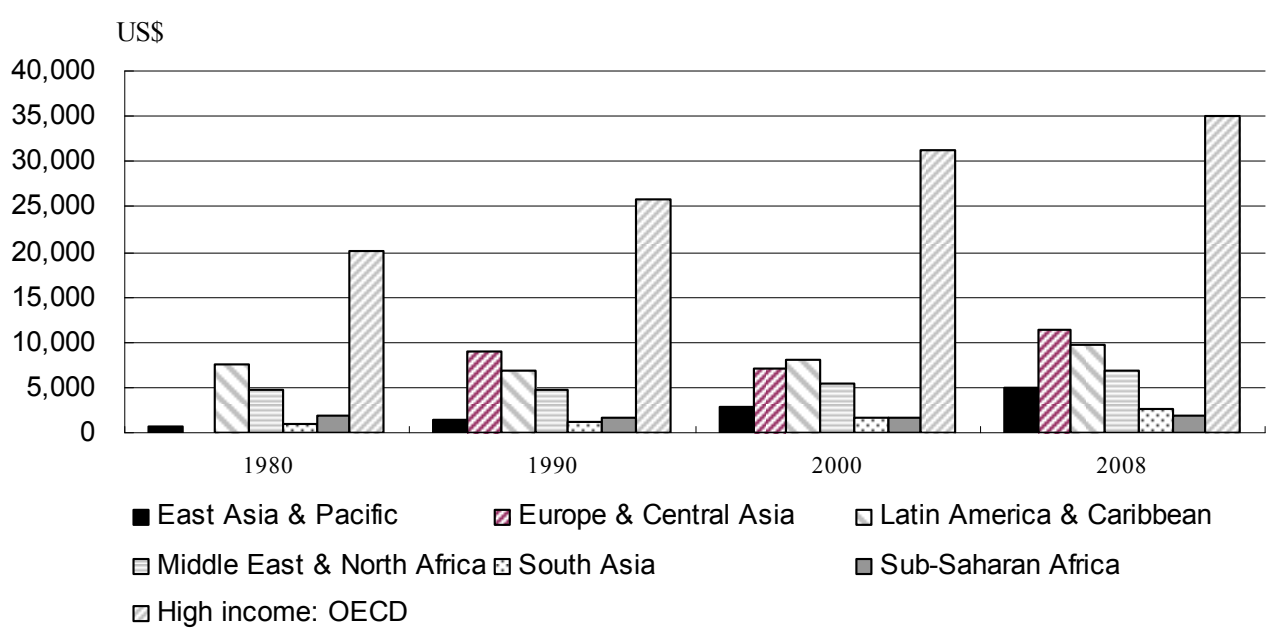

Source: World Development Indicators, World Bank. Data for Europe and Central Asia in 1980 is not available.

Table 1.2.1-1 shows the income gaps between developing economies and high-income OECD economies in selected years. It is noted that the average real GDP per capita (PPP-adjusted) of the high-income OECD countries was about 10 times of that of those countries in the Sub-Saharan Africa region in 1980. However, the corresponding figure surged to 17 times in 2008. 
Table 1.2.1-1: Income Gaps with respect to High-income OECD Countries by Regions

\begin{tabular}{lcccc}
\hline \multicolumn{1}{c}{ Region/Year } & $\mathbf{1 9 8 0}$ & $\mathbf{1 9 9 0}$ & $\mathbf{2 0 0 0}$ & $\mathbf{2 0 0 8}$ \\
\hline \hline East Asia \& Pacific & 24.59 & 17.56 & 10.46 & 5.97 \\
Europe \& Central Asia &.. & 1.87 & 3.37 & 2.05 \\
Latin America \& Caribbean & 1.70 & 2.68 & 2.84 & 2.58 \\
Middle East \& North Africa & 3.29 & 4.48 & 4.77 & 4.04 \\
South Asia & 22.17 & 20.47 & 17.98 & 12.88 \\
Sub-Saharan Africa & 10.24 & 14.98 & 19.11 & 17.06 \\
\hline
\end{tabular}

Source: World Development Indicators, World Bank. ... denotes that data is not available.

All these trigger the recent interest in studying the role of domestic institutions as the fundamental cause of such "great divergence". The IMF (2005) also advises that, to have considerable economic progress, development challenges have increasingly become how to improve the quality of the domestic institutional framework. It is because bad institutions will distort the usage of production inputs like labour and capital, the adoption and utilisation of ideas from leading nations. Hence, understanding the channels through which institutions work on the development outcomes are essential in order to put forward any policy suggestions that would achieve the objectives of sustainable development.

\subsection{What are Institutions and Which Types of Institutions are Important to Economic Development?}

\subsubsection{North's Definition}

For the sake of discussion, we must first understand the meaning of institutions. In his seminal work, North (1981) defines institutions as "the rules of the game in a society or, more formally, are the humanly devised constraints that shape human interaction. In consequence they structure incentives in human exchange, whether political, social, or economic" (also see North (1990)). In other words, the possibility choice set of an individual is defined and limited by institutions. Economic institutions in a very broad sense, such as the structure of property rights and the presence and perfection of markets, influence the 
structure of economic incentives in a society. This structure will direct individuals how resources are allocated and secure who gets the profits, revenues and the residual rights of control. In a nutshell, societies with economic institutions that facilitate factor accumulation, innovation and the efficient allocation of resources will prosper (also see Acemoglu, Johnson, and Robinson (2005)).

North further elaborates that institutions can be interpreted as informal constraints and formal rules. The informal constraints as "code of conduct, norms of behaviour, and conventions ... which come from socially transmitted information and are a part of the heritage that we call culture" (1990, P.36-37). That said, culture inherited in different societies may also significantly explain why same formal rules have made diverse outcomes in various circumstances.

For the present thesis, our key interest is on formal rules nevertheless. "Formal rules include political (and judicial) rules, economic rules, and contracts. The hierarchy of such rules, from constitutions, to statute and common laws, to specific bylaw, and finally to individual contracts defines constraints, from general rules to particular specifications" (North 1990, P. 47) ${ }^{2}$. It suggests, therefore, at least three principle aspects of institutions - (i) political rules (hereafter interpreted as political institutions), (ii) economic rules (hereafter referred as economic institutions, which shape the property rights structures) and (iii) contracts (between individuals and/or parties).

\subsubsection{Interrelationships between Political Institutions and Economic Institutions}

The IMF (2005) extends North's definition of institution by stressing the interrelationship between economic and political institutions. The term political institution refers to institutions that shape the incentives of the

\footnotetext{
${ }^{2}$ More specifically, "political rules broadly define the hierarchical structure of the polity, its basic decision structure, and the explicit characteristics of agenda control. Economic rules define property rights as the bundle of rights over the use and the income to be derived from property and the ability to alienate an asset or a resource. Contracts contain the provisions, specific to a particular agreement in exchange".
} 
political executive and determine the distribution of political power, which includes the ability to shape economic institutions and the distribution of resources. Economic institutions, by determining the relative affluence of various groups of society, also help shape political institutions. Good economic institutions are most likely to flourish in a "rent-free" environment, in which small groups are not able to take advantage of a monopoly position in a particular industry or activity, or privileged access to natural resources. More importantly, good economic institutions are also likely to be accompanied by good political institutions. If political power is broadly shared and subject to checks and balances, there is much less risk that those with political power will take advantage of their position to extract rents themselves.

Acemoglu, Johnson and Robinson (2005) provide a survey of recent work on institution and economic growth in the Handbook of Economic Growth, which summarises the approach adopted and key conclusions the subject obtained in the last decade or so. The literature developed so far, as they outlined, largely attempts to build a framework to explain why economic institutions differ across countries and how the economic institutions determine political institutions. Models of such kind, studying the political economics of institutions, largely draw on historical experiences. In retrospect, economic institutions determine the incentives of and the constraints on economic actors and thus shape economic outcomes. Groups with de facto political power also strive for the distribution of economic institutions to affect the distribution of resources.

Despite these earlier works on institutions, there is a general impression that the literature usually does not present a coherent and systematic explanation to different measures of institutions. It is due to the fact that despite all theoretical propositions and empirical evidences, there is not a strong conclusion about exactly "what" institutions matter to economic growth. One pertinent reason certainly is the lack of an operational framework and the measure of "institution". As Acemoglu (2009) also points out, the notion of institutions used in most of the literature is rather broad. There is so far little 
work on unbundling the broad cluster of institutions to understand what specific types of institutions might be important for economic outcomes.

\subsubsection{Rodrik's Taxonomy of Institutions}

To proceed with our empirical tests in a more systematic manner henceforth, we propose to adopt a conceptual framework designed by Rodrik (2005) and later adopted by Bhattacharyya (2009)3 . Rodrik (2005) identifies "good institutions" as those that deliver the first-order economic principles - i.e. protection of property rights, contract enforcement, market-based competition, appropriate incentives, sound money, debt sustainability - effectively. Without overseeing the inter-relationship between economic and political institutions, Rodrik (2005) also shares the view that political entity is also needed to be strong enough to establish property rights and enforce contracts for its own purpose. The interplay between political institution and economic institution represents a "right balance between disorder and dictatorship" and thus should be considered together.

On this basis, he suggests a taxonomy of "market-sustaining institutions". These institutional arrangements are believed to help achieve cross-country economic convergence with the level of development in the developed world. The components of market-sustaining institutions are shown in Table 1.2.3-1. His taxonomy can be understood in 4 dimensions, namely "market-creating", "market-regulating", "market-stabilising" and "market-legitimising" institutions.

\footnotetext{
${ }^{3}$ His work, nevertheless, emphasizes the direct partial impact of human capital on growth, instead of institutions.
} 
Table 1.2.3-1: A Taxonomy of Market-Sustaining Institutions

\begin{tabular}{|l|l|}
\hline * Market-creating institutions & $\begin{array}{l}* \text { Market-regulating institutions } \\
\text { o Property rights }\end{array}$ \\
o Contract enforcement & $\begin{array}{l}\text { o Regulatory bodies } \\
\text { o Other mechanisms for correcting } \\
\text { market failures }\end{array}$ \\
\hline $\begin{array}{l}\text { Market-stabilizing institutions } \\
\text { o Monetary and fiscal institutions } \\
\text { o Institutions of prudential regulation and } \\
\text { supervision }\end{array}$ & $\begin{array}{l}* \text { Market-legitimizing institutions } \\
\text { o Democracy } \\
\text { o Social protection and social insurance }\end{array}$ \\
\hline
\end{tabular}

Source: Rodrik (2005)

On market-creating institutions, since Mises (1947) and Mises (1951), Hayek (1944) and Hayek (1945), Alchian (1950), Friedman (1962) and Kirzner (1973), the importance of market process has been vastly emphasized. These pioneering works have highlighted the essence of economic institutions and their role of providing both the incentive and information in making the best use of available resources to market participants. Security of property rights and contract enforcement affect incentives, productive efforts, and the effectiveness of resource used. Without such security, the incentive structure of the economy will be seriously weakened.

Under Rodrik (2005)'s taxonomy, he is also of the view that markets require extensive regulations to minimize the abuse of market power, internalize externalities, deal with information asymmetries, establish product and safety standards etc (i.e. market-regulating institutions). Countries also need monetary, fiscal, and other arrangements to deal with business cycles (i.e. market-stabilising institutions). Finally democratic governance, also reflected in Rodrik (2000)'s views, is reckoned as the market-legitimising institutions for the realization and security of market outcomes, say through social protection and social insurance. The role of political process (political regime specifically) thus may not enter into the development process directly. It nevertheless could be understood as the institutional arrangement that provide the incentives for the market participants to realize the development outcomes 
after economic development is achieved ${ }^{4}$.

In overall terms, this classification characterises and creates synergy for economic and political institutions and policies. This thus allows us to bring both economic and political institutions together to be tested under a unified framework. In the present thesis, our understanding and clustering of institutions are by and large based on this taxonomy.

\subsection{Effects of Institutions and their Dynamics}

\subsubsection{Institutional Quality and Development Outcomes}

Indeed, when we take a snapshot of institutional quality and development outcomes, we do find a seemingly positive relationship. We consider the Fraser Institute's Economic Freedom Index as a proxy of overall quality of economic institution and four aspects of development as shown below namely GDP per capita, GDP per capita growth, foreign direct investment (FDI) and gross capital formation. Figure 1.3-1 to Figure 1.3-4 show that better quality of economic institution does associate with higher GDP per capita, average GDP per capita growth rate and FDI, yet to a less extent gross capital formation.

\footnotetext{
${ }^{4}$ The incentive-inducing property of democracy may help explain why political regime usually does not exhibit direct impact on growth in the literature. Details are to be discussed in Chapter 2.
} 
Figure 1.3-1: Economic Freedom and PPP-adjusted Real GDP Per Capita (const 2005 dollar) in 2007

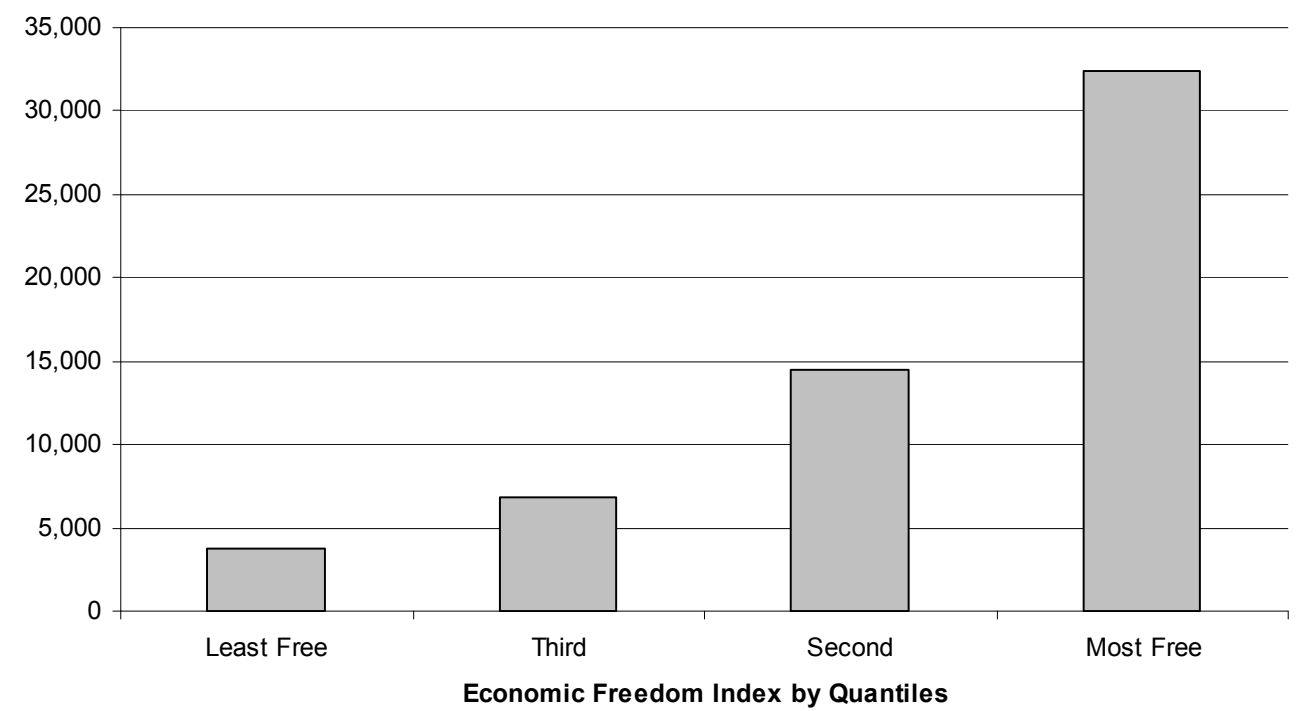

Figure 1.3-2: Economic Freedom and Average Real GDP Per Capita Growth Rate during 1990-2007

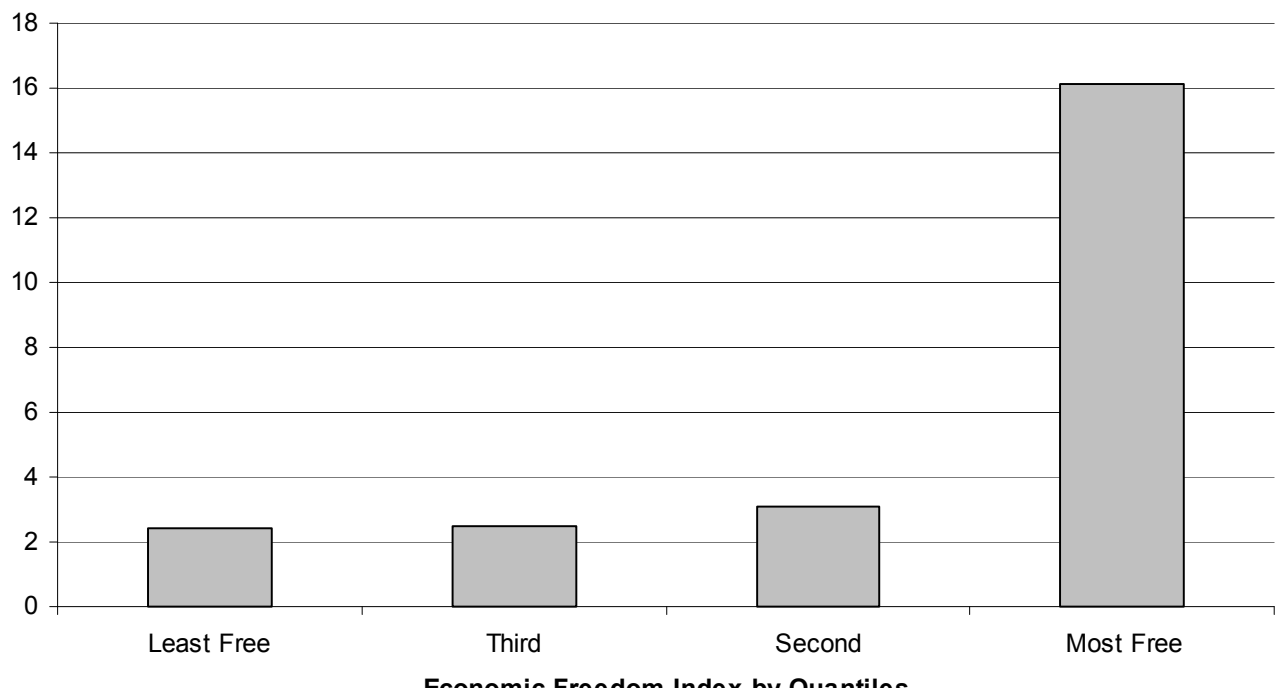


Figure 1.3-3: Economic Freedom and Net Inflows of FDI as \% of GDP during 1990-2007

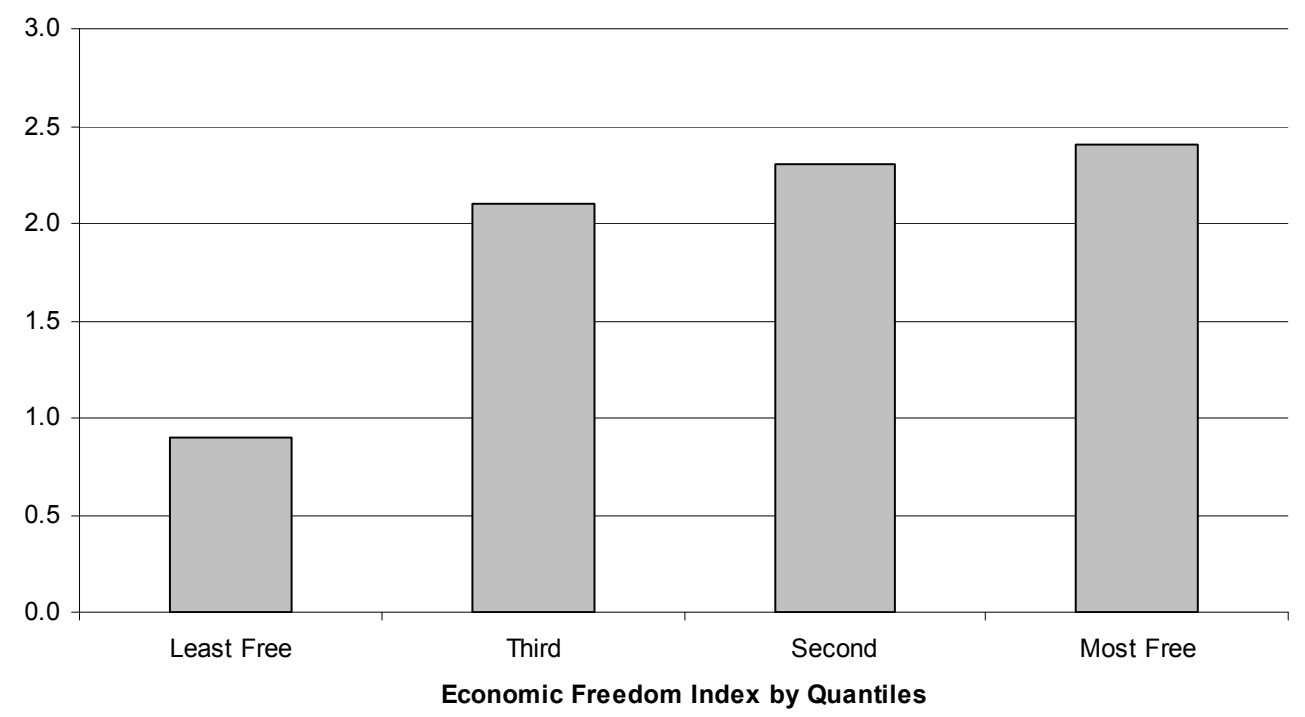

Figure 1.3-4: Economic Freedom and Gross Capital Formation during 1990 - 2007

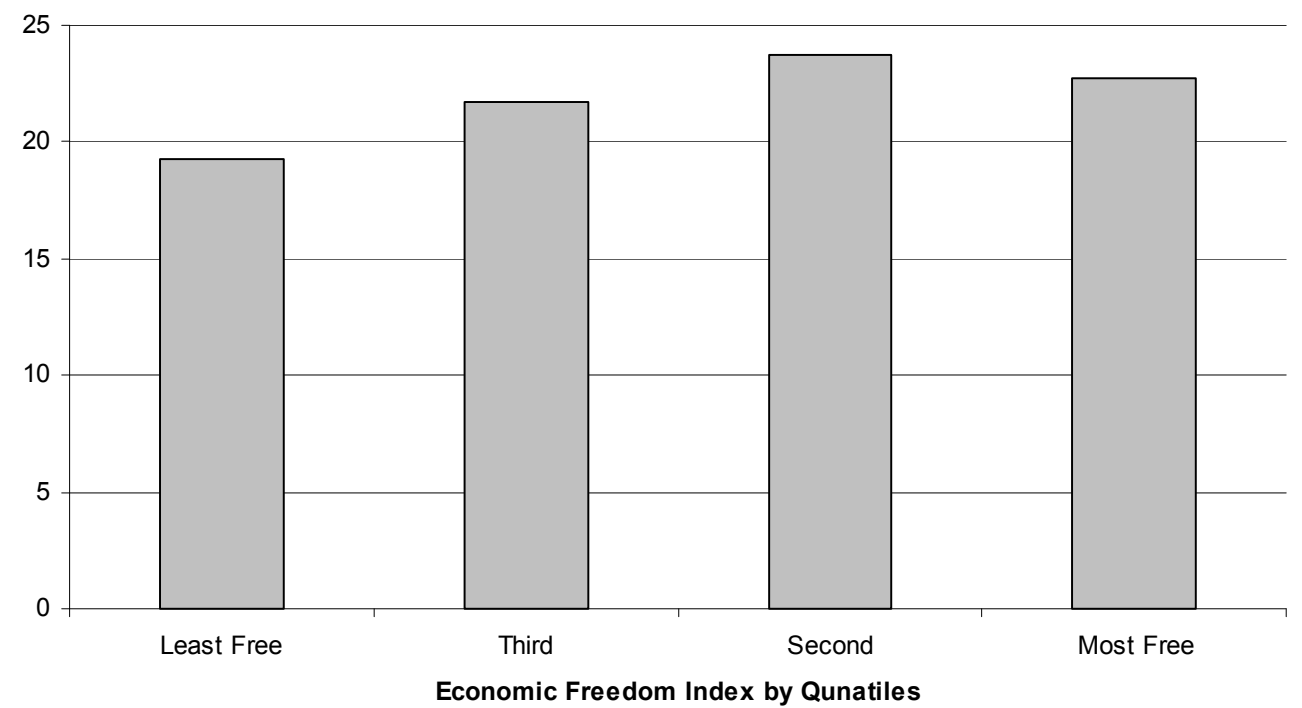

Sources: Economic Freedom of the World Report 2008, Fraser Institute.

\subsubsection{Institutional Changes and Transitions Over the Past Decades}

These figures above suggest a positive correlation between institutional quality and development outcomes around the world. However, such correlation may not imply a straightforward causal relationship and possibly invite two further 
(and perhaps related) questions. Firstly, there might be some other factors affecting both institutions and economic development. Reverse causality is also possible since richer economies may have more resources to build up better institutions. Secondly, these snapshots ignore any institutional change over time. The IMF (2005) indeed has also concurred that rapid institutional change was possible in the past 30 years despite the tendency to institutional persistence.

The regional plots of economic institutional quality from the World Bank's Governance Indicators - that we use to proxy economic institution - and political institutions from the Polity IV data are presented below in Figure 1.3-5 and Figure 1.3-6. It is shown that institutional changes, in terms of both economic and political institutions, did take place over the last few decades. It is therefore worth pursuing a study to investigate if there are any interrelationships with these institutional changes with the global development scenarios that we observe earlier. The way to undertake this investigation in a more robust manner is to perform some econometric analyses.

Figure 1.3-5: Economic Institutions (measured by Governance Indicators) by Regions (1996- 2004)

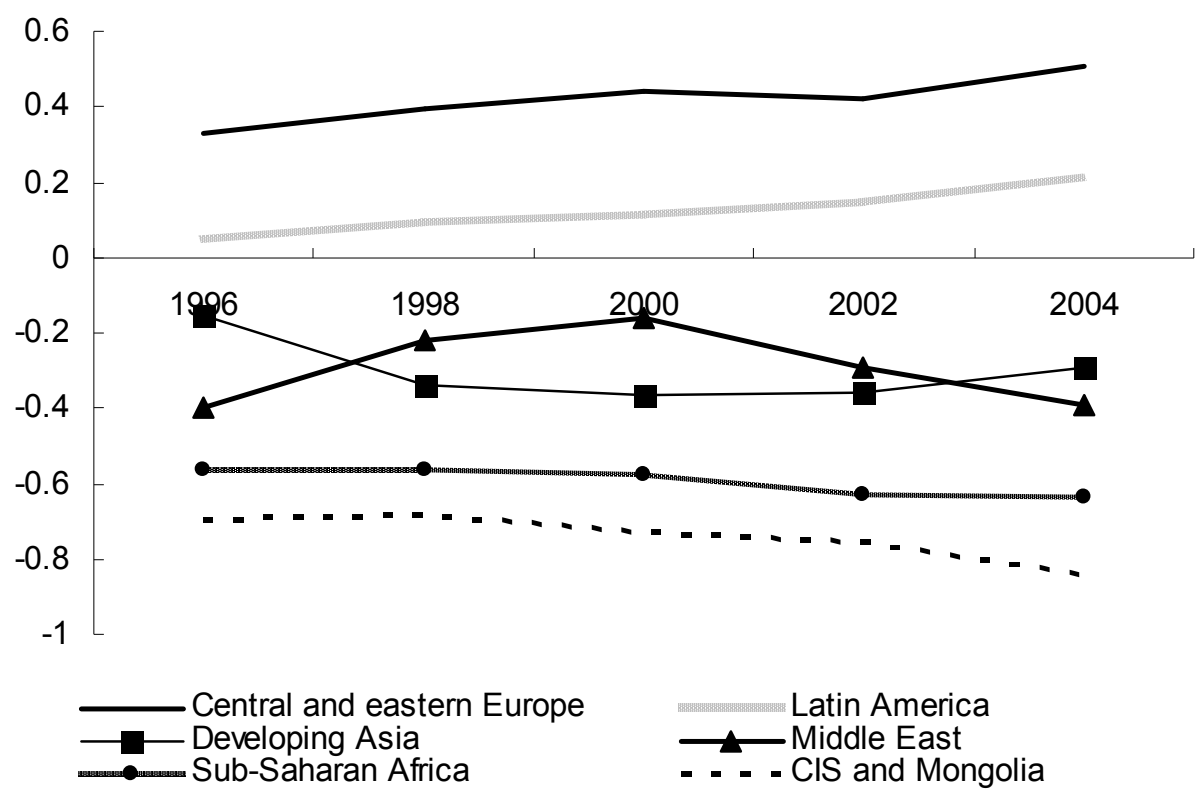

Sources: IMF and Kaufmann, Kraay, and Mastruzzi (2005). Institutional quality is the World Bank's Governance Indicators, ranging from -2.5 to 2.5. Regional scores are average scores. 
Figure 1.3-6: Political Institutions by Regions (1970 - 2003)

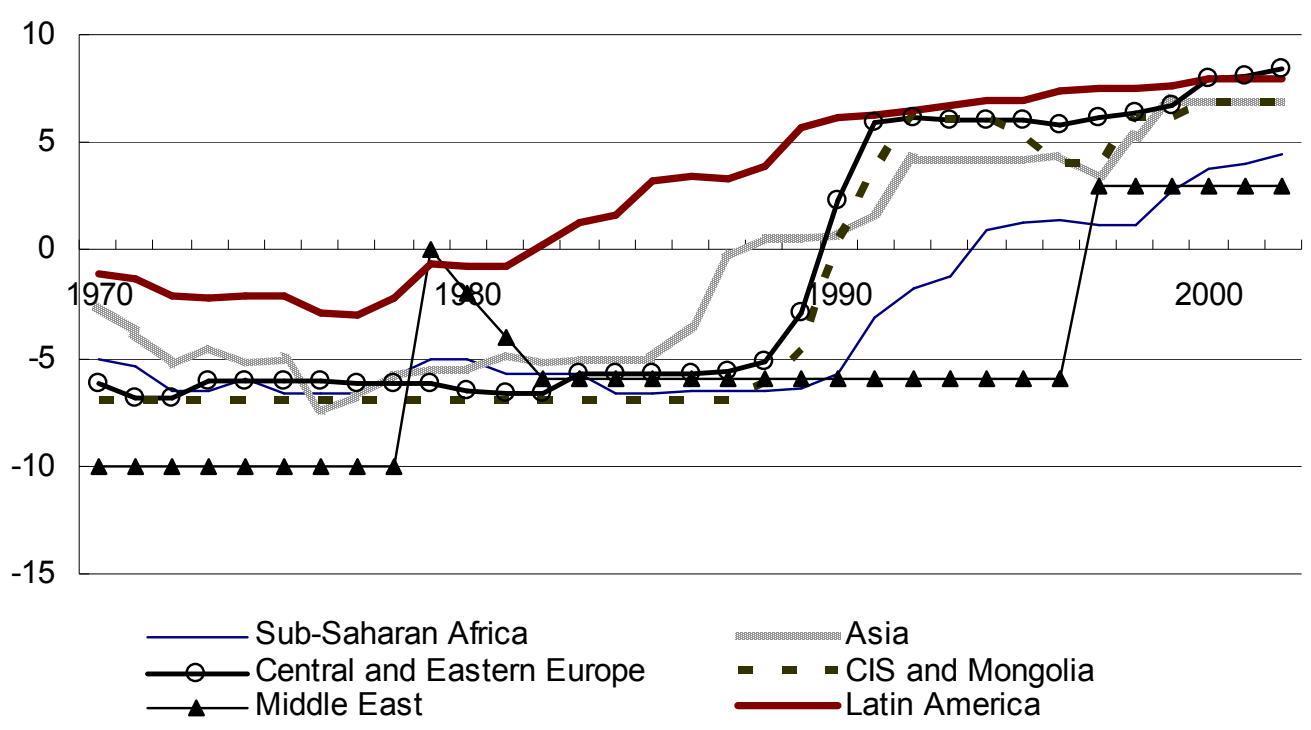

Source: IMF, Marshall and Jaggers (2003). Scores are regional average of Polity index. Scores from 0 to 10 denote democracy, whereas 0 to -10 denote autocracy.

\subsubsection{Quantitative Measures of Institutions}

However, one of the major problems of undertaking empirical work using quantitative measure of institutions is the lack of objective data for a sufficiently long time span. For this study, we have considered few data sources of measuring institutional quality and governance ${ }^{5}$. Not to mention the different aspects these variables are measuring, the time span of these data also greatly limit the proper choices we can make. We summarise the key features of selected data sources in Table 1.3.3-1 below.

For example, data from the International Country Risk Guide (ICRG), one of the most frequently used data sources in the literature, only start from 1984. The World Bank's Governance Indicators developed by Knack and Keefer (1995) on the other hand constitute different institutional measures such as quality of the bureaucracy, property rights, and the political stability of a country to measure cross-country "governance", and are only available since

\footnotetext{
5 For a complete review of governance/institutional indicators from different public and private sources, UNDP (2007)'s publication can be referred.
} 
1998. Fraser Institute's Economic Freedom Index spans relatively longer, starting from 1970. The only exception perhaps is the Polity IV dataset for measuring political institutions, which covers measurements of several decades.

Fraser Institute's Economic Freedom Index is so far, to the best of our knowledge, the most comprehensive set of indicators measuring economic freedom and, to some extent, institutional quality in general with the longest time span. It also covers a reasonable large number of economies. Data can be traced back to as early as 1970, in a 5-year interval for the earlier years and annually from 2000 onwards. As such, we rely heavily on these indices to measure economic institutions in the following chapters. 
Table 1.3.3-1 : Comparison of Selected Institutional Indicators

\begin{tabular}{|c|c|c|c|c|}
\hline & Data & $\begin{array}{l}\text { Time Span } \\
\text { Frequency }\end{array}$ & Aspects Covered & $\begin{array}{l}\text { No. of } \\
\text { Economies } \\
\text { Studied }\end{array}$ \\
\hline \multicolumn{5}{|c|}{ I. Political Institution } \\
\hline (1) & $\begin{array}{l}\text { Polity IV - Political Regime } \\
\text { and Authority Characteristics }\end{array}$ & $\begin{array}{l}\text { Start from } 1800 \\
\text { Annual }\end{array}$ & (1) Institutionalised democracy; (2) Institutionalised autocracy; (3) Regime durability & 161 \\
\hline (2) & $\begin{array}{l}\text { Freedom House - Annual } \\
\text { Survey of Freedom }\end{array}$ & $\begin{array}{l}\text { Start from } 1955 \\
\quad \text { Annual }\end{array}$ & $\begin{array}{l}\text { (1) Political rights (including electoral processes, political participation and pluralism, } \\
\text { functioning of government and discretionary questions) and (2) Civil liberties (freedom of } \\
\text { expression and belief, associational and organisational rights, rule of law and personal } \\
\text { autonomy and individual right) }\end{array}$ & 192 \\
\hline \multicolumn{5}{|c|}{ II. Economic Institution } \\
\hline (3) & $\begin{array}{l}\text { Fraser Institute - Economic } \\
\text { Freedom Index }\end{array}$ & $\begin{array}{c}\text { Start from } 1970 \\
\text { Annual since } 2000\end{array}$ & $\begin{array}{l}\text { (1) Size of government; (2) Legal structure and security of property rights; (3) Access to } \\
\text { sound money; (4) Freedom to trade internationally and (5) Regulation of credit, labour and } \\
\text { business. }\end{array}$ & 141 \\
\hline (4) & $\begin{array}{l}\text { Heritage Foundation - Index } \\
\text { of Economic Freedom }\end{array}$ & $\begin{array}{l}\text { Start from } 1994 \\
\quad \text { Annual }\end{array}$ & $\begin{array}{l}\text { (1) Trade policy; (2) Fiscal burden of government; (3) Government intervention in the } \\
\text { economy; (4) Monetary policy; (5) Capital flows and foreign investment; (6) Banking and } \\
\text { finance; (7) Wages and prices; (8) Property rights; (9) Regulation, and (10) Informal market } \\
\text { activity. }\end{array}$ & 161 \\
\hline (5) & $\begin{array}{l}\text { ICRG - International Country } \\
\text { Risk }\end{array}$ & $\begin{array}{l}\text { Start from } 1984 \\
\quad \text { Annual }\end{array}$ & (1) Economic risk; (2) Political risk, and (3) Financial Risk & 166 \\
\hline (6) & $\begin{array}{l}\text { World Bank (WB) } \\
\text { Governance Indicators }\end{array}$ & $\begin{array}{c}\text { Start from } 1996 \\
\text { Annual since } 2002\end{array}$ & $\begin{array}{l}\text { (1) Voice and accountability; (2) Political stability and absence of violence; (3) Government } \\
\text { effectiveness ; (4) Regulatory quality; (5) Rule of law, and (6) Control of corruption }\end{array}$ & 213 \\
\hline (7) & $\begin{array}{l}\text { WB Ease of Doing Business } \\
\text { Report }\end{array}$ & $\begin{array}{l}\text { Start from } 2004 \\
\quad \text { Annual }\end{array}$ & $\begin{array}{l}\text { (1) Starting a business; (2) Dealing with construction permits; (3) Employing workers; (4) } \\
\text { Registering property; (5) Getting credit; (6) Protecting investors; (7)Paying taxes; (8) } \\
\text { Trading across borders; (9) Enforcing contracts, and (10) Closing a business }\end{array}$ & 183 \\
\hline
\end{tabular}




\subsection{Research Objectives}

There is a broad agreement in academia that institutions play a fundamental role in economic development. Nevertheless, the question about which specific types of institutions actually relate to specific economic outcomes are not adequately addressed. Our primary research interest is to identify the channels through which development outcomes are affected by economic and political institutions directly.

During the course of doing so, we are aware that institutional changes did occur to various degrees across countries (see also IMF (2005)). Unlike previous studies that generally focus on cross-country long-term relationship, analysis in a dynamic setting is perhaps more relevant in this case. We also understand that economic and political institutions may take some time to change, policies could be in place sooner instead. Rodrik's taxonomy allows us to estimate the effects of institutions and policies in a unified framework. Besides, how domestic institutions relate to the role of policy and government interventions, as well as external institutions also raise our genuine curiosity to proceed with this piece of work.

Against this background, our key research questions can be summarised as a series of related themes as follows:

(a) Exactly what development outcomes are directly affected by institutional quality?

(b) Are these development outcomes affected by economic or political institutions, or macroeconomic policies or other economic fundamentals?

(c) Given that institutional changes do occur, do economic and political institutions cause changes in macroeconomic policies? Similarly, do macroeconomic policies cause institutional changes?

(d) Other than domestic institutions, do external institutions have any role to play in the development process?

With regard to development outcomes, we are interested in four specific 
aspects, namely economic growth, economic reforms, FDI and technical efficiency. With these in mind, hopefully the results can identify the channels through which institutions have direct effects on economic development. It may also help shed some light on any policy implications and help address the question of how better institutions can be built. One main characteristic of our analysis, which distinguishes ours from the previous ones surrounding this subject, is the use of panel data. Partly reflecting data limitation, existing literature is largely cross-sectional in nature. Using panel data can help taking into account of cross-sectional heterogeneity and thus minimise the risk of obtaining biased results arising from omitted variables in the specifications. Panel data also gives us more information, less collinearity, more variablility and more degree of freedom. In our case, the time dimension is important, which allows us to capture the effect of institutional changes. Using panel data can also let us study better the dynamics of adjustment. All in all, our contributions are intended to be entirely empirical.

\subsection{Organisation of the Thesis}

This thesis is composed of four empirical studies, which investigate the effects of institutions on cross-country economic development from different perspectives. In Chapter 2, we will revisit the empirical evidence of the effects of institutions on GDP per capita growth. Although the institution view literature largely suggests that institutions are the fundamental cause of growth, we find that the empirical evidences are rather inconclusive. It on one hand partly reflects that technical limitations - especially endogeneity are not adequately tackled in these studies. On the other hand, there appears no consensus to exactly what institutions cause growth as we mentioned earlier. Using Rodrik (2005)'s taxonomy aforementioned, we test the direct partial impact of these four clusters of institutions on growth using dynamic panel GMM estimation. The taxonomy provides a functional definition of institutions, allowing us to identify exactly what institutions matter to growth. At the same time, our methodology is technically improved without the need to look for "external" instruments to tackle the endogeneity problem. More 
importantly, we could estimate the effects of institutional change (i.e. the short-run effects of institutions) on growth, without assuming institutional persistence.

Chapter 3 is a brief extension of the previous one, with particular focus on the role of political institution - i.e. democratic regime. We investigate whether economic reforms are more likely to take place in democracies since greater accountability may lead the government to adopt measures that gain majority support. Economic reforms are referred as comprehensive measures that broaden the scope of the market and of the international market. Using the same methodology as in Chapter 2, we study whether democracy causes economic reforms in different sectors, namely fiscal measures, trade liberalisation, credit market liberalisation, capital account openness and labour market deregulation. Reciprocally, we will also test if economic reforms cause the democratisation process.

In Chapter 4, we will explore the determinants of FDI. Considering three sets of factors - natural barriers, "at-the-border" barrier (i.e. regional trade agreement) and "behind the border" barrier (i.e. domestic regulatory environment), we deploy an augmented gravity model to test if any one of these affect intra-OECD and inter-OECD bilateral FDI. The main aim is to study the impacts of external institution vis-à-vis domestic institution on one of the key aspects of global market extension - FDI.

In Chapter 5, our main objective is to explain the diverse economic performances across countries. We argue that different cross-country performances are the results of differences in technical inefficiency caused by the inefficient allocation of production inputs. We measure cross-country technical efficiency by means of estimating a stochastic production frontier. It represents a global production frontier, allowing us to estimate the best-practice and to segregate the effects of technical change and efficiency change for each country. We essentially intend to test the competing views of whether human capital, openness or institutions would explain such technical inefficiency. 
In Chapter 6, we will summarise all of our empirical findings obtained and briefly discuss their policy implications. We will also point out the limitations of our work and suggest extensions for further research. 
CHAPTER 2 : INSTITUTIONS AND ECONOMIC GROWTH - REVISITING THE EMPIRICAL EVIDENCE USING DYNAMIC PANEL GMM ESTIMATIONS 


\subsection{Introduction}

This is the first empirical analysis of this thesis. To explore the interaction between institution and economic development, the most direct analysis would be to study the growth impact of institution. After all, one of the means of improving the well-being of the society is through promoting economic growth, thereby narrowing the cross-country income differences.

The proposition that domestic institutions matter to economic growth is not new in the economic development literature. Nevertheless, there are competing views arguing that the role of institutions is too overplayed. Amongst others, critiques claim that geographical endowments, culture, religion, historical events are also key determinants. Other empirical works suggest that in fact human capital is an even more fundamental cause of economic growth. Exactly what institutions matter to economic growth is also very loosely defined. Others criticise that the institution view literature present evidence in a very long-run timeframe, assuming that institutions are persistent and without considering the effect of institutional change on the economic outcome today.

Although there is a vast amount of empirical evidence to support the institution view, the estimation strategies are being severely scrutinised. Critics rightly point out that the existing empirical literature is predominantly cross-sectional in nature, thereby ignoring the dynamic impact of institution on growth. Furthermore, they do not control for the country-specific and time characteristics. In addition, both institutions and economic growth understandably can be endogenously determined. Even though instrumental variable (IV) estimations are widely used to tackle such problem, the validity of instruments has called for many doubts. Last but not least, data quality and definition of institution are also subject to many criticisms.

In light of these limitations and comments, we propose to use a dynamic panel data model to revisit the issue. We attempt to test whether the institution has a direct partial impact on growth, after controlling for income level, 
time-invariant country-specific and time characteristics. Using GMM estimators in a dynamic panel data model allows us to estimate the impact of institution on economic growth without seeking "external" instruments, yet taken the problem of endogeneity into account.

In response to the question of exactly what institutions matter to growth, we adopt a unified framework developed by Rodrik (2005) for our empirical investigations. To recap, institutions refer to those that sustain the market operations of the economy under his taxonomy. He develops the taxonomy into four clusters, namely "market-creating" institution - measuring the security of property rights and contract enforcement, "market-regulating" institution - measuring the regulatory environment of the society, "market-stabilising" institution - measuring the fiscal and monetary institution to stabilise the market and finally "market-legitimising" institution - measuring the political regime which legitimises the market operation. As noted, this way of clustering brings three frequently, yet separately tested, dimensions of institutions - economic institution, political institution and policy - into synergy.

Against the background of all these inadequacies of the existing empirical literature, we attempt to revisit the empirical evidence of institution and growth for three main objectives. First, we jointly test the impact of economic and political institutions on growth using dynamic panel data models. Such methodology helps partially solve the problem of finding "external" instruments for tackling the weak endogeneity problem. Second, it allows country-fixed effect and within-country change over time to be controlled for. That said, we do not assume institutions persist. Third, we use Rodrik (2005)'s taxonomy as the operational framework for our assessment, adopting a unified approach to investigate the relative importance and direct partial impact of each type of institutions on growth.

All in all, we essentially try to answer do and what institutions cause growth. Our estimation results reflect the direct and short-run impacts of institutions on economic growth. The questions of whether they affect other dimensions of 
economic development will be further investigated in the coming Chapters.

This Chapter is organised as the following. We will present a brief literature survey in Section 2.2. Our estimation technique and data will be discussed in Section 2.3. The empirical results follow in Section 2.4. We conclude in Section 2.5.

\subsection{Literature Survey: Institution and Economic Growth}

A vast amount of theoretical and empirical work on institutions and growth has been developed in the last two decades. In the following, we briefly review the results of these key studies, their critics and empirical shortcomings. We will first compare three strands of views of cross-country economic development, namely endowment view, institution view and a combination of the two. We then proceed to the empirical results of testing the institution view with specific reference to economic and political institutions. Based on the literature survey, we summarise 6 key technical shortcomings of these empirics with an aim to provide justifications for the estimation we perform in the present Chapter.

\subsubsection{Endowment View on Economic Growth}

Traditional growth theories emphasize the role of human capital (e.g. Lucas (1988)), technological diffusion (e.g. Barro and Sala-i-Martin (1997)), public infrastructure (e.g. Barro (1990)) or incentives to innovate (e.g. Romer (1990)). North and Thomas (1973) nonetheless argue that institutions are the sources of cross-country differences in growth. This view was further echoed by Acemoglu, et al. (2005) and IMF (2005), claiming that institution is a more fundamental cause of growth. However, this institutional view of growth invites a major debate with the endowment view. The latter essentially argues that geographical factors directly shape the output, income distribution or technology adoption in the society. A third strand of the literature, hereafter developed, combines the essence of the institution and endowment views on 
growth. This strand opines that economic growth is not directly determined by natural factor endowment, but it will shape the policy and institutional choices of politicians and/or colonizers. These choices in turn have a positive and long-term effect of economic prosperity. This third strand largely dominates the empirical interests in the literature. We will discuss briefly these three competing and complementing views below.

\subsubsection{Direct Impact of Geography}

The endowment view claims that natural resources to population determine the productivity and technology in production. Earlier works like Engerman and Sokoloff (1997) provide a historical account and qualitatively argue that the composition of population, climate, soils and native populations in the United States and Canada significantly explained the relative distribution of wealth, human capital and the decentralized political power developed as compared to the development experiences of Latin America economies. Latin America economies, as they argue, enjoyed a climate and soil conditions that were extremely well suited for growing crops. Their populations then quickly generated vastly unequal distributions of wealth, human capital, and political power. The extensive native populations in the regions colonized by the Spanish were powerful factors leading to extreme inequality. In contrast, small, family-sized farms were the rule in the northern colonies of the North American mainland, where climatic conditions favoured a regime of mixed farming focused on grains and livestock that exhibited quite limited economies of scale in production and used few slaves. These regions do not appear to have been very attractive to Europeans during the first quarter of a millennium after they began to colonize the New World, since only a small fraction of the migrants to the New World opted to locate there. However, the circumstances fostered relatively homogeneous populations with relatively equal distributions of human capital and wealth.

Sachs and Warner (2001) postulate the "curse of natural resources", i.e. countries with great wealth of natural resources tend to grow more slowly than resource-poor countries. Their ordinary least square (OLS) estimations 
suggest that the average GDP per capita growth rate during 1970-1990 is negatively associated with the natural resource abundance variables. They explain that this curse may be due to the fact that resource-abundant countries are high-price economies and, thus, they tend to miss-out the opportunities of export-led growth. Arezki and Ploeg (2007) provide a more recent empirical evidence to support Sachs and Warner's hypothesis. Understandably, institutions, openness and income growth could be endogenously determined. Therefore, the authors use cross-country instrumental variable (IV) estimations to correct for the endogenous nature of institutions and openness ${ }^{1}$, they find a significant negative direct impact of natural resources on income per capita, as well as indirect effect of natural resources on institutions. In particular, the natural resource curse is particularly severe for economic performance in countries with a low degree of trade openness.

Other than natural resource endowment, disease burden provides another explanation for poor economic performance. Diamond (1997) and Gallup, Sachs, and Mellinger (1998) share similar views that adverse geographical conditions hamper agricultural productivity and habitants' health. Gallup, et al. (1998), one of the earliest empirical works supporting the endowment view, investigates the ways in which geography may matter directly for growth. Their OLS empirical results show that location and climate of the economy have large direct effects on income levels and income growth through the effects on transport costs, disease burdens and agricultural productivity. The results survive even after controlling for the quality of public institutions ${ }^{2}$. They also find that poor regions are typically characterise with locations far from the coast, implying that they face large transport costs for international

\footnotetext{
1 They incorporate the rule of law index from Kaufmann and Kraay (2002) to measure institution and de facto openness (i.e. total trade as percentage of GDP) in their estimations which suffer from endogeneity bias. Hence, they instrument the regressors with a combination of UK legal origin, log of settler mortality, fraction of population speaking English, and a bilateral gravity estimate of openness. Literature relating to the use of these instruments will be discussed further in the coming Section. The use of IV estimation helps tackle the problem of endogenetiy. If ignored, the least square estimators are biased and inconsistent estimator.

${ }^{2}$ The quality of public institutions is based on an index created by Knack and Keefer (1995), which is an average of five indicators, including (a) the perceived efficiency of the government bureaucracy, (b) the extent of government corruption, (c) efficacy of the rule of law, (d) the presence or absence of expropriation risk, and (e) the perceived risk of repudiation of contracts by the government.
} 
trade, as well as populations in tropical regions of high disease burden. Comparing different regions, Sachs (2000) similarly find that tropical areas have a higher infectious disease burden than temperate zones, leading to greater economic prosperity in the latter. Bloom and Sachs (1998) suggest that the prevalence of malaria also partially explain the poor economic performances in Sub-Saharan countries.

Inevitably, the endowment view is not free from counter-arguments. Olson (1996) argues that natural resources do not account for diverse cross-country economic performances over time since most economic activities today are separated from raw materials and arable land. Technological improvement and sectoral change (greater proportion of manufacturing and service industries) are no longer resource-dependent. Acemoglu, et al. (2005) on the other hand, by providing a real life natural experiment - North and South Korea, strongly over-rule the importance of geography. In terms of geographical features, both regions are extremely similar in almost all perspectives, not to mention their cultural heritage. The striking diverge economic performances of the two parts, as they argue, are due to political and economic institutions much more than any other possible aspects of economic development.

\subsubsection{Indirect Impact of Geography via Institutional Choice}

Built on the endowment view, another strand of literature argues that geographical conditions do not directly affect growth, but endowments determine the institutional structure brought by colonizers and policies chosen by politicians. Hall and Jones (1999) is probably the earliest core empirical paper to consider the impact of "social infrastructure" per capita. The authors explicitly link such understanding with North's criteria of institution - i.e. institutions that bring social returns of private

\footnotetext{
${ }^{3}$ As they recognise, "social infrastructure" essentially refers to an environment that supports productive activities, capital accumulation, skill acquisition, invention and technology transfer. In practice, social infrastructure is estimated by two indices in their work: (1) the average score of (a) law and order; (b) bureaucratic quality; (c) risk of expropriation; (d) government repudiation of contracts, and (e) corruption from the International Country Risk Guide (ICRG) of Political Risk Service, and (2) openness to international trade based on Sachs and Warner (1995).
} 
actions as private returns. They find that differences in social infrastructure are largely associated with cross-country differences in capital accumulation, educational attainment and productivity. This in turn explains the cross-country difference in output per worker. While they acknowledge that social infrastructure and output per worker are endogenously determined, IV estimation is used. The authors propose to instrument social infrastructure by geographical and historical factors of "Western influence". The underlying hypothesis is that the importance of property rights and systems of checks and balance in government came from Western Europe. Western influences via earlier settlers' institutional transplantation thus determine the development of social infrastructure. Western Europeans were also more likely to settle in areas further from the equator where climate is similar to Western Europe. As instruments, therefore, the geographical distance from the equator and fraction of country's population speaking one of the five Western European languages are likely to be correlated with social infrastructure.

Making reference to the effect of European diseases in the New World after 1492 and local disease environments on the colonization strategies of Europeans around the world from 1500 to 1900, Acemoglu, Johnson, and Robinson (2003) on the other hand claim that health conditions and disease environments do not have first-order effect on income, but instead on institutions. Disease environments play an important role in shaping institutional development, thereby the path of economic development. The authors hypothesise that when two previously isolated populations come into contact, disease environments influence the balance of power between these populations and the type of institutions of the more powerful imposes the institutional structure on the less powerful.

Based on this institutional transplantation argument, Acemoglu, Johnson, and Robinson (2001) propose an innovative "instruments" for the institution and growth empirics. Since IV estimation is so often used to tackle the problem of endogeneity between institution and economic growth, these proposed "instruments" naturally are so frequently used in nearly all empirical works of the subject that come after. In essence, the authors claim that an unfavorable 
climate induced a higher rate of European settlers' mortality, which discouraged them to imbed good institutions (i.e. providing protection against expropriation risk) in that colony. Under such circumstance, they were more likely to develop a predatory state without introducing good institutions for economic growth. These institutions persisted to the present, thereby affecting present economic performance. In other words, physical geography per se hardly explains growth in a direct manner, but it affects the quality of institution transplanted. In their 2SLS estimations, they regress current economic performance with current institution, with the latter instrumented by settlers' mortality rate. They conclude that once the effect of institutions is controlled for, countries in Africa or those closer to the equator do not have lower incomes due to poor institutions.

McArthur and Sachs (2001), however, use a wider sample of countries to refute the idea that geography determines institutional choice. They find that in fact both geography and institutions matter for growth. Their major critic is that it is hard to see why the determination of institutions strongly relates to physical geography. Glaeser, Porta, Lopez-de-Silanes, et al. (2004) also claim that one should not overestimate the effect of geography on economic development via institution. According to their empirical studies, a more basic source of growth may be simply human capital only, rather than institutional quality. They provide an alternative explanation to Acemoglu, et al. (2001)'s results by arguing that geographical conditions do not necessarily relate to the quality of institutions with which colonizers brought, but rather the conditions determined if the Europeans stayed in the colonies as a form of human capital which drove growth. More recently, Albouy (2008) also casts doubt on Acemoglu, et al. (2001)'s settlers mortality rate data. He finds that 36 of the 64 countries in the sample are assigned mortality rates from other countries, typically based on mistaken or conflicting evidence. Incomparable mortality rates from populations of laborers, bishops, and soldiers are combined in a manner favouring the hypothesis. After controlling for these data issues, he realises that the relationship between mortality and expropriation risk lacks robustness, and IV estimates become unreliable. 
More recently, Nunn (2009) suggests a historical view that the largest effects of geography on current economic development may work through its influence on past events (i.e. history) rather than through its direct effect on economic outcomes today. In his view, institution is the channel through which history matters to economic development. He does not postulate that geography determines institutional choice. Instead, institutions together with culture, knowledge and technology determine the movements of the economy between multiple equilibria of the state of development. All these views together weaken the causal direct relationship between geography and institutions.

\subsubsection{Institution View: Economic vs. Political Institutions}

The institution view essentially argues that institution is the fundamental source of growth. Empirical studies have been developed into two separate strands, namely the effect of economic and political institutions. We highlight few core empirical studies below.

\subsubsection{Economic Institutions and Growth}

As we have discussed before, Acemoglu, Johnson, and Robinson (2002) suggest that economic institution were developed by colonial transplantation and thus refute the endowment view completely. Their key observation of "reversal of fortune" is that, among countries colonized by European powers during the past 500 years, those that were relatively rich in 1500 are now relatively poor. They find that economic prosperity in the past, measured by urbanization and population density, does not link to geographic factors. In contrast, they suggest that this reversal actually reflects changes in the institutions resulting from European colonialism. European colonialism led to the development of institutions of private property in previously poor areas, while introducing extractive institutions or maintaining existing extractive institutions in previously prosperous places. The main reason for this is that relatively poor regions were sparsely populated, and this enabled or induced Europeans to settle in large numbers and develop institutions encouraging investment. In contrast, a large population and relative prosperity made 
extractive institutions more profitable for the colonizers. In their 2SLS regressions, they show that mortality rates faced by settlers, as proposed by Acemoglu, et al. (2001), are a good instrument for settlements of Europeans in the colonies, i.e. conditional on the other controls, the mortality rates of European settlers more than 100 years ago have no effect on GDP per capita today, other than their effects through institutional development that subsequently affects the growth rates today.

La Porta, Lopez-de-Silanes, Shleifer, et al. (1997) and La Porta, Lopez-de-Silanes, Shleifer, et al. (1998) examine specifically the importance of colonial rule in relation to financial development as a result for investor protection. They focus on how legal institutions were transplanted by the different colonial powers. Their analysis emphasises that differences between legal systems based on British common law versus French civil law provide different degrees of investor protection. In their 2SLS estimations, their results show that civil law economies, relative to those with common law countries, have less investor protection. In the second stage estimations, they show that countries with weaker investor protection have smaller debt and equity markets. As Nunn (2009) points out, nevertheless, a large amount of literature emerged which show that legal origin is also correlated with a host of other country characteristics, including labour market (Botero, Djankov, La Porta, et al. (2004)) and even economic growth (Mahoney (2001)). This inevitably calls into question the validity of using legal origins to be instruments in the IV estimation. Such problem is also mentioned by the authors themselves in La Porta, Lopez-De-Silanes, and Shleifer (2008).

More recently, Acemoglu and Johnson (2005) attempt to unbundle which institutions affect economic development. They define institutions into two forms - (i) "property rights institutions", which protect citizens against expropriation by the government and powerful elites, and (ii) "contracting institutions", which enable private contracts between citizens. In practice, they are measured by "protection against risk of expropriation" and "constraints on executives" from the Polity IV dataset respectively. Using settler mortality rate as instruments, their cross-sectional IV estimations show 
that property rights institutions have a first-order effect on long-run economic growth, investment, and financial development. Contracting institutions appear to matter only for the form of financial intermediation, including credit and stock market capitalisation.

\subsubsection{Political Institution and Growth}

Empirical results on the positive impacts of economic institution on growth are not particularly controversial despite all the diversities of views aforementioned. However, the effect of political institutions on economic growth, especially political regime like democracy, is far from conclusive. Research interests have been actively revived since Olson (1993). According to his theory, the state can either be a 'stationary bandit' or 'roving bandit'. The former possesses uncontested 'ownership' of the streams of income generated by the private agents in the economy. The stream of income becomes part of the endowment, enabling the state to prosper. A stationary bandit will invest and nurture the economy, which will increase the level of investment in the economy. On the contrary, a roving bandit possesses little incentive to conserve since the prosperity of the nation will be enjoyed by the next bandit. In short, the investment level, which determines economic growth, will depend on the incentive structure of the state.

Subsequent research followed by relating how authoritarian (or totalitarian) regime and democratic regime behave like stationary and roving bandit. Nevertheless, there has been no straightforward argument on political regimes and policy choices.

Among others, Przeworski and Limongi (1993) claim that if property rights are secured, then it promotes investment and suppresses immediate consumption sensibly. However, it is not clear why democracy secures property rights and provides this credible commitment. They propose a theoretical framework to suggest that there may exist an "optimal size of the State", in other words, either political regime implies it is more efficient than the others. An altruistic dictator may be better at mobilizing savings, while democracies are 
better at allocating investment. Democracy can potentially be positive to economic development because of the competition amongst interest groups.

The form of democracy also matters for the adoption of structural policies that promote growth. By means of cross-section and panel data analysis, Persson (2005) finds that reforms in parliamentary (as opposed to presidential) and proportional (as opposed to majoritarian) and permanent (as opposed to temporary) democracy appear to produce the most growth-promoting policies. Roll and Talbott (2002) and Persson (2005) investigate the effect of democratic transitions on income while Giavazzi and Tabellini (2005) study interactions between political and economic reforms. In overall terms, these papers suggest positive correlation between democracy and growth.

However, Andreski (1969) argues that democracy contributes to stagnation rather than growth because of the lack of investment and capital, and to the necessity of choosing between investment for the future and immediate consumption. It may also result that resources are wasted for interest groups for lobbying (Becker (1983)). In short, whether democracy has a direct growth impact is yet conclusive.

Glaeser, et al. (2004) revisit the question of whether political institution causes economic growth, or whether growth and human capital accumulation lead to improvements in political institutions. They criticise that in fact most of the political institution variables are not suitable for quantitative analysis. OLS and IV techniques are biased and mostly flawed. They discuss three sets of commonly used variables measuring political institution. The first is the survey indicators of institutional quality from International Country Risk Guide (ICRG). The second set is an aggregated index of survey assessments of government effectiveness from Kaufmann, Kraay and Mastruzzi (2003). The third is the Polity IV dataset which aims directly at measuring the limits of executive power. Glaeser, et al. (2004) criticise that the three datasets actually measure potential outcomes (e.g. bureaucratic quality or government effectiveness), but not some permanent characteristics of the political environment, i.e. the constraints imposed to the governments. From their 
point of view, the first two sets of political institutions variables are constructed in a way that dictators freely choosing good policies receive as high evaluations as governments constrained to choose them. The Polity IV variables, in their view, are the only acceptable yet imperfect measure. The Polity IV variables are intended to focus on political constraints, but they too reflect political outcomes rather than durable constraints. In any case, their OLS results using the Polity IV indicators suggest that human capital is a more fundamental source of growth than political institutions are.

On tackling the problem of endogeneity, Rigobon and Rodrik (2004) suggest that the search of exogenous instrumental variables is truly difficult to justify. In fact, existing instruments for institutional quality are correlated strongly with geographical variables and with human capital. It thus raises interpretational questions about what is being identified. To estimate the interrelationships among economic institutions, political institutions, openness, and income levels, they deploy the strategy of identification through heteroskedasticity (IH) as developed in Rigobon (2003). The main merit of this approach is no need to find proper instruments. Instead, they exploit the difference in the structural variances in two sub-samples (including (i) colonies versus non-colonies; and (ii) continents aligned on an East-West versus those aligned on a North-South axis) to gain identification. The authors reassess the competing views of economic and political institutions and trade openness on economic growth. Their empirical evidence suggests that democracy and the rule of law are both good for economic performance, with the latter having a much stronger impact on incomes. Openness (measured by trade share of GDP) has a negative impact on income levels and democracy, but a positive effect on rule of law. Reciprocally, higher income produces greater openness and better institutions, but these effects are not very strong. Rule of law and democracy tend to be mutually reinforcing.

\subsubsection{Empirical Results of Testing the Competing Views}

Against these competing hypothesises, Easterly and Levine (2003) 
systematically test three different views together - endowment view, institution view and effect of macroeconomic policy (called policy view for simplicity) using cross-country data. Their OLS estimates reject the endowment view that settler mortality rates, latitude, whether the area is landlocked and crops/minerals productions, do not have any direct impact on the real GDP per capita in 1995 nor on other policies variables (measured as trade openness, inflation, and real exchange rate overvaluation) after controlling for institutions, legal origins, religions composition or ethnolinguisitic diversity. Nevertheless, geography does associate with institutions. Using IV estimations, their empirical results show strong positive impacts of endowments on institutional development but not just on GDP per capita. Even more, macroeconomic policies do not help explain economic development after accounting for the impact of institutions.

Comparing similar competing views, Rodrik, Subramanian, and Trebbi (2004) use cross-sectional data to estimate the respective contributions of institutions, geography, and trade to cross-country income levels using IV estimations. Their key results suggest that the quality of institutions "trumps" everything else. They show that once institutions are controlled for, geography only has an indirect effect by influencing the quality of institutions. Similarly, trade is almost always insignificant. These results still stand in a series of robustness checks after using different measures of geographical variables and instruments. Sachs (2003), on the contrary, comments that IV estimates of such kind are biased. He insists that since initial settler mortality rate has a direct and persistent effect on income today, the exclusion restriction of instruments - the geographical characteristics - is thus not satisfied. In his follow-up work, he proposes that malaria risk, which is strongly affected by ecological conditions, directly affects the level of per capita income after controlling for the quality of institutions. The quality of institution, measured as average risk of expropriation, however shows no direct effect on income.

Inconclusive empirical evidence also arises from the use of different measures of geography and institutions. Presbitero (2006) argues that the institution view is not as strong as it may appear. His empirical work shows that 
geographical factors related to the health and sanitary conditions and to the accessibility to the sea of a country indeed play a more direct role in economic development. Kangur (2008) suggest that existing empirical results are not robust to alternative measures of institutional quality and/or respective instruments. In particular, settler mortality rate proposed by Acemoglu et al. (2001) is not a dominant instrument for institutional quality, which is potentially prone to fail to satisfy the exclusion restriction. He concludes that, in comparison, human capital and geography appear to come out as winners amongst all these determinants of economic development.

\subsubsection{Critics of Existing Institutions and Growth Literature}

Although the claim that institutions matter to growth has come to an academic conclusion, empirical evidence remain inconclusive. This indeed reveals several key technical problems. Even in those works that provide support to the institution view, the estimates obtained are arguably biased, primarily because of the endogeneity problem in these growth empirics. The instruments used are also subject to many critics and do not robustly show their validity. Also, despite all the positive empirical results, there is no consistent measurement of what institutions are referring to.

To discuss the various critics of the existing literature in proper perspective, we highlight 6 key shortcomings of the relevant literature below with an aim to provide justifications for the estimation strategy employed in this study. These problems generally concern the data and methodology. For easy reference, an overview of the existing empirical work of institution and growth is provided in Appendix Section A.1.

\subsubsection{Data Problem: Availability, Credibility and Comparability}

The lack of consensus of exactly what institutional variables should be used in empirics is partially caused by the availability of data. Firstly, the lack of an operational and consistent definition of institution hampers the comparability of the empirical studies. The scope of measurement also invites more 
questions than answers. In fact, most of the variables used in the empirical studies are not specifically developed or derived from theoretical models. In most of the cases, these variables are employed as different types of proxies of institutions to suit the models' particular needs. Therefore, "institutions" are fairly loosely defined. Harper (2003), for example, argues that an operational definition of, say, economic freedom is absent and the weights put on each sub-categories are very doubtful. Glaeser, et al. (2004), likewise, challenge the measures in the sense that they are not exactly measuring what "institutions" are supposed to mean, i.e. constraints of possibility choice sets.

Secondly, these variables, for example the predominantly used ICRG's quality of institution and Fraser Institute's Economic Freedom Index, are often composed of a combination of qualitative survey results and quantitative data. Inevitably, the use of subjective quantitative data is being heavily criticised. Indeed, most of the institutional data are subjective. Also, it is not uncommon to find that different qualitative measures cross-referenced from similar sources significantly. For example, Fraser Institute's Economic Freedom Index draws different measures of regulation from ICRG and World Bank's Ease of Doing Business Indicators to construct a composite regulation index. This thus presents particular difficulty to carry out robustness tests using alternative proxies.

Thirdly, the time span of data is often quite limited, in particular to those measuring economic institution. This also explains why most of the existing literature is cross-sectional in nature.

\subsubsection{Reverse Causality: Economic Growth causes Institutional Change}

The literature also suggests reverse causality between institutions and economic growth. Amongst others, Chong and Calderon (2000) argue that that most of the studies concerning institution and economic growth have not paid enough attention to the possibility that economic growth may lead to better institution. Their hypothesis is that the poorer the country, and the longer the wait, the higher the influence of institutional quality on economic 
growth once growth kicks off.

Rosenberg and Birdzell (1986) also provide a hypothesis why income can cause institutional development. They explain that systems that protect property rights, such as the judiciary, first require the development of a volume of commerce large enough before actual mechanisms and regulations can be properly instituted. Eggertsson (1990) also suggests that higher income levels may lead to stronger institutions when property rights become more valuable, more is spent to protect them. Furthermore, Mauro (1995) also opines that good economic performance increases institutional efficiency.

Farr, Lord, and Wolfenbarger (1998) test the causality relationship formally. They use the dataset from Business Environmental Risk Intelligence (BERI) to measure institutions, which covers: (i) contract enforceability, (ii) nationalisation potential, (iii) infrastructure quality, and (iv) bureaucratic delays and test the causation on income growth rates. Using Granger causality, their empirical results surprisingly show that the BERI index does not contain useful information for predicting future economic growth. Nevertheless, economic growth appears to generate higher institutional quality. The causal relationship is statistically significant and contributes about $61 \%$ of the linear association between these two variables. Even using individual BERI components, the casual direction from economic growth to institutional quality remains higher than the one from institutions to growth.

\subsubsection{Endogeneity and Validity of Instrumental Variables}

The problem of endogeneity induces biased results. Briefly discussed before, IV estimation appears to be the most favourable strategy for this subject. The instruments used for IV estimation so far are principally derived from La Porta, et al. (1997) and La Porta, et al. (1998)'s legal origin, Acemoglu, et al. (2001)'s European settler's mortality rate and Alesina, Devlieeschauwer, Easterly, et al. (2003)'s religion, ethnic and languages fractionalization. Collectively, these instruments intend to introduce time-invarying factors, e.g. geography (distance from equator and predicted trade share, oil exporters, disease burden 
etc) and colonial origins into the analysis of current income.

There are however very few justifiable variables to be used. As a result, the same instrumental variables are often naturally used in different studies for different indicators of institutions, regardless the latter is referring to expropriation risk, rule of law, or average quality of institution. Pande and Udry (2006) also wonder on the small amount of instruments developed so far despite the huge amount of empirical studies on the subject.

\subsubsection{Institutional Persistence vs. Institutional Change}

Most of the empirical works done so far are cross-sectional analyses, aiming at estimating the long-run impact of institutions on growth. They are designed in the way to investigate how the average scores of institutions over a long period of time can associate with the present GDP per capita. The use of time-invariant instruments implicitly assumes that institutions are quite persistent. Technically speaking, such design of the instruments also does not allow the researchers to identify the consequences of institutional change for growth. In other words, these cross-country studies cannot capture the effect of dynamic institutional change on growth, in particular, within country variation over time.

\subsubsection{Omitted Variables: Country- and Time-Specific Effects}

In terms of econometrics, the time-invariant instruments could not be used in a panel-setting, especially in a fixed-effect model, since all these time-invariant characteristics will be absorbed into the unobserved fixed-effects. Unfortunately, such country-specific and time-specific effects are too significant to be ignored in growth empirics. Acemoglu, et al. (2008), while showing that democracy and higher income may well be mutually reinforcing, suggest that the strong correlation between the two may be driven by variables that related to colonial heritage and early institutions. This also implies the importance of incorporating that country-specific effect in growth empirics. Only recently, there are very few studies on the subject using panel data 
analysis, although it has long been recognised that the dynamic nature of institutional change is very important (Acemoglu and Johnson (2005)).

\subsubsection{Specification Problem: Growth Rates vs. Income Level}

Sachs (2003) criticised the institution view that empirical studies of institutions and growth suffer from specification problem, in particular to static versus dynamic growth models. Economic theory suggests that per capita income should be specified as a dynamic process (e.g. Barro and Sala-i-Martin, 1997), in which the growth of income during a time interval $[0, t]$ should be a function of the income level at the start of the period and some kind of average of the values of the regressors during the time interval $[0, t]$. In short, growth models typically specify cross-country growth in country $i$ as

$$
\dot{g}=\alpha+\beta \ln y_{i T}+\gamma I_{i}+\delta X_{i}+\varepsilon_{i}
$$

where $\dot{g}$ is the average growth rate of GDP per capita, $y$, over a period, T indicates a particular chosen year, say 1960. $\ln y_{i T}$ intends to capture the initial level of development and $\beta$ represents the rate of convergence. $I$ is a vector of institutional variables and $\boldsymbol{X}$ is a vector of macroeconomic and social variables.

Sachs (2003) is of the view that it is much more likely the quality of institutions in a given time period will affect the growth rate of the economy during that period (controlling for initial income), as opposed to the contemporaneous level of national income as in Hall and Jones (1999).

Against all these limitations in the literature, we propose to use dynamic panel GMM estimation technique in the present study. In this framework, the use of panel data could incorporate country- and time-specific effects which help alleviate the problem of omitted variables. We also use GDP per capita growth rate instead of income level. The key advantage of this methodology is that we do not need to seek "external" instruments to deal with endogeneity. 
In the following section, we will discuss the estimator in greater details.

\subsection{Empirical Strategy and Data}

In this section, we will discuss the baseline specification of our model, the empirical strategy employed (i.e. dynamic panel GMM estimator) and data used.

\subsubsection{Baseline Specification}

We convert eq.(2.2-1) into a panel data setting and thus we can study within country variation as well as cross-country variations. The baseline specification model is modified as:

$$
\ln y_{i t}-\ln y_{i t-1}=\theta_{0}+\theta_{1} \ln y_{i t-1}+\theta_{2} I_{i t}+\theta_{3} X_{i t}+u_{i}+\delta_{t}+v_{i t}
$$

$\ln y_{i t}-\ln y_{i t-1}$ is the growth rate of GDP per capita of economy $i$ for period $t$. $I_{i t}$ is a vector of institutional variables. $\quad X_{i t}$ is a vector of macroeconomic and social variables. $u_{i}$ is the country-specific effect absorbs time-invariant factors, such as culture, legal origin, historical determinants and other geographical endowments being the determinants of economic development as proposed in earlier literature. $\delta_{t}$ is a period-specific dummy to capture structural changes that are common to all countries. $v_{i t}$ is an idiosyncratic error in the model.

Our specification intends to be canonical in nature. Eq.(2.3-1) forms our baseline specification. To get rid of the short-term effect of cyclical dynamics, the dependent and independent variables are taken as a non-overlapping 5-year average. Data span from 1970 to 2004 , with seven periods in total (i.e. $\mathrm{t}=$ 1970-74, 1975-79, .., 2000-04). 


\subsubsection{Estimation Strategy}

Traditional growth regressions like the one in eq.(2.2-1) generally carry the problems like endogenous regressors, measurement errors and omitted variables (e.g. Acemoglu (2009)). Given these problems, least square estimations are biased since unobserved omitted variables may potentially correlate with one of the regressors.

The use of panel data helps alleviate the problem of omitted variables by taking into account of country-specific and time-specific effects. Islam (1995) is among the first to adopt the panel data approach for growth regressions, thus allowing the unobserved time-invariant country-specific effect to be controlled for.

To tackle the problems of endogeneity and measurement error, the frequently used approach of 2SLS in the standard institution and growth literature aims at alleviating the problem of endogeneity by introducing innovative instruments, such as settlers' mortality rate, legal origins, ethnic or language fragmentation. Nevertheless, as discussed earlier, researchers recently cast doubt on the validity of these instruments in growth empirics. This reverts to the old problem of finding an "appropriate" instrument for growth regressions. Moreover, a dynamic growth model as specified as eq.(2.3-1) is also prone to “dynamic panel bias" (Nickell (1981)) since the lagged dependent variable is correlated with the disturbance terms.

Arising from this, Arellano and Bond (1991) propose the application of first-differenced generalized method of moments (GMM) estimators to estimate a dynamic panel data model. Blundell and Bond (1998) separately develop a system GMM estimator by introducing an additional stationarity restriction to the "differenced GMM" estimator. Such approach is further used in growth regressions by Caselli, Esquivel, and Lefort (1996), Benhabib and Spiegel (1997), Benhabib and Spiegel (2000), Easterly, Loayza, and Montiel (1997), Forbes (2000) and Levine, Loayza, and Beck (2000) among 
others.

\subsubsection{Linear GMM Estimator}

In the following, we will briefly discuss the linear GMM estimator and its use in a dynamic panel data model. The discussion below relies heavily on Roodman (2009). The basic set up is defined as:

$$
y=x^{\prime} \beta+\varepsilon
$$

where $\beta$ is a column vector of coefficients to be estimated in the model. $\mathbf{y}$ and $\boldsymbol{s}$ are random variables and $\mathbf{x}$ is a column vector of $\boldsymbol{k}$ regressors. Let assume there exists a $\mathbf{z}$ column vector of $j$ instruments, where $\mathbf{x}$ and $\mathbf{z}$ may share the same elements with $\mathbf{j}>k$ and $\operatorname{corr}(z, x) \neq 0$. Let $\mathbf{X}, \mathbf{Y}, \mathbf{Z}$ and $\mathbf{E}$ represent $\mathrm{N}$ observations for $\mathbf{x}, \mathbf{y}, \mathbf{z}$ and $\varepsilon$. $\hat{\mathbf{E}}$ is the empirical residual given by an estimate $\vec{\beta}$. Since all the instruments are theoretically orthogonal to the error term (i.e. $\mathbf{E}[\mathbf{z e}]=0$ ), our aim is to obtain an estimate such that $\frac{1}{\mathrm{~N}} \mathbf{Z}^{\prime} \mathbf{E}$ converges to zero or is minimized. Also, since given $\mathbb{1}>k$, the system is over-identified. Let $\mathbf{A}$ be a matrix with positive semi-definite quadratic form and weights moments, such that

a

$$
\frac{1}{\mathrm{~N}} \mathbf{Z}^{\prime} \mathbf{E} \|_{\mathbf{A}} \equiv \mathbf{N}\left(\frac{1}{\mathrm{~N}} \mathbf{Z}^{\prime} \hat{\mathbf{E}}\right)^{\prime} \mathbf{A}\left(\frac{1}{\mathrm{~N}} \mathbf{Z}^{\prime} \hat{\mathbf{E}}\right)=\frac{1}{N} \hat{E}^{\prime} Z A Z^{\prime} \hat{E}
$$

The consistent linear GMM estimator $\widehat{\beta}_{\mathrm{A}}$ solves the problem of argmin $\left.{ }_{\beta} Z^{\prime} \widehat{E}\right|_{A} \cdot$ This suggests that

$$
\bar{\beta}_{\mathrm{A}}=\left(X^{\prime} Z A Z^{\prime} X\right)^{-1} X^{\prime} Z A Z^{\prime} Y
$$


In other words, the consistent GMM estimator hinges heavily on the assumption that the instruments are orthogonal to the errors. In finite sample, nevertheless, the instruments are often at least slightly correlated with the endogenous components of the instrumented regressors. This suggests that this estimator is biased.

For efficiency, A must weight moments in inverse proportion to their variances and covariances. This indicates a possible efficient GMM (EGMM) moment weighting matrix as:

$$
\mathbf{A}_{\mathrm{EGMM}}=\operatorname{var}[\mathbf{z z}]^{-1}=\operatorname{plim}_{\mathrm{N} \rightarrow \infty} \mathrm{N} \operatorname{var}\left[\frac{1}{\mathrm{~N}} \mathbf{Z}^{\prime} \mathbf{E}\right]^{-1}
$$

The EGMM estimator can then be expressed as,

$$
\widehat{\beta}_{\text {gCMM }}=\left(\mathbf{X}^{\prime} \mathbf{Z} \operatorname{var}[\mathbf{z \varepsilon}]^{-1} \mathbf{Z}^{\prime} \mathbf{X}\right)^{-1} \mathbf{X}^{\prime} \mathbf{Z} \operatorname{var}[\mathbf{z \varepsilon}]^{-1} \mathbf{Z}^{\prime} \mathbf{Y}
$$

To turn the EGMM estimator feasible, we have to make some initial assumption relating to $\operatorname{var}[\mathbf{z \varepsilon}]$, which can be expressed as

$$
\begin{aligned}
\operatorname{var}[\mathbf{z E}] & =\operatorname{plim}_{\mathrm{N} \rightarrow \infty} \mathrm{N} \operatorname{var}\left[\frac{1}{\mathrm{~N}} \mathbf{Z}^{\prime} \mathbf{E}\right]=\operatorname{plim}_{\mathrm{N} \rightarrow \infty} \mathrm{N} E\left[\frac{1}{\mathrm{~N}^{2}} \mathbf{Z}^{\prime} \mathbf{E E}^{\prime} \mathbf{Z}\right] \\
& =\operatorname{plim}_{\mathrm{N} \rightarrow \infty} \frac{1}{\mathrm{~N}} \mathbf{E}\left[\mathbf{Z}^{\prime} \boldsymbol{\Omega Z}\right]
\end{aligned}
$$

Given eq.(2.3-7), $\mathbf{A}_{\mathbf{E G M M}}$ could then be understood as $\left(\mathbf{Z}^{\prime} \mathbf{H Z}\right)^{-1}$ as $\mathrm{N}$ increases, where $\mathbf{H}$ is an "estimate" of $\mathbf{\Omega}$.

This suggests in practical terms, we can first perform an initial GMM regression with a reasonable and arbitrary $\mathbf{H}$, such as homoskedasticity (i.e. $\mathbf{H}=\delta^{2} \mathrm{I}$ ), to yield $\overline{\beta_{1}^{-}}$( also known as a one-step GMM estimator). We can then obtain the residual's to construct a $\widehat{\Omega}_{\bar{\beta}_{1}}$. Rerun the GMM estimation by 
setting $\mathbf{A}=\left(\mathbf{z}^{\prime} \bar{\Omega}_{\widehat{\beta}_{1}} \mathbf{z}\right)^{-1}$ would bring the two-step GMM estimator ${\overline{\beta_{1}}}_{\text {EGMM }}$, which is the feasible and efficient GMM estimator. This two-step estimator, the one we will use for our estimation, is efficient and robust to any pattern of heteroskedasticity and autocorrelation.

Although the choice of $\mathbf{H}$, even if wrongly assumed, does not render inconsistent parameter estimates, the variance estimate for the parameters will be inconsistent as $\mathbf{Z}^{\prime} \mathbf{H Z}$ is not a consistent estimate of var[zz]. Arellano and Bond (1991) point out that such linear GMM estimates can produce standard errors that are downward biased when $j$ is large.

Henceforth, Windmeijer (2005) devises a small-sample correction for the two-step standard errors. He finds that two-step EGMM performs somewhat better than one-step in estimating coefficients, with lower bias and standard errors. With his correction, the two-step standard errors are quite accurate and it seems modestly superior to the cluster-robust one-step ones.

A critical post-GMM estimation test is the test of overidentification. If the model is exactly identified (i.e. $j=k$ ), the estimator will choose $\tilde{\beta}$ such that $\mathbf{Z}^{\prime} \hat{\mathbf{E}}=0$ even if $\mathbf{E}[\mathbf{z z}] \neq 0$. The Sargan/Hansen test can be carried out to provide a test statistics for the test of overidentification (i.e. a joint validity test of the moment conditions). Under the null hypothesis, the vector of $\frac{1}{\mathbf{N}} \mathbf{Z}^{\prime} \hat{\mathbf{E}}$ is randomly distributed around zero. A Wald test renders the statistic for the null to hold is

$$
\left(\frac{1}{\mathrm{~N}} \mathbf{Z}^{\prime} \mathbf{E}\right)^{\prime} \operatorname{var}[\mathbf{z \varepsilon}]^{-1} \frac{1}{\mathrm{~N}} \mathbf{Z}^{\prime} \hat{\mathbf{E}}=\frac{1}{\mathrm{~N}}\left(\mathbf{Z}^{\prime} \hat{\mathbf{E}}\right) \mathbf{A}_{\text {EGMM }} \mathbf{Z}^{\prime} \hat{\mathbf{E}} \sim \chi^{2} \text { with } d_{2} f_{x}=j-k
$$

If $\boldsymbol{\Omega}$ is scalar, then $\mathbf{A}_{\text {EGMM }}=\left(\mathbf{Z}^{\prime} \mathbf{Z}\right)^{-1}$. The Hansen (1982)'s J-test coincides with the Sargan (1958) test. In contrast, if $\Omega$ is not scalar, the 
Sargan's statistic would be inconsistent. Since $\boldsymbol{\Omega}$ is unknown to us, we rely on Hansen test for over-identification. If the null hypothesis cannot be rejected, it suggests the overidentification criterion is satisfied and the instruments used are valid.

\subsubsection{Dynamic Panel Data Models}

Let us reiterate the data-generating process of a dynamic panel model as

$$
y_{i t}=\alpha y_{i t-1}+x_{i t}^{R} \beta+\mu_{i}+v_{i t}
$$

where $\mathrm{E}\left[\mu_{i}\right]=\mathrm{E}\left[v_{i t}\right]=\mathrm{E}\left[\mu_{i} v_{i t}\right]=0$ and $\varepsilon_{i t}=\mu_{i}+\mathrm{v}_{i t}$. Alternatively, eq. $(2.3-8)$ can be written as

$$
\Delta y_{i t}=(\alpha-1) y_{i t-1}+\boldsymbol{x}_{i t}^{\prime} \beta+\varepsilon_{i t}
$$

We take first difference of (2.3-9) to remove the fixed effects that gives us

$$
\Delta y_{i t}=\alpha \Delta y_{i t-1}+\Delta x_{i t}^{\prime} \beta+\Delta v_{i t}
$$

Nickell (1981) points out that eq.(2.3-10) is prone to "dynamic panel bias" since $y_{i z-1}$ is still correlated with the disturbance terms after transformation. Such transformation also poses two problems. First, the $y_{i t-1}$ term is correlated with $v_{i t-1}$. Any predetermined variables in $\mathbf{x}$ that are not strictly exogenous become potentially endogenous as they are correlated to $v_{i t-1}$. However, Arellano and Bond (1991) suggests the use of lagged levels dated $t-2$ of the dependent variable and earlier can be used as instruments for the equations in first-differences.

GMM estimators control for endogeneity by using "internal instruments", that is, instruments based on lagged values of the explanatory variables. These models do not allow us to control for full endogeneity but for a weak version of 
it. Thus, it is assumed hereby that the explanatory variables are only "weakly exogenous", which means that they can be affected by current and past realisations of institutions but must be uncorrelated with future unanticipated shocks to institutions (the error term). This yields a consistent estimator of $\alpha$ as $N \rightarrow \infty$ with $T$ is fixed. By assuming that the transient errors are serially uncorrelated, i.e. $E\left[v_{i t} v_{i s}\right]=0$ where $s \neq t$, that the initial conditions $y_{i 1}$ are predetermined, i.e. $E\left[y_{i 1} v_{i t}\right]=0$, and the explanatory variables $\mathbf{x}_{\mathrm{it}}$ are weakly exogenous. These assumptions imply the moment restrictions to be

$$
\begin{gathered}
E\left[y_{i, t-s} \Delta v_{i t}\right]=0 \text { for } t=3, \ldots, T \text { and } s \geq 2 \\
E\left[x_{i, t-s} \Delta v_{i t}\right]=0 \text { for } t=3, \ldots, T \text { and } s \geq 2
\end{gathered}
$$

Such estimates will no longer be biased by any omitted time-invariant variables. By instrumenting the regressors in the first-differenced equations using levels of the second lags or more, it allows parameters to be estimated consistently. Bond, Hoeffler, and Temple (2001) show that the instruments used in this setting potentially allow consistent estimation even in the presence of measurement error - a common critique to the data of GDP and institution.

Nevertheless, Blundell and Bond (1998) show that this "differenced GMM" estimator may be subject to a large downward finite-sample bias, especially when the number of time periods is small. They showed that when the explanatory variables are persistent over time (like institutions in this case), lagged levels of the dependent variable are weak instruments in first differences. In these cases, severe problems of identification can lead to bias and could result in a poorly performing differenced estimator. To obtain a linear GMM estimator better suited to estimate autoregressive models with persistent panel data, they consider the additional stationarity assumption that

$$
E\left(\mu_{i} \Delta y_{i 2}\right)=0 \text { and } E\left(\mu_{i} \Delta x_{i 2}\right)=0 \text { for } i=1_{y \ldots \ldots} N \text {. }
$$


This assumption requires a stationarity restriction on the initial conditions $y_{i 1}$. This condition holds if the means of the $y_{i 1}$ series, whilst differing across individuals, are constant through time periods $1_{y} 2_{z \ldots}, T$ for each individual. This assumption yields $T-2$ further linear moment conditions

$$
E\left(\varepsilon_{i t} \Delta y_{i t-1}\right)=0 \text { for } i=1, \ldots, N \text { and } t=3,4, \ldots, T
$$

because $E\left(\varepsilon_{i t} \Delta y_{i t-1}\right)=E\left(\Delta y_{i t-1} \mu_{i}\right)+E\left(\Delta y_{i t-1} v_{i t}\right)-E\left(\Delta y_{i t-2} v_{i t}\right)$. These allow the use of lagged first-differences of the series as instruments for equations in levels, as suggested by Arellano and Bover (1995). This estimator with an additional moment condition is commonly known as the "system GMM" estimator. In other words, Blundell and Bond (1998) instruments level with differences whereas Arellano and Bond (1991) instruments differences with levels.

Secondly, eq.(2.3-10) magnifies gaps in unbalanced panels. Taking first difference may result in some $y_{i t}$ to be missing. As such, Arellano and Bover (1995) propose "orthogonal deviations". This suggests contemporaneous variable being subtracted from the average of all future available observations to minimise data loss. An added advantage of orthogonal deviation is that, lagged observations in this transformation would be valid instruments ${ }^{5}$. As T increases, the number of instruments proliferates. The instrument for the transformed $y_{i t-1}$ is $y_{i t-2}$ naturally ${ }^{6}$.

To improve efficiency, Holtz-Eakin, Newey, and Rosen (1988) suggest building a set of instruments from the second lag of the dependent variable for each time period and substitute zeros for missing observations. Alternatively, the instrument set can be collapsed, as in our estimation, into a single column like

\footnotetext{
${ }^{5}$ Orthogonal deviation, however, makes successive errors correlated (i.e. $\Delta v_{i t-1}$ correlates with $\Delta v_{\text {it }}$ ). Roodman (2009) suggests that, in practice, it is not usual to assume homoskedasticity in applying these estimators. Therefore, this property does not seriously matter.

${ }^{6}$ It is only valid if the model does not have second-order autocorrelation. Otherwise, the third lags and longer should be used.
} 


$$
\left[\begin{array}{c}
0 \\
y_{i 1} \\
* \\
= \\
y_{i T-2}
\end{array}\right]
$$

When estimating the dynamic panel model, Roodman (2009) recommends that lags 2 and up of the endogenous variables can be used as instruments in practice. One lag is valid for predetermined but not strictly exogenous variables. In addition, time dummies should be included to remove universal time-related shocks from the errors.

\subsubsection{Post-estimation Test}

The Sargan/Hansen test as discussed above for joint validity of the instruments can again be used. Additionally, Arellano and Bond (1991) develop an autocorrelation test for the idiosyncratic disturbance term $v_{i s}$ to test whether the lags are valid instruments. Since $\Delta v_{i t}$ is mathematically related to $\Delta v_{i t-1}$, negative first-order serial correlation is expected. To check for first-order serial correlation in levels, it is needed to look for whether second-order correction in difference exists (i.e. correlation between $v_{t:-1}$ in $\Delta v_{i t}$ and $v_{i t-2}$ in $\left.\Delta v_{i t-2}\right)$. A rejection of second order autocorrelation indicates no autocorrelation of the disturbance term in level. In other words, to test the validity of our preferred specification, we are looking for an AR(1) test that rejects the null hypothesis but an $\mathrm{AR}(2)$ test that cannot reject the null hypothesis.

\subsubsection{Advantages of Using Panel GMM Estimators for Growth Empirics}

Bond, et al. (2001) recommend the use of the "system GMM" estimator for growth empirics. This is due to two main reasons. First, it is often the case that researchers take a period average of output growth to get rid of cyclical 
dynamics. Hence, the number of periods used in the standard growth literature is usually small. Second, their empirical results show that if the time series are persistent e.g. growth rate of GDP per capita and institution (see Coviello and Islam (2006)), the "differenced GMM" estimator can behave poorly because lagged levels of the series only provide weak instruments. They show that the "differenced GMM" estimates of the coefficient on the lagged dependent variable tend to lie below the corresponding within-group estimates in a fixed effect model, suggesting that the "differenced GMM" estimates are seriously biased. Hence, we deploy "system GMM" estimators for our empirical analysis.

To sum up, the GMM estimators for panel analysis allow arbitrarily distributed fixed individual and time effects. This provides an added advantage over cross-sectional regressions, which are particularly prevalent in existing institution and growth literature, where cross-country fixed effects are assumed away. Under a panel set-up, studying the variations over time could also be possible. Besides, the GMM estimators allow idiosyncratic, disturbance terms which are heteroskedastic and autocorrelated. These disturbance terms, however, are assumed to be uncorrelated across individuals. With regard to the regressors, they could be endogenous, predetermined and not strictly exogenous. The estimators are also applicable for a panel set-up with a large number of cross-sections (i.e. large $\mathrm{N}$ ) and a small number of periods (i.e. small $\mathrm{T}^{7}$. A particular key advantage in our context is that it does not assume the availability of "external" instruments. In other words, all possible instruments exist readily in the dataset. The use of these "internal" instruments - based on the lagged values of the dependent variables - implies that we allow the explanatory variables to be weakly exogenous.

\subsubsection{Data}

The dependent variable of eq.(2.3-1) is the PPP-adjusted real GDP per capita growth rate $(\boldsymbol{G D P P C} \boldsymbol{g r})$ from the World Development Indicators (WDI).

\footnotetext{
7 The number of instruments used tends to explode with T in panel GMM estimations. This is one of the reasons why the GMM estimator is only applicable when T is small.
} 
Our data sample spans from 1970 to 2004 . The number of cross-sections (i.e. economies) in the estimations is around 99 countries in our main specification restricted by the country coverage of Fraser Institute's Economic Freedom Index as set out in Appendix Section A.4. In addition, we also control for human capital (SCHOOLING) in our baseline specification, as in Glaser et al (2004). As in standard growth empirics, it is proxied by the average year of schooling in the total population aged 25 or above, estimated by Barro and Lee $(2001)^{8}$.

Our measures of different institutional variables primarily come from Fraser Institute's Economic Freedom of the World Report (Gwartney, Lawson, and Norton (2008)) and Polity IV project dataset (Marshall and Jaggers (2009)). Detailed data description and descriptive statistics are at Appendix Sections A.2 and A.3. As explained in Chapter 1, the Fraser Institute's Economic Freedom Index, to the best of our knowledge, is the only available source which covers some kinds of measures of economic institution dating back to 1970. A long time series is preferred in our case as we intend to undertake dynamic analysis. Furthermore, another advantage is that the various sub-components of the Fraser's Index can be used to proxy the three facets of institutions as described above. In contrast, the commonly used alternative ICRG's rule of law index - is not used in our case. The major reason is that it covers a relatively shorter period of time, dating back to 1984 only. Nevertheless, we will use a composite index measuring the quality of government $(\boldsymbol{Q O G})$ from ICRG as robustness check for our results.

Specifically, in response to Rodrik (2000)'s 4-cluster taxonomy of market-sustaining institution, we use the Fraser Institute's legal structure and security of property rights index $(\boldsymbol{L E G A L})$ to proxy the effectiveness of property rights security and contract enforcement for "market-creating institutions" 9 . For "market-regulating institution", we use the composite

\footnotetext{
${ }^{8}$ Data can be retrieved from www.cid.harvard.edu/ciddata/ciddata.html.

9 Other than those empirical literature mentioned in Section 2.2, market-creating institutions are often tested in the context of economic liberties and economic freedom using indicators from Gwartney, et al. (2008) or Heritage Foundation (2009). Among others, Scully and Slottje (1991), De Vanssay and Spindler (1994), Gwartnet, Lawson, and Block (1996), Isham,
} 
index of regulation $(\boldsymbol{R E G})$. The index covers the regulatory burden of the credit market regulation, labour market regulation and business regulation. While some components of both $\boldsymbol{L E} \boldsymbol{G} \boldsymbol{A} \boldsymbol{L}$ and $\boldsymbol{R} \boldsymbol{E} \boldsymbol{G}$ are primarily obtained from opinion survey results, they are designed in such a way to subjectively describe the general perception of the overall environment of security of property rights and regulatory environment. On $\boldsymbol{R E} \boldsymbol{G}$ in particular, this is an overall macro-level index and is not specific to the regulatory environment of particular markets, it thus sheds no particular light on whether there exists any mechanisms for correcting market failures. Nevertheless, we consider these two proxies are sufficient in a macroeconomic growth model as in our case. It goes beyond the purpose of our estimation here to test the impact of micro-level regulation on economic growth.

For "market-stabilising institutions", we consider using the access to sound money index $(\boldsymbol{S M})$ to proxy the effectiveness of monetary and fiscal institutions. The index covers money (specifically, M2) growth, standard deviation of inflation, average inflation rate and freedom to own foreign currency bank accounts, which can duly reflect the functioning of monetary institutions and management of macroeconomic policies. All Fraser's indices range from 0 to 10 , with higher scores signifying better institutions.

For "market-legitimising institutions", we use the democracy index from the Polity IV project $(\boldsymbol{D E M O C})$. It is a composite index, ranging from 0 to 10 , measuring the competitiveness of political participation, openness and competitiveness of executive recruitment and constraints on the chief executive (XCONST). Higher score means the country is more democratic. In our robustness checks, we will also attempt to use the sub-component XCONST as

Kaufmann, and Pritchett (1997), Easton and Walker (1997) and Strum and Haan (2001) show that economic freedom (in general) is significantly related to country's growth performance (conventionally measured by GDP per capita and/or GDP growth rate). Torstensson (1994) employs the sub-index rather than the overall score of economic freedom. He finds that, among all the 23 areas measured, the degree of state ownership does not seem to affect growth rates whereas property rights structure matters more. Moreover, some studies also attempt to interpret that it has an indirect effect. Ayal and Karras (1998) show that aggregate economic freedom enhances growth both via increasing total factor productivity and via enhancing capital accumulation. Adkins, Moomaw, and Savvides (2002) similarly find that institutions that promote greater economic freedom in turn promote efficiency. 
a proxy of contract enforcement as in previous empirical studies like Acemoglu and Johnson (2005). In addition, we will also use Freedom House's indicators on political rights and civil liberties (IPOLITY2) to proxy democratic governance instead of $\boldsymbol{D E M O C}$ to check sensitivity of our results. We will discuss these alternative measures when we present our robustness tests in Section 2.4.2.3.

The pairwise correlation matrix between key variables, as show in Appendix Section A.3, suggests that the institutional variables do not strongly correlate with each other. It thus appears that multicollinearity is not a major problem in our case.

\subsection{Results and Discussion}

\subsubsection{Institution in a Growth Model: Preliminary Test}

Sachs (2003) criticises the empirical studies of institution view that the specification is not dynamic in nature. In response to this, we first take a preliminary test of institutions in a dynamic growth model framework. We make reference to three growth models in the literature and re-examine them if institutions are associated with economic growth after controlling for all the time-invariant country-specific characteristics, say geography, as well as the initial level of economic development using dynamic panel data estimations.

The first one is Hall and Jones (1999)'s baseline specification, where output per worker solely depends on "social infrastructure". We modify their model in a panel setting in response to Sachs (2003)'s criticism as follows:

$$
G D P P C_{-} g r_{i t}=\alpha_{0}+\alpha_{1} \ln (G D P P C)_{i t-1}+\alpha_{2} I_{i t}+u_{i}+\delta_{t}+v_{i t}
$$

We replace "social infrastructure" by the quality of government indicator $(\boldsymbol{Q O} \boldsymbol{O})$, which is a composite indicator of corruption, law and order and 
bureaucratic quality consolidated by Teorell, Charron, Samanni, et al. (2009). The original data source is from ICRG, the one used in the literature as in Hall and Jones (1999). We use a composite indicator here instead of unbundling different institutions is to allow comparability with the literature. This composite index we use here is scaled from 0 to 1 , with higher values indicating higher quality of government. $\boldsymbol{Q O} \boldsymbol{O}$ is the average value during a 5-year period.

The second model is modified from Mankiw, Romer, and Weil (1992) (MRW) to test the effect of human capital in an augmented Solow growth model. Following Solow (1956), the production function for country $i$ is postulated as a function of physical and human capital as well as technological progress as

$$
Y_{i}(t)=K_{i}(t)^{\alpha}\left[A_{i}(t) H_{i}(t)\right]^{1-\alpha}
$$

For simplicity, we drop the subscript $i$. We further assume that human capital is expressed in terms of education $E$, say average year of schooling of the population $H(t)=L(t) G(E) . \quad G(E)$ is assumed to be constant, where $G(E)=e^{\phi E} . \quad \dot{L}(t)=n L(t)$ and $\dot{A}(t)=g A(t) . \quad$ Given steady-state assumption, the stead-state physical capital per unit of effective labour services

$$
k^{*} \equiv K^{*} /[A G(E) L]=[s /(n+g+\eta)]^{1 /(1-\alpha)}
$$

where $s$ is the saving rate, $g$ is a common exogenous rate of technical change and $\eta$ is the depreciation rate.

We further assume common technology advances for all countries, i.e.

$$
A(t)=\bar{A} \exp (g t)
$$

Hence, steady-state output per capita can be expressed as 


$$
\ln y=\frac{\alpha}{1-\alpha} \ln \frac{s}{n+g+\eta}+(1-\alpha) \phi E+(1-\alpha) \ln \bar{A}+(1-\alpha) g t
$$

We could then re-assess the augmented Solow model in a dynamic panel data framework as in Bond, et al. (2001). Based on eq.(2.4-5), the revised specification is as eq.(2.4-6) below:

$$
\begin{aligned}
\text { GDPPC_}_{-} g r= & \gamma_{0}+\gamma_{1} \ln (G D P P C)_{i t-1}+\gamma_{2} \ln \left(s_{i t}\right)+\gamma_{3} \ln \left(n_{i t}+g+\eta\right) \\
& +\gamma_{4} \text { SCHOOLING } \\
i t & +u_{i}+\delta_{t}+v_{i t}
\end{aligned}
$$

Eq.(2.4-6) includes the natural $\log$ of saving rate $\left(\boldsymbol{I n}\left(\boldsymbol{s}_{i \boldsymbol{t}}\right)\right)$ and the natural $\log$ of population growth $\left(\boldsymbol{I n}\left(\boldsymbol{n}_{\boldsymbol{i}}\right)\right)$, plus 0.05 , where 0.05 represents the sum of a common exogenous rate of technical change $(\boldsymbol{g})$ and a common depreciation rate $(\boldsymbol{\eta})$ as in MRW. Data of saving rate and population growth come from WDI. The regressors also include a measure of human capital, i.e. the average years of schooling (SCHOOLING). The unobserved country-specific effects can be interpreted as the differences in the initial level of efficiency, whilst the period-specific intercepts capture productivity changes that are common to all countries. As in MRW, the technical progress is assumed to be common for all countries.

The third model extends that of eq.(2.4-6). The augmented Solow growth model of Bond, et al. (2001) does not incorporate institution. We thus incorporate the effect of institution as in Penalosa and Teksoz (2006), in which the authors assume that institutions interact with the level of productivity but do not enter directly as inputs.

More specifically, the level of productivity is revised as a function of institution as

$$
A(t)=\bar{A} \exp (g t+\delta I)
$$


With this assumption, the specification of our estimation can then written as (2.4-8) below.

$$
\begin{aligned}
\text { GDPPC_gr }_{-} & \gamma_{0}+\gamma_{1} \ln (G D P P C)_{i t-1}+\gamma_{2} \ln \left(s_{i t}\right)+\gamma_{3} \ln \left(n_{i t}+g+\eta\right) \\
& +\gamma_{4} \text { SCHOOLING } G_{i t}+\gamma_{5} I_{i t}+u_{i}+\delta_{t}+v_{i t}
\end{aligned}
$$

Estimation results of these three models are at Table 2.4.1-1 below. Vis-à-vis previous cross-sectional literature, estimating growth models in a dynamic panel data framework presents several interesting results. As shown in Model 2.(1), institution seems to have a significant and positive impact on economic growth. After controlling time-invariant determinants in a panel setting, institution still significantly explains cross-country economic performances. That said, our results provide support to the institution view, despite using modified specifications and estimation techniques. 
Table 2.4.1-1: Preliminary Tests of Dynamic Growth Models (Two-Step System GMM Estimation)

\begin{tabular}{|c|c|c|c|}
\hline$\frac{\text { Model }}{\text { Specification }}$ & $\begin{array}{c}\text { Hall and Jones } \\
(1999) \\
\end{array}$ & $\begin{array}{c}\frac{2 .(2)}{\text { Mankiw et al }} \\
(1992) \\
\end{array}$ & $\frac{\underline{2 .(3)}}{\text { Penalosa and Teksoz (2006) }}$ \\
\hline $\ln (G D P P C)_{t-1}$ & $\begin{array}{l}-0.0020 \\
(0.0014)\end{array}$ & $\begin{array}{l}-0.0071 \\
(0.0133)\end{array}$ & $\begin{array}{l}-0.0165 \\
(0.0125)\end{array}$ \\
\hline $\ln (s)$ & & $\begin{array}{l}0.0193 * * * \\
(0.0069)\end{array}$ & $\begin{array}{l}0.0256 * * * \\
(0.0063)\end{array}$ \\
\hline $\ln (n+g+\eta)$ & & $\begin{array}{l}-0.0932 * \\
(0.0532)\end{array}$ & $\begin{array}{l}-0.1038 * \\
(0.0617)\end{array}$ \\
\hline SCHOOLING & & $\begin{array}{l}-0.0004 \\
(0.0077)\end{array}$ & $\begin{array}{c}0.0020 \\
(0.0079)\end{array}$ \\
\hline$Q O G$ & $\begin{array}{c}0.0596 * * * \\
(0.0096)\end{array}$ & & $\begin{array}{l}0.0386 * * \\
(0.0172)\end{array}$ \\
\hline Const & $\begin{array}{c}0.0152 \\
(0.0108)\end{array}$ & $\begin{array}{l}-0.2338 \\
(0.1733)\end{array}$ & $\begin{array}{l}-0.2404 \\
(0.1869)\end{array}$ \\
\hline Obs/No. of cty & $760 / 181$ & $644 / 100$ & $424 / 90$ \\
\hline AR(1) p-value & 0.0774 & 0.0000 & 0.0000 \\
\hline AR(2) p-value & 0.613 & 0.784 & 0.402 \\
\hline Hansen Test Stat & 6.709 & 18.30 & 19.82 \\
\hline Hansen Test p-value & 0.460 & 0.147 & 0.228 \\
\hline
\end{tabular}

Dependent variable is $\boldsymbol{G D P P C \_ g r . ~ 5 - y e a r ~ i n t e r v a l ~ p a n e l ~ d a t a ~ i s ~ u s e d ~ f o r ~ e s t i m a t i o n . ~ T h e ~}$ lagged $\ln (\boldsymbol{G D P P C})$ is treated as pre-determined, while other regressors are endogenous. Period dummies are included but not reported. Standard errors are in parenthesis and Windmeijer-corrected, robust for heteroskedasticity and autocorrelation. ***,** and * denote significance levels at $1 \%, 5 \%$ and $10 \%$ respectively. Instruments are transformed by orthogonal deviation and collapsed. Hansen test is used for overidentifying restrictions.

Secondly, the cross-sectional analysis of MRW shows that human capital plays a key role in economic growth. Their results suggest that, holding all other variables constant, a country with approximately $12 \%$ school enrolment should have income per capita of about 9 times that of a country. However, our Model 2.(2) shows that human capital $^{9}$ does not appear to be statistically significant once we estimate the model in a dynamic panel data framework. In this Model, it even comes with a "wrong" sign.

\footnotetext{
${ }^{9}$ We also attempt to proxy human capital by secondary and tertiary enrolment ratios instead of average years of schooling. The statistically insignificant results remain.
} 
Thirdly, Model 2.(3) shows that the impact of institution on economic growth remains statistically significant even after controlling for human capital. Human capital, though turns correctly positive to growth in the augmented Solow model, stays statistically insignificant. One should also note that, comparing Models 2.(2) and 2.(3), all coefficients become slightly bigger once institution is included in the latter model. This may suggest that the channel through which institution affects growth may be via its effect on other factors of production.

To justify whether the two-stage system GMM estimator should be used, we see that all three models accept the AR(1) test but reject the AR(2) test, except that in Model 2.(1), it is only significant at 10\% level. It therefore suggests that there is no serial correlation at level. The Hansen test also does not reject the null hypothesis. It implies that we cannot reject the over-identification restriction. All these results suggest that dynamic panel data models can be used.

\subsubsection{Direct Partial Impact of Institution on Growth}

\subsubsection{Baseline Specification}

We then proceed to estimate the direct partial impact of institution based on the taxonomy of institutions proposed earlier. Table 2.4.2-1 below presents the empirical results of our baseline specification as described in eq.(2.3-1). 
Table 2.4.2-1: Institution and Economic Growth - Baseline Specification (Two-Step System GMM Estimation)

\begin{tabular}{|c|c|c|c|c|c|}
\hline Model & 2.(4) & 2.(5) & $2 .(6)$ & 2.(7) & $2 .(8)$ \\
\hline DEMOC & $\begin{array}{c}0.0011 \\
(0.0009)\end{array}$ & & & & $\begin{array}{c}0.0015 \\
(0.0015)\end{array}$ \\
\hline$R E G$ & & $\begin{array}{c}0.0046 \\
(0.0038)\end{array}$ & & & $\begin{array}{c}0.0042 \\
(0.0045)\end{array}$ \\
\hline$S M$ & & & $\begin{array}{l}0.0020^{*} \\
(0.0010)\end{array}$ & & $\begin{array}{l}0.0031 * \\
(0.0018)\end{array}$ \\
\hline$L E G A L$ & & & & $\begin{array}{c}0.0066^{* * *} \\
(0.0021)\end{array}$ & $\begin{array}{c}0.0052 * * * \\
(0.0020)\end{array}$ \\
\hline SCHOOLING & $\begin{array}{l}0.0102 * \\
(0.0059)\end{array}$ & $\begin{array}{l}0.0091 * \\
(0.0053)\end{array}$ & $\begin{array}{c}0.0147 * * * \\
(0.0051)\end{array}$ & $\begin{array}{c}0.0128 * * \\
(0.0056)\end{array}$ & $\begin{array}{c}0.0139 * * \\
(0.0067)\end{array}$ \\
\hline $\ln (G D P P C)_{t-1}$ & $\begin{array}{l}-0.0060 \\
(0.0108)\end{array}$ & $\begin{array}{c}-0.0090 \\
(0.0106)\end{array}$ & $\begin{array}{l}-0.0130 \\
(0.0089)\end{array}$ & $\begin{array}{c}-0.0197 * * \\
(0.0089)\end{array}$ & $\begin{array}{c}-0.0304 * * \\
(0.0118)\end{array}$ \\
\hline Const & $\begin{array}{c}-0.0042 \\
(0.0556)\end{array}$ & $\begin{array}{c}0.0030 \\
(0.0565)\end{array}$ & $\begin{array}{c}0.0112 \\
(0.0469)\end{array}$ & $\begin{array}{c}0.0553 \\
(0.0430)\end{array}$ & $\begin{array}{c}0.0843 \\
(0.0575)\end{array}$ \\
\hline Obs/No. of cty & $556 / 99$ & $500 / 95$ & $542 / 95$ & $483 / 95$ & $447 / 91$ \\
\hline AR(1) p-value & {$[0.0000]$} & {$[0.0000]$} & {$[0.0000]$} & {$[0.0000]$} & {$[0.0000]$} \\
\hline$A R(2) p$-value & {$[0.364]$} & {$[0.855]$} & {$[0.605]$} & {$[0.540]$} & {$[0.279]$} \\
\hline \multicolumn{6}{|l|}{ Hansen Test } \\
\hline $\begin{array}{l}\text { Test Stat } \\
\text { p-value }\end{array}$ & $\begin{array}{c}14.62 \\
{[0.404]} \\
\end{array}$ & $\begin{array}{c}13.63 \\
{[0.191]} \\
\end{array}$ & $\begin{array}{c}4.210 \\
{[0.838]} \\
\end{array}$ & $\begin{array}{c}6.174 \\
{[0.628]} \\
\end{array}$ & $\begin{array}{c}21.80 \\
{[0.241]} \\
\end{array}$ \\
\hline
\end{tabular}

Dependent variable is $\boldsymbol{G D P P C \_ g r . ~ 5 - y e a r ~ i n t e r v a l ~ p a n e l ~ d a t a ~ i s ~ u s e d ~ f o r ~ e s t i m a t i o n . ~ T h e ~}$ lagged $\ln (\boldsymbol{G D P P C})$ is treated as pre-determined, while other regressors are endogenous. Period dummies are included but not reported. Standard errors are in parenthesis and Windmeijer-corrected, robust for heteroskedasticity and autocorrelation. $* * * * *$ and $*$ denote significance levels at $1 \%, 5 \%$ and $10 \%$ respectively. Maximum 4 lags are used for instruments. Instruments are transformed by orthogonal deviation and collapsed. Hansen test is used for over-identifying restrictions.

The presence of the lagged $\ln (G D P P C)$ in the model means that all the estimated coefficients of institutions represent their short-run effects. A significantly negative coefficient of $\ln (\boldsymbol{G D P P C})$ signifies convergence. In the baseline specification, we control for human capital as proxied by SCHOOLING as the only macroeconomic control variable. To recap, we use DEMOC, REG, SM and LEGAL to measure the four clusters of market-sustaining institutions, namely "market-legitimising", "market-regulating", "market-stabilising" and "market-creating" institutions respectively. We test individual variable in Models 2.(4) - 2.(7) and all variables jointly in Model 2.(8). 
Our empirical results show that the signs of coefficients of DEMOC and $\boldsymbol{R E} \boldsymbol{G}$ are positive as expected. It implies that democracy and less regulation seem to associate with faster growth. However, their coefficients are not statistically significant. Similar to the results in the previous literature discussed in Section 2.2.2.2, democracy shows no significant linear effect on growth in our sample. With respect to regulation, Rodrik (2005) suggests that a more developed economy intends to have more regulation to rectify market failures, say externalities. However, the corruption literature (e.g. Mauro (1995) and Djankov, Porta, Lopez-de-Silanes, et al. (2002)) on the other hand argue that more regulations in developing economies is more likely lead to more corruption, which is socially wasteful. These two competing hypotheses probably explain the lack of linear direct effect of $\boldsymbol{R} \boldsymbol{E} \boldsymbol{G}$ in our full sample.

$\boldsymbol{L E G A L}$ and $\boldsymbol{S M}$, in contrast, show significant, positive and direct impacts on growth. In other words, security of property rights and "market-stabilising" institutions both impose direct impacts on economic growth, although $\boldsymbol{S M}$ is only statistically significant at $10 \%$ level.

In Model 2.(8), we estimate the baseline specification with all regressors being estimated jointly. The results suggest that a one sample standard deviation increase in the $\boldsymbol{L E G A L}$ and $\boldsymbol{S M}$ indices will increase growth rate by 1.0 and 0.69 percentage points ${ }^{10}$ respectively. In a dynamic panel data setting, our results generally agree with the key conclusion of the previous literature. In other words, "market-creating" and "market-stabilising" institutions have direct effect on growth, whereas "market-regulating" and "market-legitimising" institutions show no direct partial impact. While the previous literature aims at establishing a long-run direct impact of institutions, our estimations further relax the assumption of institutional persistence. We find that short-run institutional change has a direct impact on growth. More specifically, comparing to the results of Bhattacharyya (2009), our results show

\footnotetext{
${ }^{10}$ The quantitative impacts are obtained from $0.0052 * 1.9251 \approx 1.0 \%$ and $0.0031 * 2.2143 \approx 0.69 \%$ respectively.
} 
that $\boldsymbol{L} \boldsymbol{E} \boldsymbol{G} \boldsymbol{A} \boldsymbol{L}$ relatively plays a more significant role than $\boldsymbol{S} \boldsymbol{M}^{11}$.

Hansen test statistics show that the models satisfy the over-identification restrictions and do not reject the joint validity of the instruments used. This suggests the lags used in the models are valid instruments. According to the Arellano and Bond autocorrelation test in levels in our results, the disturbances terms exhibit $\mathrm{AR}(1)$ process but not $\mathrm{AR}(2)$ in our models. A rejection of the second-order autocorrelation indicates that there is no autocorrelation of the disturbance term in level. In overall terms, the post-estimation tests indicate that using GMM estimators for our models are appropriate.

\subsubsection{Choice of Estimators}

To further verify whether the Blundell and Bond (1998)'s 2-step system GMM estimator is preferred in our case, we also run both the OLS and within group fixed-effect (FE) estimators for comparison. Although there is no formal test for justifying the use of the GMM estimator, Coviello and Islam (2006) suggest a possible rule of thumb. They argue that in a dynamic panel model, the OLS estimator is biased and inconsistent as the lag dependent variable is positively correlated with the country fixed effect and the error terms. On the other hand, the FE estimator, by estimating the within group difference, can eliminate this sort of inconsistency by transforming the equation to eliminate the country specific effect. However, for panels where $\mathrm{T}$ is small relative to $\mathrm{N}$ as in our case, the first difference transformation induces a "non-negligible" correlation between the transformed lagged dependent variable and the transformed error term. The FE estimator, therefore, is also biased.

The nature of the bias of these two estimators could assist in identifying a satisfactory estimator. Nickell (1981) shows that when fixed effects are correlated with explanatory variables, then OLS overestimates the effect of the

\footnotetext{
${ }^{11}$ By way of comparison, his results show that the respective parameters have growth effects of 0.75 and 0.75 percentage points respectively.
} 
lagged dependent variable, fixed effect underestimates it and system GMM should be in between the two. Bond, et al. (2001) and Bond (2002) suggest that the OLS level estimator of the autoregressive coefficient could be regarded as the upper bound for the true estimates, whereas the FE estimator of the autoregressive coefficient can be treated as the lower bound of the true estimates. Therefore, we expect that the true estimator would lie between the OLS and FE estimates. The GMM estimator, if appropriate in our case, should lie somewhere in between or at least not to be significantly higher/lower than the upper/lower bounds.

The relevant test results are presented in Table 2.4.2-2. Models 2.(9) and 2.(10) are the OLS and FE estimations respectively. Models 2.(11) and 2.(12) show the results of our system GMM estimations. The magnitudes of coefficients in the 1-step and 2-step GMM models are not quite significantly different. The coefficient on the lag dependent variable is around -0.03 in Models 2.(11) and 2.(12), which lies between that of the OLS (-0.006) and FE $(-0.06)$ estimates. We hence conclude that the system GMM estimator could be used in our case. 
Table 2.4.2-2: Institution and Economic Growth - Baseline Specification Using Different Estimation Techniques

\begin{tabular}{|c|c|c|c|c|}
\hline $\begin{array}{r}\text { Model } \\
\text { Estimator } \\
\end{array}$ & $\underline{\text { 2.(9) }}$ & $\frac{2 .(10)}{\underline{F E}}$ & $\underline{\underline{\mathbf{2 . ( 1 1 )}}} \underline{\underline{\text {-Step GMM }}}$ & $\underline{\underline{\mathbf{2 . ( 1 2 )}}} \underline{\text { 1-Step GMM }}$ \\
\hline Lagged $\ln (G D P P C)$ & $\begin{array}{c}-0.0055^{* * *} \\
(0.0020)\end{array}$ & $\begin{array}{c}-0.0629 * * * \\
(0.0067)\end{array}$ & $\begin{array}{c}-0.0304 * * \\
(0.0118)\end{array}$ & $\begin{array}{c}-0.0283 * * \\
(0.0115)\end{array}$ \\
\hline DEMOC & $\begin{array}{c}0.0001 \\
(0.0005)\end{array}$ & $\begin{array}{l}0.0012 * \\
(0.0006)\end{array}$ & $\begin{array}{c}0.0015 \\
(0.0015)\end{array}$ & $\begin{array}{c}0.0011 \\
(0.0013)\end{array}$ \\
\hline$R E G$ & $\begin{array}{c}0.0003 \\
(0.0017)\end{array}$ & $\begin{array}{l}0.0042 * \\
(0.0023)\end{array}$ & $\begin{array}{c}0.0042 \\
(0.0045)\end{array}$ & $\begin{array}{c}0.0061 \\
(0.0046)\end{array}$ \\
\hline$S M$ & $\begin{array}{c}0.0016^{* *} \\
(0.0008)\end{array}$ & $\begin{array}{c}0.0009 \\
(0.0008)\end{array}$ & $\begin{array}{l}0.0031 * \\
(0.0018)\end{array}$ & $\begin{array}{c}0.0042 * * * \\
(0.0015)\end{array}$ \\
\hline LEGAL & $\begin{array}{c}0.0043 * * * \\
(0.0012)\end{array}$ & $\begin{array}{c}0.0035 * * * \\
(0.0012)\end{array}$ & $\begin{array}{c}0.0052 * * * \\
(0.0020)\end{array}$ & $\begin{array}{c}0.0055 * * * \\
(0.0019)\end{array}$ \\
\hline SCHOOLING & $\begin{array}{l}0.0017 * \\
(0.0009)\end{array}$ & $\begin{array}{c}0.0013 \\
(0.0024)\end{array}$ & $\begin{array}{c}0.0139 * * \\
(0.0067)\end{array}$ & $\begin{array}{l}0.0123^{*} \\
(0.0065)\end{array}$ \\
\hline Const & $\begin{array}{c}0.0127 \\
(0.0132)\end{array}$ & $\begin{array}{c}0.4528 * * * \\
(0.0543)\end{array}$ & $\begin{array}{c}0.0843 \\
(0.0575)\end{array}$ & $\begin{array}{c}0.0566 \\
(0.0593)\end{array}$ \\
\hline Obs & 447 & 447 & 447 & 447 \\
\hline No. of cty & & 91 & 91 & 91 \\
\hline $\begin{array}{l}\text { Adj. } R^{2} \\
F \text {-stat }\end{array}$ & $\begin{array}{l}0.130 \\
6.142\end{array}$ & $\begin{array}{c}0.0904 \\
13.21\end{array}$ & & \\
\hline $\begin{array}{l}A R(1) \text { p-value } \\
\text { AR(2) p-value }\end{array}$ & & & $\begin{array}{c}{[0.0000]} \\
{[0.279]}\end{array}$ & $\begin{array}{c}{[0.0000]} \\
{[0.329]}\end{array}$ \\
\hline Hansen Test & & & & \\
\hline $\begin{array}{l}\text { Test Statistics } \\
\text { p-value }\end{array}$ & & & $\begin{array}{c}21.80 \\
{[0.241]}\end{array}$ & $\begin{array}{c}21.80 \\
{[0.241]}\end{array}$ \\
\hline
\end{tabular}

Dependent variable is $\boldsymbol{G D P P C}_{\boldsymbol{g}} \boldsymbol{g}$. 5-year interval panel data is used for estimation. Period dummies are included in all models but not reported. $* * *, * *$ and $*$ denote significance levels at $1 \%, 5 \%$ and $10 \%$ respectively. For Models 2.(9) and 2.(10), robust standard errors are in parenthesis. For Models 2.(11) and 2.(12), the lagged $\ln (G D P P C)$ is treated as pre-determined, while other regressors are endogenous. Standard errors are in parenthesis and Windmeijer-corrected, robust for heteroskedasticity and autocorrelation. Maximum 4 lags are used for instruments. Instruments are transformed by orthogonal deviation and collapsed. Hansen test is used for overidentifying restrictions. 


\subsubsection{Robustness Tests}

\subsection{With Additional Covariates}

As robustness tests, we further run 8 regressions by adding extra covariates to the baseline specification. Test results are at Table 2.4.2-3. As in Barro and Sala-i-Martin (1997)'s growth empirics, we consider three additional macroeconomic control variables such as population growth rate (pop_gr), government consumption as percentage of GDP (gcon_gdp) and the natural log of investment share as percentage of GDP (In(invest_gdp)) respectively in Models 2.(13) - 2.(15). Secondly, we also use a vector of openness measures, including FDI inflows as percentage of GDP ( $\boldsymbol{f d i} \_\boldsymbol{g} \boldsymbol{d} \boldsymbol{p}$ ), natural log of total trade as percentage of GDP (In(trade_gdp)) as in Barro and Sala-i-Martin (1997) and Dollar and Kraay (2003). The results are shown in Models 2.(16) - 2.(17). Thirdly, we also consider covariates measuring financial openness and financial development on growth, following the literature arguing that financial development causes growth as in Greenwood and Jovanovic (1990), King and Levine (1993), Levine (1997), Harrison, Sussman, and Zeira (1999),Beck, Demirguc-Kunt, and Levine (2001), Beck, Demirguc-Kunt, and Levine (2003a), Rajan and Zingales (2003) and Beck and Levine (2004). We use three recently developed indicators - (i) financial integration index from Lane and Milesi-Ferretti (2006) (fin_open); (ii) capital account openness index from Chinn and Ito (2006) (ca_open), and (iii) total liquid liabilities as percentage of GDP from Beck, Demirguc-Kunt, and Levine (2009) (Iliab_gdp). Detailed description and sources of these data are set out at Appendix Section A.2. The estimations are shown in Models 2.(18) - 2.(20). Finally, in Model 2.(21), we jointly test several covariates.

We find that even after having additional covariates in the baseline specifications, our results generally survive. Our empirical results remain suggesting that only $\boldsymbol{L E G} \boldsymbol{A L}$ and $\boldsymbol{S M}$ have direct and statistically significant partial impact on economic growth amongst the four clusters of institutions. 
The only exception is Model 2.(17), with $\ln ($ trade_gdp) incorporated in the baseline model. In this Model, the security of property rights $(\boldsymbol{L E G A L})$ still imposes a direct impact on growth as in other specifications. However, the "market-stabilising" institution (measured by $\boldsymbol{S} \boldsymbol{M}$ ) no longer plays a significant role. Moreover, $\boldsymbol{D E M O C}$ and $\boldsymbol{R E G}$ now turn statistically significant at the $10 \%$ significance level. The results suggest that after controlling for the degree of openness, democracy and less regulatory burden tend to induce growth directly. As the market is more outward-orientated, institutions that are more growth-promoting are those that gear towards the interests of the foreign investors and those can sustain the linkage between the domestic market and the external environment. Very likely, foreign markets respond more positively to an economy with better security of property rights and less regulations. A democratic society, on the other hand, is likely to be more political stable, thereby becoming more favourable for foreign trade and investment. In contrast, monetary stability, e.g. inflation, may be less relevant. However, we note that such effect of openness cannot be found with regard to financial openness and capital account openness as shown in Models 2.(18) and 2.(19), but only to trade openness. 
Table 2.4.2-3: Institution and Economic Growth - Baseline Specification with Additional Covariates (2-Step System GMM Estimations)

\begin{tabular}{|c|c|c|c|c|c|c|c|c|c|}
\hline $\begin{array}{c}\text { Model } \\
\text { Additional } \\
\text { Covariates }\end{array}$ & $\begin{array}{l}\underline{2 .(13)} \\
\text { pop_gr }\end{array}$ & $\begin{array}{c}\underline{2 .(14)} \\
\text { gcon_gdp }\end{array}$ & $\begin{array}{c}\underline{\underline{2 .(15)}} \\
\ln (\text { invest_gdp) }\end{array}$ & $\begin{array}{l}\underline{2 .(16)} \\
\text { fdi_gdp }\end{array}$ & $\begin{array}{c}\underline{2 .(17)} \\
\text { In(trade_gdp) }\end{array}$ & $\begin{array}{c}\underline{2 .(18)} \\
\text { fin_open }\end{array}$ & $\begin{array}{c}\underline{2 .(19)} \\
\text { ca_open }\end{array}$ & $\begin{array}{c}\underline{2 .(20)} \\
\text { lliab_gdp }\end{array}$ & $\begin{array}{c}\underline{2 .(21)} \\
(13)+(14)+(15)+ \\
(16)+(18)+(19)\end{array}$ \\
\hline DEMOC & $\begin{array}{l}-0.0014 \\
(0.0016)\end{array}$ & $\begin{array}{c}0.0010 \\
(0.0012)\end{array}$ & $\begin{array}{c}0.0013 \\
(0.0014)\end{array}$ & $\begin{array}{c}0.0015 \\
(0.0012)\end{array}$ & $\begin{array}{c}0.0020^{*} \\
(0.0011)\end{array}$ & $\begin{array}{l}-0.0008 \\
(0.0012)\end{array}$ & $\begin{array}{c}0.0003 \\
(0.0012)\end{array}$ & $\begin{array}{c}0.0001 \\
(0.0010)\end{array}$ & $\begin{array}{c}-0.0009 \\
(0.0011)\end{array}$ \\
\hline$R E G$ & $\begin{array}{c}0.0044 \\
(0.0043)\end{array}$ & $\begin{array}{c}0.0018 \\
(0.0040)\end{array}$ & $\begin{array}{c}0.0063 \\
(0.0045)\end{array}$ & $\begin{array}{c}0.0024 \\
(0.0049)\end{array}$ & $\begin{array}{l}0.0080^{*} \\
(0.0041)\end{array}$ & $\begin{array}{c}0.0068 \\
(0.0047)\end{array}$ & $\begin{array}{c}0.0024 \\
(0.0050)\end{array}$ & $\begin{array}{c}0.0023 \\
(0.0040)\end{array}$ & $\begin{array}{c}0.0038 \\
(0.0045)\end{array}$ \\
\hline$S M$ & $\begin{array}{c}0.0044 * * \\
(0.0019)\end{array}$ & $\begin{array}{c}0.0040 * * * \\
(0.0014)\end{array}$ & $\begin{array}{l}0.0030 * \\
(0.0018)\end{array}$ & $\begin{array}{l}0.0034 * \\
(0.0018)\end{array}$ & $\begin{array}{c}0.0019 \\
(0.0017)\end{array}$ & $\begin{array}{c}0.0033 * * \\
(0.0016)\end{array}$ & $\begin{array}{c}0.0039^{* *} \\
(0.0016)\end{array}$ & $\begin{array}{l}0.0031^{*} \\
(0.0018)\end{array}$ & $\begin{array}{c}0.0032 * * \\
(0.0015)\end{array}$ \\
\hline$L E G A L$ & $\begin{array}{c}0.0035 \\
(0.0021)\end{array}$ & $\begin{array}{c}0.0041^{* *} \\
(0.0018)\end{array}$ & $\begin{array}{c}0.0050^{* *} \\
(0.0020)\end{array}$ & $\begin{array}{c}0.0048 * * * \\
(0.0018)\end{array}$ & $\begin{array}{c}0.0052 * * \\
(0.0021)\end{array}$ & $\begin{array}{l}0.0041^{*} \\
(0.0022)\end{array}$ & $\begin{array}{c}0.0048^{* *} \\
(0.0019)\end{array}$ & $\begin{array}{c}0.0042^{* *} \\
(0.0019)\end{array}$ & $\begin{array}{c}0.0037 * * \\
(0.0018)\end{array}$ \\
\hline SCHOOLING & $\begin{array}{l}0.0110^{*} \\
(0.0061)\end{array}$ & $\begin{array}{c}0.0051 \\
(0.0053)\end{array}$ & $\begin{array}{l}0.0126^{*} \\
(0.0068)\end{array}$ & $\begin{array}{c}0.0083 \\
(0.0055)\end{array}$ & $\begin{array}{c}0.0032 \\
(0.0047)\end{array}$ & $\begin{array}{c}0.0097 \\
(0.0081)\end{array}$ & $\begin{array}{c}0.0138 * * \\
(0.0062)\end{array}$ & $\begin{array}{c}0.0088 * * \\
(0.0042)\end{array}$ & $\begin{array}{c}0.0006 \\
(0.0041)\end{array}$ \\
\hline Lagged $\ln (G D P P C)$ & $\begin{array}{c}-0.0247 * * \\
(0.0114)\end{array}$ & $\begin{array}{l}-0.0087 \\
(0.0091)\end{array}$ & $\begin{array}{c}-0.0375^{* *} \\
(0.0160)\end{array}$ & $\begin{array}{c}-0.0183^{*} \\
(0.0100)\end{array}$ & $\begin{array}{l}-0.0112 \\
(0.0094)\end{array}$ & $\begin{array}{l}-0.0169 \\
(0.0156)\end{array}$ & $\begin{array}{c}-0.0246^{* *} \\
(0.0115)\end{array}$ & $\begin{array}{c}-0.0173 * * \\
(0.0078)\end{array}$ & $\begin{array}{l}-0.0054 \\
(0.0098)\end{array}$ \\
\hline Const & $\begin{array}{c}0.0915 \\
(0.0662)\end{array}$ & $\begin{array}{l}-0.0385 \\
(0.0480)\end{array}$ & $\begin{array}{c}0.0618 \\
(0.0658)\end{array}$ & $\begin{array}{c}0.0322 \\
(0.0525)\end{array}$ & $\begin{array}{l}-0.1262 \\
(0.0887)\end{array}$ & $\begin{array}{c}0.0173 \\
(0.0797)\end{array}$ & $\begin{array}{c}0.0533 \\
(0.0608)\end{array}$ & $\begin{array}{c}0.0344 \\
(0.0456)\end{array}$ & $\begin{array}{l}-0.0407 \\
(0.0507)\end{array}$ \\
\hline$\overline{\text { Obs/No. of cty }}$ & $447 / 91$ & $446 / 91$ & $446 / 91$ & $444 / 91$ & $437 / 91$ & $436 / 87$ & $442 / 91$ & $409 / 86$ & $429 / 87$ \\
\hline AR(1) p-value & $\begin{array}{l}{[0.0000]} \\
{[0.225]}\end{array}$ & $\begin{array}{l}{[0.0000]} \\
{[0832]}\end{array}$ & [0.0000] & {$[0.0000]$} & {$[0.0000]$} & [0.0000] & {$[0.0000]$} & [0.0000] & {$[0.0000]$} \\
\hline $\begin{array}{l}\text { AR(2) p-value } \\
\text { Hansen Test Stat } \\
\text { Hansen p-value }\end{array}$ & $\begin{array}{c}{[0.225]} \\
23.72 \\
{[0.307]}\end{array}$ & $\begin{array}{c}{[0.832]} \\
32.83 \\
{[0.135]}\end{array}$ & $\begin{array}{c}{[0.466]} \\
13.41 \\
{[0.767]}\end{array}$ & $\begin{array}{c}{[0.465]} \\
23.95 \\
{[0.295]}\end{array}$ & $\begin{array}{c}{[0.525]} \\
22.74 \\
{[0.302]}\end{array}$ & $\begin{array}{c}{[0.063]} \\
22.99 \\
{[0.289]}\end{array}$ & $\begin{array}{c}{[0.293]} \\
22.07 \\
{[0.281]}\end{array}$ & $\begin{array}{c}{[0.420]} \\
23.39 \\
{[0.221]}\end{array}$ & $\begin{array}{c}{[0.522]} \\
34.35 \\
{[0.356]}\end{array}$ \\
\hline
\end{tabular}

Dependent variable is $\boldsymbol{G D P P C \_ g r . ~ 5 - y e a r ~ i n t e r v a l ~ p a n e l ~ d a t a ~ i s ~ u s e d ~ f o r ~ e s t i m a t i o n . ~ T h e ~ l a g g e d ~} \boldsymbol{I n}(\boldsymbol{G D P P C})$ is treated as pre-determined, while other regressors are endogenous. Period dummies and additional covariates are included but not reported. Standard errors are in parenthesis and Windmeijer-corrected, robust for heteroskedasticity and autocorrelation. $* * *, * *$ and $*$ denote significance levels at $1 \%, 5 \%$ and $10 \%$ respectively. Maximum 4 lags are used for instruments. Instruments are transformed by orthogonal deviation and collapsed. Hansen test is used for overidentifying restrictions. 


\subsection{With Alternative Measure of Institution}

To test further the sensitivity of our results, we test the baseline specification with alternative measures of institutions in Table 2.4.2-4. Instead of DEMOC, we use the augmented Freedom House's polity index (IPOLITY2). Hadenius and Teorell (2005) suggests that averaging the Freedom House's political rights and civil liberties indices works better than simply using the individual one from the original source in terms of validity and reliability. Our Model 2.(22) in Table 2.4.2-4 shows that this alternative measure of democracy does not change our conclusion at all. Democracy still has no significant direct partial impact on economic growth.

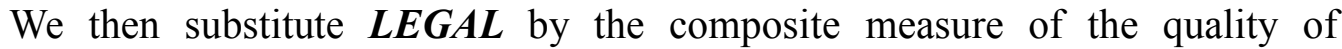
government index $\boldsymbol{Q O} \boldsymbol{O}$ (as defined in Section 2.4.1) to proxy the security of property rights and contract enforcement provided by the State in our estimation. Since this variable captures more dimensions of institutions, it is no wonder the variable dominates all the significant impact on growth as shown in Models 2.(23) and 2.(24). In these Models, only QOG remains statistically significant, possibly reflecting that the direct impact of $\boldsymbol{Q O} \boldsymbol{G}$ dominates that of other institutional variables.

To separately test "market-creating" institutions - property rights and contractual rights - as in previous literature (like in Acemoglu and Johnson (2005)), we also carry out similar tests in Models 2.(25) and 2.(26) using Polity IV's executive constraint (XCONST) as a measure of security of property

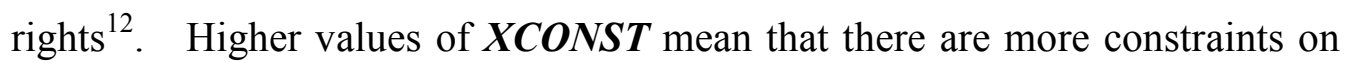
the executives, implying that the risk of expropriation from the State is less likely. Our results shall suggest that "market-creating" institutions have a direct positive impact on economic growth.

\footnotetext{
${ }^{12}$ DEMOC has not be incorporated simultaneously to avoid multicollinearity since XCONST is a component of DEMOC.
} 
Table 2.4.2-4: Institution and Economic Growth - With Alternative Measures of Institutions

(2-Step System GMM Estimations)

\begin{tabular}{|c|c|c|c|c|c|}
\hline Model & $\underline{2 .(22)}$ & $\underline{2 .(23)}$ & $\underline{2 .(24)}$ & 2.(25) & $2 .(26)$ \\
\hline DEMOC & & $\begin{array}{l}-0.0002 \\
(0.0015)\end{array}$ & & & \\
\hline IPOLITY2 & $\begin{array}{c}0.0023 \\
(0.0016)\end{array}$ & & $\begin{array}{c}0.0005 \\
(0.0023)\end{array}$ & & \\
\hline$Q O G$ & & $\begin{array}{c}0.0651 * * * \\
(0.0212)\end{array}$ & $\begin{array}{l}0.0642 * * \\
(0.0245)\end{array}$ & & \\
\hline$L E G A L$ & $\begin{array}{c}0.0052 * * * \\
(0.0019)\end{array}$ & & & & $\begin{array}{c}0.0069 * * * \\
(0.0022)\end{array}$ \\
\hline XCONST & & & & $\begin{array}{c}0.0010 * * * \\
(0.0002)\end{array}$ & $\begin{array}{c}0.0007 * * * \\
(0.0002)\end{array}$ \\
\hline$S M$ & $\begin{array}{l}0.0032 * * \\
(0.0016)\end{array}$ & $\begin{array}{c}0.0014 \\
(0.0017)\end{array}$ & $\begin{array}{c}0.0014 \\
(0.0017)\end{array}$ & & \\
\hline$R E G$ & $\begin{array}{c}0.0040 \\
(0.0044)\end{array}$ & $\begin{array}{c}0.0047 \\
(0.0045)\end{array}$ & $\begin{array}{c}0.0041 \\
(0.0047)\end{array}$ & & \\
\hline SCHOOLING & $\begin{array}{c}0.0119^{* *} \\
(0.0059)\end{array}$ & $\begin{array}{c}0.0186 * * * \\
(0.0050)\end{array}$ & $\begin{array}{c}0.0178 * * * \\
(0.0056)\end{array}$ & $\begin{array}{l}0.0143 * \\
(0.0084)\end{array}$ & $\begin{array}{c}0.0129 * * \\
(0.0058)\end{array}$ \\
\hline Lagged $\ln (G D P P C)$ & $\begin{array}{c}-0.0246 * * \\
(0.0106)\end{array}$ & $\begin{array}{c}-0.0376^{* * *} \\
(0.0100)\end{array}$ & $\begin{array}{c}-0.0327 * * * \\
(0.0095)\end{array}$ & $\begin{array}{l}-0.0185 \\
(0.0158)\end{array}$ & $\begin{array}{c}-0.0225 * * \\
(0.0094)\end{array}$ \\
\hline Const & $\begin{array}{c}0.0423 \\
(0.0510)\end{array}$ & $\begin{array}{l}0.1261 * * \\
(0.0570)\end{array}$ & $\begin{array}{l}0.0903 * \\
(0.0487)\end{array}$ & $\begin{array}{c}0.0718 \\
(0.0760)\end{array}$ & $\begin{array}{l}0.0734 * \\
(0.0437)\end{array}$ \\
\hline$\overline{O b s / N o . ~ o f ~ c t y ~}$ & $463 / 94$ & $391 / 84$ & $402 / 86$ & $559 / 99$ & $469 / 92$ \\
\hline AR(1) p-value & {$[0.0000]$} & {$[0.0000]$} & {$[0.0000]$} & [0.0443] & {$[0.0000]$} \\
\hline$A R(2) p$-value & {$[0.298]$} & {$[0.132]$} & {$[0.235]$} & {$[0.283]$} & {$[0.376]$} \\
\hline $\begin{array}{l}\text { Hansen Test Stat } \\
\text { Hansen p-value }\end{array}$ & $\begin{array}{c}22.03 \\
{[0.231]}\end{array}$ & $\begin{array}{c}17.78 \\
{[0.471]}\end{array}$ & $\begin{array}{c}20.85 \\
{[0.287]}\end{array}$ & $\begin{array}{c}5.068 \\
{[0.750]}\end{array}$ & $\begin{array}{l}7.179 \\
{[0.7087}\end{array}$ \\
\hline
\end{tabular}

Dependent variable is $\boldsymbol{G D P P C \_ g r . ~ 5 - y e a r ~ i n t e r v a l ~ p a n e l ~ d a t a ~ i s ~ u s e d ~ f o r ~ e s t i m a t i o n . ~ T h e ~}$ lagged $\ln (\boldsymbol{G D P P C})$ is treated as pre-determined, while other regressors are endogenous. Period dummies are included but not reported. Standard errors are in parenthesis and Windmeijer-corrected, robust for heteroskedasticity and autocorrelation. ***,** and * denote significance levels at $1 \%, 5 \%$ and $10 \%$ respectively. Maximum 4 lags are used for instruments. Instruments are transformed by orthogonal deviation and collapsed. Hansen test is used for overidentifying restrictions.

\subsection{With Different Sub-samples}

Finally, we use different sub-samples to test our baseline specification in Table 2.4.2-5. Following the literature on the effect of legal origins on institutions and economic outcomes ${ }^{13}$, we test the baseline model with non-English

\footnotetext{
${ }^{13}$ See La Porta, et al. (2008) for a recent survey on this strand of literature. In gist, this strand of view suggests that legal origin of an economy will directly affect its degree of security of
} 
common law origin and non-French civil law origin countries in Models 2.(27) and 2.(28). In Models 2.(29) - 2.(32), we further test different sub-samples by income levels. Our general results are largely similar. These models, again, provide empirical evidence that "market-creating" institution, measured by the protection of property rights and contract enforcement $(\boldsymbol{L E G A L})$, as well as "market-stabilising" institutions, measured by the stability of monetary and fiscal institution $(\boldsymbol{S M})$, are directly conducive to economic growth. DEMOC, on the contrary, does not have any direct impact on growth.

One interesting finding is on $\boldsymbol{R} \boldsymbol{E} \boldsymbol{G}$ - market-regulating institution. Using the full sample, we have seen that $\boldsymbol{R} \boldsymbol{E} \boldsymbol{G}$ does not have any significant direct partial effect on growth, although the sign of the coefficients indicate that a less regulated environment tends to grow faster. However, we find a positive and statistically significant direct impact of $\boldsymbol{R} \boldsymbol{E} \boldsymbol{G}$ on growth in the sub-sample of non-English common law origins (i.e. Model 2.(27)), non-industrialised countries (i.e. Model 2.(31)) and low income and lower middle income countries (i.e. Model 2.(32)). These results suggest that the negative impact of excess regulatory environment is more obvious in less developed economies. This also provides supporting evidence to the existing literature, like Djankov, et al. (2002) and Botero, et al. (2004), that there are generally more regulations in less developed economies and they are more likely to be growth-impeding. This probably relates to the bureaucratic quality to execute these regulations. In particular, more red tape may also lead to more corruption which is gorwht-hampering. However, the case of Sub-Sahara African countries is quite peculiar. We do not find the negative effect of $\boldsymbol{R} \boldsymbol{E} \boldsymbol{G}$ in this sub-sample. One, nevertheless, should note that the size of the sub-sample pertaining to Sub-Sahara African countries is significantly smaller than the other sub-samples.

property rights via judicial formalism, bureaucratic quality, the amount of red-tape and regulations, and henceforth, its economic performance. It is found that countries with English common law origin, vis-à-vis those with French civil law origin, generally perform better, with more developed financial markets as well as less corruption. 
Table 2.4.2-5: Institution and Economic Growth - Sub-Samples Estimations (2-Step System GMM Estimations)

\begin{tabular}{|c|c|c|c|c|c|c|c|}
\hline $\begin{array}{l}\text { Model } \\
\text { Sample }\end{array}$ & $\underline{\underline{2 .(11)}}$ & $\begin{array}{c}\underline{2 .(27)} \\
\text { Non-English Common } \\
\text { Law Countries }\end{array}$ & $\begin{array}{c}\underline{2 .(28)} \\
\text { Non-French Civil } \\
\text { Law Countries }\end{array}$ & $\begin{array}{l}\text { 2.(29) } \\
\text { Non Sub-Sahara } \\
\text { African Countries }\end{array}$ & $\begin{array}{c}\underline{2 .(30)} \\
\begin{array}{l}\text { Sub-Sahara African } \\
\text { Countries }\end{array}\end{array}$ & $\begin{array}{c}\underline{2 .(31)} \\
\begin{array}{c}\text { Non Industrialised } \\
\text { Countries }\end{array}\end{array}$ & $\begin{array}{c}\text { 2.(32) } \\
\text { Lower Middle } \\
\text { Income \& Low } \\
\text { Income } \\
\text { Countries } \\
\end{array}$ \\
\hline DEMOC & $\begin{array}{l}0.0015 \\
(0.0015)\end{array}$ & $\begin{array}{c}0.0006 \\
(0.0013)\end{array}$ & $\begin{array}{c}0.0002 \\
(0.0021)\end{array}$ & $\begin{array}{l}-0.0000 \\
(0.0010)\end{array}$ & $\begin{array}{c}0.0017 \\
(0.0026)\end{array}$ & $\begin{array}{l}-0.0006 \\
(0.0013)\end{array}$ & $\begin{array}{l}-0.0005 \\
(0.0016)\end{array}$ \\
\hline$R E G$ & $\begin{array}{c}0.0042 \\
(0.0045)\end{array}$ & $\begin{array}{l}0.0089^{*} \\
(0.0050)\end{array}$ & $\begin{array}{l}-0.0064 \\
(0.0069)\end{array}$ & $\begin{array}{c}0.0026 \\
(0.0039)\end{array}$ & $\begin{array}{c}0.0135 \\
(0.0107)\end{array}$ & $\begin{array}{l}0.0117^{*} \\
(0.0062)\end{array}$ & $\begin{array}{l}0.0210 * * \\
(0.0092)\end{array}$ \\
\hline$S M$ & $\begin{array}{l}0.0031^{*} \\
(0.0018)\end{array}$ & $\begin{array}{l}0.0030^{*} \\
(0.0018)\end{array}$ & $\begin{array}{l}0.0065^{* *} \\
(0.0027)\end{array}$ & $\begin{array}{l}0.0023^{*} \\
(0.0013)\end{array}$ & $\begin{array}{c}0.0035 \\
(0.0045)\end{array}$ & $\begin{array}{l}0.0030^{*} \\
(0.0017)\end{array}$ & $\begin{array}{c}0.0035 \\
(0.0035)\end{array}$ \\
\hline$L E G A L$ & $\begin{array}{c}0.0052 * * * \\
(0.0020)\end{array}$ & $\begin{array}{c}0.0073 * * * \\
(0.0024)\end{array}$ & $\begin{array}{l}0.0061^{*} \\
(0.0032)\end{array}$ & $\begin{array}{l}0.0050^{* * *} \\
(0.0018)\end{array}$ & $\begin{array}{c}0.0098 * * \\
(0.0046)\end{array}$ & $\begin{array}{l}0.0072 * * \\
(0.0030)\end{array}$ & $\begin{array}{l}0.0090 * * \\
(0.0039)\end{array}$ \\
\hline SCHOOLING & $\begin{array}{l}0.0139^{*} \\
(0.0067)\end{array}$ & $\begin{array}{l}0.0101^{*} \\
(0.0060)\end{array}$ & $\begin{array}{c}0.0015 \\
(0.0053)\end{array}$ & $\begin{array}{c}0.0092 * * \\
(0.0043)\end{array}$ & $\begin{array}{l}-0.0064 \\
(0.0107)\end{array}$ & $\begin{array}{c}0.0131 \\
(0.0088)\end{array}$ & $\begin{array}{l}-0.0018 \\
(0.0123)\end{array}$ \\
\hline Lagged $\ln (G D P P C)$ & $\begin{array}{c}-0.0304 * * \\
(0.0118)\end{array}$ & $\begin{array}{c}-0.0269 * * * \\
(0.0096)\end{array}$ & $\begin{array}{l}-0.0044 \\
(0.0091)\end{array}$ & $\begin{array}{l}-0.0218^{* *} \\
(0.0094)\end{array}$ & $\begin{array}{l}-0.0021 \\
(0.0176)\end{array}$ & $\begin{array}{l}-0.0293^{*} \\
(0.0162)\end{array}$ & $\begin{array}{c}0.0030 \\
(0.0323)\end{array}$ \\
\hline Const & $\begin{array}{c}0.0843 \\
(0.0575) \\
\end{array}$ & $\begin{array}{c}0.0509 \\
(0.0477)\end{array}$ & $\begin{array}{l}-0.0047 \\
(0.0433)\end{array}$ & $\begin{array}{r}0.0744 \\
(0.0529) \\
\end{array}$ & $\begin{array}{l}-0.1039 \\
(0.0891)\end{array}$ & $\begin{array}{c}0.0427 \\
(0.0962)\end{array}$ & $\begin{array}{l}-0.1700 \\
(0.1866)\end{array}$ \\
\hline Obs/No. of cty & $447 / 91$ & $293 / 60$ & $213 / 43$ & $354 / 70$ & $93 / 21$ & $326 / 70$ & $208 / 46$ \\
\hline AR(1) p-value & {$[0.0000]$} & {$[0.0000]$} & {$[0.0004]$} & {$[0.0000]$} & {$[0.0190]$} & {$[0.0000]$} & {$[0.0000]$} \\
\hline AR(2) p-value & {$[0.279]$} & {$[0.478]$} & {$[0.978]$} & {$[0.136]$} & {$[0.604]$} & {$[0.583]$} & {$[0.526]$} \\
\hline $\begin{array}{l}\text { Hansen Test Stat } \\
\text { Hansen Test p-value }\end{array}$ & $\begin{array}{l}21.80 \\
0.241]\end{array}$ & $\begin{array}{c}17.12 \\
{[0.194]}\end{array}$ & $\begin{array}{c}18.02 \\
{[0.115]}\end{array}$ & $\begin{array}{c}25.92 \\
{[0.169]}\end{array}$ & $\begin{array}{c}9.322 \\
{[0.952]}\end{array}$ & $\begin{array}{c}18.00 \\
{[0.456]}\end{array}$ & $\begin{array}{c}15.55 \\
{[0.342]}\end{array}$ \\
\hline
\end{tabular}

Dependent variable is $\boldsymbol{G D P P C}$ gr. 5-year interval panel data is used for estimation. The lagged $\boldsymbol{I n ( G D P P C )}$ is treated as pre-determined, while other regressors are endogenous. Period dummies are included but not reported. Standard errors are in parenthesis and Windmeijer-corrected, robust for heteroskedasticity and autocorrelation. $* * *, * *$ and $*$ denote significance levels at $1 \%, 5 \%$ and $10 \%$ respectively. Maximum 4 lags are used for instruments. Instruments are transformed by orthogonal deviation and collapsed. Hansen test is used for overidentifying restrictions.

$\S$ English common law and French civil law countries are classified based on La Porta, et al. (1997).

${ }^{\wedge}$ Industrialised economies are classified based on Chinn and Ito (2006).

"Classification of lower middle income and low income countries is based on World Bank classification. 


\subsection{Conclusion}

In this Chapter, our primary interest is to revisit the empirical evidence of institution and growth in a dynamic panel data model and investigate if and what institutions matter to growth. The research motivation is driven by the technical limitations of the existing literature. After providing a brief literature survey of the subject, we point out that the existing literature is mostly cross-sectional in nature, which ignores the dynamic and short-run impact of institutions on growth. On the technicalities front, these studies assume that there is no direct growth effect of any institutional change. Estimation results are also subject to endogeneity without using proper and valid instruments. These results are also potentially biased due to omitted variables, like country-specific characteristics which may capture the effect of natural endowments, culture, historical developments and other time-invariant factors alike. Exactly what institutions matter to economic growth is not well defined in previous studies. Therefore, although the institution view suggests a convincing case that institutions are the fundamental sources of growth, empirical results are largely inconclusive.

We employ panel GMM estimator to carry out our empirical investigation. By so doing, we do not have to seek "external" instruments to tackle the weak version of endogeneity problem between institutions and economic growth. In addition, the methodology allows us to control for country-specific characteristics, time effect and initial income level. The results obtained help demonstrate the direct and short-run partial impact of institution on growth.

So after using our suggested methodology, which appears to be technically improved, do institutions matter to growth empirically? It all depends on what institutions we refer to. The general results are positive when we first take a preliminary test of an augmented Solow growth model with institutions incorporated in the specification. In such specification, we show that institutions, as measured by a composite index, have a direct impact on growth. In contrast to, say human capital, the effect of institution is more statistically significant. 
We further attempt to test institutions into clusters. Based on Rodrik(2005)'s taxonomy described in Chapter 1, we cluster institutions into four dimensions, which essentially measures political institutions - democracy in particular, and economic institutions and policies - security of property rights, stability of monetary and fiscal policies and regulatory environment. This framework brings political institution, economic institution and policies into synergy and allows us to test institutions in a unified manner.

Our empirical results generally show that political institution, i.e. democracy in our case, does not have any direct effect on growth. This result holds even if we use alternative measures of democracy. Secondly, market-creating institutions, measured by the security of property rights as well as constraints on the executives, are directly associated with growth. This is in line with the existing literature. Thirdly, stability of monetary and fiscal policies, namely market-stabilising institutions, is also growth-promoting. Fourthly, market-regulating institutions, which measure the regulatory environment, show no direct growth impact either. It may suggest that whether regulations are growth-impeding is in relation to the stage of development of countries. In developed countries, regulations may help rectify externalities and restore market competitiveness. In the less developed economies, regulations may be growth-hampering due to the executive ability of bureaucrats and the likelihood of corruption thereby induced. Therefore, using a full sample, the impact of regulations is ambiguous. However, using a sub-sample, we find that fewer regulations directly carry a significant growth impact in less developed economies. This suggests that after controlling for the stage of development, the negative impact of regulations on growth is more pronounced. All these empirical results seem to survive after using different specifications with additional covariates and using different sub-samples.

In conclusion, the empirical evidence obtained under a coherent taxonomy demonstrates that economic institution and policies impose direct and partial growth impacts, but political institutions do not. We also provide additional empirical evidence to the institution view that institutions matter to growth, 
even after controlling for the unobserved time-invariant effects and the possible dynamics of institutional change. We should stress that we have no intention to overrule the endowment view or historical view of growth. In particular, our investigations do not take into account of the impact of historical incidences, e.g. wars, on the institutional changes. Our results merely attempt to address the concerns on and critiques of the existing institution view literature. Moreover, the observations showing that institutions that do not have direct growth impact does not mean that they play no particular role in the development process. Also, their impacts may be non-linear. With this in mind, we will try to explore other channels through which these defined clusters may affect economic development in the following Chapters. 
CHAPTER 3 : ON THE CAUSALITY OF DEMOCRACY AND ECONOMIC REFORMS 


\subsection{Introduction}

This Chapter is an extension of Chapter 2 with an aim to make progress towards understanding the effect of political institution on economic development via its causation of economic reforms. We focus on the causality between political institutions - democracy, specifically - and economic reforms. We refer the latter to, as in Giavazzi and Tabellini (2005), comprehensive reforms that broaden the scope of the market and of international markets, i.e. they are market-creating. The causal relationship is tested empirically by using indices of democracy and liberalisation reforms on various fronts - namely, fiscal sector, banking sector, capital account and trade liberalisation and labour market regulation - for the period of 1970-2005 for 114 economies.

Literature has attempted to establish the relationship between reforms and political institution, in which reforms are commonly referred as liberalisation measures. Naturally, the research questions focus on under which political institution - using a dichotomous classification of democracy vis-à-vis autocracy - is more likely to cause liberalisation and what are the ex ante and ex post growth impacts of liberalisation.

Understandably, political institution and policy choices form an interactive nexus. Since the wave of democratisation beginning from 1978 in Latin America, we saw the widespread adoption of outward orientation policies in the region. The opening up of the Central and Eastern European economies followed after the fall of Soviet-type socialism. Liberalisation reforms appear to take place together with changes in political institution. It is commonly believed that democracy renders the government to be more accountable, more sensitive to the public demand. Economic liberalisation - free exchange of goods and services, capital account liberalisation, free flow of capital or lax regulatory environment - introduces competition to the domestic market, expands the choice sets of the economy and thus improves the general welfare of the society. Liberalisation measures are more likely to gain public support 
in democracies. Reciprocally, market liberalisation also potentially leads to economic development and carries a positive feedback to the demand for democratisation process in the society (as in Schumpter (1950), Lipset (1959) and Hayek (1960)).

At first sight, data do show us that political liberalisation and economic liberalisation appear to move hand in hand. Indeed, we find more democracies over the last few decades alongside increased globalisation. Table 3.1-1 provides a very preliminary snapshot of regime transition around the world over the last few decades. Using POLITY IV's measure of institutionalised democracy (DEMOC) as defined in Chapter 2, an index ranging from 0 to 10 with higher score indicating a more democratic society, the number of democratic economies rose from 36 economies in 1970 to an overwhelmingly 95 economies in 2007 . Democracies represent over $60 \%$ of the total number of economies being studied in 2007.

Table 3.1-1: Number of economies under different political regimes

\begin{tabular}{lccc}
\hline & 1970 & 1990 & 2007 \\
\hline \hline $\begin{array}{l}\text { Democracy } \\
(\text { DEMOC } \geq 5)\end{array}$ & 36 & 59 & 95 \\
$\begin{array}{l}\text { Autocracy } \\
(\text { DEMOC }<5)\end{array}$ & 88 & 72 & 58 \\
\hline Total & 124 & 131 & 153
\end{tabular}

In parallel, economic liberalisation marched forward rapidly. During 1970-2007, the value of total world exports rose by 37.6 times ${ }^{1}$. Foreign direct investment contributed some $0.5 \%$ of world's GDP in 1970 to $3.3 \%$ in $2007^{2}$. Using the composite economic freedom index $(\boldsymbol{E F})$ from the Fraser Institute, increasingly more democracies are classified as "economic free" over the years, as shown in Table 3.1-2 below. Indeed, Milner and Kubota (2005) similarly argue that preceding and concurrent with the move to free trade, there has been a global movement toward democracy. They suggest that the two

\footnotetext{
${ }^{1}$ Data source: World Trade Organisation, International Trade Statistics 2007 (Retrieved from: http://www.wto.org/english/res e/statis_e/its2007_e/its07_appendix_e.htm).

2 Data source: UNCAD, Foreign Direct Investment Database (Retrieved from: http://www.unctad.org/Templates/Page.asp?intItemID=1923).
} 
trends are related.

Table 3.1-2: Number of economic free economies under democracy and autocracy

\begin{tabular}{clccc}
\hline Political regime & Degree of Liberalisation & $\mathbf{1 9 7 0}$ & $\mathbf{1 9 9 0}$ & $\mathbf{2 0 0 4}$ \\
\hline \hline \multirow{2}{*}{ Democracy } & Economic Free & 23 & 45 & 90 \\
& Not Economic Free & 3 & 12 & 1 \\
\hline \multirow{2}{*}{ Autocracy } & Economic Free & 17 & 22 & 24 \\
& Not Economic Free & 8 & 22 & 7 \\
\hline
\end{tabular}

Note: Democracy (Autocracy) is defined as scoring 5 or above (below 5) in Polity IV's index on institutionalised democracy. The index ranges from 0 to 10, with higher score indicating the economy is more democratic.

Degree of liberalisation is based on the Fraser Institute's economic freedom index. The index ranges from 0 to 10 , with higher score indicating the economy is more economic free. Economies are "economic free" if they receive scores with 5 or above and vice versa.

Apparently, this co-movement serves no robust foundation for arguing the causal relationship between political institution and economic reforms. For example, developed economies like Hong Kong, while enjoying the well-acclaimed "the world's most free" economy for decades (e.g. Gwartney, et al. (2008) and Heritage Foundation (2009)), has no democracy (Gwartney, et al. (2008)). It may suggest that an autocrat could be equally likely to undertake liberalisation reforms if it deems fit. In fact, from Table 3.1-2 above, we find that increasingly more autocratic economies also enjoy greater economic freedom. In other words, having reforms or not may not necessarily relate to the political regime.

The causality relationship appears to be further weakened by the spectacular growth performances in the emerging markets during the last few decades. China, as a notable exception, has adopted market liberalisation reform since 1978. On the political institution front, nevertheless, there are very few signs showing a dramatic democratisation (see Table 3.1-3 below). Amongst the four most growth-promising emerging markets - together with Brazil, Russia, India - China is the only so-called "autocratic" society. However, all four economies show a substantial improvement in economic freedom. 
Table 3.1-3: Scores on Democracy $(D E M O C)$ and Economic Freedom $(E F)$ of Selected Emerging Economies

\begin{tabular}{|l|c|c|c|c|c|c|c|c|}
\hline Year & \multicolumn{2}{|c|}{$\underline{\mathbf{1 9 8 0}}$} & \multicolumn{2}{c|}{$\underline{\mathbf{1 9 9 5}}$} & \multicolumn{2}{c|}{$\underline{\mathbf{2 0 0 0}}$} & \multicolumn{2}{c|}{$\underline{\mathbf{2 0 0 4}}$} \\
\hline & DEMOC & $\boldsymbol{E F}$ & DEMOC & $\boldsymbol{E F}$ & DEMOC & $\boldsymbol{E F}$ & DEMOC & $\boldsymbol{E F}$ \\
\hline Brazil & 2 & 4.35 & 8 & 4.42 & 8 & 5.88 & 8 & 5.88 \\
China & 0 & 4.00 & 0 & 5.20 & 0 & 5.82 & 0 & 5.66 \\
India & 0 & 5.15 & 0 & 6.42 & 7 & 5.90 & 8 & 6.03 \\
Russia &.. &.. & 8 & 4.42 & 7 & 4.95 & 7 & 5.60 \\
\hline
\end{tabular}

Note: $\boldsymbol{D E M O C}$ is defined as above - an index ranging from 0 to 10 with higher scores denote democracy. $\boldsymbol{E F}$ index is from Gwartney, et al. (2008), ranging from 0 to 10 with higher scores denote more economically free.

While a causal relationship cannot be established, the use of dichotomous classification of political regime also covers up the dynamics of changes in political institution, as well as the dynamic policy choices determined. Regime transition can happen in some economies within a fairly short period of time. For example, using DEMOC index again, Argentina scored zero in 1970, then 6 in 1975. The score fell back to zero again in 1980 and then rose to some 7-8 from 1985 onwards. Peru scored zero in the 70s, then $7 \mathrm{~s}$ in the 80 s and reverted to around 3 in the late 90 s.

Marginal changes of political institution, instead of a fundamental regime switch, happen even more often. We attempt to classify economies as democracies/autocracies using the dichotomous classification as above. The classification of the economies in our dataset is set out in Appendix Section A.4. We find that the majority of economies generally stay as democracies throughout the sample period, with marginally improving and deteriorating DEMOC scores over the sample period without a complete regime switch. It suggests that marginal changes in political institutions, rather than regime switch, are more prevalent.

Henceforth, the question we are interested in naturally is whether these marginal changes of political institution at certain period of time could affect the policy choices made in the coming periods. In return, we wonder if there will be any feedback effect of these policy choices on political institution. To test empirically these questions, we have to design a strategy to capture the 
dynamic, short-run impact of our variables of interest. We propose to use the dynamic panel GMM estimators as in Chapter 2 to this end. This would be different from the existing literature in which it is primarily interested in the effect of permanent regime transition, instead of any marginal changes of political institution. Furthermore, our proposed estimation strategy helps address the endogenous problem of political institution and policy choices, which are not often and satisfactorily dealt with in the literature.

Our research motivations also extend to investigate what kinds of reforms are more likely to be implemented in democracies. Empirical work of this kind is less frequently explored. The effects of democracy on trade liberalisation and financial liberalisation were separately investigated in earlier studies. Only until recently, however, some studies brought the two forms of liberalisations together. To measure liberalisation, quantitative statistics such as total trade as percentage of GDP or the number of credit market restrictions as defined by IMF are usually used as proxies. Since 2000, there is a new strand of literature devoting efforts in compiling indicators (or indices) to measure liberalisation from a multi-dimensional perspective. Other than trade and financial liberalisations, empirical work on reforms in other sectors is even fewer.

To sum up, unlike previous studies, our empirical investigation is designed in a dynamic setting, allowing us to investigate if the causal relationship between political institution and economic reforms can be found in a relatively short time-span. This captures the effect of marginal changes of political institution, but not necessarily a regime switch, on economic reform. In addition, we will also test the causal relationship in respect to sector-specific reforms. Our findings show that democracy seems more likely to lead to a more redistributive society and reforms in trade and financial liberalisation. The results survive even when using different measures of political institution and sub-samples. On the reverse causality, we find that redistributive policy and trade liberalisation likewise seemingly cause the economy to make progress in democratisation. However, financial liberalisation does not show such causal effect. 
In the following, we will present a brief literature survey in Section 3.2, with the emphasis on the strategies employed in previous studies. We will then discuss our model and data used in Section 3.3. Our empirical results follow in Section 3.4. We conclude in Section 3.5.

\subsection{Literature Survey: Interrelationship between Political Regime and Economic Reform}

There is no conclusive theoretical argument or empirical evidence showing that democracy will cause economic reform. Economic reforms reflect policy changes. Democratic governments may have greater legitimacy to reforms and promote institutional changes - e.g. strengthening an independent legal system to ensure political freedom and democracy - thus leading to successful market reforms (Giuliano, Mishra, and Spilimbergo (2009), hereafter abbreviated as GMS). Democracy could also create an environment conducive to economic reforms by limiting rent-seeking activities and putting a system of checks and balances in place (Dethier, Ghanem, and Zoli (1999)).

\subsubsection{Theoretical arguments}

Interest group model suggests that economic reforms reflect changes in the economic choices that political elites made to maximise their own payoffs (Acemoglu (2006)). Along a similar line, Acemoglu and Robinson (2006)'s model demonstrates that political institutions may change but economic policies could be quite persistent. In other words, political institutions do not directly cause policy choices. Their proposition is that the persistence of economic choices is not due to the persistence of political elites, but the persistence of incentives of whoever is in power. Similarly, Alesina, Ardagna, and Trebbi (2006) also argue that delayed reforms are generally caused by the political conflict over what type of stabilisation to implement, in particular over the distribution of costs of the adjustment. The rationale of their model is that stabilisation occurs when one of the competing groups can impose its desired 
policies on others that have exhausted their ability to resist the undesired stabilisation. In a nutshell, the "interest group" view of reform suggests that democracy could only lead to more reforms if reforms create more winners than losers.

Specifically with regard to trade liberalisation, the conventional literature suggests that economies in crisis, say hyperinflation, are more likely to undertake economic reforms. However, Milner and Kubota (2005) refute such proposition. Their work, with the support of empirical evidence, suggests that it is democracy that triggers trade liberalisation. As trade liberalisation is about to benefit most of the workers, thereby likely gaining political support in a democracy. Likewise, Rajan and Zingales (2003) also suggests that economic liberalizations could be associated with higher quality of democratic institutions if such reform increases the economic power of the middle class. Aidt and Gassebner (2007) similarly argue that autocracies tend to trade less than democracies do because of trade taxes imposed. Autocracies, with less political accountability, usually result in poorer bureaucratic quality as there is no incentive to build up control structures (e.g. red tape and other unobserved trade distortions). This leads to the differences in trade flows as compared to that in democracies. On the contrary, De Haan and Sturm (2003) suggests that democracies are less likely to cause trade liberalisation as it involves massive layoffs at the beginning. As they reckon, only an autocrat can possibly bear this short-term cost.

Other than trade liberalisation, democracy may also cause reforms in other aspects such as the provision of public goods. Sunde, Cervellati, and Fortunato (2006) propose an endogenous model of political institution, highlighting that democratic transition, economic development and economic policies are endogenously determined. Democratic transition, as they interpret, is essentially about provision of productive public goods and redistribution of incomes. Redistribution and public good provision are public choices made by different interest groups under both democracies and autocracies. Their model basically argues that political elites, albeit their monopolised political power, will start to invest in public goods for efficient 
production once the economy reaches beyond certain level of technology and economic development. Gradually they have to consider the trade-off between giving up some political power in exchange for a broader tax basis for the provision of public goods. Their model predicts that democracies tend to create environments which are more favourable for economic activities than the ones implemented under oligarchies. Furthermore, countries with more democratic institutions usually have a larger state, meaning more government consumption and more redistribution. Acemoglu, et al. (2005) provide a survey of cross-country evidence on the patterns of democracy. They conclude that democracies are more redistributive than oligarchies, especially with an increase in redistribution following democratisation.

\subsubsection{Empirical Evidence}

\subsubsection{Trade Liberalisation}

Empirical evidence of the causal relationship between democracy and economic reforms remains largely inconclusive. In terms of trade liberalisation reforms, empirical studies of Fidrmue (2003) and De Haan and Sturm (2003) suggest that democracy is likely to cause trade liberalisation. Milner and Kubota (2005) suggest that democratisation reduces the ability of governments to use trade barriers as a strategy for building political support. Political leaders in labour-rich countries may prefer lower trade barriers to obtain political support as democracy increases. Their empirical evidence also supports that regime change is associated with trade liberalization. In contrast, economic crises and external pressures, as conventionally believed, seem less salient.

Amongst all these empirical studies, Giavazzi and Tabellini (2005) is a more frequently cited empirical article, which explicitly investigates the causality between economic and political liberalisation. They define economic liberalisation as openness to international trade, whereas political liberalisation is a permanent regime change from autocracy to democracy. By means of 
"difference-in-difference" estimation technique and using the country-specific dates of liberalisation to cluster the pre- and post-liberalisation samples, their OLS and FE panel estimates show significant positive effects of liberalisations on economic performance (e.g. growth, investment and trade volume), macroeconomic policy (e.g. budget surplus and inflation) and structural policies (e.g. corruption). Nevertheless, they suggest no causal relationship for trade liberalisation to democracy. Their findings, however, provide support to the claim that the sequences of economic and political liberalisation do matter. Countries that first liberalise trade and then become democracies do better than those who pursue the opposite sequence in almost all dimensions.

Their work is by all means comprehensive in terms of measuring the impact of trade liberalisation on various economic outcomes. However, since they only consider a permanent regime change as political liberalisation, they inevitably have to consider merely those countries with political liberalisation and that did not reverse in the sample. Their estimation technique "difference-in-difference" estimation - also makes it difficult to estimate temporary regime change and regime reversal. As they also recognise, this may create a selection bias. Moreover, the dichotomous classification of democracy does not capture the effect of continuous progress of democratisation in the country, unless the improvements are significant enough to be classified as a complete regime change.

Other empirical work like Rudra (2005) also finds a positive impact of trade openness on democracy, subject to the fact that the levels of social spending are high enough. Papaioannou and Siourounis (2008) carry their empirical test on the initially non-democratic countries and, likewise, demonstrate a positive causality. On the contrary, Li and Reuveny (2003) use lagged trade data and report a negative impact of trade liberalisation on democracy. Rigobon and Rodrik (2004) suggest a similar negative effect through the use of identification through heteroskedasticity estimation strategy. 


\subsubsection{Financial Liberalisation}

Quinn (2000) is amongst the first to test the effect of political institution on financial liberalisation. He creates his own capital account openness indicator and estimates the causality relationship in a panel VAR setting. His conclusion is that democracies are more likely to remove capital controls. Reciprocally, financial liberalisation is associated with a decrease in democracy. Dailami (2000) provides a possible explanation for this negative relationship. He notes that capital account liberalisation may limit the ability of governments to deploy redistributive taxation, regulation and risk-sharing policies, thereby weakening support for democratic forms of governance. His empirical evidence also shows that capital account liberalisation negatively associates with democracy. Abiad and Mody (2005), on the other hand, shows no influence of financial liberalisation on political institution at all.

\subsubsection{Joint Tests of Multi-Sector Reforms}

Studies, that jointly test the effect of democracy on economic and financial liberalisation reforms, have only come up very lately. Eichengreen and Leblang $(2006)^{3}$ empirically investigate how democracy interacts with globalisation over a long historical period of 1870-2000. They refer globalisation to both trade and financial liberalisation, measured respectively by the percentage of total trade to GDP and capital controls - defined as whether there are explicit legal restrictions on capital transitions as adopted by IMF's Annual Report on Exchange Arrangements and Exchange Restrictions. They argue that most of the studies previously done either ignore the possible two-way causality relationship or endogeneity problems in the model specification. They are of the view that very little effort has been made to develop an appropriate instrumental variables strategy for dealing with the endogeneity problem. To this end, inspired by earlier work by Lopez-Cordova and Meissner (2005) and Milner and Kubota (2005), they use the gravity model to obtain instruments for trade. They suggest that the basic

\footnotetext{
${ }^{3}$ In addition, they also provide an excellent review on the empirical studies of the effect of trade and financial liberalisation on democracy.
} 
gravity model variables are plausible instruments for identifying the exogenous component of trade. Similarly, for capital account policies, instrumental variables like country size, inflation, budget deficit, the number of countries with capital control or where those countries are experiencing currency crisis can also be used. Thanks to the long time span of their database, they further segregate the full sample into several sub-periods, including the gold standard, the interwar period, the Bretton Woods and the post-Bretton Woods periods. Although the standard Hansen-J test does not always support the validity of the instruments used, their results generally point to the conclusion that there is a positive two-way relationship between democracy and globalisation. The results still hold after controlling for legal origins, geographical regions and level of economic development of the countries.

The joint tests of trade and financial liberalisation extend research interests to economic reforms in other dimensions. Naturally, this requires the development of a multi-sectoral reform dataset. The IMF (2008) has just completed a cross-country economic reform database, covering 10 sectors over the period of 1960-2004 ${ }^{4}$. Giuliano, et al. (2009) (GMS) is possibly the first to test the effect of democracy on economic reform using these indicators. After controlling for country, time and sector-specific effects, their fixed effect estimations show that democracy does cause economic reform. However, they find no empirical evidence of the reverse causality.

The fundamental question we are interested in is similar to GMS, but our investigation is different in a number of ways. First of all, we will use a different set of reform indicators, namely the sub-indicators of the Fraser Institute's economic freedom index from Gwartney, et al. (2008). On one hand, the IMF's database is not publicly accessible. On the other hand, the two sets of measures do overlap in a number of aspects. We will compare the two datasets in greater details in Section 3.3.1.1 below. Secondly, although GMS also use panel data fixed-effect model in their study, the presence of a lagged dependent variable (either democracy or economic reform) as a

${ }^{4}$ We will briefly compare this dataset to the indicators we use in our empirical study in Section 3.3.1 below. 
regressor may reflect the fact that they ignore the problem of "dynamic bias" as suggested by Nickell (1981). Yet, they do acknowledge the potential problem of endogeneity in their estimations. They suggest using the reform index of the neighbouring economy to be an instrument for their IV estimations. Nevertheless, there is no explicit theoretical justification or empirical validity test for these instruments used. Thirdly, despite a vast amount of additional covariates incorporated in their robustness check (e.g. education, inflation, real devaluation, public expenditure, bureaucratic quality etc), the authors appear to fail to control for the income level. As shown in Eichengreen and Leblang (2006)'s survey, there is indeed a large amount of literature in which they argue that income levels (i.e. GDP per capita) are directly associated with democracy and also the economy's capability to undertake economic reform. It is also argued that economic growth helps build up the expectation of deepening economic reform and promoting democratisation.

We propose to use the sub-indices of the Fraser Institute's Economic Freedom Index (EF) (Gwartney, et al. (2008)) in the present study. Testing the causality between political institution and economic freedom by using $\boldsymbol{E F}$ are not scarce in the literature. However, there are at least two limitations of these studies. They primarily use the aggregate $\boldsymbol{E F}$ indicator without considering its sub-indices, except in Lundstrom (2003). While $\boldsymbol{E F}$ measures broadly 5 areas, it is quite likely that each of them may have a different effect on the political institution ${ }^{5}$ and vice versa. Second, it seems to be quite common that using $\boldsymbol{E F}$ relies heavily on the use of Granger causality to demonstrate causal relationship, without considering the problem of endogeneity amongst variables. While $\boldsymbol{E} \boldsymbol{F}$ reflects a broad spectrum of policy choices, one should note that political institution and policies measured may be endogenously determined. Table 3.2.2-1 below summarises selective relevant empirical studies in relation to the causality between economic freedom and political institution.

\footnotetext{
5 This strand of studies often tests the causality between economic freedom and political freedom. The latter refers to the indices of political freedom and civil liberties in a country from Freedom House, which is also a common measure of political institution other than the Polity IV index. In our estimations, we will also use Freedom House indices as a robustness check.
} 
Table 3.2.2-1: Empirical Studies of Measuring the Causality between Economic Freedom and Political Institution

\begin{tabular}{|c|c|c|c|}
\hline Study & Sample & $\begin{array}{l}\text { Estimation } \\
\text { Technique }\end{array}$ & Results \\
\hline $\begin{array}{l}\text { Dawson } \\
\text { (1998) }\end{array}$ & $\begin{array}{l}92 \text { countries, } \\
1975-1990\end{array}$ & $\begin{array}{l}\text { Granger } \\
\text { causality for } \\
\text { cross-sections }\end{array}$ & $\begin{array}{l}\text { The level of EF in } 1990 \text { is } \\
\text { significantly related to political and } \\
\text { civil freedom in } 1975 .\end{array}$ \\
\hline $\begin{array}{l}\text { Farr, et al. } \\
\text { (1998) }\end{array}$ & $\begin{array}{l}22 \text { industrial and } \\
78 \text { developing } \\
\text { countries, } \\
1975-1990\end{array}$ & $\begin{array}{l}\text { Granger } \\
\text { causality for } \\
\text { cross-sections }\end{array}$ & $\begin{array}{l}\text { No Granger-causal relationship } \\
\text { between EF and political freedom and } \\
\text { vice versa; EF Granger-causes income } \\
\text { per capita, which, in turn, } \\
\text { Granger-causes political freedom. }\end{array}$ \\
\hline $\begin{array}{l}\text { Wu and } \\
\text { Davis } \\
\text { (1999) }\end{array}$ & $\begin{array}{l}\text { About } 100 \\
\text { countries, } \\
1975-1992 .\end{array}$ & $\begin{array}{l}\text { Log-linear } \\
\text { method }\end{array}$ & $\begin{array}{l}\text { Political freedom is not associated } \\
\text { with economic freedom. }\end{array}$ \\
\hline $\begin{array}{l}\text { De Haan } \\
\text { and Sturm } \\
(2003)\end{array}$ & $\begin{array}{l}\text { 55-68 developing } \\
\text { countries, } \\
1975-1995\end{array}$ & $\begin{array}{l}\text { OLS, Panel - } \\
\text { period fixed } \\
\text { effect }\end{array}$ & $\begin{array}{l}\text { The change in EF is significantly } \\
\text { related to level of democracy in 1975, } \\
\text { taking various control variables into } \\
\text { account; conclusion also holds if } \\
\text { robust estimators are used. }\end{array}$ \\
\hline $\begin{array}{l}\text { Pitlik and } \\
\text { Wirth (2003) }\end{array}$ & $\begin{array}{l}\text { Panel model } \\
1970-1999 \text { with } \\
\text { 5-year intervals } \\
\text { for 57-122 } \\
\text { countries }\end{array}$ & $\begin{array}{l}\text { Panel - country } \\
\text { fixed effect }\end{array}$ & $\begin{array}{l}\text { Strong crises lead to more } \\
\text { liberalization (i.e. higher EF); also } \\
\text { democracy is positively related to } \\
\text { increase in EF, as are some political } \\
\text { system indicators that are based on the } \\
\text { number of veto players. }\end{array}$ \\
\hline $\begin{array}{l}\text { Dawson } \\
(2003)\end{array}$ & $\begin{array}{l}\text { Granger causality } \\
\text { tests, 1970-2000 }\end{array}$ & $\begin{array}{l}\text { Granger } \\
\text { causality for } \\
\text { cross-sections } \\
\end{array}$ & $\begin{array}{l}\text { Causation runs primarily from } \\
\text { political to economic freedom. }\end{array}$ \\
\hline $\begin{array}{l}\text { Lundstrom } \\
(2003)\end{array}$ & $\begin{array}{l}58 \text { developing } \\
\text { countries, } \\
1975-1995\end{array}$ & $\begin{array}{l}\text { Panel - country } \\
\text { fixed effect }\end{array}$ & $\begin{array}{l}\text { Political freedom is related to some } \\
\text { groups of components of EF } \\
\text { ('government operations' and } \\
\text { 'regulations and restraints on } \\
\text { international exchange'), but no to } \\
\text { others. }\end{array}$ \\
\hline
\end{tabular}

Source: De Haan, Lundstrom, and Sturm (2006) and author's augmentation

All in all, this Chapter intends to contribute to the literature in three ways. First, unlike the main strand, we consider economic reform by sectors, beyond the scope of merely trade and financial liberalisation. Second, we technically deal with the problem of endogeneity between reforms and political regime by using a GMM estimator that were seldom satisfactorily addressed in the previous literature. Thirdly, unlike existing studies in relation to economic freedom, we estimate the causal relationship in a dynamic panel setting, 
allowing us to capture both the reverse relationship as well as inter-temporal and within country changes. The contribution of this Chapter is entirely empirical.

\subsection{Data and Methodology}

\subsubsection{Data}

\subsubsection{Economic Reforms}

Using index-based measures of economic reforms serves two advantages. On one hand, an index approach allows us to measure multi-dimensional aspects of reforms. On the other hand, it can help benchmark across countries.

To the best of our knowledge, there are at least three databases measuring economic reform. First is the Giavazzi and Tabellini (2005)'s dichotomy index of "economic reform". Their database is originally built up by Sachs and Warner (1995) and Wacziarg and Welch (2003). The composite index primarily measures trade openness, covering conditions like (i) average tariffs exceed $40 \%$; (ii) non-tariff barriers covering more than $40 \%$ of its imports; (iii) the economy has a socialist economic system; (iv) the black market premium on the exchange rate exceeds $20 \%$; and (v) most of its exports are controlled by a state monopoly. This index, as a dummy variable, classifies an economy as "open" or "close" based on the conditions above.

Second is the World Bank's Ease of Doing Business micro-reform database. Reforms in the database are at the micro-level, such as the improvements made in the number of days to set up or close businesses, cut of administrative costs or review of company law and alike. Based on this database, Amin and Djankov (2009) conclude that micro-reform is more likely to associate with democracies. Due to the short time span of the dataset (2004-2008), the authors can only undertake cross-sectional OLS estimations. Dynamic analysis is not possible. The authors also do not take into account of the problem of endogeneity, as they reckon, the reverse causality is unlikely given 
the reform is at micro-level.

Third is the IMF (2008) reform database, empirically tested by GMS to investigate the causal relationship between reforms and democracy. This is the only database that covers reforms in different sectors. The IMF database covers eight areas of measurements, including both the financial sector and real sector. Financial sector reform indicators include reforms pertaining to domestic financial markets and external capital account, while real sector structural reform indicators include measures of product and agriculture markets, labour, fiscal, trade and current account reforms. Each indicator contains sub-indices summarising different dimensions in each sector. GMS aggregate all the sub-indices and normalise them between 0 and 1, with higher scores representing greater degree of liberalisation. In their empirical work, after controlling for country, year and sector specific effects, democracy causes reform. The results hold true by sectors, except that democracy does not cause reforms in product market and fiscal sector.

Unfortunately, the IMF database is not publicly accessible. We therefore have to seek appropriate alternatives with comparable dimensions, sample size and time span for our estimation to pursue similar research interests. We suggest that the Fraser Institute's economic freedom index $(\boldsymbol{E F})$ (Gwartney, et al. (2008)) can be a plausible alternative. In fact, most of sectors covered in the IMF's database are also measured by the $\boldsymbol{E F}$ indices.

We compare the $E F$ indices to those in the IMF database in Table 3.3.1-1 below. In terms of coverage and time span, the two databases are quite comparable. In terms of dimensions, the IMF database is actually more superior as it includes reforms in product markets, agriculture sectors and security market liberalisation (subsumed under the index of financial sector). The product market reforms indicator covers the degree of liberalisation in the telecommunication and electricity markets, including the extent of competition in the provision of these services and the presence of an independent regulatory authority and privatisation. The agricultural market reforms indicator captures intervention in the market for the main agricultural export commodity 
in each country. The securities markets sub-indicator assesses the quality of the market framework, including the existence of an independent regulator and the extent of legal restrictions on the development of domestic bond and equity markets. These three aspects, unfortunately, are not covered in $\boldsymbol{E F}$.

The IMF reform index and $\boldsymbol{E F}$ index measure in four common aspects, namely (a) fiscal sector; (b) trade liberalisation; (c) financial liberalisation and (d) labour market regulation. The $\boldsymbol{E F}$ indices are generally composed of broader measures in these areas. With regard to the fiscal sector, for example, the IMF reform index takes an average of the revenue sub-index - measuring personal income tax, corporate income tax and import tariffs - and the expenditure sub-index - measuring solely the efficiency of public expenditures in health and education. In contrast, the $\boldsymbol{E F}$ index covers income and payroll tax rates on the revenue side and general government consumption spending as percentage of total consumption as well as transfers and subsidies as percentage of GDP on the expenditure side.

In respect to trade and current account liberalisation, the IMF database defines the former as average tariff rates and the latter as how a government is free from restricting the proceeds from international trade in goods and services. The $\boldsymbol{E F}$ index is more comprehensive on this front. The free trade index of $\boldsymbol{E F}$ is composed of taxes on international trade - including revenues from trade taxes, mean tariff rate and the variation in tariff rates as compared to a uniform tariff. In addition, the $\boldsymbol{E F}$ also captures the regulatory trade barriers, including the perception of the business impact of tariff and non-tariff barriers, the compliance cost of importing and exporting (obtained from the World Bank's Ease of Doing Business Survey), actual as compared to the expected trade size and the difference between the official and the black market exchange rate. 
Table 3.3.1-1: Comparison between IMF Economic Reform Index and Fraser Institute's Economic Freedom Index

IMF Economic Reform Index

Sample Coverage

$47-142$ countries, $1960-2006$
Fraser Institute Economic Freedom Index

141 countries, $1970-2005$

\section{Areas of Measurement}

\section{(1) Fiscal Sector}

The fiscal sector index is an average of revenue and expenditures sub-indices.

The revenue sub-index is an average of two sub-indices i) a weighted average of three rates: personal income tax, corporate income tax, and import tariffs. ii) an indicator of efficiency of revenue collection for personal income, corporate and trade taxes.

The expenditure sub-index is an average of measures of efficiency of public expenditures in health and education. The efficiency of public spending is measured by comparing actual spending with the minimum spending theoretically sufficient to produce the same actual output.
The size of government index covers expenditure, taxes and enterprises. There are four sub-indices i) general government consumption spending as a percentage of total consumption; ii) transfers and subsidies as a percentage of GDP; iii) government enterprises and investment and iv) top marginal tax rate.

\section{(2) Trade}

Trade liberalization is defined as average tariff rates.
Freedom to trade internationally index covers 5 sub-indices: i) taxes on international trade, measured by revenues from trade taxes as percentage of trade sector, mean tariff rate and standard deviation of tariff rates; ii) regulatory trade barriers, measured by non-tariff trade barriers and compliance cost of importing and exporting; iii) size to trade sector relative to expected; iv) black-market exchange rates, and v) international capital market controls, measured by foreign ownership/investment restrictions and capital controls.

\section{(3) Current Account}

Current account liberalization is defined with an indicator describing how compliant a government is with its obligations under the IMF's Article VIII to free from government restriction the proceeds from international trade in goods and services. It distinguishes between restrictions on residents (receipts for exports) and on non-residents (payments for imports).
[See the sub-indices "taxes on international trade" and "regulatory trade barriers" under Trade sector above.] 


\section{(4) Capital Account}

Qualitative indicators of restrictions on financial credits and personal capital transactions of residents and financial credits to non-residents, as well as the use of multiple exchange rates.
[See the sub-index "international capital market controls" under Trade sector above.]

\section{(5) Labour Market}

The labour index is the tax wedge, which is defined as the difference between the firm's labour costs and worker's net income.
Labour market regulations index covers both qualitative and quantitative indices on i) minimum wage, ii) hiring and tiring regulations, iii) centralized collective bargaining, iv) mandated cost of hiring, v) mandated cost of worker dismissal and vi) conscription.

\section{(6) Financial Sector}

The index of domestic financial liberalization is an average of five sub-indices related to banking and one related to the securities market. The banking sub-index is an average of the following 5 indicators: (i) interest rate controls, such as floors or ceilings; (ii) credit controls, such as directed credit and subsidized lending; (iii) competition restrictions, such as limits on branches and entry barriers in the banking sector, including licensing requirements or limits on foreign banks; (iv) the degree of state ownership; and (v) the quality of banking supervision and regulation, including power of independence of bank supervisors, adoption of Basel capital standards, and a framework for bank inspections.

The securities market sub-index generally covers policies that develop domestic bond and equity markets.
Credit market regulations index has four sub-indices: i) ownership of banks; ii) foreign bank competition; iii) private sector credit, and iv) interest rate controls / negative real interest rates.

\section{(7) Product Markets}

The electricity indicators capture (i) the degree of unbundling of generation, transmission, and distribution; (ii) whether a regulator other than government has been established; and (iii) whether the wholesale market has been liberalized; and (iv) privatization.

The telecommunication indicator captures (i) the degree of competition in local services; (ii) whether a regulator other than government has been established; (iii) the degree of liberalization of interconnection changes; and (iv) privatization. 


\section{(8) Agriculture Market}

The index captures intervention in the market for the main agricultural export commodity in each country. The index can take four values

(i) zero (public monopoly or monopsony in production, transportation, or marketing, e.g. export marketing boards); (ii) one-third (administered prices); (iii) two-thirds (public ownership of relevant producers or concession requirements); and (iv) one (no public intervention).

Source: Giuliano, et al. (2009) and Gwartney, et al. (2008).

Financial liberalisation refers to both capital account openness and credit market deregulation. On capital account openness, the IMF database measures the restrictions on financial credits and personal capital transactions of residents and restrictions on financial credits to non-residents, as well as the use of multiple exchange rates. This indicator is primarily a composite index using the IMF's definition of the 13 different types of international capital controls from its Annual Report on Exchange Arrangements and Exchange Restrictions. Similarly, the capital controls sub-component of the $\boldsymbol{E F}$ index is also constructed based on the same IMF definition. In addition, the $\boldsymbol{E F}$ supplements the capital account openness index by survey questions results on "whether foreign ownership of companies in the country is rare" and "whether rules governing FDI are damaging and discourage it”.

On financial sector reform, as mentioned before, the IMF reform index covers both the banking sector and securities market liberalisation. The IMF refers domestic banking liberalisation to (i) interest rate controls; (ii) credit controls; (iii) banking competition restrictions, e.g. limits on branches and entry barriers in the banking sector; (iv) degree of state ownership; and (v) the quality of banking supervision and regulation. In comparison, the $\boldsymbol{E F}$ only captures interest rate controls - measuring whether interest rates are determined by the market, stable monetary policy and positive real deposit and lending rates. Vis-à-vis credit market regulation, the $\boldsymbol{E F}$ index measures (a) the percentage of 
bank deposits held in privately owned banks; (b) denial rate of foreign bank license applications and on foreign bank assets; and (c) the percentage of domestic credit consumed by the private sector.

Finally, on labour market regulation, the IMF database measures the tax wedge - sum of taxes paid by the worker (e.g. personal income taxes, social security contributions etc.) and the employer (payroll tax, social security contributions paid etc) expressed as a ratio of gross wage. In contrast, the $\boldsymbol{E F}$ mostly relies on qualitative indices, including survey questions on (a) minimum wage; (b) hiring and firing regulations; (c) centralised collective bargaining; (d) mandated cost of hiring; (e) mandated cost of worker dismissal, and; (f) data on the use and duration of military conscription. Although the $\boldsymbol{E F}$ 's labour market regulation is indeed more directly relevant to labour market regulation, these indicators are also fairly subjective.

All in all, we find that the different sub-indices of $\boldsymbol{E F}$, as discussed above, can be used for our estimations as reform measures in different sectors. As Gwartney, et al. (2008) explain, the $\boldsymbol{E F}$ index does not intend to measure political institution. It, however, helps measure the consistency of the choices made by political institution. The only disadvantage of the $\boldsymbol{E F}$ index is that it is only available for every 5 year before 1990 .

\subsubsection{Democracy}

We use a continuous measure of democracy instead of a dichotomous measure. We argue that economic reform can potentially lead to marginal progress in democratisation and vice versa. We use the widely adopted Polity IV's measure of institutional democracy $(\boldsymbol{D E M O C})$ to measure political institution as defined in Chapter 2. Nevertheless, we will also use the dichotomous measure of democracy as a robustness check of our results.

\subsubsection{Controlled Variables}

As described earlier, we will control for income level in each specification. 
Natural log of PPP-adjusted GDP per capita $(\ln (\boldsymbol{G D P P C}))$ from WDI is used again. For robustness checks, we will also include additional covariates in the baseline specification. Details of these robustness checks will be discussed further in Section 3.4.3.

\subsubsection{Model Specification and Estimation Strategy}

As we intend to investigate a causality relationship, we incorporate lagged variables in our baseline specification and employ the dynamic panel GMM estimator. Such dynamic analysis has not previously used in the existing literature for estimating causality between democracy and economic reforms and/or economic freedom. In our baseline specification, unlike the work of GMS, we control for income level as proposed by Coviello and Islam (2006) ${ }^{6}$. We believe such control is essential as political institution, economic development and economic reform can be endogenously determined (see Sunde, et al. (2006)) since income level of the economy determines the capacity of policy reforms and it in turn may help build up the expectation of democratisation.

Our baseline model is basically specified as

$$
\begin{aligned}
& \text { SREFORM }_{i t}=\alpha+\mu_{i}+\delta_{t}+\beta_{1} \text { DEMOC }_{i t-1} \\
& +\beta_{2} \text { REFORM }_{i t-1}+\beta_{3} \ln (\text { GDPPC })_{i t-1}+\varepsilon_{i t}
\end{aligned}
$$

where $i$ represents the $i$-th cross-section, $t$ represents time period. All regressors are in lagged forms to demonstrate the causality relationship. $\boldsymbol{R E F O R M}$ is a sub-index from $\boldsymbol{E F}$, representing economic reform in each particular sector. We also control for the unobserved time-invariant and country-specific effect, time effect by means of period dummies and the income level in the previous period. All regressors are treated as pre-determined and endogenous variables. Due to data availability, we use

\footnotetext{
${ }^{6}$ Their work attempts to test the effect of foreign aid on institutional change. They argue that the level of economic development may well affect the capacity of institutional change in recipient economies.
} 
data in every 5-year period. That is, $t=1970,1975,1980 \ldots, 2000$ and 2005. The lagged variable represents the variable in the last period, i.e. 5 years ago.

Eq. (3.3-1) can be rewritten as

$$
\begin{aligned}
\operatorname{REFORM}_{i t}= & \alpha+\mu_{i}+\delta_{t}+\beta_{1} \text { DEMOC }_{i t-1} \\
& +\left(1+\beta_{2}\right) \text { REFORM }_{i t-1}+\beta_{3} \ln (G D P P C)_{i t-1}+\varepsilon_{i t}
\end{aligned}
$$

is our baseline specification for estimation. We will replace DEMOC as the dependent variable in the baseline specification to test the reverse causality of whether REFORM causes DEMOC. The baseline specification will be similar to eq.(3.3-2):

$$
\begin{aligned}
\text { DEMOC }_{i t}= & \alpha+\mu_{i}+\delta_{t}+\beta_{1} \text { REFORM }_{i t-1} \\
& +\left(1+\beta_{2}\right) D E M O C_{i t-1}+\beta_{3} \ln (G D P P C)_{i t-1}+\varepsilon_{i t}
\end{aligned}
$$

In terms of $\boldsymbol{R E F O R M}$, we measure 4 main sectors as discussed above: (a) fiscal sector - using indices of GOVTC, TRANSFER and TAX; (b) trade liberalisation - using indices of FREE TRADE; (c) financial liberalisation using $\boldsymbol{K}_{-} \boldsymbol{A C}$ and $\boldsymbol{C R E D I T}$, and (d) labour market - using LABOR. Data descriptions and sources are at Appendix Section A.2.

\subsection{Results}

\subsubsection{Does Democracy cause Economic Freedom?}

We first estimate the effect of democracy on economic freedom index $(\boldsymbol{E F})$ in a dynamic panel data setting ${ }^{7}$. Table 3.4.1-1 shows the impact of lagged DEMOC on the level of aggregate $\boldsymbol{E F}$ index using different estimation techniques. As explained in Chapter 2, as a rule of thumb, we look for a GMM estimator of the lagged dependent variable that lies somewhere between the OLS and fixed-effect within group (FE) estimators. Models 3.(1) and 3.(2)

\footnotetext{
${ }^{7}$ Technical details of panel system GMM estimation are set out in Chapter 2.
} 
show the OLS and FE estimations respectively, whereas Model 3.(3) shows the system GMM estimator. We can comfortably argue that system GMM estimator is an appropriate one since the coefficient of the lagged dependent variable is around 0.52 which lies somewhere between 0.72 of OLS and 0.43 of FE estimators. In addition, we also attempt to obtain the difference GMM estimator for comparison in Model 3.(4). As we can see, Model 3.(4) fails this preliminary test. The coefficient of lagged $\boldsymbol{E F}$ is significantly below that of FE estimator, indicating a downward bias. The AR(1) test of Model 3.(4) also rejects the null hypothesis that the error terms are autocorrelated. All these suggest that difference GMM estimator may not be appropriate in our case.

The lagged dependent variable $(\boldsymbol{E F})$ is positive and significant, suggesting convergence of economic freedom across countries over time. Its coefficient is also well below 1 and it signifies that $\boldsymbol{E F}$ does not seem to be explosive. The presence of the lagged dependent variable also implies the coefficients of other regressors reflect their short-run impact on the dependent variables. Model 3.(3) shows that a more democratic society appears to cause the economy to be more economically free, even after controlling for country-specific and period effects as well as the lagged level of economic development, as proxied by natural log of lagged GDP per capita (lagged $\ln (\boldsymbol{G D P P C}))^{3}$. Nevertheless, we should note that lagged DEMOC is only marginally significant at 10\% level in Model 3.(3).

\footnotetext{
${ }^{3}$ Nevertheless, one should note that the coefficients of the lagged GDP per capita are quite unstable across the four models.
} 
Table 3.4.1-1: Does Democracy Cause Economic Freedom? Different Estimation Techniques

\begin{tabular}{|c|c|c|c|c|}
\hline Model & 3.(1) & 3.(2) & 3.(3) & 3.(4) \\
\hline Estimation & OLS & FE & $\begin{array}{c}\text { System } \\
\text { GMM }\end{array}$ & $\begin{array}{c}\text { Difference } \\
\text { GMM }\end{array}$ \\
\hline Lagged EF & $\begin{array}{c}0.7155^{* * *} \\
(0.0298)\end{array}$ & $\begin{array}{c}0.4314 * * * \\
(0.0476)\end{array}$ & $\begin{array}{c}0.5186^{* * *} \\
(0.1620)\end{array}$ & $\begin{array}{c}0.2140 \\
(0.4051)\end{array}$ \\
\hline Lagged DEMOC & $\begin{array}{c}0.0291 * * * \\
(0.0076)\end{array}$ & $\begin{array}{c}0.0410 * * * \\
(0.0129)\end{array}$ & $\begin{array}{l}0.0411^{*} \\
(0.0237)\end{array}$ & $\begin{array}{l}-0.0699 \\
(0.1090)\end{array}$ \\
\hline Lagged $\ln (G D P P C)$ & $\begin{array}{c}0.0865 * * * \\
(0.0238)\end{array}$ & $\begin{array}{l}-0.1534 \\
(0.1488)\end{array}$ & $\begin{array}{c}0.1546 \\
(0.1967)\end{array}$ & $\begin{array}{l}-0.4171 \\
(0.8599)\end{array}$ \\
\hline Const & $\begin{array}{c}0.7907 * * * \\
(0.1617)\end{array}$ & $\begin{array}{c}4.7943 * * * \\
(1.1253)\end{array}$ & $\begin{array}{c}1.8405^{* * *} \\
(0.6484)\end{array}$ & \\
\hline Obs & 502 & 502 & 502 & 378 \\
\hline No. of cty & & 114 & 114 & 103 \\
\hline $\operatorname{Adj.} R^{2}$ & 0.781 & 0.423 & & \\
\hline F-stat & 257.6 & 61.08 & 85.49 & 32.12 \\
\hline AR(1) p-value & & & {$[0.0495]$} & {$[0.628]$} \\
\hline AR(2) p-value & & & {$[0.289]$} & {$[0.347]$} \\
\hline Hansen Test Statistics & & & 8.545 & 4.951 \\
\hline Hansen Test p-value & & & {$[0.576]$} & {$[0.666]$} \\
\hline
\end{tabular}

Dependent variable is $\boldsymbol{E F}$. Models 3.(2) - 3.(4) include country fixed effect and period dummies, but the results are not reported. $* * *, * *$ and $*$ denote significance levels at $1 \%, 5 \%$ and $10 \%$ respectively. For Models 3.(1) and 3.(2), robust standard errors are in parenthesis. For Models 3.(3) and 3.(4), lagged $\boldsymbol{E F}$ is treated as pre-determined, while other regressors are endogenous. Standard errors are in parenthesis and Windmeijer-corrected, robust for heteroskedasticity and autocorrelation. Instruments are transformed by orthogonal deviation and collapsed. Hansen test is used for overidentifying restrictions.

\subsubsection{Does Democracy cause Economic Reform in Different Sectors?}

Table 3.4.2-1 shows the 2-step system GMM estimations of the impact of lagged DEMOC on reforms by sectors. This baseline specification attempts to address whether democracy is more likely to cause reform in different sectors. We find that the system GMM estimators work fairly well for the models, except Model 3.(9) on capital account openness index (K_AC). All 
models reject the null hypothesis of the AR(1) test but do not reject the $\mathrm{AR}(2)$ test. The Hansen tests also do not reject the overidentification restrictions.

Models 3.(5) - 3.(7) investigate the impact of democracy on the fiscal sector, specifically the effects of government consumption (GOVTC), transfer and subsidy (TRANSFER) and marginal income tax rate $(\boldsymbol{T A X})$. The results show that a more democratic economy is more likely to have low government consumption as a percentage of total consumption, a higher level of transfer of subsidy as a percentage of GDP and higher marginal income tax rate. The effects of democracy on $\boldsymbol{G O} \boldsymbol{V} \boldsymbol{T C}$ and $\boldsymbol{T A X}$ are not statistically significant nevertheless. Strictly speaking, we only find that democracy causes the society to be more redistributive (hence lower score of TRANSFER). The effect is significant at the 5\% significance level. The insignificant effects of democracy on government spending and income are also consistent with the results obtained by GMS, where they find that democracy does not significantly cause any reform in fiscal revenue and expenditure. Our dataset extends one more dimension of the fiscal sector, i.e. redistribution through the use of transfer and subsidy. We find that this is the only dimension of fiscal sector reform which is likely to be caused by democracy.

Model 3.(8) measures whether democracy is likely to cause trade liberalisation (FREE TRADE). Our empirical findings affirm that this is the case and the effect is statistically significant. On financial liberalisation, the two indicators - capital account openness $\left(\boldsymbol{K} \_\boldsymbol{A C}\right)$ and credit market regulation (CREDIT) - in Models 3.(9) and 3.(10) respectively are used. As explained earlier, we do find democracy causes capital account openness. However, we should be very cautious when interpreting Model 3.(9) since the estimation fails the AR(2) test. Hence, the error term is suspected to be autocorrelated in level. On the other hand, our empirical evidence does support that democracy causes credit market liberalisation at $1 \%$ significance level as shown in Model 3.(10). 
Table 3.4.2-1: Does Democracy Cause Economic Reform in Different Sectors? -

2-step System GMM Estimation

\begin{tabular}{|c|c|c|c|c|c|c|c|}
\hline $\begin{array}{l}\text { Model } \\
\text { Dep. var }\end{array}$ & $\begin{array}{c}\text { 3.(5) } \\
\text { GOVTC }\end{array}$ & $\begin{array}{c}\underline{3 .(6)} \\
T R A N S F E R\end{array}$ & $\frac{\text { 3.(7) }}{T A X}$ & $\begin{array}{c}\text { 3.(8) } \\
\text { FREE } \\
T R A D E\end{array}$ & $\frac{\underline{3 .(9)}}{K_{-} A C}$ & $\begin{array}{c}\frac{3 .(10)}{C R E D I T} \\
\text { CRE }\end{array}$ & $\frac{3 .(11)}{L A B O R}$ \\
\hline Lagged DEMOC & $\begin{array}{c}0.0359 \\
(0.0511)\end{array}$ & $\begin{array}{c}-0.3394 * * \\
(0.1520)\end{array}$ & $\begin{array}{l}-0.0111 \\
(0.1304)\end{array}$ & $\begin{array}{c}0.1381 * * \\
(0.0535)\end{array}$ & $\begin{array}{c}0.7430 * * * \\
(0.2021)\end{array}$ & $\begin{array}{c}0.3895 * * * \\
(0.0788)\end{array}$ & $\begin{array}{c}-0.0973 \\
(0.0710)\end{array}$ \\
\hline Lagged dep var & $\begin{array}{c}0.6738 * * * \\
(0.0826)\end{array}$ & $\begin{array}{l}0.5395^{*} \\
(0.3130)\end{array}$ & $\begin{array}{c}0.6962 * * * \\
(0.1161)\end{array}$ & $\begin{array}{c}0.6187 * * * \\
(0.0801)\end{array}$ & $\begin{array}{c}0.6439^{*} \\
(0.3745)\end{array}$ & $\begin{array}{c}0.6249 * * * \\
(0.1160)\end{array}$ & $\begin{array}{c}0.7980 * * * \\
(0.2510)\end{array}$ \\
\hline Lagged $\ln (G D P P C)$ & $\begin{array}{l}-0.3808 \\
(0.2468)\end{array}$ & $\begin{array}{c}0.2937 \\
(0.3560)\end{array}$ & $\begin{array}{l}-0.0070 \\
(0.3978)\end{array}$ & $\begin{array}{c}0.0190 \\
(0.1405)\end{array}$ & $\begin{array}{l}-0.6091 \\
(1.0079)\end{array}$ & $\begin{array}{c}-0.5418^{* *} \\
(0.2290)\end{array}$ & $\begin{array}{c}0.1320 \\
(0.1708)\end{array}$ \\
\hline Const & $\begin{array}{l}4.7564 * * \\
(2.2107)\end{array}$ & $\begin{array}{c}3.2990 \\
(5.1499)\end{array}$ & $\begin{array}{c}2.1112 \\
(3.5003)\end{array}$ & $\begin{array}{c}1.2341 \\
(1.2061)\end{array}$ & $\begin{array}{c}1.6734 \\
(6.3390)\end{array}$ & $\begin{array}{c}5.5890 * * * \\
(1.6196)\end{array}$ & $\begin{array}{c}1.1353 \\
(2.1345)\end{array}$ \\
\hline $\begin{array}{l}\text { Obs/No. of cty } \\
\text { AR(1) p-value } \\
\text { AR(2) p-value } \\
\text { Hansen Test Statistics } \\
\text { Hansen Test p-value }\end{array}$ & $\begin{array}{c}679 / 112 \\
{[0.0000]} \\
{[0.925]} \\
15.56 \\
{[0.341]} \\
\end{array}$ & $\begin{array}{c}504 / 103 \\
{[0.0099]} \\
{[0.947]} \\
9.954 \\
{[0.268]} \\
\end{array}$ & $\begin{array}{c}458 / 96 \\
{[0.0000]} \\
{[0.879]} \\
15.93 \\
{[0.253]} \\
\end{array}$ & $\begin{array}{c}629 / 114 \\
{[0.0000]} \\
{[0.277]} \\
9.413 \\
{[0.224]} \\
\end{array}$ & $\begin{array}{c}501 / 112 \\
{[0.0822]} \\
{[0.0190]} \\
12.78 \\
{[0.120]} \\
\end{array}$ & $\begin{array}{c}665 / 112 \\
{[0.0001]} \\
{[0.449]} \\
11.81 \\
{[0.544]} \\
\end{array}$ & $\begin{array}{c}234 / 70 \\
{[0.0547]} \\
{[0.279]} \\
17.61 \\
{[0.225]} \\
\end{array}$ \\
\hline
\end{tabular}

All models include country fixed effect and period dummies. $* * *, * *$ and $*$ denote significance levels at $1 \%, 5 \%$ and $10 \%$ respectively. Lagged dep var is treated as pre-determined, while other regressors are endogenous. Standard errors are in parenthesis and Windmeijer-corrected, robust for heteroskedasticity and autocorrelation. Instruments are transformed by orthogonal deviation and collapsed. Hansen test is used for overidentifying restrictions. 
Finally, Model 3.(11) tests whether democracy causes labour market regulation relaxation (LABOR). In our estimation, we find that democracy is more likely to cause stricter labour market regulation (i.e. lower score of $\boldsymbol{L A B O R}$ ), although the result is not statistically significant. It may illustrate that more labour market regulations are more likely to be welcome by employees, because this favours the majority in a democratic society. Understandably, labour market regulations are easier to gain support and be rolled out in democracies.

$\beta_{1}$ in the dynamic models represent the short-run impact of $\boldsymbol{D E M O C}$ on economic reform. The long-run effects can be derived by dividing $\beta_{1}$ by $\beta_{2}$, i.e. 1 - coefficient of the lagged dependent variables. Based on Models 3.(6), 3.(8) and 3.(10), where the results are statistically significant, the effects of DEMOC in both the short-run and long-run in these sectors are calculated in the Table 3.4.2-2 below.

Table 3.4.2-2: Causal Impact of Democracy on Economic Reform

\begin{tabular}{lcc}
\hline & Short-run impact & Long-run impact \\
\hline \hline TRANSFER & -0.34 & -0.74 \\
FREE TRADE & 0.14 & 0.37 \\
CREDIT & 0.39 & 1.03
\end{tabular}

These results suggest that, using $\boldsymbol{F R E E} \boldsymbol{T R} \boldsymbol{A D E}$ as an example, 1 point increase in DEMOC will lead to 0.14 point and 0.37 point increases in the FREE TRADE index in the short-run and long-run respectively.

\subsubsection{Robustness Tests}

In the following, we carry out several robustness tests using different measures of democracy and additional covariates to test the sensitivity of our results. First of all, we use IPOLITY2, a composite score of political freedom and civil liberties as defined in Chapter 2, as an alternative measure of democracy. The results are presented in Table 3.4.3-1. 
Table 3.4.3-1: IPOLITY2 As An Alternative Measure of Democracy

\begin{tabular}{|c|c|c|c|c|c|c|c|}
\hline $\begin{array}{c}\text { Model } \\
\text { Dep. Var }\end{array}$ & $\begin{array}{c}\underline{3 .(12)} \\
G O V T C\end{array}$ & $\begin{array}{c}\underline{3 .(13)} \\
T R A N S F E R\end{array}$ & $\frac{\underline{3 .(14)}}{T A X}$ & $\begin{array}{c}\text { 3.(15) } \\
\text { FREE } \\
T R A D E \\
\end{array}$ & $\frac{\underline{3 .(16)}}{K_{-} A C}$ & $\begin{array}{c}\underline{3 .(17)} \\
C R E D I T\end{array}$ & $\begin{array}{c}\underline{3 .(18)} \\
L A B O R\end{array}$ \\
\hline Lagged IPOLITY2 & $\begin{array}{c}0.0498 \\
(0.0700)\end{array}$ & $\begin{array}{l}-0.4892 * \\
(0.2939)\end{array}$ & $\begin{array}{l}-0.0837 \\
(0.1814)\end{array}$ & $\begin{array}{l}0.2882 * * \\
(0.1229)\end{array}$ & $\begin{array}{c}1.3444 * * * \\
(0.4286)\end{array}$ & $\begin{array}{c}0.5413 * * * \\
(0.1168)\end{array}$ & $\begin{array}{l}-0.1320 \\
(0.0889)\end{array}$ \\
\hline Lagged dep. var & $\begin{array}{c}0.6263 * * * \\
(0.1009)\end{array}$ & $\begin{array}{c}0.4531 \\
(0.4394)\end{array}$ & $\begin{array}{c}0.6834 * * * \\
(0.0920)\end{array}$ & $\begin{array}{l}0.5635^{* * *} \\
(0.0738)\end{array}$ & $\begin{array}{c}0.3721 \\
(0.2484)\end{array}$ & $\begin{array}{c}0.5959 * * * \\
(0.0944)\end{array}$ & $\begin{array}{c}0.9461 * * * \\
(0.2281)\end{array}$ \\
\hline Lagged $\ln (G D P P C)$ & $\begin{array}{l}-0.6403 * * \\
(0.2684)\end{array}$ & $\begin{array}{c}0.1987 \\
(0.3653)\end{array}$ & $\begin{array}{c}0.0524 \\
(0.3822)\end{array}$ & $\begin{array}{c}0.0069 \\
(0.1216)\end{array}$ & $\begin{array}{l}-0.7329 \\
(0.5329)\end{array}$ & $\begin{array}{l}-0.6206^{* *} \\
(0.2401)\end{array}$ & $\begin{array}{l}0.2051^{*} \\
(0.1190)\end{array}$ \\
\hline Const & $\begin{array}{c}6.9837 * * * \\
(2.5052)\end{array}$ & $\begin{array}{c}6.0545 \\
(7.4815)\end{array}$ & $\begin{array}{c}2.2441 \\
(3.1658)\end{array}$ & $\begin{array}{c}0.5101 \\
(1.0536)\end{array}$ & $\begin{array}{l}-0.6499 \\
(2.7315)\end{array}$ & $\begin{array}{c}5.0853 * * * \\
(1.6522)\end{array}$ & $\begin{array}{c}0.1102 \\
(1.9259)\end{array}$ \\
\hline Obs/No. of cty & $647 / 118$ & $502 / 108$ & $485 / 102$ & $615 / 120$ & $448 / 118$ & $641 / 118$ & $222 / 72$ \\
\hline$A R(1) p$-value & {$[0.0002]$} & {$[0.0512]$} & {$[0.0000]$} & {$[0.0000]$} & {$[0.1340]$} & {$[0.0000]$} & {$[0.0396]$} \\
\hline AR(2) p-value & {$[0.977]$} & {$[0.785]$} & {$[0.952]$} & {$[0.118]$} & {$[0.00141]$} & {$[0.284]$} & {$[0.326]$} \\
\hline $\begin{array}{l}\text { Hansen Test Statistics } \\
\text { Hansen Test p-value }\end{array}$ & $\begin{array}{r}12.49 \\
{[0.407]} \\
\end{array}$ & $\begin{array}{r}9.936 \\
{[0.192]} \\
\end{array}$ & $\begin{array}{r}15.75 \\
{[0.203]} \\
\end{array}$ & $\begin{array}{r}6.613 \\
{[0.251]} \\
\end{array}$ & $\begin{array}{r}11.10 \\
{[0.196]}\end{array}$ & $\begin{array}{r}9.111 \\
{[0.612]}\end{array}$ & $\begin{array}{r}17.82 \\
{[0.121]} \\
\end{array}$ \\
\hline
\end{tabular}

All models include country fixed effect and period dummies. $* * *, * *$ and $*$ denote significance levels at $1 \%, 5 \%$ and $10 \%$ respectively. Lagged dep var is treated as pre-determined, while other regressors are endogenous. Standard errors are in parenthesis and Windmeijer-corrected, robust for heteroskedasticity and autocorrelation. Instruments are transformed by orthogonal deviation and collapsed. Hansen test is used for overidentifying restrictions. 
The conclusion is generally similar. Again, the dynamic setting in Model 3.(16) (where $\boldsymbol{K} \_\boldsymbol{A C}$ as dependent variable) appears to be problematic. Other than that, Models 3.(13), 3.(15) and 3.(17) show similar significant results as before, indicating that a democratic society is likely to be more redistributive, more free to international trade and to have a more liberalised credit market. Comparing the magnitudes, the coefficients of lagged IPOLITY2 are consistently larger than those using lagged DEMOC.

Like in previous literature, using a dichotomous measure of democracy, we undertake a similar exercise by constructing a dummy variable DEMOC1. DEMOC1 equals to 1 if $\mathbf{D E M O C}$ is greater than 5 and equals to 0 if otherwise. The estimations are at Table 3.4.3-2. Results of Models 3.(19) - 3.(25) show that our key results survive. The only difference is that the effect of DEMOC1 on labour market regulation $(\boldsymbol{L A B O R})$ becomes statistically significant in Model 3.(25). The negative effect is now statistically significant at $1 \%$ significance level. This reinforces the empirical evidence that democracy causes more labour market regulation. However, we should note that the AR(1) test fails in the Model, which makes one to cast doubt on the validity of the results. 
Table 3.4.3-2: Dichotomous DEMOC1 As An Alternative Measure of Democracy

\begin{tabular}{|c|c|c|c|c|c|c|c|}
\hline $\begin{array}{c}\text { Model } \\
\text { Dep. Var }\end{array}$ & $\frac{3 .(19)}{G O V T C}$ & $\begin{array}{c}\underline{3 .(20)} \\
T R A N S F E R\end{array}$ & $\frac{3 .(21)}{T A X}$ & $\begin{array}{c}\text { 3.(22) } \\
F R E E \\
T R A D E\end{array}$ & $\frac{\text { 3.(23) }}{K \_A C}$ & $\begin{array}{c}\underline{3 .(24)} \\
C R E D I T\end{array}$ & $\frac{3 .(25)}{L A B O R}$ \\
\hline Lagged DEMOC1 & $\begin{array}{c}0.0300 \\
(0.3826)\end{array}$ & $\begin{array}{l}-1.7366 * \\
(0.9386)\end{array}$ & $\begin{array}{l}-0.6070 \\
(0.8335)\end{array}$ & $\begin{array}{l}0.9042 * * \\
(0.3955)\end{array}$ & $\begin{array}{c}0.9463 \\
(1.2755)\end{array}$ & $\begin{array}{c}2.8441 * * * \\
(0.7152)\end{array}$ & $\begin{array}{c}-1.4985 * * * \\
(0.4117)\end{array}$ \\
\hline Lagged Dep. Var & $\begin{array}{c}0.6617 * * * \\
(0.0774)\end{array}$ & $\begin{array}{c}0.5576 * * \\
(0.2344)\end{array}$ & $\begin{array}{c}0.6644 * * * \\
(0.0976)\end{array}$ & $\begin{array}{c}0.6070 * * * \\
(0.0701)\end{array}$ & $\begin{array}{c}0.8545 * * * \\
(0.2279)\end{array}$ & $\begin{array}{c}0.6059 * * * \\
(0.1005)\end{array}$ & $\begin{array}{c}0.3303 \\
(0.2462)\end{array}$ \\
\hline Lagged $\ln (G D P P C)$ & $\begin{array}{l}-0.2864^{*} \\
(0.1722)\end{array}$ & $\begin{array}{l}-0.0031 \\
(0.2681)\end{array}$ & $\begin{array}{c}0.0134 \\
(0.3454)\end{array}$ & $\begin{array}{c}0.0405 \\
(0.0873)\end{array}$ & $\begin{array}{l}-0.4960 \\
(0.5012)\end{array}$ & $\begin{array}{l}-0.2703 \\
(0.2140)\end{array}$ & $\begin{array}{l}-0.0060 \\
(0.1439)\end{array}$ \\
\hline Const & $\begin{array}{c}4.2736 * * * \\
(1.5697)\end{array}$ & $\begin{array}{c}4.5944 \\
(3.9752)\end{array}$ & $\begin{array}{c}2.5570 \\
(3.0542)\end{array}$ & $\begin{array}{l}1.3595 * \\
(0.8017)\end{array}$ & $\begin{array}{c}3.9346 \\
(3.0893)\end{array}$ & $\begin{array}{l}3.9906^{* *} \\
(1.5402)\end{array}$ & $\begin{array}{l}5.2461 * * \\
(2.2407)\end{array}$ \\
\hline $\begin{array}{l}\text { Obs/No. of cty } \\
\text { AR(1) p-value } \\
\text { AR(2) p-value } \\
\text { Hansen Test Statistics } \\
\text { Hansen Test p-value }\end{array}$ & $\begin{array}{c}756 / 119 \\
{[0.0000]} \\
{[0.944]} \\
16.24 \\
{[0.299]} \\
\end{array}$ & $\begin{array}{c}561 / 110 \\
{[0.0003]} \\
{[0.725]} \\
8.355 \\
{[0.400]} \\
\end{array}$ & $\begin{array}{c}506 / 103 \\
{[0.0000]} \\
{[0.990]} \\
15.40 \\
{[0.283]} \\
\end{array}$ & $\begin{array}{c}692 / 121 \\
{[0.0000]} \\
{[0.912]} \\
13.71 \\
{[0.0566]} \\
\end{array}$ & $\begin{array}{c}556 / 119 \\
{[0.0032]} \\
{[0.209]} \\
22.22 \\
{[0.00452]} \\
\end{array}$ & $\begin{array}{c}739 / 119 \\
{[0.0001]} \\
{[0.278]} \\
14.69 \\
{[0.327]} \\
\end{array}$ & $\begin{array}{c}248 / 73 \\
{[0.1970]} \\
{[0.298]} \\
12.49 \\
{[0.567]} \\
\end{array}$ \\
\hline
\end{tabular}

All models include country fixed effect and period dummies. ***, ** and * denote significance levels at $1 \%, 5 \%$ and $10 \%$ respectively. Lagged dep var is treated as pre-determined, while other regressors are endogenous. Standard errors are in parenthesis and Windmeijer-corrected, robust for heteroskedasticity and autocorrelation. Instruments are transformed by orthogonal deviation and collapsed. Hansen test is used for overidentifying restrictions. 
We carry out further estimations for the baseline specifications for the non-high income countries ${ }^{8}$ sample and test if the estimation results are sensitive to the sample size. Moreover, we wonder whether democracy works particularly poorly in developing countries, in which economic reform is less likely to be implemented. Our estimation results in Table 3.4.3-3 below show that it is not the case. The results still suggest that democracy is more likely to cause a redistributive society, trade liberalisation and financial market liberalisation.

More robustness checks are carried out for TRANSFER, FREE TRADE and CREDIT by having additional covariates in the baseline model using our full sample again. These results are shown in Table 3.4.3-4 - Table 3.4.3-6. We controlled for human capital stock (i.e. SCHOOLING, measured by average years of schooling), government spending as percentage of GDP (gcon_gdp) and exchange rate $(\boldsymbol{E R})$ from the Penn World Table (ver 6.2) of Heston, Summers, and Aten (2006), and natural log of population (POP) from the WDI. All the control variables are in lagged terms. In conclusion, our results generally survive, suggesting democracy is likely to cause redistributive policies via transfer and subsidy, trade liberalisation as well as credit market liberalisation.

\footnotetext{
${ }^{8}$ High-income countries are classified in accordance with the World Bank's classification.
} 
Table 3.4.3-3: Baseline Specification for Non-High income Countries

\begin{tabular}{|c|c|c|c|c|c|c|c|}
\hline $\begin{array}{l}\text { Model } \\
\text { Dep. Var }\end{array}$ & $\frac{\underline{3 .(26)}}{G O V T C}$ & $\begin{array}{c}\underline{\text { 3.(27) }} \\
\text { TRANSFER }\end{array}$ & $\frac{3 .(28)}{T A X}$ & $\begin{array}{c}\text { 3.(29) } \\
F R E E \\
T R A D E\end{array}$ & $\frac{3 .(30)}{K \_A C}$ & $\begin{array}{c}\underline{\text { 3.(31) }} \\
\text { CREDIT }\end{array}$ & $\begin{array}{c}\text { 3.(32) } \\
L A B O R\end{array}$ \\
\hline Lagged DEMOC & $\begin{array}{l}-0.0211 \\
(0.0818)\end{array}$ & $\begin{array}{l}-0.1962 * \\
(0.1010)\end{array}$ & $\begin{array}{c}0.2375 \\
(0.1575)\end{array}$ & $\begin{array}{l}0.0719 * \\
(0.0422)\end{array}$ & $\begin{array}{c}0.2503 \\
(0.7819)\end{array}$ & $\begin{array}{l}0.3816^{* * *} \\
(0.1288)\end{array}$ & $\begin{array}{c}0.0881 \\
(0.1129)\end{array}$ \\
\hline Lagged dep. var & $\begin{array}{c}0.6927 * * * \\
(0.1006)\end{array}$ & $\begin{array}{c}0.5769 * * * \\
(0.1802)\end{array}$ & $\begin{array}{c}0.6425 * * * \\
(0.0883)\end{array}$ & $\begin{array}{c}0.6826 * * * \\
(0.0782)\end{array}$ & $\begin{array}{c}0.3852 \\
(0.6280)\end{array}$ & $\begin{array}{c}0.7604 * * * \\
(0.1399)\end{array}$ & $\begin{array}{c}0.1733 \\
(0.2435)\end{array}$ \\
\hline Lagged $\ln (G D P P C)$ & $\begin{array}{l}-0.1927 \\
(0.3416)\end{array}$ & $\begin{array}{c}0.2297 \\
(0.3214)\end{array}$ & $\begin{array}{l}-0.2165 \\
(0.6705)\end{array}$ & $\begin{array}{c}0.1900 \\
(0.2305)\end{array}$ & $\begin{array}{c}1.4827 \\
(0.8939)\end{array}$ & $\begin{array}{l}-0.6972 \\
(0.4667)\end{array}$ & $\begin{array}{l}-0.6970 \\
(0.8672)\end{array}$ \\
\hline Const & $\begin{array}{c}3.6302 \\
(2.5261)\end{array}$ & $\begin{array}{c}2.9148 \\
(2.7702)\end{array}$ & $\begin{array}{c}2.3758 \\
(4.8061)\end{array}$ & $\begin{array}{c}0.0391 \\
(1.7317)\end{array}$ & $\begin{array}{l}-8.9231 \\
(7.5116)\end{array}$ & $\begin{array}{l}5.8814^{*} \\
(3.0396)\end{array}$ & $\begin{array}{c}9.0994 \\
(6.1708)\end{array}$ \\
\hline Obs/No. of cty & $465 / 77$ & $314 / 68$ & $277 / 61$ & $426 / 79$ & $344 / 77$ & $452 / 77$ & $80 / 40$ \\
\hline AR(1) p-value & $\begin{array}{l}{[0.0003]} \\
{[0886]}\end{array}$ & $\begin{array}{r}{[0.0132]} \\
{[0.723]}\end{array}$ & $\begin{array}{r}{[0.0000]} \\
{[0.7317}\end{array}$ & $\begin{array}{l}{[0.0000]} \\
{[0.329]}\end{array}$ & $\begin{array}{l}{[0.3800]} \\
{[0.0203]}\end{array}$ & $\begin{array}{l}{[0.0001]} \\
{[0.626]}\end{array}$ & $\begin{array}{r}{[0.5400]} \\
{[0.262]}\end{array}$ \\
\hline $\begin{array}{l}\text { Hansen Test Statistics } \\
\text { Hansen Test p-value }\end{array}$ & $\begin{array}{c}{[0.000]} \\
17.70 \\
{[0.221]} \\
\end{array}$ & $\begin{array}{c}{[0.72 J]} \\
8.398 \\
{[0.590]}\end{array}$ & $\begin{array}{c}{[0.751]} \\
4.837 \\
{[0.979]}\end{array}$ & $\begin{array}{c}{[0.529]} \\
8.577 \\
{[0.477]} \\
\end{array}$ & $\begin{array}{c}{[4.51} \\
{[0.0695]}\end{array}$ & $\begin{array}{c}{[0.020]} \\
9.735 \\
{[0.715]} \\
\end{array}$ & $\begin{array}{c}{[0.802]} \\
{[0.886]} \\
\end{array}$ \\
\hline
\end{tabular}

All models include country fixed effect and period dummies. ***,** and * denote significance levels at $1 \%, 5 \%$ and $10 \%$ respectively. Lagged dep var is treated as pre-determined, while other regressors are endogenous. Standard errors are in parenthesis and Windmeijer-corrected, robust for heteroskedasticity and autocorrelation. Instruments are transformed by orthogonal deviation and collapsed. Hansen test is used for overidentifying restrictions. 
Table 3.4.3-4: Robustness Check for TRANSFER

\begin{tabular}{|c|c|c|c|c|c|}
\hline Model & $\underline{\text { 3.(33) }}$ & $\underline{3 .(34)}$ & $\underline{\text { 3.(35) }}$ & $\underline{3 .(36)}$ & 3.(37) \\
\hline Lagged DEMOC & $\begin{array}{c}-0.4185^{* *} \\
(0.1942)\end{array}$ & $\begin{array}{c}-0.2979 * * \\
(0.1301)\end{array}$ & $\begin{array}{c}-0.4305 * * * \\
(0.1618)\end{array}$ & $\begin{array}{l}-0.5004 * \\
(0.2614)\end{array}$ & $\begin{array}{c}-0.3316^{* *} \\
(0.1457)\end{array}$ \\
\hline $\begin{array}{l}\text { Lagged } \\
\text { TRANSFER }\end{array}$ & $\begin{array}{c}0.2631 \\
(0.3503)\end{array}$ & $\begin{array}{c}0.5538 * * * \\
(0.1849)\end{array}$ & $\begin{array}{c}0.2238 \\
(0.2521)\end{array}$ & $\begin{array}{c}0.2446 \\
(0.5602)\end{array}$ & $\begin{array}{l}0.3646^{*} \\
(0.2007)\end{array}$ \\
\hline Lagged gcon_gdp & $\begin{array}{l}-0.0462 \\
(0.0571)\end{array}$ & & $\begin{array}{c}0.0063 \\
(0.0393)\end{array}$ & $\begin{array}{l}-0.0114 \\
(0.0544)\end{array}$ & $\begin{array}{l}-0.0193 \\
(0.0260)\end{array}$ \\
\hline $\begin{array}{l}\text { Lagged } \\
\text { SCHOOLING }\end{array}$ & & $\begin{array}{l}-0.0189 \\
(0.1437)\end{array}$ & $\begin{array}{l}-0.2286 \\
(0.1875)\end{array}$ & $\begin{array}{l}-0.4268 \\
(0.4679)\end{array}$ & $\begin{array}{l}-0.3581^{*} \\
(0.2020)\end{array}$ \\
\hline Lagged ER & & & & & $\begin{array}{c}0.0000 \\
(0.0000)\end{array}$ \\
\hline $\begin{array}{l}\text { Lagged } \\
\ln (G D P P C)\end{array}$ & & & & $\begin{array}{c}0.5403 \\
(09156)\end{array}$ & 0.4000 \\
\hline Lagged POP & & & & & $\begin{array}{l}(0.5925) \\
-0.5355 \\
(1.1268)\end{array}$ \\
\hline Const & $\begin{array}{c}9.2173 * * \\
(4.5718)\end{array}$ & $\begin{array}{l}5.4864 * * \\
(2.4670)\end{array}$ & $\begin{array}{c}10.3136 * * * \\
(3.4489)\end{array}$ & $\begin{array}{c}7.7384 \\
(10.7792)\end{array}$ & $\begin{array}{c}15.3583 \\
(18.6693)\end{array}$ \\
\hline$\overline{\text { Obs/No. of cty }}$ & $517 / 105$ & $463 / 83$ & $463 / 83$ & $451 / 82$ & $451 / 82$ \\
\hline AR(1) p-value & [0.0269] & {$[0.0027]$} & {$[0.0021]$} & {$[0.0435]$} & {$[0.0022]$} \\
\hline $\begin{array}{l}\text { AR(2) p-value } \\
\text { Hansen Test }\end{array}$ & {$[0.505]$} & {$[0.942]$} & {$[0.939]$} & {$[0.563]$} & {$[0.800]$} \\
\hline $\begin{array}{l}\text { Statistics } \\
\text { p-value }\end{array}$ & $\begin{array}{c}1.196 \\
{[0.754]}\end{array}$ & $\begin{array}{c}8.204 \\
{[0.224]}\end{array}$ & $\begin{array}{c}1.301 \\
{[0.935]}\end{array}$ & $\begin{array}{c}1.935 \\
{[0.963]}\end{array}$ & $\begin{array}{c}5.052 \\
{[0.929]}\end{array}$ \\
\hline
\end{tabular}

Dependent variable is TRANSFER. All models include country fixed effect and period dummies. $* * *, * *$ and $*$ denote significance levels at $1 \%, 5 \%$ and $10 \%$ respectively. Lagged TRANSFER is treated as pre-determined, while other regressors are endogenous. Standard errors are in parenthesis and Windmeijer-corrected, robust for heteroskedasticity and autocorrelation. Instruments are transformed by orthogonal deviation and collapsed. Hansen test is used for overidentifying restrictions. 
Table 3.4.3-5: Robustness Check for FREE TRADE

\begin{tabular}{|c|c|c|c|c|c|}
\hline Model & 3.(38) & 3.(39) & 3.(40) & 3.(41) & 3.(42) \\
\hline Lagged DEMOC & $\begin{array}{l}0.0849 * \\
(0.0428)\end{array}$ & $\begin{array}{l}0.1174 * * \\
(0.0448)\end{array}$ & $\begin{array}{c}0.1032 * * \\
(0.0426)\end{array}$ & $\begin{array}{l}0.0952 * * \\
(0.0422)\end{array}$ & $\begin{array}{l}0.0792 * \\
(0.0439)\end{array}$ \\
\hline $\begin{array}{l}\text { Lagged FREE } \\
T R A D E\end{array}$ & $\begin{array}{c}0.6596 * * * \\
(0.0756)\end{array}$ & $\begin{array}{c}0.6718 * * * \\
(0.0716)\end{array}$ & $\begin{array}{c}0.6800 * * * \\
(0.0761)\end{array}$ & $\begin{array}{c}0.6774 * * * \\
(0.0713)\end{array}$ & $\begin{array}{c}0.6706 * * * \\
(0.0694)\end{array}$ \\
\hline Lagged gcon_gdp & & $\begin{array}{c}0.0087 \\
(0.0099)\end{array}$ & $\begin{array}{l}-0.0024 \\
(0.0161)\end{array}$ & $\begin{array}{c}0.0150 \\
(0.0195)\end{array}$ & $\begin{array}{c}0.0133 \\
(0.0227)\end{array}$ \\
\hline $\begin{array}{l}\text { Lagged } \\
\text { SCHOOLING } \\
\text { Lagged ER }\end{array}$ & $\begin{array}{c}0.0207 \\
(0.0539)\end{array}$ & & $\begin{array}{l}-0.0004 \\
(0.0552)\end{array}$ & $\begin{array}{c}-0.0353 \\
(0.1598) \\
0.1327 \\
(0.3211)\end{array}$ & $\begin{array}{c}-0.1068 \\
(0.1369) \\
0.2350 \\
(0.3196)\end{array}$ \\
\hline $\begin{array}{l}\text { Lagged } \\
\text { ln }(G D P P C) \\
\text { Lagged POP }\end{array}$ & & & & & $\begin{array}{c}-0.0000 \\
(0.0000) \\
-0.0022 \\
(0.2142)\end{array}$ \\
\hline Const & $\begin{array}{l}1.2184 * * \\
(0.5552)\end{array}$ & $\begin{array}{l}0.9574 * \\
(0.5266)\end{array}$ & $\begin{array}{c}1.1429 \\
(0.7407)\end{array}$ & $\begin{array}{c}0.0550 \\
(1.8639)\end{array}$ & $\begin{array}{l}-0.0944 \\
(4.0420)\end{array}$ \\
\hline $\begin{array}{l}\text { Obs/No. of cty } \\
\text { AR(1) p-value } \\
\text { AR(2) p-value } \\
\text { Hansen Test }\end{array}$ & $\begin{array}{c}568 / 94 \\
{[0.0000]} \\
{[0.393]}\end{array}$ & $\begin{array}{c}644 / 115 \\
{[0.0000]} \\
{[0.280]}\end{array}$ & $\begin{array}{c}560 / 93 \\
{[0.0000]} \\
{[0.366]}\end{array}$ & $\begin{array}{c}546 / 92 \\
{[0.0000]} \\
{[0.436]}\end{array}$ & $\begin{array}{c}546 / 92 \\
{[0.0000]} \\
{[0.429]}\end{array}$ \\
\hline $\begin{array}{l}\text { Statistics } \\
\text { p-value }\end{array}$ & $\begin{array}{c}10.89 \\
{[0.366]}\end{array}$ & $\begin{array}{c}11.00 \\
{[0.358]}\end{array}$ & $\begin{array}{c}12.63 \\
{[0.396]}\end{array}$ & $\begin{array}{c}19.29 \\
{[0.201]}\end{array}$ & $\begin{array}{c}25.91 \\
{[0.169]}\end{array}$ \\
\hline
\end{tabular}

Dependent variable is $\boldsymbol{F R E \boldsymbol { E }} \boldsymbol{T R} \boldsymbol{A D E}$. All models include country fixed effect and period dummies. $* * *, * *$ and $*$ denote significance levels at $1 \%, 5 \%$ and $10 \%$ respectively. Lagged FREE TRADE is treated as pre-determined, while other regressors are endogenous. Standard errors are in parenthesis and Windmeijer-corrected, robust for heteroskedasticity and autocorrelation. Instruments are transformed by orthogonal deviation and collapsed. Hansen test is used for overidentifying restrictions. 
Table 3.4.3-6: Robustness Check for CREDIT

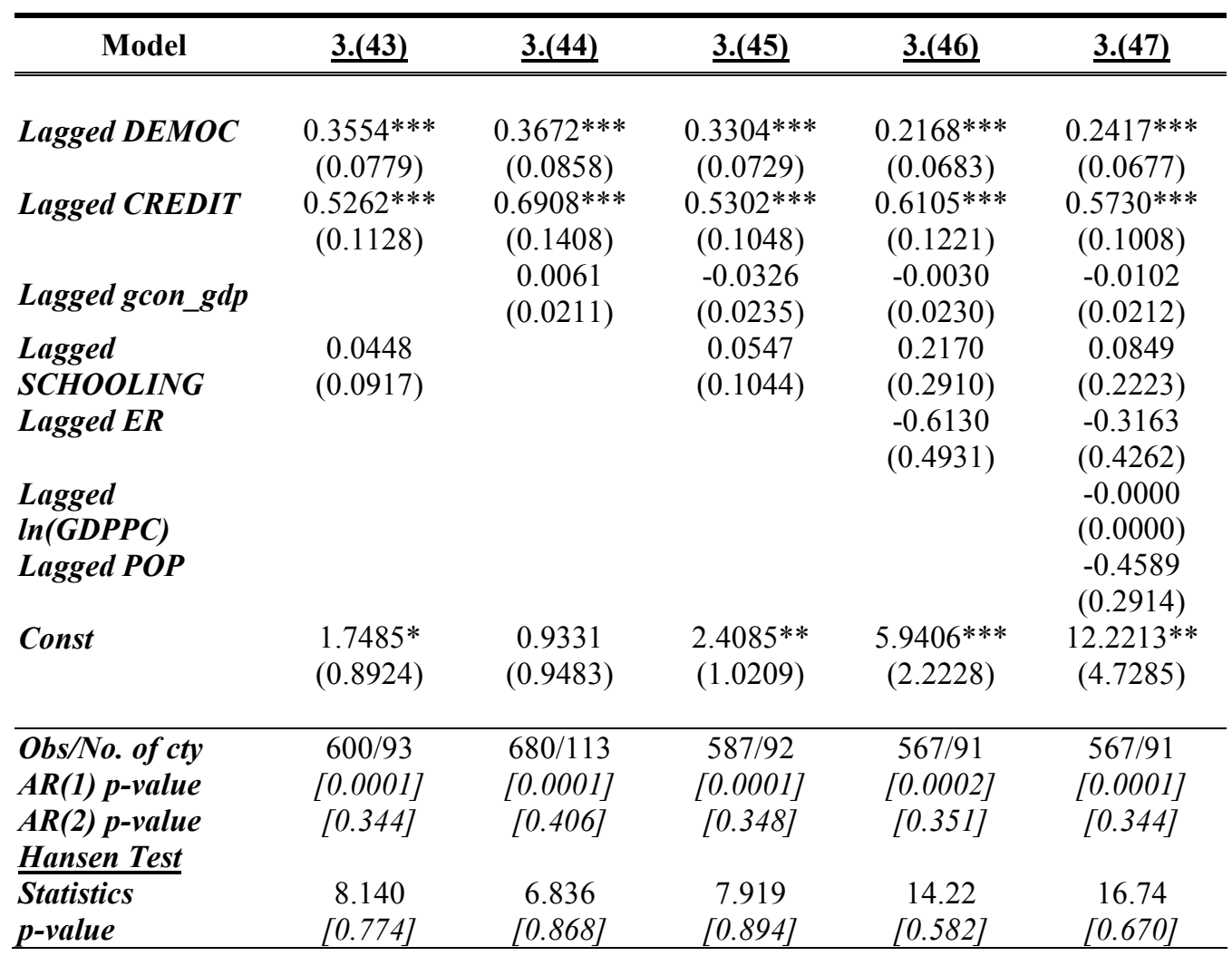

Dependent variable is $\boldsymbol{C R E D I T}$. All models include country fixed effect and period dummies. $* * *, * *$ and $*$ denote significance levels at $1 \%, 5 \%$ and $10 \%$ respectively. Lagged CREDIT is treated as pre-determined, while other regressors are endogenous. Standard errors are in parenthesis and Windmeijer-corrected, robust for heteroskedasticity and autocorrelation. Instruments are transformed by orthogonal deviation and collapsed. Hansen test is used for overidentifying restrictions.

\subsubsection{Reverse Causality: Economic Reform Causes Democratisation?}

Finally, we test the reverse causal relationship between economic reform and democratisation in Table 3.4.4-1. Our empirical results show that economic reforms generally do not improve democracy directly, except for $\boldsymbol{T R} \boldsymbol{A N S F E R}$ and FREE TRADE. In other words, a more redistributive society causes the economy to be more democratic. As one can expect, governments that spend more on transfer and subsidy are more likely to benefit the majority of the society. In turn, if the society is a democracy, it is more likely to persist. Trade liberalisation also has such an effect. While free trade may benefit the majority, it potentially provides feedback to the democratic regime. Finally, 
we find that, although a democratic society more likely leads to liberalisation of the financial market through credit market liberalisation, the reverse effect is not found empirically. A word of caution about Model 3.(54) is that we find lagged $\mathbf{L A B O R}$ does not work appropriately in this dynamic panel model as the null hypothesis of the AR(1) test is rejected.

The reverse causality results using IPOLITY2 in Table 3.4.4-2 are generally similar. We do not find particular empirical evidence to support the hypothesis that economic reforms cause democratisation. Perhaps the most interesting result is that while we use IPOLITY2 to measure democracy, we find that more government consumption (as percentage of total consumption) is more likely to improve democracy in Model 3.(55). The negative relationship between the two indices was also previously obtained when we use $\boldsymbol{D E M O C}$, but it turns out to be statistically significant only when using IPOLITY2. 
Table 3.4.4-1: Economic Reforms Cause Democracy?

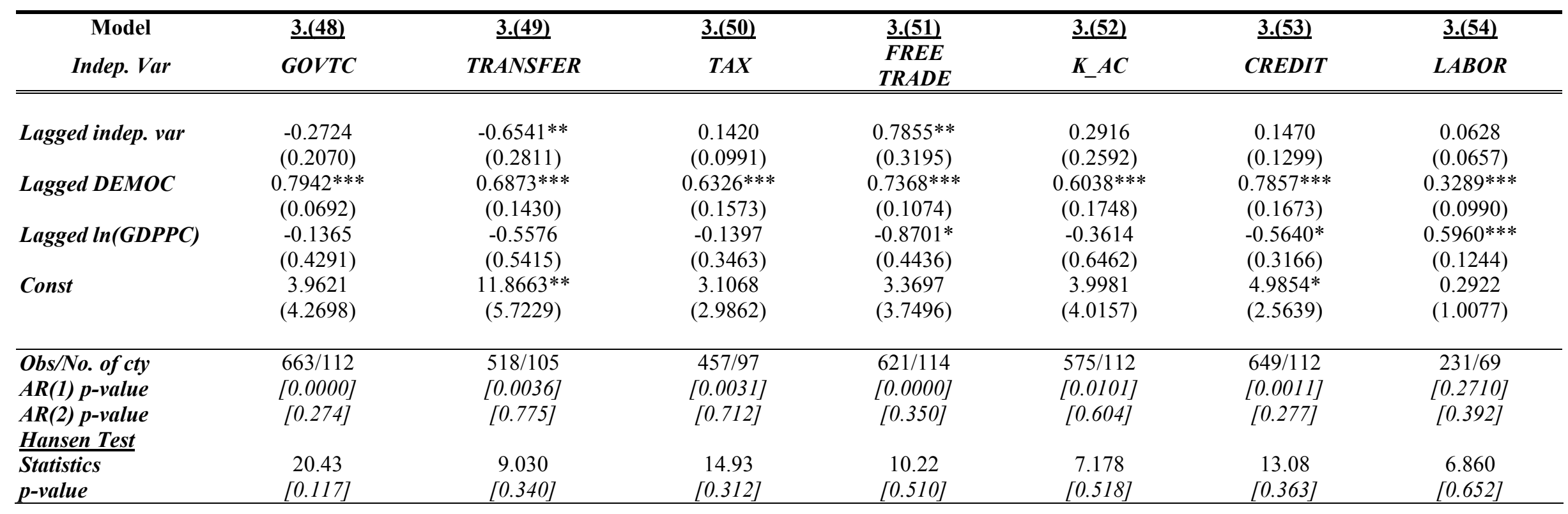

Dependent variable is DEMOC. All models include country fixed effect and period dummies. $* * *, * *$ and $*$ denote significance levels at $1 \%, 5 \%$ and $10 \%$ respectively. Lagged DEMOC is treated as pre-determined, while other regressors are endogenous. Standard errors are in parenthesis and Windmeijer-corrected, robust for heteroskedasticity and autocorrelation. Instruments are transformed by orthogonal deviation and collapsed. Hansen test is used for overidentifying restrictions. 
Table 3.4.4-2: Economic Reforms Cause Democracy? - Measured by IPOLITY2

\begin{tabular}{|c|c|c|c|c|c|c|c|}
\hline $\begin{array}{c}\text { Model } \\
\text { Indep. Var }\end{array}$ & $\frac{3 .(55)}{G O V T C}$ & $\begin{array}{c}\underline{3 .(56)} \\
T R A N S F E R\end{array}$ & $\frac{3 .(57)}{T A X}$ & $\begin{array}{c}\text { 3.(58) } \\
\text { FREE } \\
T R A D E\end{array}$ & $\frac{3 .(59)}{K \_A C}$ & $\begin{array}{c}\underline{3 .(60)} \\
C R E D I T\end{array}$ & $\begin{array}{c}\underline{3 .(61)} \\
L A B O R\end{array}$ \\
\hline Lagged indep. var & $\begin{array}{c}-0.3838^{* *} \\
(0.1798)\end{array}$ & $\begin{array}{l}-0.6020^{*} \\
(0.3503)\end{array}$ & $\begin{array}{c}0.0297 \\
(0.0676)\end{array}$ & $\begin{array}{c}0.6005 * * \\
(0.2507)\end{array}$ & $\begin{array}{c}0.2165 \\
(0.1870)\end{array}$ & $\begin{array}{c}-0.0078 \\
(0.2554)\end{array}$ & $\begin{array}{c}0.0794 \\
(0.1257)\end{array}$ \\
\hline Lagged IPOLITY2 & $\begin{array}{c}0.8052 * * * \\
(0.0660)\end{array}$ & $\begin{array}{c}0.4278 * * \\
(0.2152)\end{array}$ & $\begin{array}{c}0.7571 * * * \\
(0.1866)\end{array}$ & $\begin{array}{c}0.5019 * * * \\
(0.1157)\end{array}$ & $\begin{array}{c}0.5618^{* * * *} \\
(0.1264)\end{array}$ & $\begin{array}{c}0.6117 * * * \\
(0.1869)\end{array}$ & $\begin{array}{l}0.4996^{*} \\
(0.2947)\end{array}$ \\
\hline Lagged $\ln (G D P P C)$ & $\begin{array}{l}-0.2968 \\
(0.2677)\end{array}$ & $\begin{array}{c}0.1687 \\
(0.3146)\end{array}$ & $\begin{array}{l}-0.0240 \\
(0.2467)\end{array}$ & $\begin{array}{l}-0.4088 \\
(0.2733)\end{array}$ & $\begin{array}{l}-0.3120 \\
(0.2960)\end{array}$ & $\begin{array}{l}-0.1931 \\
(0.2313)\end{array}$ & $\begin{array}{c}0.3378 \\
(0.2173)\end{array}$ \\
\hline Const & $\begin{array}{c}6.2434 * * \\
(3.0699)\end{array}$ & $\begin{array}{c}7.7301 \\
(5.1838)\end{array}$ & $\begin{array}{c}2.1590 \\
(2.4705)\end{array}$ & $\begin{array}{c}2.9407 \\
(2.7081)\end{array}$ & $\begin{array}{c}4.8274 * * \\
(1.8964)\end{array}$ & $\begin{array}{c}4.6366 * * * \\
(1.7036)\end{array}$ & $\begin{array}{c}1.1975 \\
(1.0634)\end{array}$ \\
\hline $\begin{array}{l}\text { Obs/No. of cty } \\
\text { AR(1) p-value } \\
\text { AR(2) p-value } \\
\text { Hansen Test }\end{array}$ & $\begin{array}{c}648 / 118 \\
{[0.0000]} \\
{[0.844]}\end{array}$ & $\begin{array}{l}527 / 111 \\
{[0.0838]} \\
{[0.374]}\end{array}$ & $\begin{array}{c}493 / 103 \\
{[0.0043]} \\
{[0.941]}\end{array}$ & $\begin{array}{c}625 / 120 \\
{[0.0002]} \\
{[0.875]}\end{array}$ & $\begin{array}{c}545 / 118 \\
{[0.0014]} \\
{[0.410]}\end{array}$ & $\begin{array}{c}641 / 118 \\
{[0.0104]} \\
{[0.649]}\end{array}$ & $\begin{array}{c}223 / 72 \\
{[0.3050]} \\
{[0.384]}\end{array}$ \\
\hline $\begin{array}{l}\text { Statistics } \\
\text { p-value }\end{array}$ & $\begin{array}{c}11.64 \\
{[0.392]}\end{array}$ & $\begin{array}{c}7.993 \\
{[0.535]}\end{array}$ & $\begin{array}{c}10.35 \\
{[0.585]}\end{array}$ & $\begin{array}{c}6.982 \\
{[0.639]}\end{array}$ & $\begin{array}{c}9.308 \\
{[0.157]}\end{array}$ & $\begin{array}{c}10.55 \\
{[0.103]}\end{array}$ & $\begin{array}{c}16.12 \\
{[0.0644]}\end{array}$ \\
\hline
\end{tabular}

Dependent variable is IPOLITY2. All models include country fixed effect and period dummies. $* * *$, ** and * denote significance levels at $1 \%$, 5\% and $10 \%$ respectively. Lagged IPOLITY2 is treated as pre-determined, while other regressors are endogenous. Standard errors are in parenthesis and Windmeijer-corrected, robust for heteroskedasticity and autocorrelation. Instruments are transformed by orthogonal deviation and collapsed. Hansen test is used for overidentifying restrictions. 


\subsection{Conclusion}

In this Chapter, we make progress towards understanding the role of political institution, specifically democracy, in the development process. We intend to argue that economic reforms are more likely to be implemented in democracy. Also, we attempt to investigate empirically if there is any reverse causality of democracy from economic reforms. Unlike previous studies, which focus on the effect of democratic transition or regime change, we are interested in the marginal change in political institution.

The causal relationship from democracy to economic reforms is not definite. Theories argue that democracy is more likely to cause liberalisation since reform measures are likely to benefit the majority of workers and thus gain political support in democracies. The empirical literature shows mixed results however. In particular, these studies only focus on trade or financial liberalisation before and after a political regime switch.

To pursue our empirical investigation, we use various sub-indices from the Fraser Institute's Economic Freedom Index to explore economic reforms in four sectors - (i) fiscal sector; (ii) trade liberalisation; (iii) financial liberalisation and, (iv) labour market regulation. We use a dynamic GMM panel data estimator, which allows us to estimate the short-run causality between economic reforms and political institution, as well as tackling the problem of endogeneity between the interested variables.

From our empirical results, we find that democracy does cause redistributive policies in the form of transfer and subsidy, trade liberalisation and credit market deregulation. The causal relationship is robust to different measures of democracy and the incorporation of additional covariates in the baseline specification. Moreover, the results still survive when we use non-high income sub-samples. Reciprocally, redistributive policies and trade liberalisation is also associated with democratisation. Nevertheless, credit market deregulation does not have such a causal effect. 
Our results provide empirical support to the Sunde, et al. (2006)'s model, i.e. democracy is more redistributive. In return, redistributive policies provide feedback to strengthen the democratic institution. Also, trade and financial liberalisations are likely to associate with more choices of goods and services, less regulatory barriers and more competition. These effects, which are beneficial to most sectors, are more likely to win political support in a democracy. An autocracy, on the other hand, may be reluctant to liberalise since it may threaten the vested interest of the political elites. Trade liberalisation also causes democratisation. This is possibly due to the fact that trade liberalisation may speed up growth and introduce a more competitive environment. Economic development may provide more resources for redistribution and for the pursuit of more political rights. These bilateral causal relationships between redistributive policies, trade liberalisation and democracy may also suggest that the progressive development from economic reforms to democracy and vice versa. We hope these empirical results may shed light on those liberalised economies with democratisation not yet taken place, for example China. Our results arguably suggest that political institution may inevitably have to change when reforms continue to march forward. 
CHAPTER 4 : DETERMINANTS OF FDI - IMPACT OF NATURAL BARRIERS, REGIONAL

INTEGRATION AND "BEHIND-THE-BORDER" REGULATORY ENVIRONMENT 


\subsection{Introduction}

Extension of international market in the form of foreign direct investment (FDI) is one of the most salient features of globalisation since the 1980. For both developing and developed economies, FDI is an important source of capital, technology and skills transfer. FDI outflow on the other hand helps the source economy to enjoy market expansion, lower factor costs and facilitate "tariff-hopping". All these suggest that FDI could potentially lead to economic growth and economic development.

FDI indeed experienced a distinct upsurge in the last few decades, alongside accelerating growth worldwide (see Figure 1.1-1). Figure 4.1-1 shows that total FDI inflows ${ }^{1}$ only amounted to some US\$54 billion in 1980, subsequently increased to US\$1,833 billion in 2007. This represents an impressive average growth rate of almost $14 \%$ per annum. Although it fell dramatically to US\$561 billion in 2003 due to the burst of the IT bubble, it picked up significantly again in 2007 and reached a new peak.

\footnotetext{
${ }^{1}$ According to UNCTAD's definition, FDI inflows and outflows comprise capital provided (either directly or through other related enterprises) by a foreign direct investor to a FDI enterprise, or capital received by a foreign direct investor from a FDI enterprise. FDI includes the three following components: equity capital (foreign direct investor's purchase of shares of an enterprise in a country other than that of its residence), reinvested earnings (direct investor's share (in proportion to direct equity participation) of earnings not distributed as dividends by affiliates or earnings not remitted to the direct investor. Such retained profits by affiliates are reinvested) and intra-company loans (referring to short- or long-term borrowing and lending of funds between direct investors (parent enterprises) and affiliate enterprises).

FDI stock refers to the following. For associate and subsidiary enterprises, it is the value of the share of their capital and reserves (including retained profits) attributable to the parent enterprise (this is equal to total assets minus total liabilities), plus the net indebtedness of the associate or subsidiary to the parent firm. For branches, it is the value of fixed assets and the value of current assets and investments, excluding amounts due from the parent, less liabilities to third parties.
} 


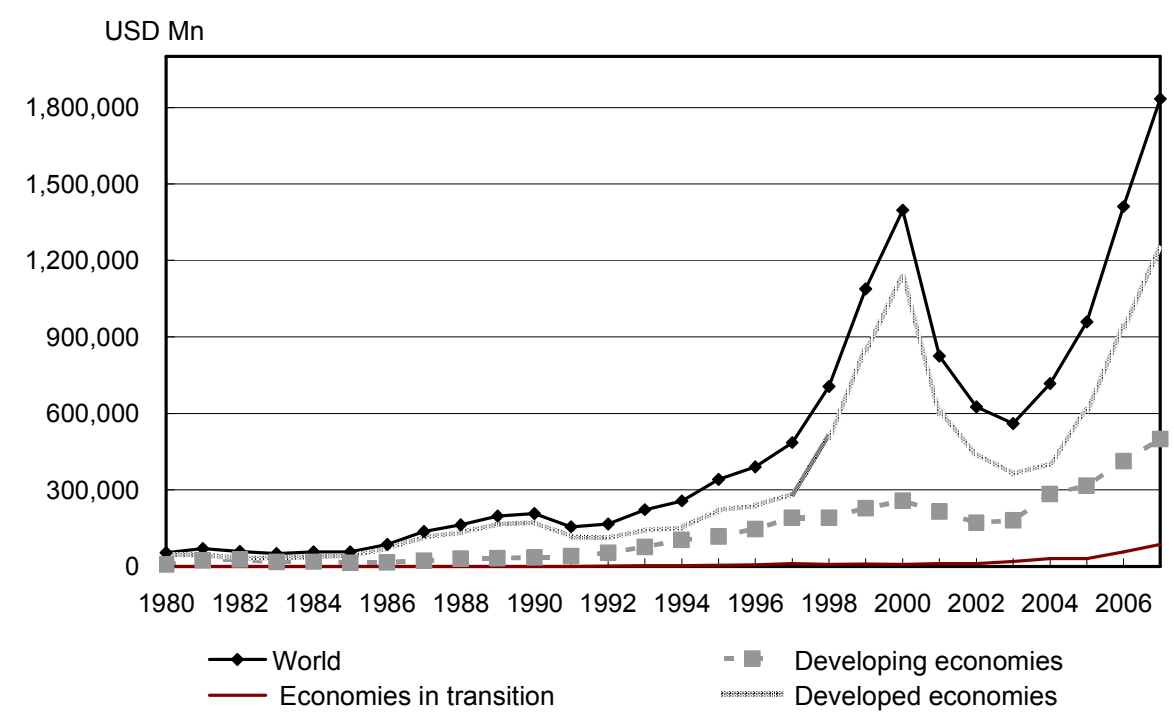

Source: UNCTAD

Albeit such distinct surge, we consistently find that the significant share of foreign capital only flow between developed economies. Analysed by regions in Figure 4.1-2, FDI inflows to the developed economies alone accounted for the largest share of some $55-86 \%$ of the world's total during the period $1980-$ 2007. The corresponding shares of the developing economies and transitional economies did pick up, yet remaining far behind in overall terms.

Figure 4.1-2: FDI Inflows as Percentage of World's Total

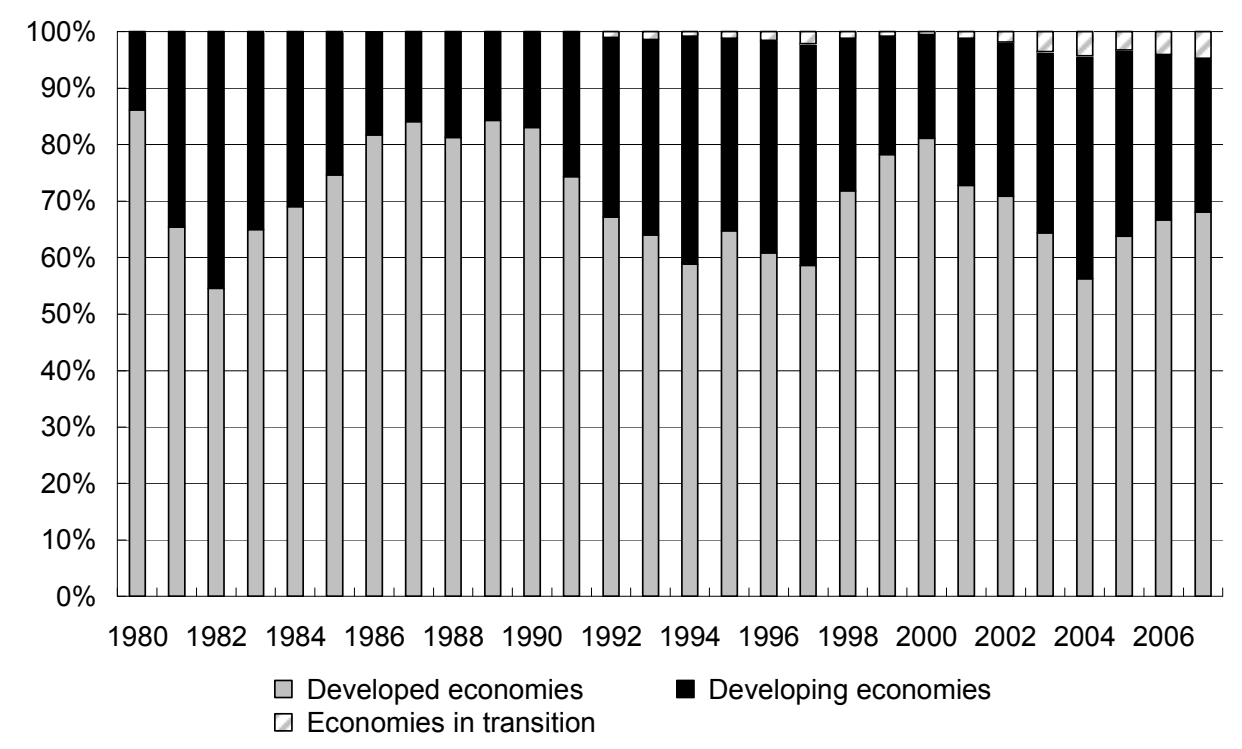

Source: UNCTAD 
Not only as the major FDI destinations, developed economies are also the major FDI sources. Table 4.1-1 shows that the top 10 FDI destinations and sources in 2007 are mostly OECD economies, except for the case of China and Hong Kong. The latter is due to the fact that a significant share of Hong Kong's FDI actually came from Mainland China, accounting for about 25\% (2007 figure) of China's total FDI outflows. OECD economies as a whole accounted for $85 \%$ of world's FDI outflows and $84 \%$ of FDI outward stock in 2007.

Table 4.1-1: Top FDI Destinations and Sources in 2007

\begin{tabular}{|c|c|c|}
\hline & Top FDI Destination (as \% of world's total FDI inflow) & 2007 \\
\hline 1 & United States of America & 12.70 \\
\hline 2 & United Kingdom of Great Britain & 12.22 \\
\hline 3 & France & 8.62 \\
\hline 4 & Canada & 5.93 \\
\hline 5 & Netherlands & 5.42 \\
\hline 6 & China (excluding Hong Kong, Macao and Taiwan) & 4.56 \\
\hline 7 & China, Hong Kong Special Administrative Region & 3.27 \\
\hline 8 & Spain & 2.91 \\
\hline 9 & Russian Federation & 2.86 \\
\hline \multirow[t]{3}{*}{10} & Germany & 2.78 \\
\hline & Total of top 10 & 61.26 \\
\hline & Top FDI Source (as \% of world's total FDI outflow) & 2007 \\
\hline 1 & United States of America & 15.72 \\
\hline 2 & United Kingdom of Great Britain & 13.31 \\
\hline 3 & France & 11.25 \\
\hline 4 & Germany & 8.39 \\
\hline 5 & Spain & 5.99 \\
\hline 6 & Italy & 4.55 \\
\hline 7 & Japan & 3.68 \\
\hline 8 & Canada & 2.70 \\
\hline 9 & China, Hong Kong Special Administrative Region & 2.66 \\
\hline 10 & Luxembourg & 2.59 \\
\hline & Total of top 10 & 70.84 \\
\hline
\end{tabular}

Source: UNCTAD

In terms of FDI inflow in developing countries (see Figure 4.1-3), Asia and Latin America countries accounted for the greatest shares of world's total FDI 
inflows of some $17.4 \%$ and $6.9 \%$ respectively in 2007 . Whilst Africa is the poorest region, its respective share has been consistently less than $5 \%$ for the last few decades.

Figure 4.1-3: FDI Inflows as Percentage of World's Total in Developing Economies

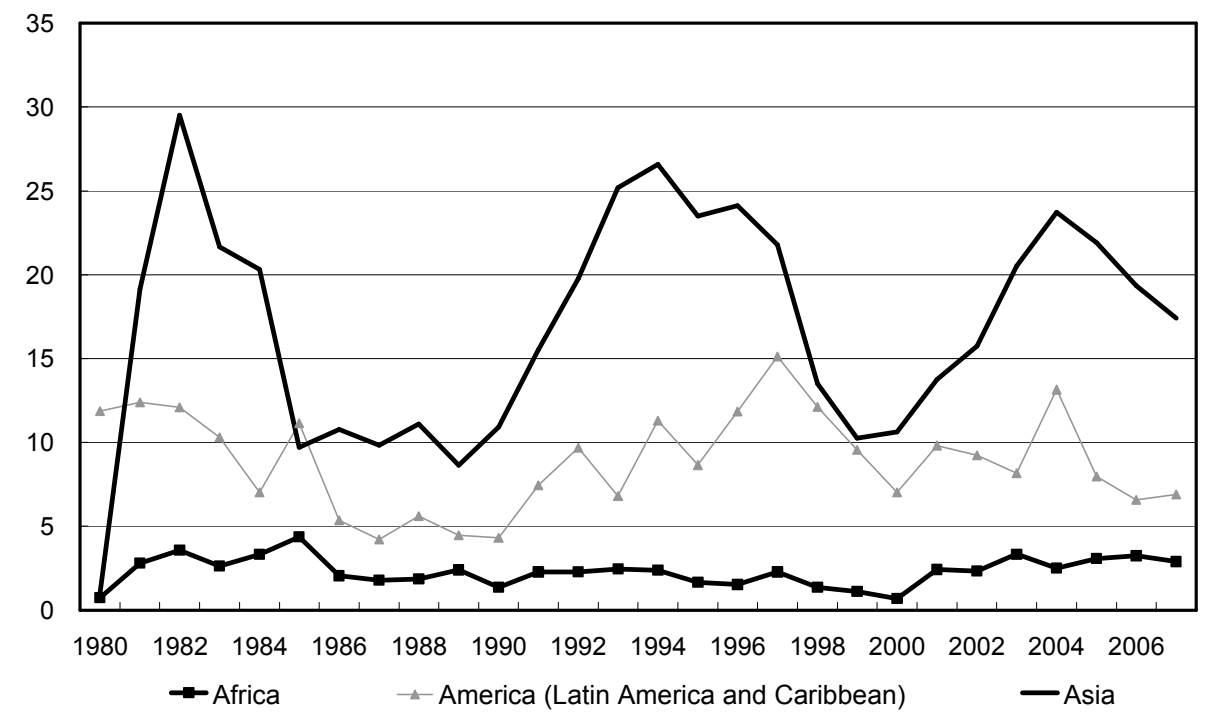

Source: UNCTAD

In fact, FDI contributes a very large share of capital formation in developing economies. In particular in those economies in transition, as shown in Table 4.1-2, FDI inflows could represent over $20 \%$ of their gross fixed capital formation.

Table 4.1-2: FDI Inflows as Percentage of Gross Fixed Capital Formation (\%)

\begin{tabular}{lccccc}
\hline & $\underline{2002}$ & $\underline{2003}$ & $\underline{2004}$ & $\underline{2005}$ & $\underline{\underline{2006}}$ \\
\hline \hline World & $\mathbf{9 . 2 8}$ & $\mathbf{7 . 3 7}$ & $\mathbf{8 . 1 9}$ & $\mathbf{9 . 8 7}$ & $\mathbf{1 3 . 1 6}$ \\
Developing economies & 10.42 & 9.59 & 12.55 & 11.70 & 12.98 \\
Economies in transition & 11.39 & 15.45 & 17.39 & 14.24 & 20.44 \\
Developed economies & 8.86 & 6.44 & 6.38 & 9.00 & 12.96 \\
\hline
\end{tabular}

Source: UNCTAD

As FDI is one of the major sources of capital accumulation and can act as a vehicle of technological progress through the use and dissemination of improved production techniques, attracting FDI therefore naturally forms part of the growth strategy of most of the developing economies. However, we are left wonder why capital does not flow from the rich economies to the poor, 
where production costs are low and marginal productivity of capital is high.

In this light, the literature has been extensively developed to study the determinants of FDI. Studies at the micro-level suggest that the structure of the industry, factor cost of production and intra-industry scale effect, amongst others, may affect investors' decisions to invest abroad in the form of greenfield FDI or merger or acquisitions. Another strand of the literature investigates the macroeconomic determinants. It essentially argues that specific characteristics of the destination economy play a significant role, such as the transportation cost between the destination economy and source economy, trade barriers, fiscal incentives, business climate and exchange rates etc. This study belongs to the latter strand, i.e. identifying the determinants of FDI at macro level.

Our key research objective of this Chapter is to assess three potential macroeconomic determinants of FDI, namely, natural barrier, de jure "at-the border" external institution and de facto "behind-the-border" domestic institution. This is motivated by the fact that regional integration and behind-the-border regulatory obstacles have lately drawn keen interests of policymakers with an aim to improve institutional frameworks, regulatory environment and government policies for attracting foreign investment. We intend to evaluate their respective impacts under a unified assessment framework.

Following the existing literature on trade and capital flow, we refer natural barriers as the geographical characteristics and historical ties between the destination and source economies. We expect that geographical and cultural proximities reduce transportation and transaction costs, thereby fostering bilateral FDI flows.

On "behind-the-border" domestic institutional environment, recent research has focused on the rule of law, development of credit market, political stability and business and investment climate etc. Our specific focus here is to investigate how the regulatory environment of the destination economy affects FDI. It is 
believed that, holding other factors constant, burdensome regulatory environment discourages foreign investors to invest due to the enormous costs of compliance and associating corruption (see Wei (2000b)), thereby hampering the dynamics of firm entry and degree of local competition. On the contrary, a less regulated environment reduces the sunk costs to invest offshore for foreign investors and is thus more likely to attract FDI.

"At-the-border" external institution refers to regional integration, reflected by bilateral (or regional) trade agreements (henceforth RTAs). Although most RTAs aim at facilitating trade liberalisation, the positive impacts on FDI are also possible. This is because closer integration is also likely to associate with an expansion of the total market size.

We intentionally test de jure "at-the border" external institution (i.e. RTAs) and de facto "behind-the-border" domestic institution together. We consider the former as an externally imposed institution, while the latter is de facto institution in the sense that the variable we used measures the subjective perception of the regulatory environment. The scores are collected from foreign investors in the respective economies. This score to a certain extent, albeit imperfectly, reflects the domestic regulatory environment. Our investigation hence may allow us to understand which type of barriers, natural or institutional, determines the relative locational advantages of FDI.

Our work in the following is entirely empirical and uses an augmented gravity model for our estimations. We hypothesise that better domestic regulatory environment may lead to more FDI inflows. Reciprocally, more FDI inflows may also lead to a better regulatory environment since the domestic government may respond to the needs of foreign investors. Such endogeniety will be taken into account in our study. Unlike the existing literature, which focuses on the impacts of the overall institutional environment and regional agreements on aggregate FDI inflows ${ }^{2}$, we use bilateral FDI data instead of

\footnotetext{
${ }^{2}$ Nevertheless, it is not our intention to assess the impact of each regional trade agreement on FDI, nor the effectiveness of each agreement. Studies have been done to assess the impact of individual regional trade agreement on bilateral trade, especially the effect of WTO accession
} 
aggregate FDI data. As we discussed earlier, OECD economies are the key FDI destinations and sources. Our dataset will thus focus on bilateral FDI data of OECD economies as sources. Using bilateral FDI data at the same time could also improve the accuracy of our estimations. It is because aside from the variables of our interest, there may also be some characteristics which are specific to the destination and source economies. Hence, to minimise omitted variable bias, we can control for the specific country-pair heterogeneity when using bilateral data, which cannot be achieved using aggregate FDI data.

This paper is probably among the very first few to assess the impact of natural barriers, regional integration and regulatory environment altogether on bilateral FDI. The results may help develop policy implications by identifying the macroeconomic determinants of FDI.

The rest of the paper is organised as follows. Section 4.2 provides a brief literature survey. We describe the data used in Section 4.3. In Section 4.4, we discuss the estimation strategies. Empirical results are presented in Section 4.5. We conclude and set out the policy implications in Section 4.6.

\subsection{Literature Survey: Regulations and Regional Integration as Determinants of FDI}

The first generation of literature on FDI was largely devoted to its macroeconomic impacts. It is argued that FDI promotes economic growth and development since FDI provides a new source of capital, thereby allowing investment in both human and physical capital on one hand. On the other hand, it also serves as a means to incorporate new knowledge and technology from abroad. Amongst others, Borensztein, De Gregorio, and Lee (1998) use data on FDI flows from industrial countries to 69 developing countries from 1970 to 1989 and suggest that FDI is an important vehicle for the transfer of technology, contributing relatively more to growth than domestic investment

(see Subramanian and Wei (2007) and Eicher and Henn (2009)). 
does. Empirical results from Balasubramanyam, Salisu, and Sapsford (1996) on the other hand suggest that FDI may be growth-promoting only in export-promoting countries rather than in import-substituting ones. More recently, Li and Liu (2005) use data of 84 countries for the period of 1970-1999. Both single equation and 3SLS estimations show that there is a robust positive relationship between FDI and economic growth.

The second generation of literature focuses more on the determinants of FDI and investigates the underlying factors of the locations of foreign affiliates. In particular, the quality of institutions increasingly plays a pivotal role in attracting foreign investment since good governance is usually associated with better security of property rights, effective legal system and enforcement of regulations, well-built physical and financial infrastructure and generally more productive environment.

In his survey, Lim (2001) has succinctly summarised seven key macroeconomic aspects of FDI determinants. Four of them are particularly relevant to our work. They include (1) economic distance/transport costs; (2) size of the destination market; (3) business/investment climate and (4) trade barriers/openness ${ }^{3}$. Their net impact, however, depends on the nature of FDI - vertical or horizontal FDI.

\subsubsection{Natural Barriers and FDI}

Lim (2001) argues that the impact of economic distance (and hence transport costs) on FDI is conceptually unclear. Horizontal FDI (i.e. "market-seeking" FDI) will tend to replace exports and thus increase if the cost of market access through exports is high or if the distance between the source and destination markets is large. Nevertheless, as vertical FDI (i.e. "production cost-minimising" FDI) is generally export-oriented, it may then be discouraged by high transport costs.

\footnotetext{
${ }^{3}$ Another three factors include agglomeration effects, factor costs and fiscal incentives, which are not the factors of our direct interest in this Chapter. Recent research studies additionally emphasize the effect of exchange rate on FDI flows (see Froot and Stein (1991), Blonigen (1997) and Blonigen (2005)).
} 
Similarly for market size - measured in terms of economic activity, population or area, larger destination market will encourage horizontal FDI as it will reduce the cost of supplying that market as a result of economies of scale and lower unit fixed cost. For vertical FDI, on the other hand, it may be indifferent to this factor.

In overall terms, there is no conclusive argument about the combined effect of economic distance and market size on FDI inflows. Along this line, our estimations will capture the effect of natural barriers on FDI and empirically test these two effects.

\subsubsection{Regulations and FDI}

Lim (2001) further identifies that the lower costs of doing business in a foreign country, holding other factors constant, is more attractive to FDI. These costs may include regulatory, bureaucratic, and judicial hurdles, issues of property rights, enforceability of contracts, labour regulation, political and macroeconomic stability.

The literature relating the institutional quality of the destination economy as the determinant of FDI often rely on the use of an aggregate index of institutions. The choice of "institutional" variables is also different in different studies. Wheeler and Mody (1992) is amongst the first to investigate the impact of institution on FDI. They use a composite index of risk factors, which include bureaucratic red tape, political instability, corruption and quality of the legal system, and show that there is no significant impact of institutions on determining the location of US foreign affiliates. Singh and Jun (1995), in contrast, show that a general qualitative index of business operation conditions is an important determinant of FDI in countries that receive high flows. In addition, they also find that these countries also show a positive relationship between taxes on international transactions and FDI flows - i.e. supporting the "tariff jumping" hypothesis. 
Wei (2000a) focuses on one specific aspect of institution - corruption. $\mathrm{He}$ finds that corruption and so as uncertainty of corruption have significant negative effects on FDI. Likewise, Stein and Daude (2002) show that inward FDI is significantly influenced by the quality of institutional variables. Political instability and violence, government effectiveness, regulatory burden, rule of law and graft all matter for FDI. Political institutions, e.g. political representation and accountability indicators, on the other hand do not.

By studying the effects of institutions on capital structure, Aizenman and Spiegel (2004) find that the ratio of FDI to gross fixed investment, as well as the ratio of FDI to private domestic investment, is negatively and significantly correlated with the level of corruption. This suggests that FDI is more sensitive than domestic investment to the level of institutional quality. By using the law and order variable of ICRG instead of corruption, Albuquerque (2003) likewise finds a negative yet insignificant effect.

More specifically on regulation, its impacts on various economic outcomes are extensively studied ${ }^{4}$. Its role in attracting FDI is less frequently explored. Regulations are generally justified as a way for governments to serve the public interest and address externalities or market failures. Indeed, there are legitimate and important functions fulfilled by regulations. However, regulations can also carry costs in terms of bureaucratic delays or expenses to meet compliance that too often have little bearing on the rationale of the regulation. Particularly in developing countries, excessive regulations usually lead to widespread corruption.

Only recently, there are few papers specifically devoted to regulation and FDI. Hermes and Lensink (2003) and Alfaro, Chanda, Kalemli-Ozcan, et al. (2004)

\footnotetext{
${ }^{4}$ For example, a number of papers find important effects of labour regulations on firm entry, job creation and economic growth (e.g. Botero, Djankov, Porta, et al. (2003), Besley and Burgess (2004), Almeida and P. (2005), Haltiwanger, Scarpetta, and Schweiger (2006), Petrin and Sivadasan (2006) and Autor, Kerr, and Kugler (2007)). Other papers examine the effect of business regulations on firm entry, growth and informality (see Djankov, Porta, Lopez-de-Silane, et al. (2003b) and Loayza, Oviedo, and Servén (2004)). Others look at regulatory developments in financial market (e.g. Beck, Demirguc-Kunt, and Maksimovic (2005), Demirguc-Kunt and Maksimovic (1998), Galindo and Micco (2005)). Almost all of them focus on cross-country variations.
} 
examine the linkages between financial market regulations, FDI and growth. They both concur that countries with better financial systems and financial market regulations can exploit FDI more effectively and thus achieve high growth rates. A well-functioning financial market allows entrepreneurs to obtain credit for their new businesses or for business expansion. As such, countries could benefit from inward investment to promote economic growth.

Busse and Groizard (2006), on the other hand, study the impact of broader government regulations on the interaction between FDI and growth. They argue that countries need sound business environment in the form of good government regulations to be able to benefit from FDI. Countries may only benefit from foreign investment flows if they have appropriate local government regulations and institutions in place. Excessive regulations are likely to restrict growth through FDI if human and capital resources are prevented from reallocation. Using the World Bank's Ease of Doing Business Indicators, they find evidence that excessive regulations restrict growth through FDI only in the most regulated economies. This result holds true for both OLS and 2SLS estimations. Their findings also suggest that FDI does not stimulate growth in economies with excessive business and labour regulations, after controlling for GDP growth rates.

Our work follows the line of Busse and Groizard (2006) to examine the impact of government regulations on FDI. However, our approach has a number of differences. Firstly, we use various sub-indices from the Fraser Institute's Economic Freedom Index to measure government regulations. Like the World Bank's survey, our indicators are also subjective in nature. However, our time span covered is longer, which allows us to undertake panel data analysis. Therefore, unlike Busse and Groizard (2006), which is cross-sectional in nature, our models introduce a greater degree of freedom. As their analysis is cross-sectional, they have to rely on clustering samples or incorporating regional dummies to capture the specific heterogeneity of the destination economies partially. In our case, panel data models readily allow us to capture the unobserved panel-specific heterogeneity. Finally, like other empirical work studying the impact of institutions on FDI, aggregate FDI data 
are often used. One limitation as such, as pointed out by Bénassy-Quéré, Coupet, and Mayer (2007), is that the specific characteristics of the destination and source economies cannot be included at the same time since the estimations do not rely on bilateral FDI data. In other words, these empirical studies primarily assessed the impact of the overall institutional environment of the destination economy on FDI inflows.

More recent research henceforth has started to explore the FDI determinants more specifically in respect of characteristics of the destination and source economies. Using bilateral FDI data is therefore inevitable. Table 4.2.2-1 below summarises some recent empirical studies estimating the impact of institutions on bilateral FDI flows/stocks. However, as we note, the majority of these empirical estimations still relies on cross-country analyses due to the short time span of institution data. Specific analyses on the three determinants as we proposed do not yet exist so far.

Table 4.2.2-1: Selected Recent Empirical Studies Estimating the Impact of Institutions on Bilateral FDI

\begin{tabular}{|c|c|c|c|}
\hline Study & $\begin{array}{c}\text { Institutional } \\
\text { Variables }\end{array}$ & $\begin{array}{l}\text { Estimation } \\
\text { Techniques }\end{array}$ & $\begin{array}{c}\text { Year/ } \\
\text { Country Coverage }\end{array}$ \\
\hline $\begin{array}{l}\text { Daude and Stein } \\
\qquad(2004)\end{array}$ & $\begin{array}{l}\text { World Bank's Governance } \\
\text { Indicators (all } 6 \text { clusters) }\end{array}$ & $\begin{array}{l}\text { OLS } \\
\text { Tobit }\end{array}$ & $\begin{array}{l}1998 \\
\text { Source economies: } 20 \\
\text { OECD } \\
\text { Destination economies: } \\
58\end{array}$ \\
\hline $\begin{array}{l}\text { Liu, Chow, and Li } \\
\text { (2006) }\end{array}$ & $\begin{array}{l}\text { International country Risk } \\
\text { Guide (ICRG) indicators }\end{array}$ & OLS & $\begin{array}{l}90-95 ; 96-99 ; 00-05 \\
\text { Source economies: } \\
\text { OECD } \\
\text { Destination economies: } 7 \\
\text { East Asian economies }\end{array}$ \\
\hline $\begin{array}{l}\text { Mishra and Daly } \\
\text { (2007) }\end{array}$ & $\begin{array}{l}\text { ICRG indicators : law and } \\
\text { order, government stability, } \\
\text { bureaucracy quality and } \\
\text { corruption }\end{array}$ & $\begin{array}{l}\text { OLS } \\
\text { IV }\end{array}$ & $\begin{array}{l}\text { 1991-2001 } \\
\text { Source economies: } 11 \\
\text { OECD } \\
\text { Destination economies: } \\
19 \text { OECD and Asian } \\
\text { economies }\end{array}$ \\
\hline $\begin{array}{l}\text { Bénassy-Quéré, et al. } \\
\text { (2007) }\end{array}$ & $\begin{array}{l}\text { Fraser Institute Economic } \\
\text { Freedom Index and } \\
\text { Institutional Profiles (1P) } \\
\text { Database from French } \\
\text { Ministry of Finance }\end{array}$ & $\begin{array}{l}\text { OLS } \\
\text { Panel }\end{array}$ & $\begin{array}{l}\text { 1985-2000 } \\
\text { Source economies: } \\
\text { OECD economies } \\
\text { Destination economies: } \\
\text { OECD and developing } \\
\text { economies }\end{array}$ \\
\hline
\end{tabular}




\begin{tabular}{|c|c|c|c|}
\hline $\begin{array}{c}\text { Hattari and Rajan } \\
\text { (2008) }\end{array}$ & ICRG political risk index & $\begin{array}{c}\text { OLS } \\
\text { Tobit }\end{array}$ & $\begin{array}{l}\text { 1990-2005 } \\
\text { Source economies: } 14 \\
\text { Asian economies } \\
\text { Destination economies: } \\
10 \text { Asian economies }\end{array}$ \\
\hline
\end{tabular}

\subsubsection{Regional Integration and FDI}

One of the most essential elements of regional integration is the promotion of free trade. However, on openness, Lim (2001) suggests that its net impact on FDI could be uncertain. Horizontal FDI, aiming at getting behind trade barriers (i.e. "tariff-jumping"), may decrease with an increase in openness, e.g. low tariffs. In contrast, vertical FDI that requires substantial intermediate inputs and goods flows in or out of the destination economy will benefit from a liberal trade environment. Furthermore, a liberal and open trade environment is also positively conducive to the general business climate. It may thus attract horizontal FDI.

Conceptually, regional trade agreements (RTAs) provide the benefits of free trade within the confined regional group. Jaumotte (2004) suggests that these benefits include the exploitation of comparative advantage with partner countries, increased competition leading to greater efficiency, and a larger market allowing the exploitation of economies of scale. These efficiency gains can turn into dynamic gains by increasing growth, as well as domestic and foreign investment. FDI may also act as an essential catalyst for these dynamic benefits to materialise.

Regionalism is indeed one of the key features of recent global development. According to the World Trade Organisation (WTO) ${ }^{5}$, RTAs in recent years have become a very prominent feature of the Multilateral Trading System. The surge in the number of RTAs has continued unabated since the early 1990s. Some 421 RTAs have been notified to the GATT/WTO up to December 2008. At that same date, 230 agreements were in force ${ }^{6}$. RTAs were used to focus

\footnotetext{
${ }^{5}$ Source: www.wto.org

${ }^{6}$ If we take into account RTAs which are in force but have not been notified, those signed but
} 
on removing trade barriers on goods, but are later expanded to cover trade in services and bilateral investment.

Figure 4.2-1: No. of RTAs notified to WTO

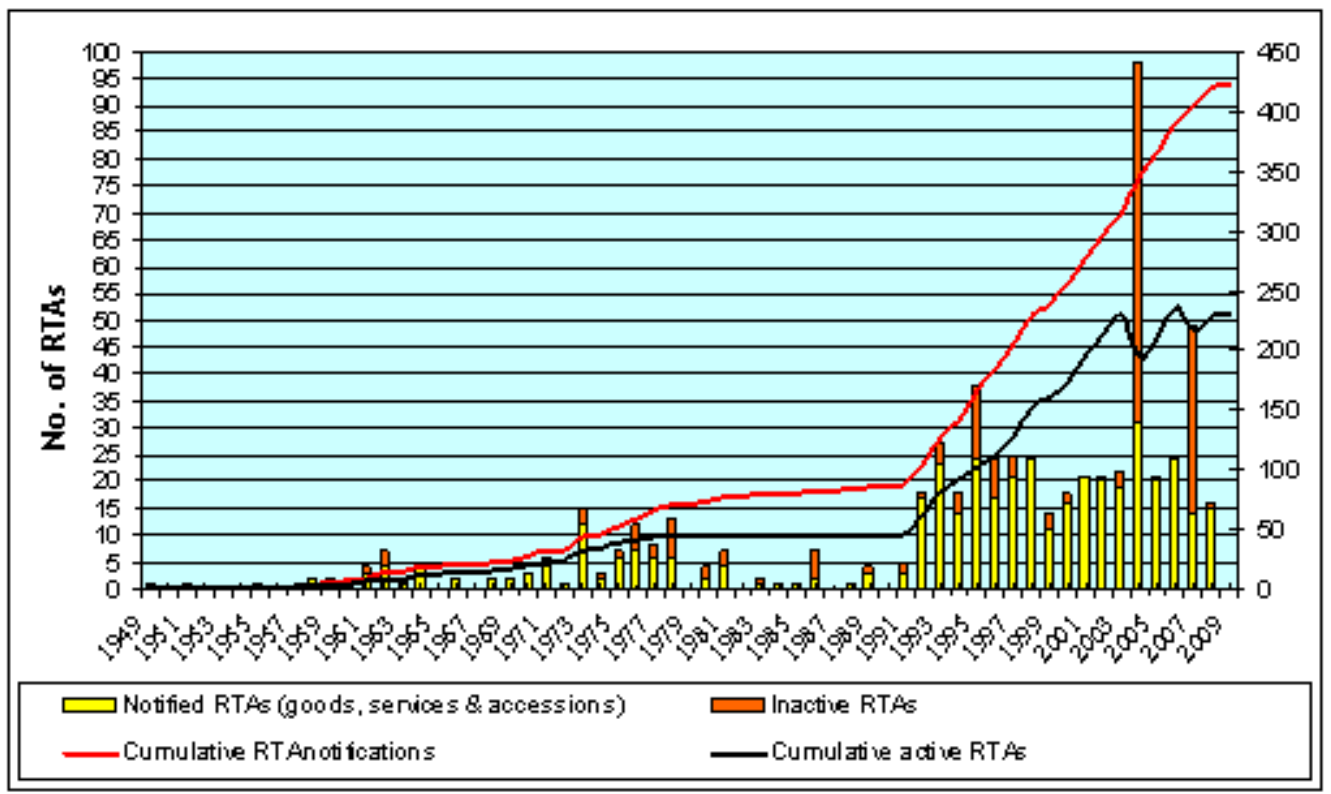

Source: WTO Secretariat

(retrieved from http://www.wto.org/english/tratop_e/region_e/regfac e.htm)

Blomstrom and Kokko (1997) is amongst the first to assess the impact of regional integration on FDI. Focusing on three specific RTAs ${ }^{7}$, they find that the impacts of a regional agreement on FDI largely depend on the environmental change brought about by the agreement. If the regional agreement leads to improved resource allocation and increased competition, overall economic efficiency is expected to be enhanced and as growth rate. The effects also depend on the locational advantages of the participating countries and industries. Their empirical findings also suggest that RTAs bring more positive significant impact on FDI if RTAs coincide with domestic liberalisation and macroeconomic stabilisation in the member economies.

The ambiguous results, as they argue, may also arise from the potentially

not yet in force, those currently being negotiated, and those in the proposal stage, the figure is close to 400 RTAs which are scheduled to be implemented by 2010. Of these RTAs, free trade agreements (FTAs) and partial scope agreements account for over $90 \%$, while customs unions account for less than $10 \%$.

7 Their work assessed North-North integration (Canada joining CUSFTA), North-South integration (Mexico's accession to NAFTA) and South-South integration (MERCOSUR). 
offsetting influences from two dimensions. On one hand, some FDI continues to be motivated primarily by the desire to get behind trade barriers. Other FDI is motivated by foreign investors seeking to exploit input or output markets located abroad in activities where operating a foreign affiliate is the most efficient governance structure. Nevertheless, a reasonable generalization is that regional integration should enhance the attractiveness of investing in the region as a whole by creating a large common market and contributing to improved overall efficiency and higher income levels in that market.

To test such expanded market size effect could be resulted from RTAs, Jaumotte (2004) examines a sample of 71 developing countries during the period of 1980-99 and concludes that the aggregate market size of the RTA imposed a positive impact on FDI inflows of the member countries. Nevertheless, not all countries in the RTA benefitted to the same extent. In particular, countries with a relatively more educated labour force and/or a relatively more stable financial situation tend to attract a larger share of FDI at the expense of their RTA partners. He also suggests that for all RTA countries, it is essential to improve the business environment. More generally, the creation of an RTA may stimulate virtuous competition between the participating countries, forcing them to improve their investment environment to the best available in the region.

To sum up, the positive effects of RTAs on inward investments can go through two channels. The first-order effect of RTAs is the market size effect. An expanded market size as a result of RTA also encourages both inter-regional and intra-regional vertical FDI. The second-order effect is the result of keener competition amongst member states, leading to greater efficiency and perhaps better business environment. These, thereafter, may increase interregional FDI as a result of the RTA. 


\subsection{Data}

\subsubsection{Dependent Variable}

The dependent variable we use for the present study is the bilateral outward FDI stock from the OECD International Direct Investment Statistics (Vol. 2008 release 01). As Bénassy-Quéré, et al. (2007) suggest, there are several advantages in working on stocks rather than flows. Firstly, foreign investors decide on the global allocation of output, hence on capital stocks. Second, stocks account for FDI being financed through local capital markets. It is therefore a better measure of capital ownership. Last but not least, stocks are much less volatile than flows which are sometimes skewed by one or two large takeovers, especially in relatively small countries. Implicitly, by using stock figures, we assume that capital can be flowing in and out of the economy instantaneously in response to the determinants we identified.

As we explained earlier, OECD economies account for the largest share of global FDI inflows and outflows. Hence, the aforementioned OECD database in fact covers a significant share of global capital flows. The database covers most of the observations corresponding to FDI sourcing from each of the 30 OECD member economies, to destination economies which are either OECD economies or emerging and developing economies. Our dataset covers 28 OECD source economies (except Belgium and Mexico due to data limitation) and 60 destination economies (30 OECD and 30 non-OECD economies). A full list of economies covered is at Appendix Section A.4. Bilateral FDI stock data covers the period of $1985-2006$.

A total of 16,183 observations are available. A non-negligible portion of them are zero observations, amounting to 2,169 observations (around $13 \%$ of the total). Since we will work on the log-form of FDI data, dropping zero observation may give rise to selection bias. As such, a conventional solution to this problem is to estimate $\ln (a+F D I)$ (where $a$ is a constant) instead of estimating $\ln (F D I)$. We use $a=0.3$, and therefore the dependent variable for 
estimation, labelled as $\operatorname{lnfdi}$, implies $\ln (0.3+\mathrm{FDI})^{8}$ as in Bénassy-Quéré, et al. (2007).

\subsubsection{Independent Variables}

\subsubsection{Gravity Variables}

Since we will use an augmented gravity model (to be discussed in details in the next Section) to estimate the impacts of natural barriers, regional integration and regulatory environment on FDI, the specification will include some standard gravity variables. To capture the market sizes of the source and destination economies (denoted by subscript $i$ and $j$ respectively), we will use three measures. First is the natural log of real GDP (expressed in constant US dollars) (i.e. $\ln \left(G D P_{i}\right)$ and $\left.\ln \left(G D P_{j}\right)\right)$. Second is the natural $\log$ of population $\left(\boldsymbol{\operatorname { l n }}\left(\boldsymbol{P O P} \boldsymbol{P}_{\boldsymbol{i}}\right)\right.$ and $\left.\ln \left(\boldsymbol{P O P} \boldsymbol{P}_{j}\right)\right)$. These data come from the World Development Indicators (WDI). The third is the log product of land areas of economies $i$ and $j\left(\boldsymbol{I n}\left(\boldsymbol{A r e a}_{i j}\right)\right)$ to demonstrate the combined market size impact. Data are from Rose (2004).

With regard to "natural barriers" in the gravity model framework, we incorporate the geographical and historical variables as in Rose (2004)'s specification. These include the natural log of distance between economy $i$ and $j(\ln (\boldsymbol{D i s t}))$, land border dummy for the pair of economies sharing the same border (Border), common language dummy (Common Lang), dummy for the economy-pairs ever in colonial relationship (Colony $\left.y_{i j}\right)$, dummy for having common colonizer (Common coloniser) and dummy for the destination economy is an island (Island). These time-invarying variables are obtained from Rose (2004).

\footnotetext{
${ }^{8}$ Putting $\mathrm{a}=1$ is also quite frequently used in the existing literature. Such transformation nevertheless does not change our results significantly. Indeed, it is also interesting to study these zero observations in greater details in respect to their regulatory environment. However, this is beyond the scope of this Chapter.
} 


\subsubsection{Regional Integration and Regulatory Variables}

"At-the-border" barrier refers to whether the two economies are in a RTA (RTA), a constructed dummy variable to proxy regional integration. Based on Rose (2004)'s database on bilateral RTA membership ${ }^{9}$, we further update the database in respect to the 60 economies of our interest for 2000 onwards. Information is gathered from the WTO's website. In total, an addition of 20 more RTAs or bilateral trade agreements are augmented in our dataset. Details of these information are at Appendix Section A.5.

To measure "behind-the-border" domestic regulatory institutions, we employ sub-indicators of the Fraser Institute's Economic Freedom Index from Gwartney, et al. (2008). We use the "catch-all" index of regulation (REG) as a measure of the overall regulatory environment, ranging from 0 to 10 with higher score signifying less regulatory burden in the economy. Sub-indices on measuring credit market regulations (Credit Reg), labour regulations (Labour Reg) and business regulations (Business Reg) will also be tested separately. That said, a total 4 different regulatory variables will be used, ranging from a "catch-all" broadest measure to specific components. Nevertheless, ratings on business regulation are only available since 1995. Hence the sample size is significantly reduced.

The regulatory index intends to measure the regulatory restraints of the credit, labour and product markets. Credit Reg measures the degree of using a private banking system to allocate credit to private parties. Economies which refrain from controlling interest rates receive higher ratings from these components. Labour Reg measures the regulation of labour market. If wages are largely determined by market forces, hiring and firing conditions are well established and the use of conscription is retrained, the economy will have a higher score. Business $\boldsymbol{R e g}$ identifies the extent to which regulations and bureaucratic procedures restrain entry and reduce competition. Less business

\footnotetext{
${ }^{9}$ Rose (2004)'s RTAs dataset covers EU, USIS, NAFTA, CARICOM, PATCRA, ANZD, CACM, MERCOSUR, ASEAN and SPARTECA. Only EU, NAFTA and SPARTECA are relevant to the economies covered in our dataset. See Appendix Section A.5 for the full names of these abbreviations.
} 
regulations result in higher scores.

The composite index of $\boldsymbol{R} \boldsymbol{E} \boldsymbol{G}$ is calculated based on quantitative hard data (e.g. percentage of domestic credit consumed by the private sector) where appropriate as well as qualitative business survey data from compiled sources such as the World Economic Forum's Executive Opinion Survey and World Bank's Ease of Doing Business (EoDB) Survey ${ }^{10}$. The latter data source, as we discussed in our literature survey, is also very prevalently used in the empirical literature since it provides a consistent and comparable methodology for measuring cross-country regulatory environment. We, however, do not directly employ EoDB's data to measure regulation because the survey only started in 2003. Such short time period imposes many difficulties and limitations to carry out panel data analysis. In contrast, by constructing a composite index on regulation from various sources, the Fraser Institute's indices span over reasonably long time. A detailed description of the regulation index and its sub-components is at Appendix Section A.2.

\subsubsection{Instrumental Variables}

FDI and regulatory environment could be endogenously determined. More foreign investment may prompt the government to response closely to the needs of foreign investors by improving the business environment and relieving excessive regulatory burden of doing business. In return, destination economies, with better quality of regulatory environment, are more appealing for foreign investors and are more likely to attract inward investment. Nevertheless, there is so far neither theoretical nor empirical work suggests any sound and valid instrumental variable which directly affects domestic regulatory environment but not FDI.

As discussed in Chapter 2, existing economic growth and institution literature also mentions extensively such endogeneity problem. Despite their imperfections, similar instrumental variables will also be employed for our

10 Further information on the Ease of Doing Business Report can be retrieved from http://www.doingbusiness.org/. 
estimations to tackle endogeneity. The instrumental variables used in our estimation are primarily from Alesina, et al. (2003). They provide a new set of measures of ethnic fragmentation, religion fragmentation and language fragmentation for about 190 economies $^{11}$. Also, as in Glaeser and Shleifer (2002), UK legal origin and latitude of the destination economy are also used as instrumental variables for our IV estimations.

\subsubsection{Data Limitation}

One major limitation of this study is data. First of all, our bilateral FDI data are restricted to OECD economies as FDI source economies only. Further study is worth pursuing for developing economies as source to investigate if they have any different investment behaviour. Secondly, although our dataset constitutes a longer time span of regulatory indices than those used in the existing literature, our variables are only available from 1990. Apparently, using longer time span is more desirable in our case. This also explains partially why previous literature generally adopted a cross-sectional approach, for example using OLS and Tobit models ${ }^{12}$.

\subsection{Model and Estimation Strategy}

\subsubsection{Augmented Gravity Model}

Our estimation is based on an augmented gravity model. Gravity models have been extensively used in empirical economics, in particular in relation to regional integration and international flows of goods, capital as well as labour

\footnotetext{
${ }^{11}$ The aim of their paper is to revisit the effects of all these variables on economic growth and the quality of institution. They suggest that the degrees of endogeneity of these instrumental variables to the dependent variables are actually quite different.

${ }^{12}$ Using Tobit model is due to censoring of the dependent variable, FDI. We do not undertake panel Tobit estimations in our case. As Greene (2008) has pointed out, most of the attention in the theoretical literature on panel data methods for the Tobit model has been focused on fixed effects. Fixed effects models will assume away all the time-invarying effects. Therefore, the impact of natural barriers in our case cannot be assessed. More importantly, empirical evidences suggest that unconditional estimation of the Tobit model behaves essentially like that for the linear regression model. For further research, a generalised Tobit model could be considered, especially it is more conceptually appealing by allowing the two parts of the model (whether the economy has FDI or not) to be correlated.
} 
movement. The simple form of the model assumes that the bilateral flow of commodities increase with economic sizes (measured by national incomes) and decrease with the cost of transportation (measured by the distance between the two economic centres). An augmented gravity model implies an extension of the model to incorporate factors on top of these two.

There have been critics arguing that, despite the empirical success in explaining various types of bilateral trade and FDI movements, the gravity model lacks theoretical foundation to justify any addition of policy variables. Furthermore, it also implies that estimation may suffer from omitted variables bias and that comparative static analysis is unfounded. In this light, based on earlier theoretical foundations of gravity model developed in Anderson (1979), Anderson and Wincoop (2003) derive a general equilibrium model relating bilateral trade to size, bilateral trade barriers and, most importantly, multilateral price indices. They argue that this form of multilateral resistance reflects the average relative trade costs. Average trade costs faced by a country will influence its bilateral commodity or investment flow decisions. Estimations that fail to control for such countries' average trade costs would induce omitted variable bias. They apply the model to investigate the impact of national border on trade and find that national borders reduce trade between US and Canada by a considerable amount of $20-50 \%$.

On the other hand, when assessing the WTO effect on trade, Eicher and Henn (2009) reiterate the importance of controlling for unobserved bilateral heterogeneity to help further reduce omitted variable bias. They argue that a bilateral relationship is typically defined by characteristics extending beyond distance, geography and others that can be explicitly controlled, for examples cultural, personal, political and/or civic factors.

In practice, Cheng and Wall (2005) show that using standard pooled-cross-section methods to estimate gravity models of trade typically suffers from omitted or misspecification bias. Unless heterogeneity is accounted for correctly, gravity models can greatly overestimate the effects of integration on trade flows. To alleviate these problems, they suggest using a 
two-way fixed-effects model with country-pair and period dummies to reflect the bilateral relationship between trading partners.

Against these concerns on estimating gravity models, we will specify our model by introducing a country-pair dummy to capture unobserved country-pair heterogeneity. As in Rose (2004) and Rose (2006), we will also incorporate a period dummy to capture the changing trade costs over time to reflect multilateral resistance so as to minimise omitted bias as far as possible. Nevertheless, we are also aware that by introducing a country-pair dummy also significantly increases the number of parameters estimated and thus loses a large degree of freedom.

\subsubsection{Specification}

The basic model to be estimated is an augmented gravity model as specified in Rose (2004) and is further extended to incorporate regulation variables as below:

$$
\begin{aligned}
\ln f d i_{i j t}= & \beta_{0}+\beta_{1} G R A V_{i j t}+\beta_{2} R E G_{j t}+\beta_{3} R T A_{i j t} \\
& +\beta_{4} \text { REGION }_{j}+\beta_{5} \text { EASIA }_{i}+u_{i j}+\delta_{t}+\varepsilon_{i j t}
\end{aligned}
$$

The dependent variable is defined as before. Subscripts $i, j$ and $t$ represent the source economy, the destination economy and time respectively. $\boldsymbol{G R} \boldsymbol{A} \boldsymbol{V}_{i j t}$ and $\boldsymbol{R} \boldsymbol{E} \boldsymbol{G}_{\boldsymbol{j} \boldsymbol{t}}$ are vectors of gravity and regulatory variables respectively. The former may include time-invarying variable like distance. $\quad \boldsymbol{R} \boldsymbol{T} \boldsymbol{A}_{i j t}$ is a dummy variable for regional trade agreement for mutual membership for economies $i$ and $j$ in year $t$. Regional dummies for the destination economies are also included. Impact of East Asian OECD economies as source is captured by the dummy variable $\boldsymbol{E A S I} \boldsymbol{A} . \quad u_{i j}$ estimates the unobserved country-pair heterogeneity. $\delta_{t}$ captures time effect. $\quad \varepsilon_{i j t}$ is the residual.

\subsubsection{Estimation Strategies}




\subsubsection{Linear Panel Data Models}

Since we have a dataset in panel form, we could estimate eq.(4.4-1) using the standard, yet most restricted, form of linear panel models - fixed effects (FE) and random effects (RE) models. In the FE model, $u_{i j}$ and $\delta_{t}$ are assumed to be fixed parameters and the stochastic disturbances are assumed to be $\varepsilon_{i j t} \sim \operatorname{IID}\left(0, \sigma_{\varepsilon}^{2}\right)$. The right-hand sided regressors, collectively called $x_{i j t}$, are assumed to be independent of the $\varepsilon_{i j t}$ for all $i$ and $t$. Although we have the unobserved individual effect $u_{i j}$ and time effect $\delta_{t}$ (i.e. two-way error component model), the estimation technique is essentially similar to that of a one-way error component model, where only the unobserved individual effect is present. In the case of a two-way error component model, using dummy variables to perform least square estimations is undesirable as we have a matrix of NT xT time dummies, where $N$ is the number of country-pair and $T$ is the number of time periods. Since $N$ is large in our case, there will be too many dummies (i.e. $[(N-1)+(T-1)])$ in the regression. This causes an enormous loss in degree of freedom.

One can obtain the Within estimator in a one-way error component model by averaging over individuals using the restriction that $\sum_{i} u_{i}=0$. For simplicity, let us denote subscript $i$ to be a panel unit, instead of $i j$ as in our specification for demonstration purpose in eqs.(4.4-2)-(4.4-3). We get

$$
\bar{y}_{. t}=\beta_{0}+\beta \bar{x}_{. t}+\delta_{t}+\bar{\varepsilon}_{. t}
$$

where $\mathrm{y}$ is the dependent variable.

By imposing $\sum_{t} \delta_{t}=0$, we can similarly deduce that

$$
\begin{aligned}
\left(y_{i t}-\bar{y}_{i .}-\bar{y}_{. t}+\bar{y}_{. .}\right)= & \left(x_{i t}-\bar{x}_{i .}-\bar{x}_{. t}+\bar{x}_{. .}\right) \beta+ \\
& \left(\varepsilon_{i t}-\bar{\varepsilon}_{i .}-\bar{\varepsilon}_{. t}+\bar{\varepsilon}_{. .}\right)
\end{aligned}
$$


One can note that the Within estimator thus obtained cannot estimate the effect of time-invariant and individual-invariant variables due to the transformation in eq.(4.4-3). However, its advantage is that it allows $u_{i j}$ be correlated with the regressors as it will be ultimately differenced away.

In a two-way random effect model $(\mathrm{RE}), u_{i j} \sim \operatorname{IID}\left(0, \sigma_{u}^{2}\right), \delta_{t} \sim \operatorname{IID}\left(0, \sigma_{\delta}^{2}\right)$ and $\varepsilon_{i j t} \sim \operatorname{IID}\left(0, \sigma_{\varepsilon}^{2}\right)$ are assumed to be independent of each other. $x_{i j t}$ is independent of $u_{i j}, \delta_{t}$ and $\varepsilon_{i j t}$. The disturbances are assumed to be homoskedastic with variances $\sigma_{u}^{2}+\sigma_{\delta}^{2}+\sigma_{\varepsilon}^{2}$.

The RE estimator is a generalised least squares (GLS) estimator. A one-way error component RE model uses both within-group (deviation from individual mean) and between-group (individual mean) variations, but weights them according to the relative sizes of $\sigma_{\varepsilon}^{2}+T_{i} \sigma_{u}^{2}$ and $\sigma_{\varepsilon}^{2}$. The estimation follows 2 steps: (i) transform $y_{i t}^{*}=y_{i t}-\theta_{i} \bar{y}_{i}$ and $x_{i t}^{*}=x_{i t}-\theta_{i} \bar{x}_{i}$ where $\theta_{i}=1-\sqrt{\frac{\sigma_{\varepsilon}^{2}}{\sigma_{\varepsilon}^{2}+T_{i} \sigma_{u}^{2}}}$; (ii) regress $y_{i t}^{*}$ on $x_{i t}^{*}$. The variance parameters of the stochastic disturbance and the individual specific term can be estimated from the within-group and between-group regression residuals.

On choosing between random effects model and fixed effects model, Hausman (1978) suggests a specification test comparing the RE estimator and the FE estimator. A rejection would be interpreted as an adoption of the fixed effects model and non-rejection as an acceptance of the random effects model. This test is done and discussed further in Appendix Section A.6.

As Greene (2008) suggests, the RE model would be appropriate if we believed that sampled cross-sectional units were drawn from a large population. The payoff of this model is that it greatly reduces the number of parameters to be estimated. The cost is the possibility of inconsistent estimates, should the 
assumption turn out to be inappropriate.

\subsubsection{Feasible Generalised Least Squares (FGLS) Estimation}

Nevertheless, it is rather typical in panel data that the covariance matrix is heteroskedastic and autocorrelated. If we ignore heteroskedasticity, the estimates of the linear panel data models are still consistent and unbiased but inefficient. If we ignore autocorrelation, the estimates would be biased and inconsistent. As it is unlikely that the variance components are known, we also adopt the FGLS procedure. It allows estimation in the presence of AR(1) autocorrelation within panels (i.e. $\varepsilon_{i j t}=\rho \varepsilon_{i j, t-1}+v_{i j t}$, where $|\rho|>1$ and cross-sectional correlation and heteroskedasticity across panels ${ }^{13}$.

\subsubsection{Hausman and Taylor Estimator}

As shown earlier, the RE model hinges heavily on the assumption that the individual effects are strictly uncorrelated with the regressors. Otherwise, modelling the individual specific constant terms as randomly distributed across cross-sectional units might be inappropriate.

In our case, it is also likely that regulatory environment and having RTA may correlate with the country-pair heterogeneity. The RE effect model may not be appropriate in this case. Using FE model can get rid of this problem completely. However, it will sweep the time-invarying variables, such as geographical and historical factors in the gravity model. To take a middle-point between FE and RE models, Hausman and Taylor (1981) propose a model where some of the explanatory variables are correlated with the unobserved individual-level random effect, while keeping the time-invarying variables in the estimation. Their model is in the form:

$$
y_{i t}=x_{1 i t}^{\prime} \beta_{1}+x_{2 i t}^{\prime} \beta_{2}+z_{1 i}^{\prime} \alpha_{1}+z_{2 i}^{\prime} \alpha_{2}+\varepsilon_{i t}+u_{i}
$$

All individual effects denoted as $z_{i}$ are observed. Hausman and Taylor define

${ }^{13}$ Technical details can be referred to Chapter 5 of Baltagi (2001). 
four sets of observed variables in the model:

- $x_{1 i t}$ is $\mathrm{K}_{1}$ variables that are time varying and uncorrelated with $u_{i}$

- $\quad z_{1 i}$ is $L_{1}$ variables that are time invariant and uncorrelated with $u_{i}$;

- $x_{2 i t}$ is $\mathrm{K}_{2}$ variables that are time varying and are correlated with $u_{i}$

- $\quad z_{2 i}$ is $L_{2}$ variables that are time invariant and are correlated with $u_{i}$

The model assumes that

$$
\begin{gathered}
E\left[u_{i} \mid x_{1 i t}, z_{i t}\right]=0 \text { although } E\left[u_{i} \mid x_{2 i t}, z_{2 i}\right] \neq 0, \\
\operatorname{var}\left[u_{i} \mid x_{1 i t}, z_{1 i}, x_{2 i t}, z_{2 i}\right]=\sigma_{u}^{2} \\
\operatorname{cov}\left[\varepsilon_{i t}, u_{i} \mid x_{1 i t}, z_{1 i}, x_{2 i t}, z_{2 i}\right]=0 \\
\operatorname{var}\left[\varepsilon_{i t}+u_{i} \mid x_{1 i t}, z_{1 i}, x_{2 i t}, z_{2 i}\right]=\sigma^{2}=\sigma_{\varepsilon}^{2}+\sigma_{u}^{2} \\
\operatorname{corr}\left[\varepsilon_{i t}+u_{i}, \varepsilon_{i s}+u_{i} \mid x_{1 i t}, z_{1 i}, x_{2 i t}, z_{2 i}\right]=\rho=\sigma_{u}^{2} / \sigma^{2}
\end{gathered}
$$

The strategy for estimation, first by taking deviations from group means,

$$
y_{i t}-\bar{y}_{i .}=\left(x_{1 i t}-\bar{x}_{1 i .}\right)^{\prime} \beta_{1}+\left(x_{2 i t}-\bar{x}_{2 i .}\right)^{\prime} \beta_{2}+\varepsilon_{i t}-\bar{\varepsilon}_{i .}
$$

which implies that the Bs can be consistently estimated by least squares (as in FE model), in spite of the correlation between $x_{2}$ and $u$. For efficiency, the authors show that the group mean deviations can be used as $\left(K_{1}+K_{2}\right)$ instrumental variables for estimation of $(\beta, \alpha)$. Because $z_{1}$ is uncorrelated with the disturbances, it can likewise serve as a set of $L_{1}$ instrumental variables. Group means for $x_{1}$ can serve as the remaining instruments for $L_{2}$. For identification purposes, then $K_{1}$ must be at least as large as $L_{2}{ }^{14}$.

\footnotetext{
${ }^{14}$ Greene (2008) (p.338) provides a summary of steps for consistent and efficient estimation of the model.
} 
The main advantage of the Hausman and Taylor approach is that one does not have to use external instruments, but has to identify the endogenous variables. Moreover, it combines the advantage of taking into account the fixed effect and keeping the time-invariant variables in the equation.

\subsubsection{Two Stage Least Squares Instrumental Variable (IV) estimation}

Endogeneity causes inconsistency of the least square estimates and requires instrumental variable methods like two-stage least squares (2SLS) to obtain consistent parameter estimates. Given some of the right-hand-side covariates are potentially endogenous, we also consider to deploy estimators using two-stage least-squares generalizations of simple panel-data estimators for exogenous variables as described in Baltagi (1981).

As compared to Fixed effects IV (FE2SLS) and random effects IV (RE2SLS), Baltagi (1981)'s error component two-stage least squares (EC2SLS) estimates are preferred in our case. While FE2SLS cannot provide estimates for time invariant variables, this would not be desirable for our case. By contrast, Baltagi's EC2SLS is a matrix-weighted average of between 2SLS and fixed effects 2SLS.

It should be noted that although both Hausman and Taylor estimator and IV estimator use the method of instrumental variables, they have different underlying assumptions. The IV estimator assumes that a subset of the explanatory variables in the model is correlated with the idiosyncratic error $\varepsilon_{\mathrm{it}}$. In contrast, the Hausman and Taylor estimator assumes that some of the explanatory variables are correlated with the individual-level random effects $u_{i}$, but that none of the explanatory variables are correlated with the idiosyncratic error $\varepsilon_{i t}$. In short, they are designed to tackle different assumptions. In practice, Hausman and Taylor estimator uses "internal" transformed endogenous variables and exogenous variables as instruments. IV estimator, on the other hand, seeks "external" instruments. 
In retrospect, our empirical study first starts from estimating the gravity model in eq.(4.4-1) using pooled OLS. We proceed to panel analysis, starting from RE and FE models and further extend to FGLS and Hausman and Taylor (1981) estimators to take into account of the problem of autocorrelation and correlation between unobserved country-pair effect and regressors. Finally, to tackle endogeneity, we also perform IV estimations. In the following, unless otherwise stated, all panel data analyses incorporate country-pair and period-specific effects. Estimations using inter-OECD and intra-OECD sub-samples will also be carried out to test the sensitivity of our results.

\subsection{Results}

\subsubsection{Pooled Regressions}

We first estimate the augmented gravity model as specified in eq.(4.4-1) by pooled regression using OLS. Such estimation will ignore the country-pair heterogeneity, as a result leading to bias results. However, as a preliminary test and check if the gravity model works, we start from the OLS estimations and intend to suggest that we cannot ignore the country-pair heterogeneity. The results are presented as Models OLS(1) - OLS(4) in Table 4.5.1-1. 
Table 4.5.1-1: Pooled OLS Regression Results: Full Sample

\begin{tabular}{|c|c|c|c|c|}
\hline Model & OLS(1) & OLS(2) & OLS(3) & OLS(4) \\
\hline $\ln \left(\mathrm{GDP}_{\mathrm{i}}\right)$ & $\begin{array}{c}2.9954 * * * \\
(0.0268)\end{array}$ & $\begin{array}{c}2.9764 * * * \\
(0.0267)\end{array}$ & $\begin{array}{c}3.1574 * * * \\
(0.0318)\end{array}$ & $\begin{array}{c}3.1344 * * * \\
(0.0317)\end{array}$ \\
\hline $\ln \left(\mathrm{GDP}_{\mathrm{j}}\right)$ & $\begin{array}{c}0.9458 * * * \\
(0.0317)\end{array}$ & $\begin{array}{c}0.9605 * * * \\
(0.0318)\end{array}$ & $\begin{array}{c}0.7488 * * * \\
(0.0436)\end{array}$ & $\begin{array}{c}0.7552 * * * \\
(0.0435)\end{array}$ \\
\hline $\ln \left(\mathrm{POP}_{\mathrm{i}}\right)$ & $\begin{array}{c}-1.8325 * * * \\
(0.0294)\end{array}$ & $\begin{array}{c}-1.8214 * * * \\
(0.0293)\end{array}$ & $\begin{array}{c}-1.9473 * * * \\
(0.0357)\end{array}$ & $\begin{array}{c}-1.9297 * * * \\
(0.0355)\end{array}$ \\
\hline $\ln \left(\mathrm{POP}_{\mathrm{j}}\right)$ & $\begin{array}{c}-0.1004 * * * \\
(0.0326)\end{array}$ & $\begin{array}{c}-0.1249 * * * \\
(0.0328)\end{array}$ & $\begin{array}{c}0.1966^{* * *} \\
(0.0464)\end{array}$ & $\begin{array}{c}0.1800 * * * \\
(0.0464)\end{array}$ \\
\hline $\ln$ (Dist) & $\begin{array}{c}-0.9691 * * * \\
(0.0228)\end{array}$ & $\begin{array}{c}-0.9125^{* * *} \\
(0.0242)\end{array}$ & $\begin{array}{c}-1.1413 * * * \\
(0.0300)\end{array}$ & $\begin{array}{c}-1.0887 * * * \\
(0.0316)\end{array}$ \\
\hline Landlock & $\begin{array}{c}0.0474 \\
(0.0388)\end{array}$ & $\begin{array}{c}0.1116 * * * \\
(0.0403)\end{array}$ & $\begin{array}{c}0.2487 * * * \\
(0.0495)\end{array}$ & $\begin{array}{c}0.3073 * * * \\
(0.0509)\end{array}$ \\
\hline Colony $_{\mathrm{ij}}$ & $\begin{array}{c}1.3014 * * * \\
(0.0807)\end{array}$ & $\begin{array}{c}1.3275^{* * *} * \\
(0.0801)\end{array}$ & $\begin{array}{c}1.3664 * * * \\
(0.1071)\end{array}$ & $\begin{array}{c}1.3906^{* * *} * \\
(0.1065)\end{array}$ \\
\hline Common Lang & $\begin{array}{c}1.1063 * * * \\
(0.0497)\end{array}$ & $\begin{array}{c}1.1042 * * * \\
(0.0492)\end{array}$ & $\begin{array}{c}0.7956 * * * \\
(0.0656)\end{array}$ & $\begin{array}{c}0.7952 * * * \\
(0.0647)\end{array}$ \\
\hline Common Coloniser & $\begin{array}{c}4.7286 * * * \\
(0.1692)\end{array}$ & $\begin{array}{c}4.7065 * * * \\
(0.1694)\end{array}$ & $\begin{array}{c}4.2028 * * * \\
(0.1368)\end{array}$ & $\begin{array}{c}4.1854 * * * \\
(0.1360)\end{array}$ \\
\hline Island & $\begin{array}{c}0.0195 \\
(0.0433)\end{array}$ & $\begin{array}{c}0.0499 \\
(0.0433)\end{array}$ & $\begin{array}{l}-0.0691 \\
(0.0611)\end{array}$ & $\begin{array}{l}-0.0394 \\
(0.0607)\end{array}$ \\
\hline Border & $\begin{array}{c}0.3972 * * * \\
(0.0711)\end{array}$ & $\begin{array}{c}0.4036 * * * \\
(0.0713)\end{array}$ & $\begin{array}{c}0.4327 * * * \\
(0.0980)\end{array}$ & $\begin{array}{c}0.4356 * * * \\
(0.0983)\end{array}$ \\
\hline $\ln \left(\right.$ Area $\left._{\mathrm{ij}}\right)$ & $\begin{array}{c}-0.0460 * * * \\
(0.0091)\end{array}$ & $\begin{array}{c}-0.0413 * * * \\
(0.0091)\end{array}$ & $\begin{array}{c}-0.0529 * * * \\
(0.0121)\end{array}$ & $\begin{array}{c}-0.0485 * * * \\
(0.0121)\end{array}$ \\
\hline RTA & & $\begin{array}{c}0.3959 * * * \\
(0.0529)\end{array}$ & & $\begin{array}{c}0.3863 * * * \\
(0.0671)\end{array}$ \\
\hline $\begin{array}{l}\text { REG } \\
\text { (catch-all) }\end{array}$ & & & $\begin{array}{c}0.5565 * * * \\
(0.0311)\end{array}$ & $\begin{array}{c}0.5575 * * * \\
(0.0311)\end{array}$ \\
\hline Obs & 15876 & 15876 & 9210 & 9210 \\
\hline Adj. R-sq & 0.695 & 0.696 & 0.722 & 0.723 \\
\hline
\end{tabular}

The dependent variable is Infdi. Regional dummies with year effects are included. Intercepts are not reported. Robust standard errors are in parentheses. $* * *, * *$ and $*$ denote significance levels at $1 \%, 5 \%$ and $10 \%$ respectively.

It is shown that the gravity variables generally fit well in explaining bilateral FDI. Gravity variables (including region and time dummies) alone account for about $70 \%$ of bilateral FDI in our sample data (see Model OLS(1)). Economic sizes of both source and destination economies are significantly and positively related to FDI while geographical distance, as expected, is negatively related. Populations in both source and destination economies, contrary to our expectation, is negatively related to FDI. In our sample, therefore, it suggests that economies with smaller populations attract more FDI from OECD economies. In particular, the effect is more prominent for the source economies having small population. However, we note that in Model 
OLS(4), a larger population in the destination economy actually attracts more FDI. This suggests the possible market size effect.

On geographical characteristics, both economies sharing common border is also conducive to bilateral FDI. The cross-product of land area is also negatively related to FDI. These indicate a negative and significant impact of high transport costs on attracting FDI. Landlocked economies in our sample show significant and positive results on attracting FDI. In our sample, the landlocked economies are more likely to share national borders with other countries and are thus more likely to attract FDI nearby due to lower transport costs as a result of geographical proximity. Island economy, generally believed to have higher transport costs, does not show any significant impact on FDI in our estimations. In fact, the estimation results on this variable are quite sensitive to additional covariates. Its coefficients are positive in Models OLS (1) and (2), but negative in Models OLS (3) and (4).

Cultural and historical ties between the economy pair also matter for FDI. Colonial relationship of the pair, sharing common language and having common colonizer all positively and significantly determine inward investment between the country pair.

Model OLS(4) is the final specification of our interest, with $\boldsymbol{R T A}$ and the “catch-all" regulation index $\boldsymbol{R} \boldsymbol{E} \boldsymbol{G}$ incorporated. The results show that, despite controlling for all the factors of natural barriers, forming a RTA with the source economy and domestic regulatory environment of the destination economy remain to be significantly positive to FDI.

To test the sensitivity of the results, we further divide the sample into intra-OECD and inter-OECD bilateral FDI stock and perform pooled OLS estimations again (as shown in Models OLS(5) - (12) in Table 4.5.1-2 - Table 4.5.1-3 respectively). The results do not show striking difference. 
Table 4.5.1-2: Pooled OLS Regression Results: Intra-OECD Sample

\begin{tabular}{|c|c|c|c|c|}
\hline Model & OLS(5) & OLS(6) & OLS(7) & OLS(8) \\
\hline$\overline{\ln \left(\mathrm{GDP}_{\mathrm{i}}\right)}$ & $\begin{array}{c}.2672 * * * \\
(0.0340)\end{array}$ & $\begin{array}{c}3.2406 * * * \\
(0.0356)\end{array}$ & $\begin{array}{c}.4231 * * * \\
(0.0425)\end{array}$ & $\begin{array}{c}3.3915 * * * \\
(0.0430)\end{array}$ \\
\hline $\ln \left(\mathrm{GDP}_{\mathrm{j}}\right)$ & $\begin{array}{c}1.0563 * * * \\
(0.0310)\end{array}$ & $\begin{array}{c}1.0802 * * * \\
(0.0667)\end{array}$ & $\begin{array}{c}0.6549 * * * \\
(0.0984)\end{array}$ & $\begin{array}{c}0.7378 * * * \\
(0.0987)\end{array}$ \\
\hline $\ln \left(\mathrm{POP}_{\mathrm{i}}\right)$ & $\begin{array}{c}-2.1639 * * * \\
(0.0362)\end{array}$ & $\begin{array}{c}-2.1483 * * * \\
(0.0379)\end{array}$ & $\begin{array}{c}-2.2558 * * * \\
(0.0463)\end{array}$ & $\begin{array}{c}-2.2362 * * * \\
(0.0462)\end{array}$ \\
\hline $\ln \left(\mathrm{POP}_{\mathrm{j}}\right)$ & $\begin{array}{c}-0.2450 * * * \\
(0.0357)\end{array}$ & $\begin{array}{c}-0.2627 * * * \\
(0.0720)\end{array}$ & $\begin{array}{c}0.2413^{* *} \\
(0.1062)\end{array}$ & $\begin{array}{c}0.1485 \\
(0.1069)\end{array}$ \\
\hline $\ln$ (Dist) & $\begin{array}{c}-1.0772 * * * \\
(0.0316)\end{array}$ & $\begin{array}{c}-0.9372 * * * \\
(0.0366)\end{array}$ & $\begin{array}{c}-1.0914 * * * \\
(0.0503)\end{array}$ & $\begin{array}{c}-1.0408 * * * \\
(0.0501)\end{array}$ \\
\hline Landlock & $\begin{array}{c}0.0166 \\
(0.0456)\end{array}$ & $\begin{array}{l}0.0876^{*} \\
(0.0529)\end{array}$ & $\begin{array}{l}-0.0317 \\
(0.0654)\end{array}$ & $\begin{array}{c}0.0494 \\
(0.0687)\end{array}$ \\
\hline Colony $_{\mathrm{ij}}$ & $\begin{array}{c}1.0666^{* * *} \\
(0.1107)\end{array}$ & $\begin{array}{c}1.0218 * * * \\
(0.1091)\end{array}$ & $\begin{array}{c}0.8034 * * * \\
(0.1489)\end{array}$ & $\begin{array}{c}0.8372 * * * \\
(0.1471)\end{array}$ \\
\hline Common Lang & $\begin{array}{c}1.4241 * * * \\
(0.0667)\end{array}$ & $\begin{array}{c}1.4906 * * * \\
(0.0658)\end{array}$ & $\begin{array}{c}1.0589 * * * \\
(0.0985)\end{array}$ & $\begin{array}{c}1.0565 * * * \\
(0.0967)\end{array}$ \\
\hline Common Coloniser & $\begin{array}{c}5.3003 * * * \\
(0.1676)\end{array}$ & $\begin{array}{c}5.2805 * * * \\
(0.1686)\end{array}$ & $\begin{array}{c}4.9434 * * * \\
(0.1719)\end{array}$ & $\begin{array}{c}4.8882 * * * \\
(0.1688)\end{array}$ \\
\hline Island & $\begin{array}{c}-0.3318 * * * \\
(0.0615)\end{array}$ & $\begin{array}{c}-0.3687 * * * \\
(0.0626)\end{array}$ & $\begin{array}{c}-0.6850 * * * \\
(0.0918)\end{array}$ & $\begin{array}{c}-0.6474 * * * \\
(0.0912)\end{array}$ \\
\hline Border & $\begin{array}{c}-0.1499 * * \\
(0.0723)\end{array}$ & $\begin{array}{c}-0.0772 \\
(0.0741)\end{array}$ & $\begin{array}{c}0.0761 \\
(0.1021)\end{array}$ & $\begin{array}{c}0.0886 \\
(0.1012)\end{array}$ \\
\hline $\ln \left(\right.$ Area $\left._{\mathrm{ij}}\right)$ & $\begin{array}{c}0.0540 * * * \\
(0.0130)\end{array}$ & $\begin{array}{l}0.0374 * * \\
(0.0156)\end{array}$ & $\begin{array}{c}-0.0541 * * \\
(0.0212)\end{array}$ & $\begin{array}{c}-0.0433 * * \\
(0.0215)\end{array}$ \\
\hline RTA & & $\begin{array}{c}0.4425 * * * \\
(0.0594)\end{array}$ & & $\begin{array}{c}0.3344 * * * \\
(0.0780)\end{array}$ \\
\hline $\begin{array}{l}\text { REG } \\
\text { (catch-all) }\end{array}$ & & & $\begin{array}{c}0.7973 * * * \\
(0.0404)\end{array}$ & $\begin{array}{c}0.7913 * * * \\
(0.0403)\end{array}$ \\
\hline Obs & 9180 & 9180 & 5055 & 5055 \\
\hline Adj. R-sq & 0.722 & 0.725 & 0.754 & 0.754 \\
\hline
\end{tabular}

The dependent variable is Infdi. Regional dummies with year effects are included. Intercepts are not reported. Robust standard errors are in parentheses. $* * *, * *$ and $*$ denote significance levels at $1 \%, 5 \%$ and $10 \%$ respectively. 
Table 4.5.1-3: Pooled OLS Regression Results: Inter-OECD Sample

\begin{tabular}{|c|c|c|c|c|}
\hline Model & OLS(9) & OLS(10) & OLS(11) & OLS(12) \\
\hline $\ln \left(\mathrm{GDP}_{\mathrm{i}}\right)$ & $\begin{array}{c}2.7718 * * * \\
(0.0387)\end{array}$ & $\begin{array}{c}2.7629 * * * \\
(0.0387)\end{array}$ & $\begin{array}{c}2.9889 * * * \\
(0.0446)\end{array}$ & $\begin{array}{c}2.9786 * * * \\
(0.0447)\end{array}$ \\
\hline $\ln \left(\mathrm{GDP}_{\mathrm{j}}\right)$ & $\begin{array}{c}1.4514 * * * \\
(0.0522)\end{array}$ & $\begin{array}{c}1.4403 * * * \\
(0.0522)\end{array}$ & $\begin{array}{c}1.3064 * * * \\
(0.0694)\end{array}$ & $\begin{array}{c}1.2897 * * * \\
(0.0698)\end{array}$ \\
\hline $\ln \left(\mathrm{POP}_{\mathrm{i}}\right)$ & $\begin{array}{c}-1.5390 * * * \\
(0.0451)\end{array}$ & $\begin{array}{c}-1.5340 * * * \\
(0.0451)\end{array}$ & $\begin{array}{c}-1.7253 * * * \\
(0.0529)\end{array}$ & $\begin{array}{c}-1.7208 * * * \\
(0.0530)\end{array}$ \\
\hline $\ln \left(\mathrm{POP}_{\mathrm{j}}\right)$ & $\begin{array}{c}-0.4386^{* * *} \\
(0.0427)\end{array}$ & $\begin{array}{c}-0.4284 * * * \\
(0.0429)\end{array}$ & $\begin{array}{c}-0.1781 * * * \\
(0.0641)\end{array}$ & $\begin{array}{c}-0.1675 * * * \\
(0.0644)\end{array}$ \\
\hline $\ln$ (Dist) & $\begin{array}{c}-1.0490 * * * \\
(0.0470)\end{array}$ & $\begin{array}{c}-1.0429 * * * \\
(0.0470)\end{array}$ & $\begin{array}{c}-1.2739 * * * \\
(0.0570)\end{array}$ & $\begin{array}{c}-1.2628 * * * \\
(0.0573)\end{array}$ \\
\hline Landlock & $\begin{array}{c}0.2094 * * * \\
(0.0777)\end{array}$ & $\begin{array}{c}0.1959 * * \\
(0.0777)\end{array}$ & $\begin{array}{c}0.6253 * * * \\
(0.0946)\end{array}$ & $\begin{array}{c}0.6098 * * * \\
(0.0949)\end{array}$ \\
\hline Colony $_{\mathrm{ij}}$ & $\begin{array}{c}1.5629 * * * \\
(0.1113)\end{array}$ & $\begin{array}{c}1.5744 * * * \\
(0.1111)\end{array}$ & $\begin{array}{c}1.8061 * * * \\
(0.1484)\end{array}$ & $\begin{array}{c}1.8157 * * * \\
(0.1482)\end{array}$ \\
\hline Common Lang & $\begin{array}{c}0.6180 * * * \\
(0.0727)\end{array}$ & $\begin{array}{c}0.5999 * * * \\
(0.0731)\end{array}$ & $\begin{array}{c}0.4398 * * * \\
(0.0925)\end{array}$ & $\begin{array}{c}0.4208 * * * \\
(0.0926)\end{array}$ \\
\hline Island & $\begin{array}{c}0.5396 * * * \\
(0.0642)\end{array}$ & $\begin{array}{c}0.5333 * * * \\
(0.0641)\end{array}$ & $\begin{array}{c}0.5574 * * * \\
(0.0895)\end{array}$ & $\begin{array}{c}0.5368 * * * \\
(0.0898)\end{array}$ \\
\hline Border & $\begin{array}{c}2.8389 * * * \\
(0.1943)\end{array}$ & $\begin{array}{c}2.8341 * * * \\
(0.1942)\end{array}$ & $\begin{array}{c}2.8731 * * * \\
(0.2096)\end{array}$ & $\begin{array}{c}2.8705^{* * *} * \\
(0.2094)\end{array}$ \\
\hline $\ln \left(\right.$ Area $\left._{\mathrm{ij}}\right)$ & $\begin{array}{c}-0.1130 * * * \\
(0.0184)\end{array}$ & $\begin{array}{c}-0.1130 * * * \\
(0.0184)\end{array}$ & $\begin{array}{c}-0.0717 * * * \\
(0.0245)\end{array}$ & $\begin{array}{c}-0.0698 * * * \\
(0.0244)\end{array}$ \\
\hline RTA & & $\begin{array}{c}0.5308 * * * \\
(0.1561)\end{array}$ & & $\begin{array}{c}0.4920 * * * \\
(0.1699)\end{array}$ \\
\hline $\begin{array}{l}\text { REG } \\
\text { (catch-all) }\end{array}$ & & & $\begin{array}{c}0.3539 * * * \\
(0.0521)\end{array}$ & $\begin{array}{c}0.3489 * * * \\
(0.0521)\end{array}$ \\
\hline Obs & 6696 & 6696 & 4155 & 4155 \\
\hline Adj. R-sq & 0.663 & 0.664 & 0.68 & 0.681 \\
\hline
\end{tabular}

The dependent variable is $\boldsymbol{I n f d i}$. Regional dummies with year effects are included. Dummy for common coloniser is dropped from the specification due to nil sample. Intercepts are not reported. Robust standard errors are in parentheses. $* * *, * *$ and $*$ denote significance levels at $1 \%, 5 \%$ and $10 \%$ respectively.

The gravity variables alone fit the model slightly better with adjusted $\mathrm{R}^{2}=$ 0.722 for the intra-OECD sub-sample (comparing Models OLS(1) vs. OLS(5)) but only 0.663 for the inter-OECD sub-sample (comparing Models OLS(1) vs. $\operatorname{OLS}(9))$.

We concentrate our discussion on the full baseline models (i.e. Models OLS(8) and OLS(12)). With regard to geographical variables, landlocked economies in the intra-OECD sample do not have any significant result, but it carries a significantly positive impact in the inter-OECD sample. It suggests that landlocked non-OECD economy attracts more FDI than the non-landlocked ones. Island economies on the other hand carry significantly negative impact 
on FDI in the intra-OECD sample but significantly positive impact in the inter-OECD sample. Theoretically, an island economy may reflect certain level of isolation in the region and thus it may incur higher transport costs for others to access the entity. Nevertheless, having a coastal line by its very own nature may also imply easier access for foreign goods and capital. The effect of being an island economy on FDI is therefore ambiguous, as shown in our dataset. Having a common border significantly determines FDI in the inter-OECD region, whereas such effect is not significant in the intra-OECD region. In both sub-samples, physical areas are negatively related to FDI. It possibly reflects the higher transport costs from one economic centre to another.

Cultural ties significantly explain bilateral FDI in both samples. If the FDI destination economy and the source were ever in a colonial relationship, the volume of FDI is also likely to be greater. Such effect is comparatively more prominent in the inter-OECD region as expected since there are very few OECD countries ever in a colonial relationship with each other. In contrast, the effects of common language and having a common coloniser play a more significant role in the intra-OECD sub-sample, demonstrating that the effect of cultural ties are equally played between the rich country pair. All these effects are statistically significant at $1 \%$ level in both sub-samples.

On the variables of our interest - $\boldsymbol{R} \boldsymbol{T A}$ and $\boldsymbol{R E G}$, the baseline specifications using the three sets of samples (i.e. Models OLS(4) vs. OLS(8) vs. OLS(12)) are largely consistent. The coefficients remain statistically significant. Comparing the two sub-samples, we find that the coefficients of $\boldsymbol{R} \boldsymbol{E} \boldsymbol{G}$ impose a much greater impact on FDI in the intra-OECD sample than that in the inter-OECD sample. It signifies that domestic regulatory environment comparatively explains intra-OECD FDI more. Amongst the intra-OECD countries, those with better domestic regulatory environment are also more likely to attract FDI. In contrast, the coefficient of $\boldsymbol{R} \boldsymbol{T A}$ is slightly bigger in the inter-OECD sample. In other words, for inter-OECD region, FDI from OECD economies is more responsive to $\boldsymbol{R} \boldsymbol{T} \boldsymbol{A}$ than the domestic regulatory environment of the destination economy. 


\subsubsection{Linear Panel Data Regressions}

As shown above, all OLS results point to the positive association of regional integration and favourable regulatory environment with FDI. Nevertheless, as discussed before, pooled regressions ignore country-pair specific heterogeneity. In addition, this does not take into account multilateral resistance. All these may inflate the coefficients on $\boldsymbol{R} \boldsymbol{T A}$ and $\boldsymbol{R} \boldsymbol{E} \boldsymbol{G}$ and lead to biased inference. Hence, we proceed to undertake our panel data analyses. We start from the most restricted FE and RE models. Comparing the test results between OLS and FE estimates, as well as between OLS and RE estimates allows us to test if the country-pair specific heterogeneity is present or not. Breusch and Pagen Lagrangian multiplier test is used to test the RE estimate as against that of OLS. The F-test is used to test the FE estimates as against the one from OLS. These diagnostic test results are shown in Appendix Section A.6. Both tests suggest that country-specific heterogeneity cannot be ignored and pooled regressions are therefore not preferred.

Since most of the gravity variables for capturing geographical factors and cultural ties are time invariant, FE model cannot assess their effects individually since these characteristics will be absorbed into the fixed effects. Nevertheless, we have still performed the fixed effect estimations for the sake of comparison.

RE and FE estimations with country-pair specific effect and time-specific effect are shown in Table 4.5.2-1 and Table 4.5.2-2 respectively. To compare the results on the gravity variables, we can only make reference to the OLS results and RE results obtained. Generally speaking, the magnitudes of the gravity variables in the RE models do not show significant differences as compared to that in the pooled OLS regressions (Models OLS(4) vs. RE(1)). The signs and the magnitudes of the coefficients are largely similar.

However, the coefficients of both $\boldsymbol{R} \boldsymbol{T} \boldsymbol{A}$ and $\boldsymbol{R} \boldsymbol{E} \boldsymbol{G}$ systematically become smaller in the RE models, but they remain statistically significant at $1 \%$ level. 
The coefficients on $\boldsymbol{R T A}$ fell from 0.37 in Model OLS(4) to 0.25 in Model $\mathrm{RE}(1)$. The coefficients on $\boldsymbol{R} \boldsymbol{E} \boldsymbol{G}$ in the corresponding models decrease even more notably from 0.56 to 0.29 .

Table 4.5.2-1: RE Models for Full Sample

\begin{tabular}{|c|c|c|c|c|}
\hline Model & $\underline{\operatorname{RE}(1)}$ & $\underline{\mathrm{RE}(2)}$ & RE(3) & RE(4) \\
\hline $\ln \left(\mathrm{GDP}_{\mathrm{i}}\right)$ & $\begin{array}{c}2.8304 * * * \\
(0.0802)\end{array}$ & $\begin{array}{c}2.8262 * * * \\
(0.0804)\end{array}$ & $\begin{array}{c}2.8329 * * * \\
(0.0812)\end{array}$ & $\begin{array}{c}2.7999 * * * \\
(0.0844)\end{array}$ \\
\hline $\ln \left(\mathrm{GDP}_{\mathrm{j}}\right)$ & $\begin{array}{c}1.0977 * * * \\
(0.0861)\end{array}$ & $\begin{array}{c}1.0642 * * * \\
(0.0864)\end{array}$ & $\begin{array}{c}1.3304 * * * \\
(0.0866)\end{array}$ & $\begin{array}{c}1.2524 * * * \\
(0.0929)\end{array}$ \\
\hline $\ln \left(\mathrm{POP}_{\mathrm{i}}\right)$ & $\begin{array}{c}-1.5873 * * * \\
(0.0861)\end{array}$ & $\begin{array}{c}-1.5792 * * * \\
(0.0869)\end{array}$ & $\begin{array}{c}-1.5766 * * * \\
(0.0888)\end{array}$ & $\begin{array}{c}-1.5347 * * * \\
(0.0927)\end{array}$ \\
\hline $\ln \left(\mathrm{POP}_{\mathrm{j}}\right)$ & $\begin{array}{c}-0.2363 * * \\
(0.0942)\end{array}$ & $\begin{array}{c}-0.2201 * * \\
(0.0943)\end{array}$ & $\begin{array}{c}-0.4762 * * * \\
(0.0937)\end{array}$ & $\begin{array}{c}-0.3746 * * * \\
(0.0996)\end{array}$ \\
\hline $\ln ($ Dist $)$ & $\begin{array}{c}-1.2150 * * * \\
(0.0815)\end{array}$ & $\begin{array}{c}-1.1667 * * * \\
(0.0814)\end{array}$ & $\begin{array}{c}-1.1834 * * * \\
(0.0818)\end{array}$ & $\begin{array}{c}-1.1891 * * * \\
(0.0835)\end{array}$ \\
\hline Landlock & $\begin{array}{c}0.3228 * * \\
(0.1411)\end{array}$ & $\begin{array}{c}0.3648 * * \\
(0.1421)\end{array}$ & $\begin{array}{l}0.3321 * * \\
(0.1423)\end{array}$ & $\begin{array}{l}0.3184 * * \\
(0.1488)\end{array}$ \\
\hline Colony $_{\mathrm{ij}}$ & $\begin{array}{c}1.7521 * * * \\
(0.3033)\end{array}$ & $\begin{array}{c}1.7440 * * * \\
(0.3096)\end{array}$ & $\begin{array}{c}1.7823 * * * \\
(0.3156)\end{array}$ & $\begin{array}{c}1.7651 * * * \\
(0.3221)\end{array}$ \\
\hline Common Lang & $\begin{array}{c}0.8074 * * * \\
(0.1802)\end{array}$ & $\begin{array}{c}0.8617 * * * \\
(0.1826)\end{array}$ & $\begin{array}{c}0.8318 * * * \\
(0.1837)\end{array}$ & $\begin{array}{c}0.8232 * * * \\
(0.1858)\end{array}$ \\
\hline Common Coloniser & $\begin{array}{c}3.7050 * * * \\
(0.3584)\end{array}$ & $\begin{array}{c}3.7776 * * * \\
(0.4534)\end{array}$ & $\begin{array}{c}3.7070 * * * \\
(0.3946)\end{array}$ & $\begin{array}{c}3.7169 * * * \\
(0.4242)\end{array}$ \\
\hline Island & $\begin{array}{c}0.0596 \\
(0.1429)\end{array}$ & $\begin{array}{c}0.061 \\
(0.1443)\end{array}$ & $\begin{array}{c}0.0798 \\
(0.1415)\end{array}$ & $\begin{array}{c}0.0898 \\
(0.1414)\end{array}$ \\
\hline Border & $\begin{array}{l}0.4867^{*} \\
(0.2583)\end{array}$ & $\begin{array}{l}0.4874 * \\
(0.2590)\end{array}$ & $\begin{array}{l}0.4708 * \\
(0.2679)\end{array}$ & $\begin{array}{l}0.4661 * \\
(0.2690)\end{array}$ \\
\hline $\ln \left(\right.$ Area $\left._{\mathrm{ij}}\right)$ & $\begin{array}{l}-0.0211 \\
(0.0305)\end{array}$ & $\begin{array}{l}-0.0239 \\
(0.0307)\end{array}$ & $\begin{array}{l}-0.0313 \\
(0.0310)\end{array}$ & $\begin{array}{l}-0.0459 \\
(0.0311)\end{array}$ \\
\hline RTA & $\begin{array}{c}0.2455^{* * *} \\
(0.0819)\end{array}$ & $\begin{array}{c}0.2685 * * * \\
(0.0824)\end{array}$ & $\begin{array}{c}0.2754 * * * \\
(0.0844)\end{array}$ & $\begin{array}{c}0.1477 \\
(0.0999)\end{array}$ \\
\hline $\begin{array}{l}\text { REG } \\
\text { (catch-all) }\end{array}$ & $\begin{array}{c}0.2902 * * * \\
(0.0330)\end{array}$ & & & \\
\hline Credit Reg & & $\begin{array}{c}0.1711 * * * \\
(0.0200)\end{array}$ & & \\
\hline Labour Reg & & & $\begin{array}{c}0.0598 * * * \\
(0.0174)\end{array}$ & \\
\hline Business Reg & & & & $\begin{array}{c}0.0393 * * \\
(0.0193)\end{array}$ \\
\hline $\begin{array}{l}\text { Obs } \\
\text { chi2 } \\
\text { p-value }\end{array}$ & $\begin{array}{c}9210 \\
9475 \\
{[0.0000]}\end{array}$ & $\begin{array}{c}9211 \\
9481 \\
{[0.0000]}\end{array}$ & $\begin{array}{c}8967 \\
8938 \\
{[0.0000]}\end{array}$ & $\begin{array}{c}8517 \\
6549 \\
{[0.0000]}\end{array}$ \\
\hline
\end{tabular}

The dependent variable is $\boldsymbol{I n f d i}$. Regional dummies with year effects are included. Intercepts are not reported. Robust standard errors are in parentheses, clustering by country-pairs. ***, ** and $*$ denote significance levels at $1 \%, 5 \%$ and $10 \%$ respectively. 
Table 4.5.2-2: FE Models for Full Sample

\begin{tabular}{|c|c|c|c|c|}
\hline Model & FE(1) & FE(2) & FE(3) & FE(4) \\
\hline$\overline{\ln \left(\mathrm{GDP}_{\mathrm{i}}\right)}$ & $\begin{array}{c}2.0998 * * * \\
(0.2484)\end{array}$ & $\begin{array}{c}2.0883 * * * \\
(0.2438)\end{array}$ & $\begin{array}{c}1.9803 * * * \\
(0.2665)\end{array}$ & $\begin{array}{l}0.5548^{*} \\
(0.3133)\end{array}$ \\
\hline $\ln \left(\mathrm{GDP}_{\mathrm{j}}\right)$ & $\begin{array}{c}1.3031 * * * \\
(0.1545)\end{array}$ & $\begin{array}{c}1.1217 * * * \\
(0.1542)\end{array}$ & $\begin{array}{c}1.5761 * * * \\
(0.1679)\end{array}$ & $\begin{array}{c}1.0506 * * * \\
(0.1967)\end{array}$ \\
\hline $\ln \left(\mathrm{POP}_{\mathrm{i}}\right)$ & $\begin{array}{c}-3.0266^{* * *} \\
(0.8003)\end{array}$ & $\begin{array}{c}-2.9762 * * * \\
(0.7916)\end{array}$ & $\begin{array}{c}-2.7927 * * * \\
(0.8580)\end{array}$ & $\begin{array}{c}-3.2234 * * * \\
(1.2086)\end{array}$ \\
\hline $\ln \left(\mathrm{POP}_{\mathrm{j}}\right)$ & $\begin{array}{c}-4.6574 * * * \\
(0.4152)\end{array}$ & $\begin{array}{c}-4.3910^{* * *} \\
(0.3965)\end{array}$ & $\begin{array}{c}-5.0683 * * * \\
(0.5004)\end{array}$ & $\begin{array}{c}-5.6375 * * * \\
(0.6074)\end{array}$ \\
\hline $\ln$ (Dist) & -- & -- & -- & -- \\
\hline Landlock & -- & -- & -- & -- \\
\hline Colony $_{\mathrm{ij}}$ & -- & -- & -- & -- \\
\hline Common Lang & -- & -- & -- & -- \\
\hline $\begin{array}{l}\text { Common } \\
\text { Coloniser }\end{array}$ & -- & -- & -- & -- \\
\hline Island & -- & -- & -- & -- \\
\hline Border & -- & -- & -- & -- \\
\hline $\ln \left(\right.$ Area $\left._{\mathrm{ij}}\right)$ & -- & -- & -- & -- \\
\hline$\overline{\text { RTA }}$ & $\begin{array}{c}0.1495 \\
(0.0919)\end{array}$ & $\begin{array}{l}0.1673 * \\
(0.0917)\end{array}$ & $\begin{array}{c}0.1945 * * \\
(0.0961)\end{array}$ & $\begin{array}{c}0.0975 \\
(0.1184)\end{array}$ \\
\hline $\begin{array}{l}\text { REG } \\
\text { (catch-all) }\end{array}$ & $\begin{array}{c}0.1441 * * * \\
(0.0337)\end{array}$ & & & \\
\hline Credit Reg & & $\begin{array}{c}0.1206 * * * \\
(0.0206)\end{array}$ & & \\
\hline Labour Reg & & & $\begin{array}{c}0.0028 \\
(0.0194)\end{array}$ & \\
\hline Business Reg & & & & $\begin{array}{l}-0.0014 \\
(0.0202)\end{array}$ \\
\hline Obs & 9210 & 9211 & 8967 & 8517 \\
\hline RMSE & 0.712 & 0.71 & 0.691 & 0.659 \\
\hline R-sq (within) & 0.455 & 0.46 & 0.425 & 0.302 \\
\hline
\end{tabular}

The dependent variable is Infdi. Regional dummies with year effects are included. Intercepts are not reported. Robust standard errors are in parentheses, clustering by country-pairs. $* * *, * *$ and $*$ denote significance levels at $1 \%, 5 \%$ and $10 \%$ respectively. 
In the panel analysis, we also investigate the impact of three sub-indices of $\boldsymbol{R E G}$, including Credit Reg, Labour Reg and Business Reg on FDI. As shown in Models $\mathrm{RE}(2)-\mathrm{RE}(4)$, all three measures of regulation stay statistically significant. As expected, the impact of individual sub-index is less than that of the "catch-all" aggregate measure. Yet the significant results imply that less credit regulations, labour regulations and business regulations in the destination economy are significant determinants of FDI even after controlling for country-pair heterogeneity and other factors of natural barriers. Nevertheless, the coefficients of Labour Reg and Business Reg are much smaller. This may be affected by the reduced sample size due to quite a large number of missing observations for these two sub-indices.

On $\boldsymbol{R T A}$, the only insignificant coefficient is in Model RE(4). Coefficients in the other three models are quite consistent and comparable. In overall terms, $\boldsymbol{R E} \boldsymbol{G}$ explains FDI more than $\boldsymbol{R T A}$ (see Model RE(1)). This implies that, generally speaking, domestic regulatory environment plays a more significant role in attracting FDI than having a regional trade agreement alone.

As discussed earlier, RE models restrictively assume that all the regressors are independent of the unobserved country-pair specific effect. Or else, the results will not be consistent. The results of our FE models suggest that it may be the case for our sample. As shown in Models FE(1) to FE(4), the coefficients of $\boldsymbol{R} \boldsymbol{T A}$ and $\boldsymbol{R} \boldsymbol{E} \boldsymbol{G}$ are generally smaller. The coefficients of $\boldsymbol{R} \boldsymbol{T} \boldsymbol{A}$ are even not statistically significant in Models $\mathrm{FE}(1)$ and $\mathrm{FE}(4)$. For the various measures of regulatory environment, the broad aggregate $\boldsymbol{R} \boldsymbol{E} \boldsymbol{G}$ index remains positively associating with bilateral FDI and so as Credit Reg. However, Labour Reg and Business Reg are no longer significant in Models $\mathrm{FE}(3)$ and $\mathrm{FE}(4)$.

To verify whether the RE estimations are sensitive to sample selection, RE estimates using intra-OECD and inter-OECD sub-samples are also carried out. Results on the key variables are presented below in Table 4.5.2-3 and Table 4.5.2-4. Comparing to the Models $\mathrm{RE}(1)$ - RE(4), we argue that the key results are not particularly sensitive to the sample selection. $\boldsymbol{R E G}$ and $\boldsymbol{C r e d i t}$ 
Reg of the destination economy are positively associated with FDI. Labour reg is only significant in the intra-OECD sample (i.e. Model RE(7)), but not in the inter-OECD sample (i.e Model RE(11)). It may suggest that labour costs of the developing economies are so low that labour regulation, albeit burdensome, will not hamper FDI. In developed countries, where they do not have comparative advantages on labour costs, labour regulations (i.e. institutional costs) in turn will determine foreign investors' decisions significantly. Business Reg does not have any significant impact in both sub-samples.

Table 4.5.2-3: RE Estimations by Sub-samples (Key Variables): Intra-OECD Sample

\begin{tabular}{|c|c|c|c|c|}
\hline Model & RE(5) & RE(6) & RE(7) & RE(8) \\
\hline RTA & $\begin{array}{c}0.3082 * * * \\
(0.1021)\end{array}$ & $\begin{array}{c}0.2473 * * \\
(0.1048)\end{array}$ & $\begin{array}{c}0.3512 * * * \\
(0.1035)\end{array}$ & $\begin{array}{c}0.0570 \\
(0.1319)\end{array}$ \\
\hline $\begin{array}{l}\text { REG } \\
\text { (catch-all) }\end{array}$ & $\begin{array}{c}0.2818 * * * \\
(0.0592)\end{array}$ & & & \\
\hline Credit Reg & & $\begin{array}{c}0.1968 * * * \\
(0.0430)\end{array}$ & & \\
\hline Labour Reg & & & $\begin{array}{c}0.0618 * * \\
(0.0274)\end{array}$ & \\
\hline Business Reg & & & & $\begin{array}{c}0.0212 \\
(0.0278) \\
\end{array}$ \\
\hline Obs & 5055 & 5055 & 5017 & 4656 \\
\hline chi2 & 5117 & 5096 & 4944 & 3362 \\
\hline p-value & {$[0.0000]$} & {$[0.0000]$} & {$[0.0000]$} & [0.0000] \\
\hline
\end{tabular}

The dependent variable is Infdi. Specification is eq.(4.4-1). Regional dummies with year effects are included. Results on other variables and intercepts are not shown. Robust standard errors are in parentheses, clustering by country-pairs. $* * *, * *$ and $*$ denote significance levels at $1 \%, 5 \%$ and $10 \%$ respectively. 
Table 4.5.2-4: RE Estimations by Sub-samples (Key Variables): Inter-OECD Sample

\begin{tabular}{|c|c|c|c|c|}
\hline Model & RE(9) & $\mathrm{RE}(10)$ & RE(11) & $\mathrm{RE(12)}$ \\
\hline RTA & $\begin{array}{c}0.1777 \\
(0.1320)\end{array}$ & $\begin{array}{c}0.3237 * * \\
(0.1322)\end{array}$ & $\begin{array}{l}0.2414 * \\
(0.1389)\end{array}$ & $\begin{array}{c}0.3024 * * \\
(0.1437)\end{array}$ \\
\hline $\begin{array}{l}\text { REG } \\
\text { (catch-all) }\end{array}$ & $\begin{array}{c}0.2733 * * * \\
(0.0400)\end{array}$ & & & \\
\hline Credit Reg & & $\begin{array}{c}0.1801 * * * \\
(0.0200)\end{array}$ & & \\
\hline Labour Reg & & & $\begin{array}{c}0.0211 \\
(0.0230)\end{array}$ & \\
\hline Business Reg & & & & $\begin{array}{c}0.022 \\
(0.0265) \\
\end{array}$ \\
\hline Obs & 4155 & 4156 & 3950 & 3861 \\
\hline chi2 & 4085 & 4140 & 3533 & 2833 \\
\hline p-value & {$[0.0000]$} & {$[0.0000]$} & {$[0.0000]$} & {$[0.0000]$} \\
\hline
\end{tabular}

The dependent variable is Infdi. Specification is eq.(4.4-1). Regional dummies with year effects are included. Results on other variables and intercepts are not shown. Robust standard errors are in parenthesis, clustering by country-pairs. $* * *, * *$ and $*$ denote significance levels at $1 \%, 5 \%$ and $10 \%$ respectively.

In panel data analysis, the presence of autocorrelation is fairly likely. In this case, the standard errors obtained from the estimates tend to be underestimated, thereby inflating the coefficients. Supported by the test results of Wooldridge (2002)'s autocorrelation test for panel data in Appendix Section A.6, we confirm that the null hypothesis of no autocorrelation can be rejected. In other words, it suggests that the error terms may undergo an AR(1) process. Against this background, FGLS estimation is also carried out. In theory, FGLS estimators are more efficient than the RE estimates (which are GLS estimators). We present the coefficients of the key variables in Table 4.5.2-5 below. 
Table 4.5.2-5: FGLS Estimation Results by Sub-Samples (Key Variables)

\begin{tabular}{|c|c|c|c|c|c|c|}
\hline & RTA & $\begin{array}{c}\text { REG } \\
\text { (catch-all) }\end{array}$ & $\begin{array}{c}\text { Credit } \\
\text { Reg }\end{array}$ & $\begin{array}{c}\text { Labour } \\
\text { Reg }\end{array}$ & $\begin{array}{c}\text { Business } \\
\text { Reg } \\
\end{array}$ & Obs chi2 p-value \\
\hline \multirow{4}{*}{$\begin{array}{l}\text { Inter-OECD } \\
\text { Sample }\end{array}$} & $\begin{array}{c}0.2904 * * * \\
(0.0968)\end{array}$ & $\begin{array}{c}0.1234 * * * \\
(0.0178)\end{array}$ & & & & 410417620 [0.0000] \\
\hline & $\begin{array}{c}\mathbf{0 . 3 3 5 7} * * * \\
(\mathbf{0 . 0 9 7 0})\end{array}$ & & $\begin{array}{c}0.1004 * * * \\
(0.0091)\end{array}$ & & & 410518433 [0.0000] \\
\hline & $\begin{array}{c}0.2213 * * \\
(0.0919)\end{array}$ & & & $\begin{array}{c}0.0314 * * * \\
(0.0107)\end{array}$ & & 390126749 [0.0000] \\
\hline & $\begin{array}{c}0.2293 * * * \\
(0.0838)\end{array}$ & & & & $\begin{array}{c}0.0004 \\
(0.0111)\end{array}$ & 381321027 [0.0000] \\
\hline \multirow{4}{*}{$\begin{array}{l}\text { Intra-OECD } \\
\text { Sample }\end{array}$} & $\begin{array}{c}0.2544 * * * \\
(0.0471)\end{array}$ & $\begin{array}{c}0.2432 * * * \\
(0.0201)\end{array}$ & & & & $501825022[0.0000]$ \\
\hline & $\begin{array}{c}0.2480 * * * \\
(0.0460)\end{array}$ & & $\begin{array}{c}0.1899 * * * \\
(0.0137)\end{array}$ & & & $501825823[0.0000]$ \\
\hline & $\begin{array}{c}0.2751 * * * \\
(0.0459)\end{array}$ & & & $\begin{array}{c}0.1124 * * * \\
(0.0115)\end{array}$ & & 497924821 [0.0000] \\
\hline & $\begin{array}{c}0.1741^{* * * *} \\
(0.0525)\end{array}$ & & & & $\begin{array}{c}0.0414 * * * \\
(0.0100)\end{array}$ & 461826327 [0.0000] \\
\hline
\end{tabular}

The dependent variable is $\boldsymbol{I n f d i}$. Regional dummies with year effects are included. Results on other variables and intercepts are not shown. Robust standard errors are in parenthesis, clustering by country-pairs. $\quad * * *, * *$ and $*$ denote significance levels at $1 \%, 5 \%$ and $10 \%$ respectively.

If we compare the results of Table 4.5.2-3 and Table 4.5.2-4 against Table 4.5.2-5, we note that the coefficients on $\boldsymbol{R} \boldsymbol{T} \boldsymbol{A}$ do not differ a lot even after controlling for heteroskedasticity and AR(1) in the FGLS estimations. For the inter-OECD sample, the effect of $\boldsymbol{R} \boldsymbol{T} \boldsymbol{A}$ lies somewhere between 0.22 to 0.34 . For the intra-OECD sample, the corresponding parameter ranges from 0.17 to 0.28. Seemingly, RTA plays a slightly more significant role in attracting FDI in the inter-OECD region than that in the intra-OECD region, after controlling for most of the geographical and cultural factors. However, the difference is very small. In any case, countries having the same membership in a regional trade agreement tend to increase their bilateral FDI.

In terms of domestic regulatory environment, not only the broad aggregate measure of regulation has a positive and statistically significant impact on bilateral FDI, but so do its sub-indices. Perhaps except business regulation, its coefficient is relatively small as compared to that of credit market regulation and labour regulation. In the inter-OECD sub-sample, it even shows no 
significant effect. We reckon that it is very likely due to data limitation. Unlike the other two sub-indices which have a reasonably good coverage in the sample period, a more comprehensive coverage of business regulation is only available since 2000 . The sample size is inevitably greatly reduced.

Comparing the effects of domestic regulatory environment in the intra-OECD region vis-à-vis inter-OECD region in Table 4.5.2-5, we find consistently that the effects of regulation are stronger in the intra-OECD region. It may suggest that, in the inter-OECD region, the non-OECD economies have comparative advantages in production costs. Despite their institutional inadequacy, they still have locational advantages in attracting foreign capital. However, amongst OECD economies, comparative advantages do not lie on production costs. Institutional differences would turn out to be a more significant factor to be considered by foreign investors.

Furthermore, we can also note that credit market regulations exert the largest effects on FDI amongst the three types of regulations. These results are also consistent with the IMF (2005)'s view that one of the most prominent constraint for foreign investors are credit constraints.

A final extension of our linear panel data model before we proceed to IV estimation is to test our specification using Hausman and Taylor estimator. We are aware that there is no prior reason to justify that the correlation between the regressors and the unobserved country-pair heterogeneity does not exist. In addition, our FE models are supported by the test results of Hausman specification tests (see Appendix Section A.6) instead of RE models, suggesting that we cannot reject that the country-pair specific effects correlate with the regressors. As a robustness check, henceforth, we further relax this assumption and employ the Hausman and Taylor estimators in order to accommodate time-invariant variables as well as to allow the unobserved country-pair specific effects to be correlated with the regressors. In our case, we assume that $\boldsymbol{R} \boldsymbol{E} \boldsymbol{G}$ and $\boldsymbol{R} \boldsymbol{T} \boldsymbol{A}$ are correlated with the unobserved country-pair specific effects. 
Table 4.5.2-6 to Table 4.5.2-8 show our Hausman and Taylor estimation results using the full sample, inter-OECD and intra-OECD sub-samples respectively. After using Hausman and Taylor estimators, different geographical variables behave differently in the two sub-samples. Basic gravity variables, e.g. GDP, population and distance between the two economies, have the expected signs. Other than that, being an island economy is negatively affecting FDI inflows in the intra-OECD region. However, such effect is not found in the inter-OECD region. Having common border positively explains FDI between two economies, but this effect is not statistically significant in the intra-OECD sub-sample. Area product is not significant at all in both sub-samples. In overall terms, geographical variables do account partially for bilateral FDI. However, the effects of specific geographical characteristics will differ slightly in the inter-OECD and intra-OECD regions.

In terms of cultural linkages, similar to the qualitative results obtained from our OLS estimates, we find that the effect of common language is significant in determining bilateral FDI. The effect, however, primarily comes from the intra-OECD sample. In other words, for OECD economies, whether the destination economy has common language as the source is not a statistically significant determinant when they consider outward investment to non-OECD economies. However, if the destination economy is also an OECD economy, such factor will be significant. For the inter-OECD region, such sort of cultural proximity may have been captured by the colonial relationship variable instead of the common language variable. We find that in the inter-OECD region, if the FDI source and destination economies are ever in a colonial relationship, they are more likely to have more bilateral FDI.

The positive and significant impacts of $\boldsymbol{R} \boldsymbol{T} \boldsymbol{A}$ and $\boldsymbol{R} \boldsymbol{E} \boldsymbol{G}$ survive even if we use Hausman and Taylor estimators. The results still hold after using sub-samples. In respect to individual regulatory sub-index, only credit market regulations are statistically significant throughout. Labour market regulations and business regulations are not significant in either sub-sample. This reiterates earlier results that an economy with less regulated credit markets fosters a more favourable business environment, thereby inducing more inward investment. 
Table 4.5.2-6: Hausman and Taylor Estimation Results -- Full Sample

\begin{tabular}{|c|c|c|c|c|}
\hline Model & HT(1) & HT(2) & HT(3) & HT(4) \\
\hline $\ln \left(\mathrm{GDP}_{\mathrm{i}}\right)$ & $\begin{array}{c}2.3165 * * * \\
(0.1249)\end{array}$ & $\begin{array}{c}2.3132 * * * \\
(0.1280)\end{array}$ & $\begin{array}{c}2.3627 * * * \\
(0.1374)\end{array}$ & $\begin{array}{c}2.4406^{* * * *} \\
(0.1371)\end{array}$ \\
\hline $\ln \left(\mathrm{GDP}_{\mathrm{j}}\right)$ & $\begin{array}{c}1.1949 * * * \\
(0.1037)\end{array}$ & $\begin{array}{c}1.1015 * * * \\
(0.1052)\end{array}$ & $\begin{array}{c}1.6484 * * * \\
(0.1169)\end{array}$ & $\begin{array}{c}1.6303 * * * \\
(0.1262)\end{array}$ \\
\hline $\ln \left(\mathrm{POP}_{\mathrm{i}}\right)$ & $\begin{array}{c}-1.4091 * * * \\
(0.1471)\end{array}$ & $\begin{array}{c}-1.4037 * * * \\
(0.1555)\end{array}$ & $\begin{array}{c}-1.3984 * * * \\
(0.1637)\end{array}$ & $\begin{array}{c}-1.3453 * * * \\
(0.1564)\end{array}$ \\
\hline $\ln \left(\mathrm{POP}_{\mathrm{j}}\right)$ & $\begin{array}{c}-0.8712 * * * \\
(0.1376)\end{array}$ & $\begin{array}{c}-0.9038 * * * \\
(0.1451)\end{array}$ & $\begin{array}{c}-1.3159 * * * \\
(0.1503)\end{array}$ & $\begin{array}{c}-0.9261 * * * \\
(0.1509)\end{array}$ \\
\hline $\ln$ (Dist) & $\begin{array}{c}-1.2075^{* * *} \\
(0.1806)\end{array}$ & $\begin{array}{c}-1.2132 * * * \\
(0.1973)\end{array}$ & $\begin{array}{c}-1.1692 * * * \\
(0.2050)\end{array}$ & $\begin{array}{c}-1.0497 * * * \\
(0.1888)\end{array}$ \\
\hline Colony $_{\mathrm{ij}}$ & $\begin{array}{l}1.6920 * * \\
(0.7506)\end{array}$ & $\begin{array}{l}1.6978 * * \\
(0.8204)\end{array}$ & $\begin{array}{c}1.7597 * * \\
(0.8533)\end{array}$ & $\begin{array}{l}1.6811 * * \\
(0.7798)\end{array}$ \\
\hline Common Lang & $\begin{array}{l}1.0269 * * \\
(0.4348)\end{array}$ & $\begin{array}{c}1.0567 * * \\
(0.4749)\end{array}$ & $\begin{array}{c}0.9904 * * \\
(0.4934)\end{array}$ & $\begin{array}{l}1.0009 * * \\
(0.4541)\end{array}$ \\
\hline Island & $\begin{array}{l}-0.4094 \\
(0.3221)\end{array}$ & $\begin{array}{l}-0.4127 \\
(0.3516)\end{array}$ & $\begin{array}{l}-0.3355 \\
(0.3668)\end{array}$ & $\begin{array}{l}-0.2312 \\
(0.3402)\end{array}$ \\
\hline Border & $\begin{array}{c}0.4788 \\
(0.6269)\end{array}$ & $\begin{array}{c}0.4167 \\
(0.6852)\end{array}$ & $\begin{array}{c}0.3877 \\
(0.7124)\end{array}$ & $\begin{array}{c}0.7595 \\
(0.6518)\end{array}$ \\
\hline $\ln \left(\right.$ Area $\left._{\mathrm{ij}}\right)$ & $\begin{array}{c}0.1556 * * \\
(0.0663)\end{array}$ & $\begin{array}{l}0.1822 * * \\
(0.0720)\end{array}$ & $\begin{array}{l}0.1394 * \\
(0.0756)\end{array}$ & $\begin{array}{c}0.0657 \\
(0.0705)\end{array}$ \\
\hline Common Coloniser & $\begin{array}{c}3.6104 \\
(3.2345) \\
\end{array}$ & $\begin{array}{c}3.8589 \\
(3.5349) \\
\end{array}$ & $\begin{array}{c}3.6456 \\
(3.6721) \\
\end{array}$ & $\begin{array}{c}3.5165 \\
(3.3679) \\
\end{array}$ \\
\hline RTA & $\begin{array}{c}0.2053 * * * \\
(0.0711)\end{array}$ & $\begin{array}{c}0.2430 * * * \\
(0.0708)\end{array}$ & $\begin{array}{c}0.2540 * * * \\
(0.0710)\end{array}$ & $\begin{array}{c}0.0806 \\
(0.0851)\end{array}$ \\
\hline $\begin{array}{l}\text { REG } \\
\text { (catch-all) }\end{array}$ & $\begin{array}{c}0.2635 * * * \\
(0.0231)\end{array}$ & & & \\
\hline Credit Reg & & $\begin{array}{c}0.1597 * * * \\
(0.0117)\end{array}$ & & \\
\hline Labor Reg & & & $\begin{array}{c}0.0400 * * * \\
(0.0148)\end{array}$ & \\
\hline Business Reg & & & & $\begin{array}{c}0.0230 \\
(0.0164)\end{array}$ \\
\hline Obs & 9210 & 9211 & 8967 & 8517 \\
\hline chi2 & 7457 & 7523 & 6423 & 3707 \\
\hline$p$-value & {$[0.0000]$} & {$[0.0000]$} & {$[0.0000]$} & \\
\hline
\end{tabular}

The dependent variable is Infdi. Regional dummies with year effects are included. Results on intercepts are not shown. Robust standard errors are in parenthesis, clustering by country-pairs. $\quad * * *, * *$ and $*$ denote significance levels at $1 \%, 5 \%$ and $10 \%$ respectively. 
Table 4.5.2-7: Hausman and Taylor Estimation Results -- Inter-OECD Sample

\begin{tabular}{|c|c|c|c|c|}
\hline Model & HT(5) & HT(6) & HT(7) & HT(8) \\
\hline $\ln \left(\mathrm{GDP}_{\mathrm{i}}\right)$ & $\begin{array}{c}2.0891 * * * \\
(0.1588)\end{array}$ & $\begin{array}{c}2.1933 * * * \\
(0.1515)\end{array}$ & $\begin{array}{c}2.1206^{* * * *} \\
(0.1779)\end{array}$ & $\begin{array}{c}2.2612 * * * \\
(0.1694)\end{array}$ \\
\hline $\ln \left(\mathrm{GDP}_{\mathrm{j}}\right)$ & $\begin{array}{c}1.2873 * * * \\
(0.1320)\end{array}$ & $\begin{array}{c}1.3034 * * * \\
(0.1278)\end{array}$ & $\begin{array}{c}2.0861 * * * \\
(0.1560)\end{array}$ & $\begin{array}{c}2.4236 * * * \\
(0.1766)\end{array}$ \\
\hline $\ln \left(\mathrm{POP}_{\mathrm{i}}\right)$ & $\begin{array}{c}-1.1381 * * * \\
(0.1905)\end{array}$ & $\begin{array}{c}-1.1123 * * * \\
(0.1773)\end{array}$ & $\begin{array}{c}-0.9789 * * * \\
(0.2065)\end{array}$ & $\begin{array}{c}-0.9457 * * * \\
(0.1897)\end{array}$ \\
\hline $\ln \left(\mathrm{POP}_{\mathrm{j}}\right)$ & $\begin{array}{c}-0.8779 * * * \\
(0.1737)\end{array}$ & $\begin{array}{c}-0.6518 * * * \\
(0.1615)\end{array}$ & $\begin{array}{c}-1.2744 * * * \\
(0.1797)\end{array}$ & $\begin{array}{c}-1.1645 * * * \\
(0.1765)\end{array}$ \\
\hline $\ln ($ Dist $)$ & $\begin{array}{c}-1.3559 * * * \\
(0.2584)\end{array}$ & $\begin{array}{c}-1.3150 * * * \\
(0.2338)\end{array}$ & $\begin{array}{c}-1.3410 * * * \\
(0.2672)\end{array}$ & $\begin{array}{c}-1.1493 * * * \\
(0.2429)\end{array}$ \\
\hline Colony $_{\mathrm{ij}}$ & $\begin{array}{c}2.1268^{* *} \\
(0.9336)\end{array}$ & $\begin{array}{c}2.0188 * * \\
(0.8446)\end{array}$ & $\begin{array}{c}2.0914 * * \\
(0.9737)\end{array}$ & $\begin{array}{c}2.0535^{* *} \\
(0.8716)\end{array}$ \\
\hline Common Lang & $\begin{array}{c}0.6784 \\
(0.5315)\end{array}$ & $\begin{array}{c}0.6720 \\
(0.4811)\end{array}$ & $\begin{array}{c}0.6101 \\
(0.5545)\end{array}$ & $\begin{array}{c}0.4823 \\
(0.4970)\end{array}$ \\
\hline Island & $\begin{array}{c}0.0236 \\
(0.3875)\end{array}$ & $\begin{array}{c}0.1573 \\
(0.3516)\end{array}$ & $\begin{array}{c}0.3580 \\
(0.4081)\end{array}$ & $\begin{array}{c}0.7470 * * \\
(0.3749)\end{array}$ \\
\hline Border & $\begin{array}{l}2.5592 * * \\
(1.1933)\end{array}$ & $\begin{array}{c}2.5788 * * \\
(1.0801)\end{array}$ & $\begin{array}{l}2.5280 * * \\
(1.2451)\end{array}$ & $\begin{array}{c}2.8226^{* *} \\
(1.1163)\end{array}$ \\
\hline $\ln \left(\right.$ Area $\left._{\mathrm{ij}}\right)$ & $\begin{array}{l}0.1812 * \\
(0.0956)\end{array}$ & $\begin{array}{c}0.0750 \\
(0.0874)\end{array}$ & $\begin{array}{c}0.0099 \\
(0.1028)\end{array}$ & $\begin{array}{l}-0.0881 \\
(0.0932)\end{array}$ \\
\hline RTA & $\begin{array}{l}0.1785 * \\
(0.1015)\end{array}$ & $\begin{array}{c}0.3208 * * * \\
(0.1012)\end{array}$ & $\begin{array}{l}0.2490 * * \\
(0.1023)\end{array}$ & $\begin{array}{c}0.3041 * * * \\
(0.1030)\end{array}$ \\
\hline $\begin{array}{l}\text { REG } \\
\text { (catch-all) }\end{array}$ & $\begin{array}{c}0.2544 * * * \\
(0.0286)\end{array}$ & & & \\
\hline Credit Reg & & $\begin{array}{c}0.1745 * * * \\
(0.0138)\end{array}$ & & \\
\hline Labor Reg & & & $\begin{array}{c}0.0101 \\
(0.0200)\end{array}$ & \\
\hline Business Reg & & & & $\begin{array}{c}0.0144 \\
(0.0237)\end{array}$ \\
\hline Obs & 4155 & 4156 & 3950 & 3861 \\
\hline chi2 & 3047 & 3215 & 2163 & 1584 \\
\hline p-value & {$[0.0000]$} & {$[0.0000]$} & {$[0.0000]$} & {$[0.0000]$} \\
\hline
\end{tabular}

The dependent variable is Infdi. Regional dummies with year effects are included. Results on intercepts are not shown. Robust standard errors are in parenthesis, clustering by country-pairs. $\quad * * *, * *$ and $*$ denote significance levels at $1 \%, 5 \%$ and $10 \%$ respectively. 
Table 4.5.2-8: Hausman and Taylor Estimation Results -- Intra-OECD Sample

\begin{tabular}{|c|c|c|c|c|}
\hline Model & HT(9) & HT(10) & HT(11) & HT(12) \\
\hline $\ln \left(G P_{i}\right)$ & $\begin{array}{c}2.5982 * * * \\
(0.1875)\end{array}$ & $\begin{array}{c}2.6227 * * * \\
(0.1865)\end{array}$ & $\begin{array}{c}2.6464 * * * \\
(0.1891)\end{array}$ & $\begin{array}{c}2.5129 * * * \\
(0.2130)\end{array}$ \\
\hline $\ln \left(\mathrm{GDP}_{\mathrm{j}}\right)$ & $\begin{array}{c}1.9852 * * * \\
(0.2048)\end{array}$ & $\begin{array}{c}1.9173 * * * \\
(0.2045)\end{array}$ & $\begin{array}{c}2.2953 * * * \\
(0.2145)\end{array}$ & $\begin{array}{c}1.9234 * * * \\
(0.2631)\end{array}$ \\
\hline $\ln \left(\mathrm{POP}_{\mathrm{i}}\right)$ & $\begin{array}{c}-1.7436 * * * \\
(0.2327)\end{array}$ & $\begin{array}{c}-1.7162 * * * \\
(0.2308)\end{array}$ & $\begin{array}{c}-1.7485 * * * \\
(0.2349)\end{array}$ & $\begin{array}{c}-1.6027 * * * \\
(0.2681)\end{array}$ \\
\hline $\ln \left(\mathrm{POP}_{\mathrm{j}}\right)$ & $\begin{array}{c}-1.5930 * * * \\
(0.2513)\end{array}$ & $\begin{array}{c}-1.5141 * * * \\
(0.2499)\end{array}$ & $\begin{array}{c}-1.8785 * * * \\
(0.2583)\end{array}$ & $\begin{array}{c}-1.4054 * * * \\
(0.3152)\end{array}$ \\
\hline $\ln ($ Dist $)$ & $\begin{array}{c}-0.9277 * * * \\
(0.3233)\end{array}$ & $\begin{array}{c}-0.9312 * * * \\
(0.3193)\end{array}$ & $\begin{array}{c}-0.8701 * * * \\
(0.3272)\end{array}$ & $\begin{array}{c}-1.0634 * * * \\
(0.3804)\end{array}$ \\
\hline Colony $_{\mathrm{ij}}$ & $\begin{array}{c}1.2106 \\
(1.2267)\end{array}$ & $\begin{array}{c}1.2153 \\
(1.2118)\end{array}$ & $\begin{array}{c}1.2542 \\
(1.2423)\end{array}$ & $\begin{array}{c}1.1719 \\
(1.4324)\end{array}$ \\
\hline Common Lang & $\begin{array}{l}1.3157^{*} \\
(0.7465)\end{array}$ & $\begin{array}{l}1.3188^{*} \\
(0.7375)\end{array}$ & $\begin{array}{l}1.3310^{*} \\
(0.7553)\end{array}$ & $\begin{array}{l}1.5299 * \\
(0.8757)\end{array}$ \\
\hline Island & $\begin{array}{c}-1.1288 * * \\
(0.5745)\end{array}$ & $\begin{array}{l}-1.0069 * \\
(0.5676)\end{array}$ & $\begin{array}{l}-1.0879 * \\
(0.5818)\end{array}$ & $\begin{array}{l}-0.9061 \\
(0.6743)\end{array}$ \\
\hline Border & $\begin{array}{c}0.1974 \\
(0.8716)\end{array}$ & $\begin{array}{c}0.1228 \\
(0.8610)\end{array}$ & $\begin{array}{c}0.1855 \\
(0.8823)\end{array}$ & $\begin{array}{c}0.1583 \\
(1.0194)\end{array}$ \\
\hline $\ln \left(\right.$ Area $\left._{\mathrm{ij}}\right)$ & $\begin{array}{c}0.1269 \\
(0.1324)\end{array}$ & $\begin{array}{c}0.1085 \\
(0.1308)\end{array}$ & $\begin{array}{c}0.1141 \\
(0.1344)\end{array}$ & $\begin{array}{c}0.1469 \\
(0.1591)\end{array}$ \\
\hline Common Coloniser & $\begin{array}{c}4.2548 \\
(3.8186) \\
\end{array}$ & $\begin{array}{c}4.4887 \\
(3.7720) \\
\end{array}$ & $\begin{array}{c}4.5291 \\
(3.8636) \\
\end{array}$ & $\begin{array}{c}3.6807 \\
(4.4764)\end{array}$ \\
\hline RTA & $\begin{array}{c}0.2539 * * \\
(0.0997)\end{array}$ & $\begin{array}{c}0.2048 * * \\
(0.0997)\end{array}$ & $\begin{array}{c}0.2957 * * * \\
(0.0988)\end{array}$ & $\begin{array}{l}-0.1577 \\
(0.1456)\end{array}$ \\
\hline $\begin{array}{l}\text { REG } \\
\text { (catch-all) }\end{array}$ & $\begin{array}{c}0.2265 * * * \\
(0.0390)\end{array}$ & & & \\
\hline Credit Reg & & $\begin{array}{c}0.1714 * * * \\
(0.0208)\end{array}$ & & \\
\hline Labor Reg & & & $\begin{array}{c}0.0189 \\
(0.0232)\end{array}$ & \\
\hline Business Reg & & & & $\begin{array}{c}0.0038 \\
(0.0234)\end{array}$ \\
\hline Obs & 5055 & 5055 & 5017 & 4656 \\
\hline chi2 & 4437 & 4496 & 4279 & 2227 \\
\hline$p$-value & {$[0.0000]$} & {$[0.0000]$} & {$[0.0000]$} & {$[0.0000]$} \\
\hline
\end{tabular}

The dependent variable is Infdi. Regional dummies with year effects are included. Results on intercepts are not shown. Robust standard errors are in parenthesis, clustering by country-pairs. $\quad * * *, * *$ and $*$ denote significance levels at $1 \%, 5 \%$ and $10 \%$ respectively.

To sum up so far, we use several linear panel data estimators to assess the effects of natural barriers, RTA and regulatory environment on bilateral FDI in an augmented gravity model. The various estimators have their own merits 
and shortcomings. Despite so, the qualitative conclusion is largely similar. Our empirical findings suggest that the gravity model fits our data fairly well. Geographical characteristics and cultural ties are essential FDI determinants, although they are not particularly robust to different samples used. More importantly, both external institution - RTA and domestic regulatory environment are also significant determinants of bilateral FDI in both the intra-OECD and inter-OECD regions.

This conclusion is encouraging from the economic development perspective. While we understand that FDI is growth-promoting, we provide empirical evidence to support that improving regulatory environment and being actively engaged in regional integration are two possible channels to promote FDI. More specifically, relaxing credit market regulations carries even more pronounced impacts. These results have been controlled for physical and historical elements, like geography and culture, which are time-invarying and deterministic.

To quantify the results we have for easy reference, the following tables show the impact of our key variables on FDI based on the Hausman and Taylor estimators. Table 4.5.2-9 shows that if a source country $\mathrm{k}$ has a mutual membership of RTA with a destination country $j$, it is estimated that $\mathrm{j}$ would receive around $19.5 \%$ to $37.8 \%$ more FDI stock from country $k$. The magnitude depends on whether country $\mathrm{j}$ is an OECD economy in our case.

Table 4.5.2-9: Effect of RTA on FDI

\begin{tabular}{llc}
\hline \multirow{2}{*}{ Inter-OECD Region } & Model HT(5) & $\mathrm{e}^{0.1785}-1=19.5 \%$ \\
& Model HT(6) & $37.8 \%$ \\
\hline \multirow{2}{*}{ Intra-OECD Region } & Model HT(9) & $28.9 \%$ \\
& Model HT(10) & $22.7 \%$ \\
\hline
\end{tabular}

Table 4.5.2-10 estimates the impact of $\boldsymbol{R E} \boldsymbol{G}$ and Credit Reg on bilateral FDI. In our sample, the standard deviations of the two variables are 1.15 and 2 respectively. The estimated impact, therefore, means that a one standard deviation improvement in the respective regulatory indices increases overall 
received FDI stock by $30 \%-40 \%$ accordingly. The positive impact of improvements in domestic institutional environment on FDI is quite substantial.

Table 4.5.2-10: Effect of REG and Credit Reg on FDI

\begin{tabular}{lll}
\hline \multirow{2}{*}{ Inter-OECD Region } & REG: Model HT(5) & $33 \%$ \\
& Credit Reg: Model HT(6) & $40 \%$ \\
\hline \multirow{2}{*}{ Intra-OECD Region } & $\boldsymbol{R} \boldsymbol{E G}:$ Model HT(9) & $30 \%$ \\
& Credit Reg: Model HT(10) & $40 \%$ \\
\hline
\end{tabular}

\subsubsection{Estimations}

Finally, along the line of the existing literature on institution and growth, we tackle the potential endogeneity problem between regulation and FDI by means of IV estimation. More specifically, we use the Baltagi (1981)'s EC2SLS estimator. The hypothesis is that destination economies with less burdensome regulatory environment will be more likely to attract FDI. Simultaneously, more FDI may also induce structural reform to improve business environment by reducing regulations.

Before we discuss the IV estimation results, we deploy the Hausman specification test to test whether various measures of regulation correlate with the disturbance terms in our models. Test details are in Appendix Section A.6. The test results suggest that there is no evidence to show $\boldsymbol{R E G}$ and $\mathbf{L a b o r} \boldsymbol{R e g}$ are endogenous variables. However, Credit Reg and Business Reg do correlate with the disturbance terms. With the absence of endogeneity, using IV estimates or least square estimations yield consistent results. However, if endogeneity does exist, only IV estimators provide consistent results. In any case, we perform IV estimators for all 4 indices of regulatory environment to facilitate comparison.

Following Alesina, et al. (2003) and Bénassy-Quéré, et al. (2007), we consider 
using ethnic fragmentation, religion fragmentation, latitude of the economy and UK legal origin of the destination economies as instruments. Sargan-Hansen test, as shown in Appendix Section A.6 and in the results tables follow, supports that our instruments used are relevant.

The estimation results using panel EC2SLS for the full sample and sub-samples are shown in Table 4.5.3-1 - Table 4.5.3-3. Key gravity variables (GDP, population and distance) and variables measuring cultural and historical ties remain significantly associating with bilateral FDI. Other geographical variables such as area, common border and island economy are no longer significant. However, their effects are statistically significant in different sub-samples and behaving differently.

On the effects of $\boldsymbol{R} \boldsymbol{T} \boldsymbol{A}$, the results using the full sample show that the coefficients of the IV estimations are systematically larger than those previously obtained in various linear models, for example in the RE models (i.e. Models IV(1) - IV(4) vs. RE(1) - RE(4)). Comparing the coefficients of $\boldsymbol{R} \boldsymbol{A} \boldsymbol{A}$ of the intra-OECD sample (i.e. Models IV(9) - IV(12)) vis-à-vis inter-OECD sample (i.e. Models IV(5) - IV(8)), the results generally suggest that RTA exerts stronger impact on inter-OECD bilateral FDI.

The overall impact of regulation also turns out to be more significant in Models IV(1) - IV(4) after controlling for endogeneity. One point to note is that the “catch-all' index of $\boldsymbol{R E} \boldsymbol{G}$ consistently has larger coefficients than those of $\boldsymbol{R} \boldsymbol{T A}$ in the full samples and both sub-samples.

With respect to the three sub-indices, we find that the effects of both Credit $\boldsymbol{R e g}$ and Business $\boldsymbol{R e g}$ are statistically significant in both sub-samples (i.e. Model IV(6) vs. IV(10) and Model IV(8) vs. IV(12) respectively). The effect of credit market regulation is more profound in the intra-OECD sample, whereas the effect of business regulations is greater in the inter-OECD sample. Labour Reg, on the other hand, only associates positively with FDI in the intra-OECD sample (i.e. Model IV(11)), whereas such an effect is not statistically significant in the inter-OECD sample at all (i.e. Model IV(7)). In 
sum, we find empirical evidence to show that regulatory environment positively and significantly relates to bilateral FDI, in particular to intra-OECD region.

One may wonder if RTA is also a potential endogenous variable, such that economies with more bilateral FDI flows in-between are more likely to engage in an RTA or vice versa. However, as Rose (2004) reckons, there is no theoretical basis for choosing an appropriate instrument for RTA. Despite so, we have attempted to use the same instruments as in our IV estimations for considering both RTA and regulation as endogenous. Nevertheless, the Sargan-Hansen test rejects the validity of the instruments for RTA. Hence, we do not show this set of IV estimations here.

In sum, we find that even having considered the potential endogeneity problem of regulation, our qualitative conclusion does not change. That said, regional integration and regulatory environment of the destination economy do matter for bilateral FDI. However, we should note that our IV estimation results tend to inflate the coefficients of the variables of our key interest when compared to those obtained in our linear panel data models. Although the Sargan-Hansen test supports the validity of our instruments, we should be very cautious when interpreting the IV estimation results. 
Table 4.5.3-1: IV Estimation Results - Full Sample

\begin{tabular}{|c|c|c|c|c|}
\hline Model & IV(1) & IV(2) & IV(3) & IV(4) \\
\hline $\ln \left(\mathrm{GDP}_{\mathrm{i}}\right)$ & $\begin{array}{c}2.9091 * * * \\
(0.0693)\end{array}$ & $\begin{array}{c}3.0960 * * * \\
(0.0721)\end{array}$ & $\begin{array}{c}3.1114 * * * \\
(0.0624)\end{array}$ & $\begin{array}{c}2.6777 * * * \\
(0.1547)\end{array}$ \\
\hline $\ln \left(\mathrm{GDP}_{\mathrm{j}}\right)$ & $\begin{array}{c}0.9511 * * * \\
(0.1019)\end{array}$ & $\begin{array}{c}0.8644 * * * \\
(0.1099)\end{array}$ & $\begin{array}{c}1.5215 * * * \\
(0.0778)\end{array}$ & $\begin{array}{c}0.6267 * * * \\
(0.1854)\end{array}$ \\
\hline $\ln \left(\mathrm{POP}_{\mathrm{i}}\right)$ & $\begin{array}{c}-1.7141 * * * \\
(0.0773)\end{array}$ & $\begin{array}{c}-1.8497 * * * \\
(0.0823)\end{array}$ & $\begin{array}{c}-1.8832 * * * \\
(0.0695)\end{array}$ & $\begin{array}{c}-1.3497 * * * \\
(0.1720)\end{array}$ \\
\hline $\ln \left(\mathrm{POP}_{\mathrm{j}}\right)$ & $\begin{array}{l}-0.0435 \\
(0.1129)\end{array}$ & $\begin{array}{c}0.1302 \\
(0.1274)\end{array}$ & $\begin{array}{c}-0.6351 * * * \\
(0.0832)\end{array}$ & $\begin{array}{c}0.7029 * * * \\
(0.2439)\end{array}$ \\
\hline $\ln ($ Dist $)$ & $\begin{array}{c}-1.3519 * * * \\
(0.0834)\end{array}$ & $\begin{array}{c}-1.3053 * * * \\
(0.0916)\end{array}$ & $\begin{array}{c}-1.2971 * * * \\
(0.0760)\end{array}$ & $\begin{array}{c}-1.3895 * * * \\
(0.1890)\end{array}$ \\
\hline Colony $_{\mathrm{ij}}$ & $\begin{array}{c}1.5451 * * * \\
(0.3210)\end{array}$ & $\begin{array}{c}1.5130 * * * \\
(0.3546)\end{array}$ & $\begin{array}{c}1.5608 * * * \\
(0.2907)\end{array}$ & $\begin{array}{l}1.4654 * * \\
(0.7326)\end{array}$ \\
\hline Common Lang & $\begin{array}{c}0.7088 * * * \\
(0.1920)\end{array}$ & $\begin{array}{c}0.7065 * * * \\
(0.2119)\end{array}$ & $\begin{array}{c}0.6985 * * * \\
(0.1753)\end{array}$ & $\begin{array}{l}0.7772 * \\
(0.4373)\end{array}$ \\
\hline Island & $\begin{array}{l}-0.0419 \\
(0.1436)\end{array}$ & $\begin{array}{c}0.0428 \\
(0.1582)\end{array}$ & $\begin{array}{l}-0.0049 \\
(0.1310)\end{array}$ & $\begin{array}{c}0.2668 \\
(0.3329)\end{array}$ \\
\hline Border & $\begin{array}{c}0.1733 \\
(0.2698)\end{array}$ & $\begin{array}{c}0.0677 \\
(0.2979)\end{array}$ & $\begin{array}{c}0.1647 \\
(0.2441)\end{array}$ & $\begin{array}{c}0.1590 \\
(0.6153)\end{array}$ \\
\hline Landlock & $\begin{array}{l}0.3016^{* *} \\
(0.1242)\end{array}$ & $\begin{array}{c}0.5280 * * * \\
(0.1360)\end{array}$ & $\begin{array}{c}0.3838 * * * \\
(0.1141)\end{array}$ & $\begin{array}{c}0.0506 \\
(0.2810)\end{array}$ \\
\hline $\ln \left(\right.$ Area $\left._{\mathrm{ij}}\right)$ & $\begin{array}{c}0.0252 \\
(0.0370)\end{array}$ & $\begin{array}{c}0.0133 \\
(0.0409)\end{array}$ & $\begin{array}{c}0.0160 \\
(0.0338)\end{array}$ & $\begin{array}{l}-0.1734 * \\
(0.0929)\end{array}$ \\
\hline Common Coloniser & $\begin{array}{c}4.1363 * * \\
(1.8264)\end{array}$ & $\begin{array}{c}4.3895^{* *} \\
(2.0172)\end{array}$ & $\begin{array}{c}4.0915 * * \\
(1.6486)\end{array}$ & $\begin{array}{c}4.0523 \\
(4.1771)\end{array}$ \\
\hline RTA & $\begin{array}{c}0.2545 * * * \\
(0.0823)\end{array}$ & $\begin{array}{c}0.3410 * * * \\
(0.0857)\end{array}$ & $\begin{array}{c}0.4330 * * * \\
(0.0802)\end{array}$ & $\begin{array}{l}0.2497 * \\
(0.1409)\end{array}$ \\
\hline $\begin{array}{l}\text { REG } \\
\text { (catch-all) }\end{array}$ & $\begin{array}{c}0.6289 * * * \\
(0.0683)\end{array}$ & & & \\
\hline Credit Reg & & $\begin{array}{c}0.6413 * * * \\
(0.0641)\end{array}$ & & \\
\hline Labor Reg & & & $\begin{array}{c}0.2292 * * * \\
(0.0585)\end{array}$ & \\
\hline Business Reg & & & & $\begin{array}{c}1.5933 * * * \\
(0.2150)\end{array}$ \\
\hline Obs & 8278 & 8279 & 8062 & 7635 \\
\hline chi2 & 8617 & 7447 & 8679 & 2073 \\
\hline p-value & {$[0.0000]$} & {$[0.0000]$} & {$[0.0000]$} & {$[0.0000]$} \\
\hline $\begin{array}{l}\text { Sargan-Hansen Stat } \\
\text { Chi-sq(1) p-value }\end{array}$ & $\begin{array}{c}1.0160 \\
{[0.3135]}\end{array}$ & $\begin{array}{c}1.3190 \\
{[0.2507]}\end{array}$ & $\begin{array}{c}2.1500 \\
{[0.1426]}\end{array}$ & $\begin{array}{c}0.0040 \\
{[0.9509]}\end{array}$ \\
\hline
\end{tabular}

The dependent variable is $\boldsymbol{l n f d i}$. Regional dummies with year effects are included. Intercepts are not reported. Standard errors are in parentheses. Discussion on Sargan-Hansen tests is at Appendix Section A.6. The IV estimators are EC2SLS estimators. ***, ** and * denote significance levels at $1 \%, 5 \%$ and $10 \%$ respectively. 
Table 4.5.3-2: IV Estimation Results - Inter-OECD Sample

\begin{tabular}{|c|c|c|c|c|}
\hline Model & IV $(5)$ & IV(6) & IV(7) & IV $(8)$ \\
\hline $\ln \left(\mathrm{GDP}_{\mathrm{i}}\right)$ & $\begin{array}{c}2.6341 * * * \\
(0.1120)\end{array}$ & $\begin{array}{c}2.7288 * * * \\
(0.1000)\end{array}$ & $\begin{array}{c}2.7895 * * * \\
(0.1051)\end{array}$ & $\begin{array}{c}2.8227 * * * \\
(0.1233)\end{array}$ \\
\hline $\ln \left(\mathrm{GDP}_{\mathrm{j}}\right)$ & $\begin{array}{c}1.3140 * * * \\
(0.1522)\end{array}$ & $\begin{array}{c}1.3843 * * * \\
(0.1152)\end{array}$ & $\begin{array}{c}1.6840 * * * \\
(0.1176)\end{array}$ & $\begin{array}{l}-0.0464 \\
(0.2925)\end{array}$ \\
\hline $\ln \left(\mathrm{POP}_{\mathrm{i}}\right)$ & $\begin{array}{c}-1.3712 * * * \\
(0.1309)\end{array}$ & $\begin{array}{c}-1.4379 * * * \\
(0.1161)\end{array}$ & $\begin{array}{c}-1.4279 * * * \\
(0.1182)\end{array}$ & $\begin{array}{c}-1.4655 * * * \\
(0.1332)\end{array}$ \\
\hline $\ln \left(\mathrm{POP}_{\mathrm{j}}\right)$ & $\begin{array}{l}-0.3045^{*} \\
(0.1789)\end{array}$ & $\begin{array}{c}-0.3605 * * * \\
(0.1330)\end{array}$ & $\begin{array}{c}-0.6173 * * * \\
(0.1315)\end{array}$ & $\begin{array}{c}1.2836 * * * \\
(0.3322)\end{array}$ \\
\hline $\ln$ (Dist) & $\begin{array}{c}-1.6428 * * * \\
(0.1629)\end{array}$ & $\begin{array}{c}-1.6255^{* * *} \\
(0.1427)\end{array}$ & $\begin{array}{c}-1.6414 * * * \\
(0.1409)\end{array}$ & $\begin{array}{c}-1.7587 * * * \\
(0.1556)\end{array}$ \\
\hline Colony $_{\mathrm{ij}}$ & $\begin{array}{c}2.2773 * * * \\
(0.5731)\end{array}$ & $\begin{array}{c}2.2086 * * * \\
(0.5013)\end{array}$ & $\begin{array}{c}2.2604 * * * \\
(0.4968)\end{array}$ & $\begin{array}{c}2.3454 * * * \\
(0.5414)\end{array}$ \\
\hline Common Lang & $\begin{array}{c}0.2764 \\
(0.3249)\end{array}$ & $\begin{array}{c}0.3193 \\
(0.2845)\end{array}$ & $\begin{array}{c}0.2364 \\
(0.2840)\end{array}$ & $\begin{array}{c}0.2080 \\
(0.3084)\end{array}$ \\
\hline Island & $\begin{array}{l}0.6342 * * \\
(0.2473)\end{array}$ & $\begin{array}{c}0.5893 * * * \\
(0.2185)\end{array}$ & $\begin{array}{c}0.7966 * * * \\
(0.2180)\end{array}$ & $\begin{array}{c}0.9622 * * * \\
(0.2487)\end{array}$ \\
\hline Border & $\begin{array}{c}2.9837 * * * \\
(0.7996)\end{array}$ & $\begin{array}{c}3.0543 * * * \\
(0.6991)\end{array}$ & $\begin{array}{c}3.1575 * * * \\
(0.6921)\end{array}$ & $\begin{array}{c}3.3006 * * * \\
(0.7558)\end{array}$ \\
\hline Landlock & $\begin{array}{l}0.5325 * * \\
(0.2540)\end{array}$ & $\begin{array}{l}0.5636^{* *} \\
(0.2228)\end{array}$ & $\begin{array}{c}0.5926^{* * *} \\
(0.2216)\end{array}$ & $\begin{array}{c}0.7021 * * * \\
(0.2441)\end{array}$ \\
\hline $\ln \left(\right.$ Area $\left._{\mathrm{ij}}\right)$ & $\begin{array}{l}-0.0095 \\
(0.0723)\end{array}$ & $\begin{array}{l}-0.0316 \\
(0.0637)\end{array}$ & $\begin{array}{l}-0.0839 \\
(0.0646)\end{array}$ & $\begin{array}{l}-0.0371 \\
(0.0730)\end{array}$ \\
\hline RTA & $\begin{array}{l}0.3179 * * \\
(0.1392)\end{array}$ & $\begin{array}{c}0.4960 * * * \\
(0.1354)\end{array}$ & $\begin{array}{l}0.3410 * \\
(0.1761)\end{array}$ & $\begin{array}{c}0.1549 \\
(0.2234)\end{array}$ \\
\hline $\begin{array}{l}\text { REG } \\
\text { (catch-all) }\end{array}$ & $\begin{array}{c}0.3881 * * * \\
(0.1134)\end{array}$ & & & \\
\hline Credit Reg & & $\begin{array}{c}0.2045 * * * \\
(0.0474)\end{array}$ & & \\
\hline Labor Reg & & & $\begin{array}{c}0.1093 \\
(0.1140)\end{array}$ & \\
\hline Business Reg & & & & $\begin{array}{c}1.7151 * * * \\
(0.2924)\end{array}$ \\
\hline Obs & 3511 & 3512 & 3329 & 3258 \\
\hline chi2 & 2848 & 3087 & 2536 & 1489 \\
\hline p-value & {$[0.0000]$} & {$[0.0000]$} & {$[0.0000]$} & {$[0.0000]$} \\
\hline $\begin{array}{l}\text { Sargan-Hansen Stat } \\
\text { Chi-sq(1) p-value }\end{array}$ & $\begin{array}{c}0.3480 \\
{[0.5553]}\end{array}$ & $\begin{array}{c}0.2970 \\
{[0.5856]}\end{array}$ & $\begin{array}{l}3.2390 \\
{[0.1980]}\end{array}$ & $\begin{array}{c}0.6910 \\
{[0.4057]}\end{array}$ \\
\hline
\end{tabular}

The dependent variable is $\boldsymbol{I n f d i}$. Regional dummies with year effects are included. Dummy for common coloniser is dropped from the specification due to nil sample. Intercepts are not reported. Standard errors are in parentheses. Discussion on Sargan-Hansen tests is at Appendix Section A.6. The IV estimators are EC2SLS estimators. ***, ** and * denote significance levels at $1 \%, 5 \%$ and $10 \%$ respectively. 
Table 4.5.3-3: IV Estimation Results - Intra-OECD Sample

\begin{tabular}{|c|c|c|c|c|}
\hline Model & IV(9) & IV(10) & IV(11) & IV(12) \\
\hline $\ln \left(\mathrm{GDP}_{\mathrm{i}}\right)$ & $\begin{array}{c}3.1775 * * * \\
(0.0891)\end{array}$ & $\begin{array}{c}3.3599 * * * \\
(0.0872)\end{array}$ & $\begin{array}{c}3.3555 * * * \\
(0.0644)\end{array}$ & $\begin{array}{c}2.9452 * * * \\
(0.1849)\end{array}$ \\
\hline $\ln \left(\mathrm{GDP}_{\mathrm{j}}\right)$ & $\begin{array}{c}1.2292 * * * \\
(0.1909)\end{array}$ & $\begin{array}{c}0.9567 * * * \\
(0.1746)\end{array}$ & $\begin{array}{c}1.3380 * * * \\
(0.1258)\end{array}$ & $\begin{array}{c}1.6504 * * * \\
(0.2886)\end{array}$ \\
\hline $\ln \left(\mathrm{POP}_{\mathrm{i}}\right)$ & $\begin{array}{c}-2.0327 * * * \\
(0.0981)\end{array}$ & $\begin{array}{c}-2.0861^{* * *} \\
(0.0954)\end{array}$ & $\begin{array}{c}-2.2306^{* * *} \\
(0.0695)\end{array}$ & $\begin{array}{c}-1.7338^{* * * *} \\
(0.2060)\end{array}$ \\
\hline $\ln \left(\mathrm{POP}_{\mathrm{j}}\right)$ & $\begin{array}{l}-0.3957 * * \\
(0.2007)\end{array}$ & $\begin{array}{c}0.0911 \\
(0.1908)\end{array}$ & $\begin{array}{c}-0.5668 * * * \\
(0.1283)\end{array}$ & $\begin{array}{c}-0.5924 * * \\
(0.3012)\end{array}$ \\
\hline $\ln$ (Dist) & $\begin{array}{c}-0.9983 * * * \\
(0.1090)\end{array}$ & $\begin{array}{c}-1.0466^{* * * *} \\
(0.1059)\end{array}$ & $\begin{array}{c}-0.9990 * * * \\
(0.0764)\end{array}$ & $\begin{array}{c}-0.9164 * * * \\
(0.2427)\end{array}$ \\
\hline Colony $_{\mathrm{ij}}$ & $\begin{array}{c}0.9018 * * \\
(0.3906)\end{array}$ & $\begin{array}{l}0.6410^{*} \\
(0.3789)\end{array}$ & $\begin{array}{c}0.8330 * * * \\
(0.2706)\end{array}$ & $\begin{array}{c}0.8044 \\
(0.8792)\end{array}$ \\
\hline Common Lang & $\begin{array}{c}1.2982 * * * \\
(0.2488)\end{array}$ & $\begin{array}{c}0.9868 * * * \\
(0.2438)\end{array}$ & $\begin{array}{c}0.9656^{* * *} \\
(0.1781)\end{array}$ & $\begin{array}{l}1.3920 * * \\
(0.5594)\end{array}$ \\
\hline Island & $\begin{array}{c}-0.7376^{* * *} \\
(0.1919)\end{array}$ & $\begin{array}{l}-0.3342 * \\
(0.1879)\end{array}$ & $\begin{array}{c}-1.0022^{* * *} \\
(0.1380)\end{array}$ & $\begin{array}{l}-0.7437^{*} \\
(0.4326)\end{array}$ \\
\hline Border & $\begin{array}{c}0.0037 \\
(0.2870)\end{array}$ & $\begin{array}{c}0.0653 \\
(0.2780)\end{array}$ & $\begin{array}{c}0.1807 \\
(0.2007)\end{array}$ & $\begin{array}{c}0.1102 \\
(0.6453)\end{array}$ \\
\hline Landlock & $\begin{array}{l}-0.0095 \\
(0.1536)\end{array}$ & $\begin{array}{l}-0.0269 \\
(0.1499)\end{array}$ & $\begin{array}{l}-0.0267 \\
(0.1097)\end{array}$ & $\begin{array}{l}-0.2935 \\
(0.3369)\end{array}$ \\
\hline $\ln \left(\right.$ Area $\left._{\mathrm{ij}}\right)$ & $\begin{array}{l}-0.0427 \\
(0.0466)\end{array}$ & $\begin{array}{c}-0.1572 * * * \\
(0.0469)\end{array}$ & $\begin{array}{l}-0.0208 \\
(0.0325)\end{array}$ & $\begin{array}{l}-0.1949^{*} \\
(0.1103)\end{array}$ \\
\hline Common Coloniser & $\begin{array}{c}4.9015 * * * \\
(1.6861) \\
\end{array}$ & $\begin{array}{c}4.7629 * * * \\
(1.6314) \\
\end{array}$ & $\begin{array}{c}4.8501 * * * \\
(1.1663) \\
\end{array}$ & $\begin{array}{c}4.8709 \\
(3.8049) \\
\end{array}$ \\
\hline RTA & $\begin{array}{c}0.2730 * * * \\
(0.0998)\end{array}$ & $\begin{array}{c}0.0423 \\
(0.1211)\end{array}$ & $\begin{array}{c}0.5872 * * * \\
(0.0968)\end{array}$ & $\begin{array}{c}0.0693 \\
(0.1708)\end{array}$ \\
\hline $\begin{array}{l}\text { REG } \\
\text { (catch-all) }\end{array}$ & $\begin{array}{c}0.5252 * * * \\
(0.0863)\end{array}$ & & & \\
\hline Credit Reg & & $\begin{array}{c}1.4175 * * * \\
(0.1287)\end{array}$ & & \\
\hline Labor Reg & & & $\begin{array}{c}0.5879 * * * \\
(0.0550)\end{array}$ & \\
\hline Business Reg & & & & $\begin{array}{c}0.8464 * * * \\
(0.1650)\end{array}$ \\
\hline $\begin{array}{l}\text { Obs } \\
\text { chi2 } \\
\text { p-value }\end{array}$ & $\begin{array}{c}4767 \\
5641 \\
{[0.0000]}\end{array}$ & $\begin{array}{c}4767 \\
4581 \\
{[0.0000]}\end{array}$ & $\begin{array}{c}4733 \\
7297 \\
{[0.0000]}\end{array}$ & $\begin{array}{c}4377 \\
1948 \\
{[0.0000]}\end{array}$ \\
\hline $\begin{array}{l}\text { Sargan-Hansen Stat } \\
\text { Chi-sq(1) p-value }\end{array}$ & $\begin{array}{c}1.4890 \\
{[0.2224]} \\
\end{array}$ & $\begin{array}{r}0.0040 \\
{[0.9505]} \\
\end{array}$ & $\begin{array}{r}0.0850 \\
{[0.7705]} \\
\end{array}$ & $\begin{array}{c}1.9460 \\
{[0.1630]}\end{array}$ \\
\hline
\end{tabular}

The dependent variable is $\boldsymbol{l n f d i}$. Regional dummies with year effects are included. Intercepts are not reported. Standard errors are in parentheses. Discussion on Sargan-Hansen tests is at Appendix Section A.6. The IV estimators are EC2SLS estimators. ***, ** and * denote significance levels at $1 \%, 5 \%$ and $10 \%$ respectively. 


\subsection{Conclusion}

In this Chapter, we investigate the impacts of natural barriers, "at-the-border" regional integration and domestic regulatory environment in the destination economy on FDI. Our study demonstrates that all three factors do matter for bilateral inward FDI stock.

The existing literature argues that favourable institutional quality of the destination economy attracts more FDI. Nevertheless, these studies are usually based on cross-sectional data. Not only is the use of panel data limited, country-specific characteristics of the source and destination economies are not controlled simultaneously. Furthermore, there is not yet any study specifically devoted to the impact of domestic regulatory environment on FDI. On the impact of regional integration on FDI, as proxied by mutual membership in an RTA, earlier studies show mixed results. We are also interested in examining the impact of such external institution vis-à-vis domestic institution on FDI.

We use a bilateral FDI stock dataset of 60 FDI destination economies sourcing from OECD economies during 1985 - 2006. The augmented gravity framework fits our data quite well. Our empirical results suggest that geographical, historical and cultural factors generally explain bilateral FDI significantly, even after controlling for unobserved country-pair heterogeneity and time effect. However, the effects of geographical determinants on FDI are differently felt in the intra-OECD and inter-OECD regions.

Panel data analysis shows that a lax regulatory environment and an RTA are positively associating with inter- and intra-OECD bilateral FDI. These qualitative results survive when we use different estimation techniques, including FE, RE, FGLS and Hausman and Taylor estimations. All sub-indices of regulation show the results that less burdensome regulatory environment is favourable to FDI. With regard to specific type of regulation, results of credit market regulations are most robust to different estimators. Results on labour market regulation and business regulation, though positive, 
are insignificant in some cases. These results on one hand suggest that credit market constraints are perhaps one of the key concerns for foreign investors. This also echoes the view that financial development is important to economic development (amongst others, see Rajan and Zingales (1998)). On the other hand, labour market rigidity and business regulation may not be such prime concerns for foreign investors as one anticipates. According to our Hausman and Taylor estimation results, engaging in an RTA could possibly lead to more bilateral FDI stock by $19.5 \%-37.8 \%$. Improving domestic regulatory environment by, say, around 1.5 to 2 points in our sample, bilateral FDI stock could increase by some $30 \%$ to $40 \%$.

To investigate the potential endogeneity problem of regulation, we also carry out IV estimation. For the inter-OECD region, RTA is significantly associating with FDI and shows a more significant impact than that in the intra-OECD sample. For the intra-OECD region, regulatory environment of the destination economies plays a more significant role. Indeed, using IV estimations reinforces further the significance of regulatory environment of the destination economy in attracting FDI than the results obtained in panel data linear models where endogeneity is not accounted for.

Regionalism remains a key issue, in particular during the financial turmoil the world is experiencing. Despite global trade imbalances, world leaders remain committed to prevent the surge of protectionism. The empirical results presented here may add some support on this commitment. Regionalism does not only foster trade. As shown here, it also leads to more FDI. Furthermore, it also strengthens the investment linkage between groups of economies with different stages of economic development and institutional environments.

As a strategy for long-term growth, domestic structural reform efforts have been made across the board to improve domestic institutional frameworks so that the efficient functioning of markets can be supported. Our sub-sample analysis also demonstrates that even amongst the developed economies (i.e. the intra-OECD sample), regulatory environment still plays a significant role in 
attracting foreign capital. In particular, when the comparative advantages of the economy do not lie on the production costs, institutional strengths and differences turn out to be more essential in affecting foreign investors' decisions. As shown in our findings, regulatory environment affects intra-OECD bilateral FDI equally as (or even more than that) in the inter-OECD sub-sample.

From a policy implication perspective, this paper highlights the importance of removing "behind-the-border" regulatory barriers to attract foreign investment irrespective to the stage of development of the economies. In our work, we nevertheless do not provide enough evidence to conclude that RTAs are necessarily desirable. In particular, we have not considered the cost and trade diversion brought about by RTAs. However, our findings support that promoting regional integration may also open up a channel of development, i.e. to attract FDI. 


\title{
CHAPTER 5 : INSTITUTIONS AS THE SOURCE OF CROSS-COUNTRY ECONOMIC
}

\author{
PERFORMANCES - A STOCHASTIC
}

PRODUCTION FRONTIER APPROACH*

\footnotetext{
* An earlier version of this paper was presented at the 29th General Conference of International Association for Research in Income and Wealth (IARIW) on August 20-26, 2006 at Joensuu, Finland. During the meeting, the author received useful comments which are duly reflected in the present version.
} 


\subsection{Introduction}

Previous Chapters have attempted to provide some empirical evidence on the interrelationships between institutions and economic development from different dimensions (such as economic growth, economic reform and FDI). We essentially try to argue that institutions matter to different economic outcomes. This last Chapter discusses the role of institutions in cross-country economic performances.

In Chapter 2, we have investigated the effect of institutions on economic growth. The key research questions there are asking primarily asking $d o$ and what institutions matter. Nevertheless, institutions are not production inputs. The mechanism of how they affect output is not demonstrated. The existing literature suggests that institutions may affect productivity, as measured by total factor productivity (TFP) obtained in standard growth accounting framework. This strand of literature argues that cross-country economic performances are due to different rates of technical change. However, one should note that such TFP obtained as residual from growth accounting implicitly assumes that input allocations are efficient in all economies. This assumption is indeed fairly strong in cross-country analysis.

In this light, this Chapter proposes to measure technical efficiency instead of TFP growth. We propose that institutional differences affect inputs allocations, thereby resulting in diverse economic performances across countries.

Earlier work by Olson (1996) succinctly points out that an institution is probably one of the most important factors to explain the consistent growth divergence among countries. He argues,

“... large differences in per capita income across countries cannot be explained by differences in access to the world's stock of productive knowledge or to its capital markets, by differences 
in the ratio of population to land or natural resources, or by differences in the quality of marketable human capital or personal culture."

His empirical findings show that not all poor economies grow faster than the rich ones as what the theory of convergence has predicted. Even worse, the gap in per capita incomes between the relatively poor and relatively rich countries has increased over time. Prichett (1997) estimates that the proportional gap in GDP per capita between the richest and poorest countries has grown more than five-fold from 1870 to 1990 . The proportional gap between the richest group of countries and the poorest grew from 3 in 1820 to 19 in 1998 (see Maddison (2001)).

North (1990) argues that all those determinants of growth - human capital, technological diffusion and innovations as traditional growth theories suggested - shed no light on the source of growth because they are growth. North and Thomas (1973) note that,

"We are left wondering: if all that is required for economic growth is investment and innovation, why have some societies missed this desirable outcome? ... The factors we have listed (innovation, economies of scale, education, capital accumulation, etc.) are not causes of growth; they are growth. ... Growth will simply not occur unless the existing economic organization is efficient. Individuals must be lured by incentives to undertake the socially desirable activities. Some mechanism must be devised to bring social and private rates of return into closer parity."

A better understanding of the source of growth may be efficiency. Countries are "inefficient" in the sense that there is a considerable discrepancy between private benefit and social benefit whenever an economic transaction occurs ${ }^{1}$. Given an institutional arrangement, undertaking an economic activity may be socially profitable, but individuals rationally will not do it if private cost

\footnotetext{
${ }^{1}$ North and Thomas (1973) suggest that this discrepancy is caused and shaped by the institutional structure, especially when property rights are poorly defined.
} 
exceeds private benefit. Hence, the gains from transaction cannot be realized. In other words, there actually exists a Pareto optimal (more efficient) outcome, but it cannot be achieved. It is, thus, interesting to investigate how much institutional rigidity could explain such disparity.

Against North (1990)'s analytical framework aforementioned, estimating technical efficiency (TE) may help explain the diverse cross-country performances. Hultberg, Nadiri, and Sickles (1999), while measuring international TPF growth, also concur that technology diffusion and technical inefficiency are possibly caused by institutional rigidities. Unlike the previous work, on the methodology front, we propose to adopt the stochastic production frontier (SPF) model. This technique allows us to compare the level of technical inefficiency across countries vis-à-vis the global best practice. In addition, the model can also incorporate explanatory factors of technical inefficiency, namely, institutions in our case.

Similar "benchmarking" exercise is not new in cross-country analysis. The standard way is to assume the United States to be the best practice and be used for comparison. These studies then address how far the poor economies are falling behind the best practice. While the key focus of these studies is the comparative performances vis-à-vis the US, time-varying "best practice" is often neglected. In our study, we do not impose such comparison. Instead, we estimate the world frontier without prior assumption. In other words, we allow the global stochastic production frontier to shift over time.

With regard to the source of technical inefficiency, we consider to test the effects of institutions, human capital and openness. The literature survey we discussed in Chapter 2 has set out the competing debate amongst these three parameters. In an alternative framework as we now propose, we will see if we can contribute some renewed empirical evidence to the debate - i.e. whether institutions, human capital and/or openness explain cross-country economic performances, measured in terms of technical efficiency.

In short, there are three research objectives of this Chapter. Firstly, instead of 
using TFP measurement obtained from growth-accounting to understand the divergence of cross-country economic performances, we propose to use the stochastic production frontier model to measure technical efficiency. It does not assume away the inefficiency resulted from input misallocation. Yet, the technique allows us to construct a TFP index if we so wish. Subject to the model specification, the model can also capture any inter-temporal changes of both technological progress and technical efficiency.

Secondly, while understanding the fact that an institution is not a production input, we attempt to investigate exactly what role institutions play in the production process. Based on North's seminal work on institutions and economic development, we propose to measure the impact of institutions on cross-country technical efficiency, i.e. the efficiency of input allocations across economies.

Thirdly, we revisit the competing debate between the institutional view vis-à-vis the impacts of openness and human capital on economic development. From our empirical results, we will evaluate whether cross-country technical efficiency can be explained by any or all of these three factors.

This Chapter is organised as the following. First, we will survey the previous relevant literature of the effects of institution, openness, human capital on productivity in Section 5.2. We outline the fundamental concepts of stochastic production frontier in Section 5.3. The model we adopted for estimation is further elaborated in Section 5.4. Data used are discussed in Section 5.5. Section 5.6 presents the estimation results. We conclude in Section 5.7. 


\subsection{Literature Survey: Human Capital, Openness and Institutions as Sources of Efficiency}

Productivity is the source of growth and deep determinants of cross-country economic development. Sources of TFP growth are considered to provide an opportunity for enhancing general welfare of the society. The large and growing literature consistently provides support to the claim that productivity, rather than factor accumulation, is the key explanation for international income disparities.

Productivity, frequently measured in terms of TFP, can be further segregated into technical progress and efficiency change. The former represents the country's knowledge as to how factors of production can best be combined. This can be the results of innovations or learning and imitation. Efficiency, on the other hand, represents how effective a country's factors are actually used. A distinct point between the two dimensions worth noting is that the presence of obsolete production techniques does not necessarily imply a technology gap. In fact, it may reflect a situation in which producers are discouraged from adopting best-practice techniques. The presence of suboptimal technologies may be a symptom of poor efficiency instead of resulting from unavailable technology.

Most of the existing empirical literature focuses on the source of TFP. From these empirical studies, nevertheless, we are unable to tell whether the differences in cross-country TFP growth are the results of technical change or efficiency change. In fact, there are views that technology is quite readily available, especially in this globalised era. The differences in economic performances across countries are believed to be the results of technical inefficiency.

Efficiency becomes more prominent in recent studies of economic development. Echoing the view of North on the role of efficiency differences 
as the source of diverge economic performances, Parente and Prescott (2005) lately also develop a theory to explain international income levels. From a historical perspective, they develop a relative efficiency theory of economic development to explain the evolution of international income levels in the last millennium.

The essence of their theory provides a sensible link between efficiency and institutions. They argue that a country starts to experience sustained increases in its living standard when production efficiency reaches a critical point. Countries reach this critical level of efficiency at different dates not because they have access to different stocks of knowledge, but rather because they differ in the amount of society-imposed constraints on the technology choices of their citizenry. Their theory argues that country-specific TFP, which they refer to as a theory of relative efficiency, is a consequence of policy differences. Their theory predicts that after a country reaches a critical point of efficiency, it begins to grow. Its income gap with the leader eventually stops increasing. Nevertheless, to reduce such a gap (i.e. to improve efficiency), the late starter has to use resources in the modern production function by making improvements in its policies and institutions. Growth miracles, as observed in Japan, South Korea, and Taiwan, are also the results of large increase in a late starter's relative efficiency. Parente and Prescott (2005) provide an essential theoretical foundation of our empirical investigation, even though technically speaking, we adopt a more refined measurement of cross-country technical efficiency instead of TFP, which we will discuss in the next section.

While efficiency is essential to close income gap, it is natural henceforth for us to explore the potential factors determining efficiency ${ }^{2}$. Sources of international technical efficiency are not frequently explored. Therefore, we will consider key factors previously examined in the productivity literature and see if they are applicable in our context. In our study, we consider three key dimensions: (i) human capital; (ii) openness, and (iii) institutions and macroeconomic policies. We will review the arguments and the empirical

\footnotetext{
${ }^{2}$ See Isaksson (2007a) for a comprehensive survey on the sources of productivity.
} 
evidence put forth in the literature in turn.

\subsubsection{Human Capital}

Human capital enhances productivity in two possible ways. On one hand, it improves average labour productivity. On the other hand, it strengthens the innovation capacity and promotes technological progress. When summarising recent empirical work on the relationship between human capital and economic growth, Isaksson (2002) concludes that empirical results are diverse with respect to statistical significance (significant or not), magnitude (small or large) and sign (positive or negative) of the estimated parameter. Incorporating human capital or not in the production process produces mixed and somehow puzzling empirical results. For relatively rich countries, human capital is important, while its effect is negative for the relatively poor ones.

In terms of empirical evidence, Benhabib and Spiegel (2005) refine their own established model in Benhabib and Spiegel (1994) by allowing for different functional forms for predicting TFP growth. Studying 84 countries between 1960 and 1995, they find a positive role for human capital as an engine of innovation, as well as a facilitator of TFP catch-up. The predictive capacity of the model seems very good because 22 of 27 countries that were forecast to fall behind did in fact do so.

Along the line of Acemoglu, Aghion, and Zilibotti (2006), Vandenbussche, Aghion, and Meghir (2006) specifically develops a theoretical model to understand the ambiguous effect of human capital on technological improvements. They argue that labour composition determines the form of technological improvements, either innovation or imitation, in an economy. Innovation requires relatively more skilled labour, whereas unskilled labour better suits imitations. A country's level of technological development therefore depends on the endogenous labour allocations across these two activities. The authors opine that both the economy's distance to the technological frontier and on the composition of its human capital determine 
economic development. Skilled labour (i.e. human capital) is growth-enhancing only when the country is proximate to the frontier.

\subsubsection{Openness: Trade, FDI and Financial Integration}

Isaksson (2007a) reckons that knowledge is only created by a few leading technologically advanced developed economies. Elsewhere, technology is just being acquired. Identifying the channels through which technology can be transferred effectively is thus important. Amongst different forms of technology transfer, international trade, in particular imports, and FDI have a relatively high knowledge content embodied. Thus understandably openness is treated as the source of learning. It then presents indirect effects on productivity. Trade liberalisation may lead to increased competition and reduce a firm's X-inefficiency. Foreign competition may also lead domestic producers to expand or cease operation to improve overall efficiency. As Tybout (1992) recognises, demand shifts accompanied by trade liberalisation, market flexibility (entry and exit) and the nature of competition may all affect the net effect of liberalisation on TFP.

FDI is also generally viewed as the key channel for the transfer of advanced technology from industrialised to developing economies. It is also believed to generate positive externalities in the form of knowledge spillovers to domestic firms. However, foreign capital may also crowd-out domestic investment, replace domestic production and reduce competition. Hence, the net effect of technology transfer and efficiency gain as a result of openness is not definite.

Empirical studies of whether FDI spurs productivity are mostly micro-level in nature. Granér and Isaksson (2001) find that both mixed and pure foreign ownership is positively correlated with productivity growth. Keller (2004) uses case studies to show large positive FDI spillovers. On the contrary, Aitken and Harrison (1999) show a negative effect from FDI on productivity among Venezuelan plants, explaining that foreign firms recruit most skilled workers and hence deprive domestic plants of their services. Cases in Hanson 
(2001) also show that spillovers from foreign capital are limited.

Also using SPF, Nourzad (2008) investigates the effect of FDI at macro-level technical inefficiency. His results suggest that increased FDI increases potential output in both developed and developing countries with the effect being more profound in the former. Furthermore, FDI reduces technical inefficiencies in developed economies, but not in those developing ones.

In a nutshell, these empirical results point to a general conclusion that FDI only has a positive impact on TFP growth in industrialised countries, while such positive results are harder to observe in developing countries. Isaksson (2007a) explains that it may be because technology transfer can be costly. Different absorptive capacity across countries may also help explain such pattern.

This also suggests that openness and human capital may have to interact together to have any impact on productivity. Mayer (2001) attempts to interact technology transfer with human capital in a cross-country growth regression. The proxy of absorptive capacity is captured by an interaction term between human capital and imports of machinery and equipment (as percentage of GDP). During the studied period of 1970-1990 in 53 developing countries, the results show that the interaction term has a significant coefficient, meaning human capital is significant for technology adoption.

Separately, Isaksson (2001) uses data on 73 countries between 1960 and 1994 and shows that trade can be viewed as a significant carrier of knowledge or technology unless the recipient countries have the necessary level of human capital. Miller and Upadhyay (2000), covering 83 countries over the period 1960 and 1989, present a statistically significant impact of the interaction of exports and human capital on productivity. More specifically, they argue that the interactive term works differently in countries with different income levels. At low-income levels, human capital is negatively associated with TFP growth, while for middle- and high-income countries the effect is positive. Nevertheless, in the case of Harrison (1996), while analysing 51 countries 
between 1960 and 1987, shows that such interaction terms are seldom statistically significant.

In sum, empirical studies prevalently show that openness has positive effects for industrialised countries, while not necessarily for the case of developing countries. Again, this leads one to suspect that institutional quality may affect absorptive capacity, which in turn affects productivity growth. Although the trade channel could in principal facilitate technology transfer, the absorptive capacity of the recipient country, mainly depending on human capital and capital intensity, determines the magnitude of technology transfer.

Other than trade openness and FDI, financial openness also raises the issue of financing capital accumulation, which may have repercussions for productivity growth (Isaksson (2007a)). In economies where the financial system is well developed, investment opportunities can readily be seized, resources are more likely to be allocated optimally. Specialisation can thus be promoted. However, in developing countries with less sophisticated financial systems, firms may have to rely on retained earnings for investment or forego the opportunity. Financial constraints therefore may prevent poor countries from taking full advantage of technology transfer. Financial repression, often exemplified by negative or artificially low real interest rates, thwarts incentives to save. It also distorts the efficient allocation of savings into investment and hence brings negative effect on TFP growth.

The association between financial development and productivity growth receives great research interests lately. Fisman and Love (2004) study the relationship between industrial growth (covering 37 developed and developing industries with good growth opportunities in 42 countries between 1980 and 1990) and financial development. Based on Rajan and Zingales (1998)'s framework, they conclude that financial development spurs productivity growth. At the macro-level, Aghion, Howitt, and Mayer-Foulkes (2005) study 71 countries between 1960 and 1995. They find that financial development is a threshold variable, which affects convergence mainly through TFP growth rather than capital accumulation. 
Recent studies also suggest that there are many channels through which financial openness can have a positive impact on productivity growth. For example, Kose, Prasad, and Terrones (2008) argue that financial openness could have a positive impact on TFP growth because they lead to more efficient resource allocation as Mishkin (2006) suggests. More specifically, the authors find that de jure capital account openness has a robust positive effect on TFP growth. The effect of de facto financial integration, measured by the stock of external liabilities to GDP, on TFP growth is less clear. FDI and portfolio equity liabilities boost TFP growth while external debt is actually negatively correlated with TFP growth. They explain that financial openness might affect the return to capital, thereby leading to changes in the entry and exit decisions of firms/plants. Aggregate factor productivity will increase because new plants are more productive than exiting plants. This reallocation from less productive to more productive plants would ultimately increase total factor productivity with no significant gains in employment. These productivity gains from both learning and selection effects may also have to spread over longer periods. It may turn out the net effect on TFP seems insignificant.

\subsubsection{Institution and Macroeconomic Policies}

The institution view argues that differences in efficiency across countries are the results of the underlying market-friendly institutions, including the set of formal and informal constraints that shape an individual's ability to act productively and cooperatively in the society. The role of institutions ensures efficient allocation of resources across sectors. On the other hand, policy instruments may also compensate for weak underlying institutions.

According to Isaksson (2007a)'s survey, the existing literature generally highlights three main institutional issues, namely, (i) enforcement of property rights (encourages investment), (ii) constraints on the actions of elitist, political and other groups with power (thus reduce risks of expropriation of incomes and 
others' investments), and (iii) equal opportunity for broad segments of society (e.g. enhanced investment in human capital and participation in productive activities). Theories argue that better security of property rights creates more incentives for savings and investment, leading to TFP growth. As defined in Chapter 2, we consider institutions as a measure composed of economic and political institutions, macroeconomic policies and regulations.

Openness, policy and institution are three typical deep determinants of productivity growth. Empirical studies frequently test their competing roles simultaneously. Alcalá and Ciccone (2004) claim that the way to measure trade matters to the empirical results. They use real openness (i.e. as predicted trade shares estimated based on gravity model), instead of trade share to GDP, and find a strong positive and statistically significant effect on productivity. Their results remain robust after controlling for geography and institutional quality. Nevertheless, Bosworth and Collins (2003), in respect of 84 countries during 1960-2000, show that trade renders insignificant effect in the presence of institutional quality. One possible explanation is that macro studies mask the heterogeneity bias. In reality, trade liberalisation might only benefit large firms. The removal of protective measures could be harmful for smaller enterprises. The net effect may therefore become insignificant.

Hall and Jones (1999), as previously discussed in Chapter 2, strongly believe that the primary and fundamental determinant of a country's long-run economic performance (as measured by output per worker) is its social infrastructure. They argue that differences in social infrastructure cause large differences in capital accumulation, educational attainment and productivity, resulting in huge income disparities across countries. Nevertheless, Glaeser, et al. (2004) suggest that human capital may be more fundamental.

More specifically in terms of political regime, Przeworski and Limongi (1993) appear to favour dictatorships in terms of mobilising savings. However, the authors also recognise that methodological limitations, such as endogeneity problem of institutions and economic development, may hamper one to draw reliable conclusion. In the empirical work of Ulubasoglu and Doucouliagos 
(2004), their results support that both political and economic institutional variables are important to TFP. Their results show that higher levels of democracy have a positive and statistically significant effect on TFP and human capital. Using both economic and political freedom variables in the estimations, their results show that these two variables have positive effects on TFP.

Loko and Diouf (2009) consider altogether the effects of macroeconomic stability (in terms of inflation), FDI, trade openness and business environment on TFP in Maghreb countries in a dynamic panel data setting. They attempt to test the complementary effect of policies to trade openness following Chang, Kaltani, and Loayaza (2005). Their results demonstrate that macroeconomic stability, openness and the level of education are all important for productivity growth. In particular, higher inflation hampers productivity gains significantly, confirming the negative impact of macroeconomic instability. Notwithstanding, their three alternative measures of institutions - the degree of regulation of credit, labor, and business; law and order; and the economic freedom index - all point to the importance of institutions to high TFP growth.

On regulations, its effect on productivity appears to be straightforward. A less regulatory environment is conducive to a more competitive environment, thereby promoting productivity and efficiency growth. Stringent regulation is a hindrance to technology adoption and innovation, possibly because it reduces competitive pressures, technology spillovers and the entry of new high-tech firms. Crafts (2006) argues that regulation can be thought of as rules imposed by the State. Such rule can be used to correct market failures through acting to reduce the costs of negative externalities or imperfections of information by providing insurance or public goods. However, such action also typically imposes costs on the private sector. So there is a danger of excessive regulation where additional costs exceeded extra benefits. All in all, the effectiveness of regulation depends on enforcement as well as legislation.

One of the empirical studies investigating the effect of regulation and the institutional environment on productivity is Scarpetta, Hemmings, Tressel, et al. 
(2002). They note that, across OECD countries, growth paths have become increasingly disparate in the past decade. They suggest two possible reasons: (i) differences in productivity patterns of certain high-tech industries and (ii) differences in the adoption of information and communications technology (ICT). They find that stringent regulatory settings in the product market negatively affect TFP. In addition, labour market regulations that induce high hiring and firing costs also have a negative effect on TFP. In particular, such negative effects are worse for firms in countries which are far from the technological leader.

Based on the World Bank's investment climate survey in five transition economies - the Kyrgyz Republic, Moldova, Poland, Tajikistan and Uzbekistan, Bastos and Nasir (2004) similarly conclude that productivity differences across countries can be explained largely by differences in the investment climate, e.g. policy, institutional and regulatory environment, in which businesses operate. In particular, competition seems to be the most important factor behind productivity performance, followed in the second place by infrastructure, while rent predation (e.g. corruption) occupies the third place.

To sum up, we have reviewed some of the recent theoretical and mostly empirical literature, discussing the sources of productivity in this Section. The deep determinants of productivity include human capital, openness and institutions. Studies examining the effects of these factors alone do not bring conclusive evidence. Conflicting results are often found between developed and developing economies. The literature suggests that one would expect the determinants of productivity growth in technological leaders and recipients to be different (i.e. their relative positions in the global technology frontier matter). However, exactly how much the less developed economies are falling behind the technological leaders is not clear. By its very own nature, TFP per se does not allow us separately to understand how technical change and efficiency change take place. We fail to know if the economy does not "catch-up" because of the barriers of technological adoption or inefficient allocation of resources. In this regard, we consider an alternative measurement technique - i.e. stochastic production frontier - to estimate the 
efficiency change across countries.

\subsection{Fundamentals of Stochastic Production Frontier (SPF)}

To estimate the efficiency of production, Farrell (1957) suggests that the efficiency of an individual cross-section, say a firm, consists of two components: (i) technical efficiency, measuring the ability of a firm to obtain maximal output from a given set of inputs; (ii) allocative efficiency, measuring the ability of a firm to use the inputs in optimal proportions, given their respective prices. In a cross-country context, our primary research interests lie on the measurement of technical efficiency. In this section, we will discuss the basis of our estimation methodology, i.e. stochastic production frontier (SPF), and present a brief survey of some of its applications.

Generally speaking, efficiency measurement relies on estimating a "global" production frontier of a number of cross-sections. Data envelopment analysis (DEA) and stochastic frontiers are two convention methods for such purpose. Coelli, Rao, and Battese (1998) compare the merits and characteristics between these two, which are summarised in Table 5.2.3-1 below:

Table 5.2.3-1: Comparison of Stochastic Production Frontier and Data Envelopment Analysis

\begin{tabular}{|c|c|}
\hline Stochastic Production Frontier & Data Envelopment Analysis \\
\hline (a) Estimation method & Non-parametric \\
\hline Parametric & No \\
\hline (b) Account for stochastic disturbance \\
(more realistic)
\end{tabular}

Source: Coelli, et al. (1998) 
As compared to DEA (also known as deterministic frontiers), although it ignores the stochastic effect on production frontier, they are more consistent with economic theory. DEA is also more advantageous in terms of obtaining the exact measure of technical inefficiency for each observation instead of its distribution. However, its chief disadvantage is that they are bound to be confounded by statistical 'noise', whereas stochastic frontiers are more realistic, at least in terms of econometrics. Moreover, due to its non-parametric approach, DEA is more sensitive to outliers. Since this study is primarily empirical in nature, the readiness of hypothesis tests developed for SPF provides an added advantage for us to choose SPF over DEA for our estimation.

\subsubsection{Basic Framework}

SPF is an estimation of a "global" production frontier of a number of cross-sections while incorporating stochastic assumptions. Based on this concept of productivity, we can measure the economic performance of each country relative to the world's best possible output given the available resources and technology at each time period. This comparative measurement of economic performance against the world production frontier is regarded as technical efficiency.

SPF assumes a mixture of one-sided and two-sided (e.g. normal) errors. The error term is composed of two parts. The one-sided component captures the effects of inefficiency relative to the stochastic frontier. The two-sided component permits random variation of the frontier across cross-sections, and captures the effects of measurement error, other statistical 'noise', and random shocks outside the cross-sections' control.

In a nutshell, the measurement attempts to capture that given the quantities of a list of inputs, there is a maximal possible output. However, this maximum level is random (to be precise, which is randomly distributed as a function) rather than exact. This assumes that some inputs or external effects have maximal possible effects, but others have potentially unbounded effects, e.g. 
weather.

In general form, a production function can be specified as followed:

$$
y_{i}=a_{i} f\left(x_{i} ; \beta\right) \quad 0<a_{i} \leq 1
$$

where $i$ denotes the $i$-th cross-section. $y$ denotes the unit of output. $a$ measures the technology parameters. $x$ is a $(1 \times k)$ vector of inputs of production and other explanatory variables and $\beta$ is a vector of coefficients of inputs to be estimated.

Rewriting eq.(5.3-1) in log-form gives:

$$
\ln y_{i}=\ln f\left(x_{i} ; \beta\right)-u_{i}
$$

where $u_{i}=-\ln a_{i} \geq 0$ represents technical inefficiency. Thus technical efficiency (TE) is given by $\exp \left(-u_{i}\right)$. A Taylor-series expansion of $\exp \left(-u_{i}\right)$ around $u=0$ yields $\exp (-u)=1-u+u^{2} / 2-u^{3} / 3 !+\ldots$. Hence for small values of $u_{i}, \exp \left(-u_{i}\right) \approx 1-u_{i}$ as Cornwell and Schmidt (1996) suggest.

Following Aigner, Lovell, and Schmidt (1977) and Meeusen and Broeck (1977), an SPF can thus be expressed as an error-component model:

$$
y_{i}=f\left(x_{i} ; \beta\right) \exp \left(v_{i}-u_{i}\right)
$$

$v \sim$ iid $N\left(0, \sigma_{v}^{2}\right)$ is a stochastic error independently distributed of $u$. It accounts for the measurement such as the effects of weather, strikes, luck etc on the value of the output variable together with the combined effects of unspecified input variables in the production function. Therefore it is simply treated as random disturbances.

$u$, on the other hand, is assumed to be a non-negative random variable 
associated with technical inefficiency of production and is again assumed to be independently distributed. Among the different cross-sectional SPF models, there are a number of specifications of $u$ commonly proposed. For examples, Aigner, et al. (1977) and Meeusen and Broeck (1977) assume $u_{i} \sim$ iid $N^{+}\left(0, \sigma_{u}^{2}\right)$, Stevenson (1980) assumes $u_{i} \sim$ iid $N^{+}\left(\mu, \sigma_{u}^{2}\right)$ whereas Greene (1990) assumes $u_{i} \sim$ iid gamma ${ }^{3}$.

Since it is assumed that $u_{i} \geq 0$, it implies that, for each cross-section, its output must lie on or below its frontier $\left[f\left(x_{i} ; \beta\right)+v_{i}\right]$. Any deviation implies technical and economic inefficiency. That said, the ratio of the output for the $i$-th firm relative to the maximum potential output, defined by the frontier function given the input vector $x_{i}$, can be used to obtain technical efficiency of the $i$-th firm:

$$
T E_{i}=\exp \left\{-u_{i}\right\}=\frac{y_{i}}{f\left(x_{i} ; \beta\right) \cdot \exp \left\{v_{i}\right\}}
$$

By definition, $T E_{i}$ takes a value of zero to one.

Eq.(5.3-4) suggests that if $u_{i}=0$, then $\varepsilon_{i}$ (sum of 2-sided errors, $u+v$ ) is $v_{\mathrm{i}}$, the error term is symmetric, and the data do not support a technical inefficiency story. However, if $u_{i}>0$, then $\varepsilon_{i}=v_{i}-u_{i}$ is negatively skewed, and there is evidence of technical inefficiency in the data. In other words, the production process is subject to two random disturbances, namely $u$ and $v$. The frontier is stochastic with random disturbance of $v_{i} \leq$ or $\geq 0$. Technically speaking, we can estimate the variances of $v_{i}$ and $u_{i}$ for each cross-section.

\subsubsection{Some Applications of SPF}

There are numerous studies using the stochastic frontier approach for various

\footnotetext{
${ }^{3}$ We do not aim at providing a survey on various SPF models for cross-sectional analysis since we will carry out panel data analysis. For further reference, Coelli, et al. (1998) and Kumbhakar and Lovell (2000) provide excellent surveys of different SPF models.
} 
applications, mostly for firm-level and industry-level analyses. Models derived from different assumptions and techniques have been extensively employed. The technique was initially developed for the applications at firm-level and industry-level studies, especially on agricultural economics (such as in Battese and Coelli (1992) and Battese and Coelli (1995)) concerning the measurement of inefficiency across different producers. Meeusen and Broeck (1977) were probably among the first to test their model on several manufacturing industries.

After developing panel data stochastic frontier models ${ }^{4}$, recent work like Paul, Johnson, and Frengley (2000), Bhattacharyya, Bhattacharyya, and Mitra (1997), Mahadevan (2002) and Kruger, Canter, and Hanusch (2000) deploy several variations of panel data SPF models for their micro-level studies.

Empirical applications of SPF have been reasonably extended to country-level data. Macro-level work mostly intends to estimate the efficiency levels across countries under different political environment and/or regime changes. In particular, the political changes that took place in Eastern Europe facilitate the comparison of efficiency levels in market-oriented vis-à-vis planned economies. For examples, Koop, Osiewalski, and Steel (1999) initially focus their measurement exercise in 17 OECD countries. Koop, Osiewalski, and Steel (2000) extend further the measurement and make special reference to Poland and Yugoslavia in comparison to 20 Western economies. Moroney and Lovell (1997) share a similar interest and measure the relative efficiencies of 7 transition economies in comparison to other Western economies.

Klein and Luu (2003), on the other hand, use the indices of economic freedom and political constraints as independent variables for explaining inefficiencies in 39 countries from 1975 to 1990 . Their results show that technical efficiency relates positively to policies supporting laissez-faire and political structures that promote policy stability. Adkins, et al. (2002) on the other

\footnotetext{
${ }^{4}$ Among others, more prevalently used panel data SPF models include Schmidt and Sickles (1984), Cornwell, Schmidt, and Sickles (1990) and Battese and Coelli (1992) and Battese and Coelli (1995). See Appendix Section A.7 for details.
} 
hand investigate the impact of economic freedom on promoting efficiency.

However, SPF models are mostly applied to mere measurements of technical efficiency. The sources of technical inefficiencies are not considered and/or incorporated in these models. To incorporate exogenous variables to explain the sources of technical inefficiency, some of the researchers approach the problem using a 2-stage approach. In the first stage, they use the aforementioned SPF models to obtain the technical inefficiency measures, typically by maximum likelihood estimation (ML). In the second stage, the estimated technical inefficiency is treated as dependent variables to be regressed on a vector of explanatory variables in the form such as

$$
E\left(u_{i} \mid v_{i}-u_{i}\right)=g\left(z_{i} ; \gamma\right)+\varepsilon_{i}
$$

where $\mathrm{z}_{\mathrm{i}}$ is the vector of exogenous variables given $\gamma=\frac{\sigma_{u}^{2}}{\sigma_{u}^{2}+\sigma_{v}^{2}}$.

In some cases, it is recognised that since the dependent variable $u$ lies between 0 and 1, OLS estimates cannot be used. Instead, estimation technique such as Tobit for limited dependent variable estimation is employed.

Amongst various studies of such kind, Liu, Liu, and Wei (2001) make special reference to trade openness in the case of India and China. They first employ a dynamic approach on the estimation of a production function and then in the second stage, technical efficiency is treated as dependent variable. Their key results show the relationship of trade openness and their relative technical inefficiencies for the case of India and China.

Although it is fairly often that early literature associating technical inefficiency and its sources uses the aforementioned 2-stage approach, estimations of such kind are fundamentally problematic in terms of econometrics. As Battese and Coelli (1995), Coelli, et al. (1998) and Kumbhakar and Lovell (2000) argue, such an approach has at least 2 obvious flaws. Firstly, 2-stage estimations 
ignore the fact that SPF models in the first stage have assumed a particular distribution of the level of technical inefficiency, $u$. In other words, $u$ is frequently assumed to be an independent random variable with particular distribution. This contradicts with the second stage, where the predicted mean efficiencies are assumed to have a functional form of $z_{i}$. It is thus statistically inconsistent to assume $u$ again at the second stage with any form of specification.

Secondly, the 2-stage approach imposes a restricted assumptions that $z_{i}$ are uncorrelated with $x_{i}$, the production inputs. Otherwise, the estimates obtained in the first stage are biased due to omitted variables. The biased estimates of technical inefficiency being used as dependent variables inevitably undermine the validity of results obtained in the second stage of estimation.

Since our primary research interest of this Chapter is to investigate whether institutions can explain the cross-country technical inefficiencies, SPF models that allow us to incorporate exogenous explanatory factors are essential. While recognising the inadequacies of using a 2-stage approach as in the current literature, we will employ an alternative approach to tackle the problem of such kind. The models we use will be discussed in more details in the next section (i.e. Section 5.4).

\subsubsection{General Critics on SPF}

We do not intend to argue that SPF models are strictly superior to DEA. Indeed, we fully recognise the limitations of this methodology. As Førsund, Lovell, and Schmidt (1980) point out, even though SPF captures a more realistic world, unfortunately there is no way of determining whether the observed performance of a particular observation compared with the deterministic kernel of the frontier is due to inefficiency or to random variation in the frontier. This constitutes the main weakness of the SPF model - i.e. it is not possible to decompose individual residuals into their two components, and so it is not possible to estimate technical inefficiency by observation. What we are estimating is simply the mean inefficiency over the sample, but 
not its "true" value.

Secondly, Coelli, et al. (1998) realise that when using the stochastic frontier approach, the specification of the functional form of the production function matters for the results. Monte Carlo simulation results from Giannakas, Tran, and Tzouvelekas (2003) indicate that the bias in the mean efficiency measures from stochastic frontier methods due to misspecification of functional form is sizeable. It can suggest a high level of inefficiency (10-30\%) of output for the most efficient producers. As Ravallion (2003) also criticises; the approach using non-parametric methods is more preferable in some cases, especially when measuring social efficiency using social indicators. Parametric estimation, like SPF, is very sensitive to outliers and one must assume a continuous frontier. Likewise, the distribution of the inefficiency term also has to be specified.

The stability and reliability of the results are also concerns too. The measured efficiency is only relative to the best cross-section in the sample. Including extra cross-sections may alter the efficiency scores. Furthermore, measurement error and other noise may influence the slope and position of the frontier. Not surprisingly, measurement errors and outliers will likewise influence results significantly. In our estimations, we attempt to alleviate some of these problems by using a reliable source of data to minimize the measurement errors as far as possible.

\subsection{Model Estimation and Specification}

There are primarily four dimensions of SPF models developed and could be considered in our case. These include cross-sectional versus panel data models and with or without assuming time-varying technical efficiency. We will consider the most flexible forms of SPF models - i.e. panel data model with time-varying technical efficiency. The availability of panel data generally implies that there is a large number of degree of freedom for estimation. It also permits the simultaneous investigation of both technical 
change and technical efficiency change over time.

There is also one added advantage of using panel data SPF models. Specification of the error term and the inefficiency term is one of the major challenges of using stochastic production frontier estimation. However, Schmidt and Sickles (1984) show that when panel data are available, assumptions on the distribution of technical inefficiency could be relaxed since the parameters can be estimated using the traditional panel data methods of fixed-effects estimation or error-components estimation. Measuring the technical efficiencies of the sample can be rather straightforward hereafter as they can be obtained relative to the most efficient one(s). This view is also shared by Kumbhakar and Lovell (2000).

The basic framework of panel SPF model is generally similar to the cross-sectional one set out in Section 5.3.1. Appendix Section A.7 summarises some key panel time-varying SPF models, which are often used in the existing literature.

\subsubsection{Battese and Coelli (1993) and (1995) Model}

Our model of estimation is based on the Battese and Coelli (1993) and Battese and Coelli (1995) model. The key advantage of their model is that it allows incorporating the technical efficiency model in the stochastic production frontier estimation to perform a one-stage simultaneous estimation.

Following eq. (5.3-2), the stochastic production frontier in panel data form is defined as:

$$
Y_{i t}=x_{i t} \beta+\mathrm{E}_{i t}
$$

where $\mathrm{E}_{i t}=V_{i t}-U_{i t}$ and $i=1, \ldots, N$ and $t=1, \ldots T$ 
$Y_{i t}$ is the logarithm of production output. $V_{i t}$ is assumed to be iid $\sim N\left(0, \sigma_{v}^{2}\right)$, independently distributed of the $U_{i t}$, which are non-negative random errors associated with technical inefficiency of production.

The technical efficiency model is specified as:

$$
U_{i t}=z_{i t} \delta+W_{i t}
$$

where $W_{i t}$ is a random variable and is defined by the truncation of the normal distribution with zero mean and variance $\sigma^{2}$ and $W_{i t} \geq-z_{i t} \delta$. Technical inefficiency $\left(U_{i t}\right)$ is assumed to be independently distributed for all $t$ and $i$ and is obtained by truncation (at zero) of the normal distribution with mean $z_{i t} \delta$ and variance $\sigma_{u}^{2} . \quad z_{i t}$ is a $(1 \mathrm{x} \mathrm{m})$ vector of country specific institutional environment which may vary over time. $\delta$ is an ( $\mathrm{m} \times 1)$ vector of unknown coefficients. Technical efficiency of production can be defined as:

$$
T E_{i t}=\exp \left(-U_{i t}\right)=\exp \left(-z_{i t} \delta-W_{i t}\right)
$$

Therefore, the density functions for $V_{i t}$ and $U_{i t}$ are:

$$
\begin{array}{cc}
f_{V}(v)=\frac{\exp \left(-\frac{1}{2} v^{2} / \sigma_{v}^{2}\right)}{\sqrt{2 \pi} \sigma_{V}} & -\infty<v<\infty \\
f_{U}(u)=\frac{\exp \left[-\frac{1}{2}(u-z \delta)^{2} / \sigma^{2}\right]}{\sqrt{2 \pi} \sigma \Phi(z \delta / \sigma)} & u \geq 0
\end{array}
$$

where subscripts $i$ and $t$ are omitted for simplicity. $\Phi(\cdot)$ represents the distribution function for the standard normal random variable.

The joint density function for $E=V-U$ and $U$ is 


$$
\begin{aligned}
f_{E, U}(\varepsilon, u) & =\frac{\left.\exp -\frac{1}{2}\left\{(\varepsilon+u)^{2} / \sigma_{v}^{2}\right]+\left[(u-z \delta)^{2} / \sigma^{2}\right]\right\}}{2 \pi \sigma \cdot \sigma_{v} \cdot \Phi(z \delta / \sigma)} \\
& =\frac{\left.\exp -\frac{1}{2}\left\{\left(u-\mu_{*}\right)^{2} / \sigma_{*}^{2}\right]+\left(\varepsilon^{2} / \sigma_{v}^{2}\right)+(z \delta / \sigma)^{2}-\left(\mu_{*} / \sigma_{*}\right)^{2}\right\}}{2 \pi \sigma \cdot \sigma_{v} \cdot \Phi(z \delta / \sigma)}
\end{aligned}
$$

Alternatively,

$$
f_{E, U}(\varepsilon, u)=\frac{\left.\exp -\frac{1}{2}\left\{\left(u-\mu_{*}\right)^{2} / \sigma_{*}^{2}\right]+\left[(\varepsilon+z \delta)^{2} /\left(\sigma_{v}^{2}+\sigma^{2}\right)\right]\right\}}{2 \pi \sigma \cdot \sigma_{v} \cdot \Phi(z \delta / \sigma)}
$$

$$
\text { where } \mu_{*}=\frac{\sigma_{v}^{2} z \delta-\sigma^{2} \varepsilon}{\sigma_{v}^{2}+\sigma^{2}} \text { and } \sigma_{*}^{2}=\sigma^{2} \sigma_{v}^{2} /\left(\sigma^{2}+\sigma_{v}^{2}\right)
$$

Such that the density function for $E=V-U$ is

$$
\begin{aligned}
f_{E}(\varepsilon) & =\frac{\exp -\frac{1}{2}\left[\left(\varepsilon^{2} / \sigma_{v}^{2}\right)+(z \delta / \sigma)^{2}-\left(\mu_{*} / \sigma_{*}\right)^{2}\right]}{\sqrt{2 \pi} \sigma_{v} \sigma \cdot \Phi(z \delta / \sigma)} \cdot \int_{0}^{\infty} \frac{\exp -\frac{1}{2}\left[\left(u-\mu_{*}\right)^{2} / \sigma_{*}^{2}\right]}{\sqrt{2 \pi}} d u \\
& =\frac{\exp -\frac{1}{2}\left[\left(\varepsilon^{2} / \sigma_{v}^{2}\right)+(z \delta / \sigma)^{2}-\left(\mu_{*} / \sigma_{*}\right)^{2}\right]}{\sqrt{2 \pi}\left(\sigma^{2}+\sigma_{v}^{2}\right)^{1 / 2}\left[\Phi(z \delta / \sigma) / \Phi\left(\mu_{*} / \sigma_{*}\right)\right]}
\end{aligned}
$$

Alternatively,

$$
f_{\mathrm{E}}(\varepsilon)=\frac{\exp \left\{-\frac{1}{2}(\varepsilon+z \delta)^{2} /\left(\sigma_{v}^{2}+\sigma^{2}\right)\right\}}{\sqrt{2 \pi}\left(\sigma^{2}+\sigma_{v}^{2}\right)^{1 / 2}\left[\Phi(z \delta / \sigma) / \Phi\left(\mu_{*} / \sigma_{*}\right)\right]}
$$

The conditional density function for $U$ given $E=\varepsilon$ is thus 


$$
f_{U \mid \mathrm{E}=\varepsilon}(u)=\frac{\exp -\frac{1}{2}\left[\left(u-\mu_{*}\right)^{2} / \sigma_{*}^{2}\right]}{\sqrt{2 \pi} \sigma_{*} \Phi\left(\mu_{*} / \sigma_{*}\right)} \quad u \geq 0
$$

Conditional expectation of $\varepsilon^{-U}$ given $E=\varepsilon$ is

$$
E\left(\varepsilon^{-U} \mid E=\varepsilon\right)=\left[\exp \left(-\mu_{*}+\frac{1}{2} \sigma_{*}^{2}\right)\right]\left\{\frac{\Phi\left[\left(\mu_{*} / \sigma_{*}\right)-\sigma_{*}\right]}{\Phi\left(\mu_{*} / \sigma_{*}\right)}\right\}
$$

such that the density function for $Y_{i t}$ in eq.(5.4-1) can be derived from eq.(5.4-9):

$$
f_{Y_{i t}}\left(Y_{i t}\right)=\frac{\exp -\frac{1}{2}\left\{\frac{\left(Y_{i t}-x_{i t} \beta+z_{i t} \delta\right)^{2}}{\sigma_{v}^{2}+\sigma^{2}}\right\}}{\sqrt{2 \pi}\left(\sigma_{v}^{2}+\sigma^{2}\right)^{1 / 2}\left[\Phi\left(d_{i t}\right) / \Phi\left(d_{i t}^{*}\right)\right]}
$$

where $d_{i t}=z_{i t} \delta / \sigma, d_{i t}^{*}=\mu_{i t}^{*} / \sigma_{*}$ and

$$
\mu_{i t}^{*}=\left[\sigma_{v}^{2} z_{i t} \delta-\sigma^{2}\left(Y_{i t}-x_{i t} \beta\right)\right] /\left(\sigma_{v}^{2}+\sigma^{2}\right)
$$

The logarithm of the likelihood function for the sample observations $\boldsymbol{y}$ is:

$$
\begin{aligned}
& L^{*}\left(\theta^{*} ; y\right)=-\frac{1}{2}\left(\sum_{i=1}^{N} T_{i}\right)\left\{\ln 2 \pi+\ln \left(\sigma^{2}+\sigma_{v}^{2}\right)\right\} \\
& -\frac{1}{2} \sum_{i=1}^{N} \sum_{t=1}^{T_{i}}\left[\left(Y_{i t}-x_{i t} \beta+z_{i t} \delta\right)^{2} /\left(\sigma_{v}^{2}+\sigma^{2}\right)\right] \\
& -\sum_{i=1}^{N} \sum_{t=1}^{T_{i}}\left[\ln \Phi\left(d_{i t}\right)-\ln \Phi\left(d_{i t}^{*}\right)\right]
\end{aligned}
$$

where $\theta^{*}=\left(\beta^{\prime}, \delta^{\prime}, \sigma_{v}^{2}, \sigma^{2}\right)^{\prime}$. 
Put $\sigma_{s}^{2} \equiv \sigma_{v}^{2}+\sigma^{2}$ and $\gamma \equiv \sigma^{2} / \sigma_{s}^{2}$, eq.(5.4-13) can be expressed as

$$
\begin{aligned}
& L^{*}\left(\theta^{*} ; y\right)=-\frac{1}{2}\left(\sum_{i=1}^{N} T_{i}\right)\left\{\ln 2 \pi+\ln \sigma_{s}^{2}\right\} \\
& -\frac{1}{2} \sum_{i=1}^{N} \sum_{t=1}^{T_{i}}\left[\left(Y_{i t}-x_{i t} \beta+z_{i t} \delta\right)^{2} / \sigma_{s}^{2}\right] \\
& -\sum_{i=1}^{N} \sum_{t=1}^{T_{i}}\left[\ln \Phi\left(d_{i t}\right)-\ln \Phi\left(d_{i t}^{*}\right)\right]
\end{aligned}
$$

where $\quad d_{i t}=z_{i t} \delta /\left(\gamma \sigma_{S}^{2}\right)^{1 / 2}$

$$
\begin{aligned}
& d_{i t}^{*}=\mu_{i t}^{*} /\left[\gamma(1-\gamma) \sigma_{s}^{2}\right]^{1 / 2} \\
& \mu_{i t}^{*}=(1-\gamma) z_{i t} \delta-\gamma\left(y_{i t}-x_{i t} \beta\right) \\
& \sigma_{*}=\left[\gamma(1-\gamma) \sigma_{s}^{2}\right]^{1 / 2}
\end{aligned}
$$

and $\theta=\left(\beta^{\prime}, \delta^{\prime}, \sigma_{s}^{2}, \gamma\right)^{\prime}$.

The partial derivatives of eq.(5.4-13) with respect to $\beta, \delta, \sigma_{s}^{2}, \gamma$ are,

$$
\begin{aligned}
\frac{\partial L^{*}}{\partial \beta}= & \sum_{i=1}^{N} \sum_{t=1}^{T_{i}}\left\{\frac{\left(Y_{i t}-x_{i t} \beta+z_{i t} \delta\right)}{\sigma_{s}^{2}}+\frac{\phi\left(d_{i t}^{*}\right)}{\Phi\left(d_{i t}^{*}\right)} \cdot \frac{\gamma}{\sigma_{*}}\right\} \cdot x_{i t}^{\prime} \\
\frac{\partial L^{*}}{\partial \delta}= & -\sum_{i=1}^{N} \sum_{t=1}^{T_{i}}\left\{\frac{Y_{i t}-x_{i t} \beta+z_{i t} \delta}{\sigma_{s}^{2}}+\left[\frac{\phi\left(d_{i t}\right)}{\Phi\left(d_{i t}\right)} \cdot \frac{1}{\left(\gamma \sigma_{s}^{2}\right)^{1 / 2}} \cdot\right.\right. \\
& \left.\left.-\frac{\phi\left(d_{i t}\right)}{\Phi\left(d_{i t}\right)} \cdot \frac{1-\gamma}{\sigma_{*}}\right]\right\} \cdot z_{i t}^{\prime}
\end{aligned}
$$

$$
\begin{aligned}
\frac{\partial L^{*}}{\partial \sigma_{s}^{2}}= & -\frac{1}{2}\left(\frac{1}{\sigma_{s}^{2}}\right)\left\{\left(\sum_{i=1}^{N} T_{i}\right)-\sum_{i=1}^{N} \sum_{t=1}^{T_{i}}\left[\frac{\phi\left(d_{i t}\right)}{\Phi\left(d_{i t}\right)} d_{i t}\right.\right. \\
& \left.\left.-\frac{\phi\left(d_{i t}^{*}\right)}{\Phi\left(d_{i t}^{*}\right)} d_{i t}^{*}\right]-\sum_{i=1}^{N} \sum_{t=1}^{T_{i}} \frac{Y_{i t}-x_{i t} \beta+z_{i t} \delta}{\sigma_{s}^{2}}\right\}
\end{aligned}
$$




$$
\begin{aligned}
\frac{\partial L^{*}}{\partial \gamma}= & \sum_{i=1}^{N} \sum_{t=1}^{T_{i}}\left\{\frac{\phi\left(d_{i t}\right)}{\Phi\left(d_{i t}\right)} \frac{d_{i t}}{2 \gamma}+\right. \\
& \left.\frac{\phi\left(d_{i t}^{*}\right)}{\Phi\left(d_{i t}^{*}\right)}\left[\frac{Y_{i t}-x_{i t} \beta+z_{i t} \delta}{\sigma_{*}}+\frac{d_{i t}^{*}(1-2 \gamma)}{2 \gamma(1-\gamma) \sigma_{*}^{2}}\right]\right\}
\end{aligned}
$$

where $\phi(\cdot)$ is the density function for the standard normal random variable. The necessary condition for maximizing the log-likelihood function is that these partial derivatives equal 0 .

Estimation output can be obtained from the FRONTIER 4.1 program devised by Coelli (1996). The estimation follows a three-step procedure in estimating the maximum likelihood estimates of the parameters of a stochastic frontier production function. The three steps involve:

1) OLS estimates of the production function (including $\beta_{0}$ and $\sigma_{\mathrm{S}}{ }^{2}$ are obtained), such that all coefficients (except the intercept and $\sigma_{\mathrm{S}}{ }^{2}$ ) will be unbiased.

2) A two-phrase grid search of $\gamma$ (between zero and one) is conducted. The OLS estimates of $\sigma_{\mathrm{S}}{ }^{2}$ and $\beta_{0}$ are adjusted $\sigma_{S}^{2}=\sigma_{O L S}^{2}[\pi(T-K)] /[T(\pi-2 \hat{\gamma})] \quad$ and $\quad \hat{\beta}_{0}=\hat{\beta}_{0(O L S)}+\sqrt{\frac{2 \hat{\gamma} \hat{\sigma}_{S}^{2}}{\pi}}$ respectively. The OLS estimates are used for the remaining parameters in $\beta$.

3) The values selected in the grid search are used as starting values in an iterative procedure to obtain the final maximum likelihood estimates. 


\subsubsection{Post-estimation Test}

The one-sided generalized likelihood-ratio test (hereafter called LR-Test) can be used for hypothesis testing. This aims at providing a statistical test of the goodness-of-fit between two models. In short, a relatively more complex model is compared to a simpler model to see if it fits a particular dataset significantly better. If so, the additional parameters of the more complex model are often used in subsequent analyses. The LR-Test is only valid if it is used to compare hierarchically nested models. That is, the more complex model must differ from the simple model only by the addition of one or more parameters. Further addition of parameters will always result in a higher likelihood score. However, there comes a point when adding additional parameters is no longer justified in terms of significant improvement in the goodness of fit for the model to a particular dataset. The LR-Test provides one objective criterion for selecting different possible models. This will also serve as the basis of our model selection among different specifications.

The LR-Test begins with a comparison of the likelihood scores of the two models. The likelihood-ratio test statistic is calculated as:

$$
\lambda=-2\left[\log \left(\operatorname{likelihood}\left(\mathrm{H}_{0}\right)\right)-\log \left(\operatorname{likelihood}\left(\mathrm{H}_{1}\right)\right)\right]
$$

which has approximately chi-square distribution with degree of freedom equal to the number of parameters assumed to be equal to zero in the null hypothesis, $H_{0}$. Kodde and Palm (1986) design a Wald test to jointly test the equality of restrictions and provide the critical values for the LR-Test. 


\subsubsection{Model Specification}

We specify our stochastic production frontier in the translog form as proposed by Christensen, Jorgenson, and Lau (1973):

$$
\begin{aligned}
\ln Y_{i t}= & \beta_{0}+\beta_{K} \ln K_{i t}+\beta_{L} \ln L_{i t}+\beta_{K K}\left(\ln K_{i t}\right)^{2}+\beta_{L L}\left(\ln L_{i t}\right)^{2}+ \\
& \beta_{K L}\left(\ln K_{i t} \cdot \ln L_{i t}\right)+\beta_{K t}\left(\ln K_{i t} \cdot t\right)+\beta_{L t}\left(\ln L_{i t} \cdot t\right)+\beta_{t} t+\beta_{t t} t^{2}+v_{i t}-u_{i t}
\end{aligned}
$$

where $v_{i t} \sim$ iid $N\left(0, \sigma_{v}^{2}\right)$ is a random disturbance. $u_{i t}$ is the level of technical inefficiency of $i$-th cross-section at time $t . \quad \beta_{0}$ is the constant term in the production function to capture the initial level of technology. The translog production function does not restrict the returns to scale of the production function and substitution possibilities. It is thus a more general and flexible form of specification in comparison to Cobb-Douglas production function for example.

As suggested by Coelli, et al. (1998), we also incorporate a time trend (t) to capture the potential shifts of the production frontier over time, which reflects the rate of technological change. In our specification, therefore, the coefficient $\beta_{t}$ provides an estimate of the annual percentage change in output resulting from technological change. Since the translog specification is a second-order approximation, $t^{2}$ is also included. An estimate of the annual percentage change in output resulting from technological change is provided by the first partial derivative of eq.(5.4-20) with respect to $t$.

For the time-varying technical inefficiency model, our general form of specification is

$$
\begin{aligned}
u_{i t}= & \delta_{0}+\delta_{i} \text { instit }_{i t}+\delta_{H} H+\delta_{i H} \text { instit }_{i t} \cdot H_{i t} \\
& +\delta_{\text {open }} \text { openness }+\delta_{t} t+w_{i t}
\end{aligned}
$$


where $w_{i t}$ is a random disturbance with a truncated normal distribution. instit is a set of variables measuring institutions. $H$ measures human capital. The interaction term of human capital and institution allows us to see if the institution affects technical efficiency given the necessary level of human capital. openness is a set of variables measures openness to trade, financial integration and capital account openness. $\delta$ is a vector of coefficients of the respective areas to be estimated. The final specification of the model will depend on the LR-Test results for different specifications.

All in all, our empirical investigation primarily concerns the sources of cross-country technical inefficiency. With regard to methodology, our work intends to contribute in three ways. Firstly, compared to the other growth-accounting (e.g. TFP growth measurement) literature, we extend the work to decompose the different sources of growth and attempt to seek the sources of cross-country divergence, in terms of technical change and efficiency change. Secondly, our study uses a one-stage approach to estimate the stochastic production frontier while incorporating the explanatory factors of technical inefficiency. Such design will avoid the inconsistent assumptions used when employing two-stage estimations. Finally, as we will discuss in the following, we use a relatively large number of economies comparing to other studies for a longer period of time. We are of the view that only employing a substantial amount of economies would bring the estimation of a "world frontier" more meaningful.

\subsection{Data}

We have a panel dataset for 108 cross-sections covering 24 OECD economies and 78 economies in East Asia and Pacific, Europe and Central Asia, Middle East and North Africa, Latin American and Caribbean, South Asia and Africa. Six high-income economies are also included but they are not classified by regions ${ }^{5}$. The full list of economies covered in our study is at Appendix

\footnotetext{
${ }^{5}$ Country classification by income groups and regions are based on World Bank Country
} 


\section{Section A.4.}

The study period starts from 1971 to 2000, signifying the beginning of globalization, free flow of information and capital. It also better reflects the uprising of emerging markets, in particular towards the latter periods of the studied period. The sample is nevertheless limited by the availability of institutional variables, which are only in place starting from 1970.

\subsubsection{Output and Production Inputs}

Output is measured as chain-weighted real GDP in constant 1996 prices, which is PPP-adjusted to facilitate cross-country comparison. We derive output $(\boldsymbol{Y})$ data from the Penn World Table (PWT ver 6.1) (Heston, Summers, and Aten (2002)), where $\boldsymbol{Y}$ is obtained from real GDP per capita multiplied by population.

The labour force $(\boldsymbol{L})$ is the number of workers from PWT, derived from real GDP per worker data. We understand that using employment data is a more accurate measure of production input than total labour force. However, as far as we understand, only the OECD and Asia Development Bank (ADB) produce employment data. The International Labour Organisation (ILO) also collects cross-country unemployment rates, which could also be used to derive employment from labour force data. However, the sample size will be significantly reduced if these data sources are used.

Based on Isaksson (2007b), capital stock $(\boldsymbol{K})$ can be calculated from real investment data. Total real investment is measured as real total output ( $\boldsymbol{Y}$ ) multiplied by investment share of real GDP per capita in PWT. For missing values, we follow Isaksson (2009) to interpolate the series by taking the average of two years.

Our capital stock estimates are heavily based on Isaksson (2007b). As in

Classification. 
King and Levine (1994), Benhabib and Spiegel (1997) and Limam and Miller (2004), amongst others, the standard way is to use the perpetual inventory method with the steady-state initial capital stock. The 1960 capital stock is assumed to be the initial steady-state value for each country ${ }^{11}$ and it is then incorporated with investment data to derive the capital stock for subsequent periods (till 2000).

It is commonly assumed that the capital-output ratio is constant in the steady-state. That said, physical capital and real output grow at the same rate. The depreciation rate $\delta$ is assumed to be $6 \%$ across countries over time. Hence, the steady-state capital-output ratio for country $i$ is derived as:

$$
\kappa_{i}=i_{i} /\left(\delta+\lambda g_{i}+(1-\lambda) g_{w}\right)
$$

$i_{i}$ is the steady-state investment rate for country $i$, which is proxied by average real investment rate for the first 10 years. $\lambda g_{i}+(1-\lambda) g_{w}$ is the steady-state growth rate which is the weighted average of the country's growth rate and the world growth rate. $\lambda$ is a measure of mean reversion of growth rates and equals to 0.25 as in Easterly, Kremer, Prichett, et al. (1993). $g_{i}$ is the country's average growth rate over the period 1960 to $1969 . g_{w}$ is the world growth rate and is approximated to be $4 \%$.

Initial capital stock in year 1960 (or earliest possible year in our sample) can thus be expressed as:

$$
K_{i, 60}=\kappa_{i} \cdot Y_{i, 60}
$$

where $Y_{i, 60}$ is real GDP of country $i$ in year 1960 .

The calculation of capital stock for the remaining years, using perpetual inventory method, comes as the following:

\footnotetext{
${ }^{11}$ Alternatively, we use data in the earliest possible year during the 60's subject to availability.
} 


$$
K_{i t+1}=I_{i t}+(1-\delta) K_{i t}
$$

The series of capital stock from 1960 to 2000 can thus be obtained.

We further take a non-overlapping 5-year average for all the variables to get rid of the business cycle effect. Islam (1995) also suggests that using a 5-year average series is less likely to be serially correlated. Our dataset therefore collapses to 6 periods in total.

\subsubsection{Explanatory Variables for TE Models}

Regressors for the TE models have been defined in details in previous Chapters and set out in details in Appendix Section A.2. Descriptive statistics of our sample are at Appendix Section A.3. To recap, we consider three aspects of explanatory variables in the TE model, which include:

1. Human capital $(\boldsymbol{H})$ : average years of schooling of aged 15 or above from Barro and Lee (2001).

2. Institution: Our measures of different institutional variables primarily come from the Fraser Institute's Economic Freedom of the World Report of Gwartney, et al. (2008) and Polity IV project dataset of Marshall and Jaggers (2009). As in Chapter 2, Rodrik (2000)'s taxonomy of institutions are again adopted. We will first use the composite quality of government index (QOG) from ICRG for testing the various specifications of the production function. In our key models, specifically, we use the Fraser's legal structure and security of property rights index $(\boldsymbol{L E G A L})$ for "market-creating institutions". We use the composite index of regulation ( $\boldsymbol{R} \boldsymbol{E} \boldsymbol{G})$ as a measure of "market-regulating institution". For "market-stabilising institutions", we consider the use of the access to sound money index $(\boldsymbol{S M})$ to proxy the effectiveness of monetary policy. For "market-legitimising institutions", we use 
the institutionalised democracy index from Polity IV project (DEMOC).

3. Openness: We use four indicators (i) financial integration index from Lane and Milesi-Ferretti (2006) (FIN); (ii) capital account openness index from Chinn and Ito (2006) (KAOPEN), and (iii) total trade to GDP (TRADE), and; (iv) total FDI inflows to GDP (FDI). Both (iii) and (iv) are from World Development Indicators.

\subsection{Estimation Results}

\subsubsection{Specification of Production Function}

We first take a preliminary test of the specification of the production function as set out in eq.(5.4-20). For simplicity, we incorporate $\boldsymbol{Q O} \boldsymbol{G}$, a composite index of the quality of government, as the only explanatory variable in the technical inefficiency model at this stage. The key aim of the results is to provide support to our specification of the production function. Test results are given in Table 5.6.1-1.

A Cobb-Douglas production function is specified in SPF Model (1), A Hicks-neutral translog production function is used for SPF Model (2) and a non-neutral translog production function is at SPF Model (3). As we explained earlier, the translog production function is a more flexible form of the Cobb-Douglas production function. Comparing SPF Models (2) and (3), the former model only accounts for Hicks-neutral technical change. That is, the production function shifts up and down but their slopes (e.g. marginal rate of technical substitution) do not alter. In SPF Model (3), non-neutral technical change is also accounted for by including terms involving the interactions of the other regressors and time. Non-neutral technical change is also referred to as biased technical change. That said, the movement of the production function will be biased in favour of certain inputs and against 
others.

All three SPF models show that the signs of elasticities of both capital and labour $\left(\beta_{K}\right.$ and $\left.\beta_{L}\right)$ are positive as the theory predicted. Compared to the standard assumption of input shares of capital and labour to be one-third and two-third respectively, the parameters in SPF Model (1) show rather awkward results $-\beta_{K}$ is around 0.6 whereas $\beta_{L}$ is around 0.3. In SPF Models (2) and (3), the input elasticities are more sensible. The production functions in both models exhibit a decreasing return to scale, with $\beta_{K}$ is around 0.25 and $\beta_{L}$ is around 0.6. 
Table 5.6.1-1: Maximum Likelihood Estimation of Stochastic Production Frontier Models

\begin{tabular}{|c|c|c|c|}
\hline & $\begin{array}{c}\text { SPF Model (1) } \\
\text { Coeff. } \\
\text { (std. error) } \\
\end{array}$ & $\begin{array}{c}\text { SPF Model (2) } \\
\text { Coeff. } \\
\text { (std. error) } \\
\end{array}$ & $\begin{array}{c}\text { SPF Model (3) } \\
\text { Coeff. } \\
\text { (std. error) } \\
\end{array}$ \\
\hline \multicolumn{4}{|l|}{ Dep var: $\ln (Y)$} \\
\hline \multirow[t]{2}{*}{$\beta_{0}$} & $1.6486 * * *$ & $3.0593 * * *$ & $2.8515 * * *$ \\
\hline & $\begin{array}{l}(0.1282) \\
0.6258 * * *\end{array}$ & $\begin{array}{l}(0.7104) \\
0 . * 6\end{array}$ & $(0.7104)$ \\
\hline$\beta_{\mathrm{K}}$ & $(0.0065)$ & $(0.0686)$ & $(0.0686)$ \\
\hline \multirow{2}{*}{$\beta_{\mathrm{L}}$} & $0.3321 * * *$ & $0.5897 * * *$ & $0.6132 * * *$ \\
\hline & $(0.0091)$ & (0.0909) & $(0.0909)$ \\
\hline \multirow[t]{2}{*}{$\beta_{\mathrm{KK}}$} & - & $0.0254 * * *$ & $0.0219 * * *$ \\
\hline & & $(0.0036)$ & $(0.0036)$ \\
\hline \multirow[t]{2}{*}{$\beta_{\mathrm{LL}}$} & - & $0.0101 *$ & 0.0086 \\
\hline & & $(0.0061)$ & $(0.0061)$ \\
\hline \multirow[t]{2}{*}{$\beta_{\mathrm{KL}}$} & - & $-0.0329 * * *$ & $-0.0284 * * *$ \\
\hline & & $(0.0086)$ & $(0.0086)$ \\
\hline \multirow[t]{2}{*}{$\beta_{\mathrm{t}}$} & $-0.1790 * * *$ & $-0.1580 * * *$ & $-0.1579 * * *$ \\
\hline & $(0.0340)$ & $(0.0318)$ & $(0.0318)$ \\
\hline \multirow[t]{2}{*}{$\beta_{\mathrm{tt}}$} & $0.0207 * * *$ & $0.0184 * * *$ & $0.0160 * * *$ \\
\hline & $(0.0045)$ & $(0.0043)$ & $(0.0043)$ \\
\hline \multirow[t]{2}{*}{$\beta_{\mathrm{Kt}}$} & - & - & $0.0140 * * *$ \\
\hline & & & $(1.6482)$ \\
\hline \multirow[t]{2}{*}{$\beta_{\mathrm{Lt}}$} & - & - & $-0.0152 * * *$ \\
\hline & & & $(1.8987)$ \\
\hline \multicolumn{4}{|l|}{ Dep. var: $u_{i t}$} \\
\hline \multirow[t]{2}{*}{$\delta_{0}$} & -3.4124 & $-3.5042 * *$ & $-3.3153 * * *$ \\
\hline & $(2.8724)$ & $(1.6482)$ & $(0.4794)$ \\
\hline \multirow[t]{2}{*}{$\delta_{\mathrm{QOG}}$} & -6.2458 & $-5.9513 * * *$ & $-5.9151 * * *$ \\
\hline & (3.9504) & (1.8987) & $(0.0091)$ \\
\hline \multirow[t]{2}{*}{$\sigma^{2}$} & 1.4331 & $1.3565 * * *$ & $1.2926 * * *$ \\
\hline & $(0.9350)$ & $(0.4794)$ & $(0.3263)$ \\
\hline \multirow[t]{2}{*}{$\gamma$} & $0.9731 * * *$ & $0.9757 * * *$ & $0.9750 * * *$ \\
\hline & $(0.0190)$ & $(0.0091)$ & $(0.0058)$ \\
\hline Log(likelihood) & -141.5746 & -106.6068 & -100.2863 \\
\hline
\end{tabular}

$* * *, * *$ and $*$ denote $1 \%, 5 \%$ and $10 \%$ statistical significance respectively.

We use the LR-test described in Section 5.4.2 as a basis for model selection. The test results are summarised in Table 5.6.1-2. The hypothesis test suggests that SPF Model (3) is supported. It will also form the baseline specification of our models. 
Table 5.6.1-2: Hypothesis Testing for SPF Models (1) - (3)

\begin{tabular}{|c|c|c|c|c|}
\hline & Null Hypotheses $\left(\mathrm{H}_{0}\right)$ & $\begin{array}{c}\chi^{2}- \\
\text { stat }\end{array}$ & $\chi^{2}$-critical ${ }^{7}$ & Decision \\
\hline (1) & $\begin{array}{l}\quad \beta_{\mathrm{KK}}=\beta_{\mathrm{LL}}=\beta_{\mathrm{KL}}=\beta_{\mathrm{Kt}}=\beta_{\mathrm{Lt}}=0 \\
\text { (i.e. Model (1) vs. Model (3)) }\end{array}$ & 82.58 & 10.371 & $\begin{array}{c}\text { Reject } \mathrm{H}_{0} \\
\text { (i.e. Accept Model (3)) }\end{array}$ \\
\hline (2) & $\begin{array}{c}\beta_{\mathrm{Kt}}=\beta_{\mathrm{Lt}}=0 \\
\text { (i.e. Model (2) vs. Model (3)) }\end{array}$ & 12.64 & 5.138 & $\begin{array}{c}\text { Reject } \mathrm{H}_{0} \\
\text { (i.e. Accept Model (3)) }\end{array}$ \\
\hline
\end{tabular}

Since panel data are used, the SPF Model (3) also suggests that we can estimate the rate of technological change in our specification. The percentage change in output over periods resulting from technological change is provided by $\beta_{t}+2 t \beta_{t t}$, varying for different values of period $t$. Since $\beta_{t t}$ is positive in our model, our results suggest that the rate of technological change increased over the measured periods. Moreover, it is also noted that $\beta_{K L}$ and $\beta_{L t}$ are negative, implying a possible substitution effect between $\mathrm{K}$ and $\mathrm{L}$ over time and technical change is biased toward the use of capital.

The bottom panel of Table 5.6.1-1 is the technical inefficiency model. The parameter of $\beta_{Q O G}$ is negative at the $1 \%$ statistically significance level. Results of SPF Model (3) imply a negative relationship between $\boldsymbol{Q O} \boldsymbol{G}$ and technical inefficiency. $\gamma$, representing the percentage of variance of technical inefficiency to the total variance of the model, is around $98 \%$. In other words, $98 \%$ of the variation of the model can be explained by the technical efficiency model. The figure is also statistically significant at $1 \%$ level, providing support to the technical inefficiency story.

\subsubsection{Sources of Technical Inefficiency}

Our main research interest is to investigate the sources of technical inefficiency. As specified in eq.(5.4-21), the estimation results of this full model (i.e. TE Model (1)) are in Table 5.6.2-1. The stochastic production function is

\footnotetext{
${ }^{7}$ Critical values of test statistics are obtained from Kodde and Palm (1986).
} 
specified in a way similar to SPF Model (3), i.e. a non-neutral translog production function. The technical inefficiency model incorporates $\delta_{t}$, allowing technical inefficiency $\left(u_{i t}\right)$ to be time-varying.

Table 5.6.2-1: Maximum Likelihood Estimation of Stochastic Production Frontier Model (TE Model (1))

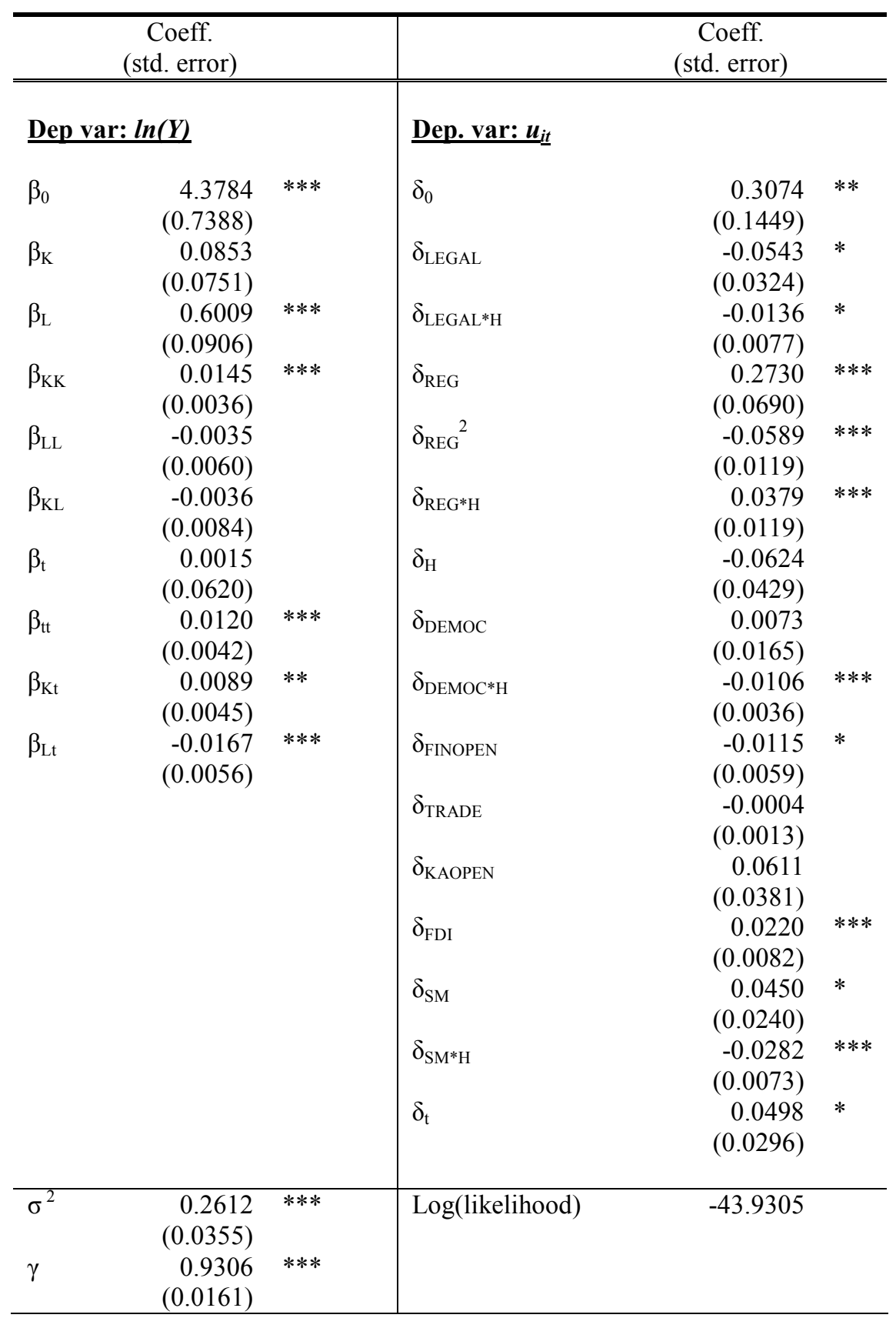

$* * *, * *$ and $*$ denote $1 \%, 5 \%$ and $10 \%$ statistical significance respectively. 
First of all, on the effect of human capital $(\boldsymbol{H})$ on technical inefficiency, the estimated parameter $\left(\delta_{H}\right)$ suggests negative association between the two. This implies that economies with more human capital tend to be more technically efficient, but the effect is not statistically significant.

In terms of institutions, the full model tests their direct impact on technical inefficiency as well as the interactive term of institutions with human capital, which attempts to measure the impact of institutions given a necessary level of

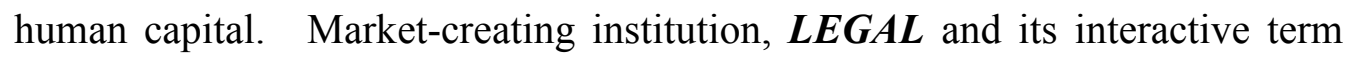
with $\boldsymbol{H}$ are both negative and statistically significant, albeit at $10 \%$ level only. In other words, economies with better secured property rights and legal system are less technically inefficient. $\delta_{L E G A L *_{H}}$ is negative, signifying economies with more human capital are less technically inefficient even if their market-creating institutions are comparable.

Such a negative relationship is also found to be statistically significant for parameters of $\delta_{S M^{*} H}$ and $\delta_{D E M O C^{*} H}$. However, the direct impact of the market-stabilising institution, $\boldsymbol{S M}$, and the market-legitimising institution, DEMOC, are found to be positive, although the former is only at $10 \%$ significance level and the latter is not statistically significant. These results are not in line with our hypothesis - better institutions tend to reduce technical inefficiency. This prompts us to test the validity of these parameters in the model.

On the impact of market-regulating institution - $\boldsymbol{R E} \boldsymbol{G}$, the results are less straightforward. $\delta_{R E G}$ is positive, suggesting that less regulation is more technically inefficient. It may first appear to be odd. However, this may also imply that there is a potential optimal level of regulation. As we argue earlier, market-regulating institution could be either market-promoting by rectifying monopoly and promoting competition or market-hampering by generating red-tape and bureaucratic delay. In this light, we incorporate a square term $\boldsymbol{R} \boldsymbol{E} \boldsymbol{G}^{2}$ to capture such an effect, which is statistically significant at 1\% level. Taking both parameters together, our results suggest a U-shape relationship between technical inefficiency and the level of regulation. It 
implies that when the economy has a too low level of regulations, introducing more regulations can improve technical inefficiency. However, once the level of regulation reaches a critical point, more regulation will lead to worsening technical inefficiency.

For openness parameters, trade openness and capital account openness $\left(\delta_{\text {TRADE }}\right.$ and $\left.\delta_{K A O P E N}\right)$ do not have statistically significant impact on $u_{i t .}$. Financial openness has a positive impact on improving technical efficiency, although it is only statistically significant at $10 \%$ level. Unexpectedly, more FDI inflows associate with technical inefficiency. This is contrary to our expectation that more foreign capital leads to more foreign competition and more efficient use of production inputs. Our results, however, suggest that foreign firms (in the form of FDI) could possibly be more competitive and thus dominate the domestic markets. It thus crowds out the competition from domestic firms.

Against the estimation results of unexpected signs of some parameters obtained in TE Model (1), we deploy the formal LR-Test to test the validity of the coefficients more robustly. The test results are presented in Table 5.6.2-2 below.

Table 5.6.2-2: Hypothesis Testing for TE Model (1)

\begin{tabular}{|c|c|c|c|}
\hline Null Hypotheses & Log(likelihood) & $\chi^{2}$-stat & Decision \\
\hline$\overline{\delta_{\text {LEGAL }}}=0$ & -45.79 & 3.72 & Reject $\mathrm{H}_{0}$ \\
\hline$\delta_{\mathrm{LEGAL} * \mathrm{H}}=0$ & -45.20 & 2.54 & Accept $\mathrm{H}_{0}$ \\
\hline$\delta_{\mathrm{REG}}=0$ & -49.30 & 10.74 & Reject $\mathrm{H}_{0}$ \\
\hline$\delta_{\mathrm{REG}}{ }^{2}=0$ & -53.34 & 18.82 & Reject $\mathrm{H}_{0}$ \\
\hline$\delta_{\mathrm{REG}^{* H} \mathrm{H}}=0$ & -49.08 & 10.30 & Reject $\mathrm{H}_{0}$ \\
\hline$\delta_{\mathrm{H}}=0$ & -44.77 & 1.68 & Accept $\mathrm{H}_{0}$ \\
\hline$\delta_{\text {DEMOC }}=0$ & -43.97 & 0.08 & Accept $\mathrm{H}_{0}$ \\
\hline$\delta_{\mathrm{DEMOC} * \mathrm{H}}=0$ & -46.22 & 4.58 & Reject $\mathrm{H}_{0}$ \\
\hline$\delta_{\text {FINOPEN }}=0$ & -45.13 & 2.40 & Accept $\mathrm{H}_{0}$ \\
\hline$\delta_{\mathrm{TRADE}}=0$ & -44.66 & 1.46 & Accept $\mathrm{H}_{0}$ \\
\hline$\delta_{\mathrm{KAOPEN}}=0$ & -45.44 & 3.02 & Reject $\mathrm{H}_{0}$ \\
\hline$\delta_{\mathrm{FDI}}=0$ & -46.11 & 4.36 & Reject $\mathrm{H}_{0}$ \\
\hline$\delta_{\mathrm{SM}}=0$ & -45.22 & 2.58 & Accept $\mathrm{H}_{0}$ \\
\hline$\delta_{\mathrm{SM}^{* \mathrm{H}}}=0$ & -49.05 & 10.24 & Reject $\mathrm{H}_{0}$ \\
\hline
\end{tabular}

Note: The critical value of the log likelihood ratio test for degree of 1 is 2.706 . 
Table 5.6.2-2 points out that the LR-test rejects the validity and significance of some parameters in our full model - TE Model (1). This facilitates us to re-specify TE Model (1) into TE Model (2). In the latter model, we drop all parameters that can be accepted as zero in the LR-test. The estimation results of TE Model (2) are in Table 5.6.2-3.

Table 5.6.2-3: Maximum Likelihood Estimation of Stochastic Production Frontier Model (TE Model (2))

\begin{tabular}{|c|c|c|c|c|c|}
\hline \multicolumn{3}{|c|}{$\begin{array}{c}\text { Coeff. } \\
\text { (std. error) } \\
\end{array}$} & \multicolumn{3}{|c|}{$\begin{array}{c}\text { Coeff. } \\
\text { (std. error) } \\
\end{array}$} \\
\hline \multicolumn{3}{|c|}{ Dep var: $\ln (Y)$} & \multicolumn{3}{|l|}{ Dep. var: $u_{i t}$} \\
\hline$\beta_{0}$ & $\begin{array}{r}4.1879 \\
(0.8048)\end{array}$ & $* * *$ & $\delta_{0}$ & $\begin{array}{r}0.3675 \\
(0.1173)\end{array}$ & $* * *$ \\
\hline$\beta_{\mathrm{K}}$ & $\begin{array}{r}0.0760 \\
(0.0800)\end{array}$ & & $\delta_{\text {LEGAL }}$ & $\begin{array}{r}-0.0905 \\
(0.0201)\end{array}$ & $* * *$ \\
\hline$\beta_{\mathrm{L}}$ & $\begin{array}{r}0.6322 \\
(0.0904)\end{array}$ & $* * *$ & $\delta_{\mathrm{REG}}$ & $\begin{array}{r}0.3206 \\
(0.0688)\end{array}$ & $* * *$ \\
\hline$\beta_{\mathrm{KK}}$ & $\begin{array}{r}0.0168 \\
(0.0038)\end{array}$ & $* * *$ & $\delta_{\mathrm{REG}}^{2}$ & $\begin{array}{r}-0.0524 \\
(0.0111)\end{array}$ & $* * *$ \\
\hline$\beta_{\mathrm{LL}}$ & $\begin{array}{r}-0.0012 \\
(0.0061)\end{array}$ & & $\delta_{\mathrm{REG} * \mathrm{H}}$ & $\begin{array}{r}0.0055 \\
(0.0055)\end{array}$ & \\
\hline$\beta_{\mathrm{KL}}$ & $\begin{array}{r}-0.0087 \\
(0.0086)\end{array}$ & & $\delta_{\mathrm{DEMOC}^{*} \mathrm{H}}$ & $\begin{array}{r}-0.0096 \\
(0.0027)\end{array}$ & $* * *$ \\
\hline$\beta_{\mathrm{t}}$ & $\begin{array}{r}0.0166 \\
(0.0618)\end{array}$ & & $\delta_{\mathrm{KAOPEN}}$ & $\begin{array}{r}0.0577 \\
(0.0342)\end{array}$ & $*$ \\
\hline$\beta_{\mathrm{tt}}$ & $\begin{array}{r}0.0112 \\
(0.0043)\end{array}$ & $* * *$ & $\delta_{\mathrm{FDI}}$ & $\begin{array}{r}0.0180 \\
(0.0075)\end{array}$ & $* * *$ \\
\hline$\beta_{\mathrm{Kt}}$ & $\begin{array}{r}0.0098 \\
(0.0045)\end{array}$ & $* *$ & $\delta_{\mathrm{SM}^{* \mathrm{H}}}$ & $\begin{array}{r}-0.0179 \\
(0.0046)\end{array}$ & $* * *$ \\
\hline$\beta_{\mathrm{Lt}}$ & $\begin{array}{r}-0.0185 \\
(0.0054)\end{array}$ & $* * *$ & $\delta_{t}$ & $\begin{array}{r}0.0409 \\
(0.0281)\end{array}$ & \\
\hline$\sigma^{2}$ & $\begin{array}{r}0.2329 \\
(0.0311)\end{array}$ & & Log(likelihood) & -49.4510 & \\
\hline$\gamma$ & $\begin{array}{r}0.9188 \\
(0.0164) \\
\end{array}$ & $* * *$ & & & \\
\hline
\end{tabular}

$* * *, * *$ and $*$ denote $1 \%, 5 \%$ and $10 \%$ statistical significance respectively.

The qualitative results remain. Comparing TE Model (1) and TE Model (2), the chi-square statistics of the LR-test is 11.041, which is below the critical value of chi-square with 6 degree of freedom (i.e. 11.911). In this case, we can argue that TE Model (2) indeed is a better model and fits better our data sample. 
Similarly, we further test the nested model of TE Model (2) based on LR Test in Table 5.6.2-4. One point to note is that TE Model (2) suggests the absence of $\delta_{0}$. We proceed to our final model specification - TE Model (3) - as the hypothesis tests suggest.

Table 5.6.2-4: Hypothesis Testing for TE Model (2)

\begin{tabular}{lccc}
\hline \multicolumn{1}{c}{ Null Hypotheses } & $\log ($ likelihood $)$ & $\chi^{2}$-stat & Decision \\
\hline \hline$\delta_{0}=0$ & -50.50 & 2.10 & Accept $\mathrm{H}_{0}$ \\
$\delta_{\text {REG*H }}=0$ & -50.55 & 2.20 & Accept $\mathrm{H}_{0}$ \\
$\delta_{\text {KAOPEN }}=0$ & -50.42 & 1.94 & Accept $\mathrm{H}_{0}$ \\
\hline
\end{tabular}

Note: The critical value of the log likelihood ratio test for degree of 1 is 2.706 .

Table 5.6.2-5: Maximum Likelihood Estimation of Stochastic Production Frontier Model (TE Model (3)) - Final Model

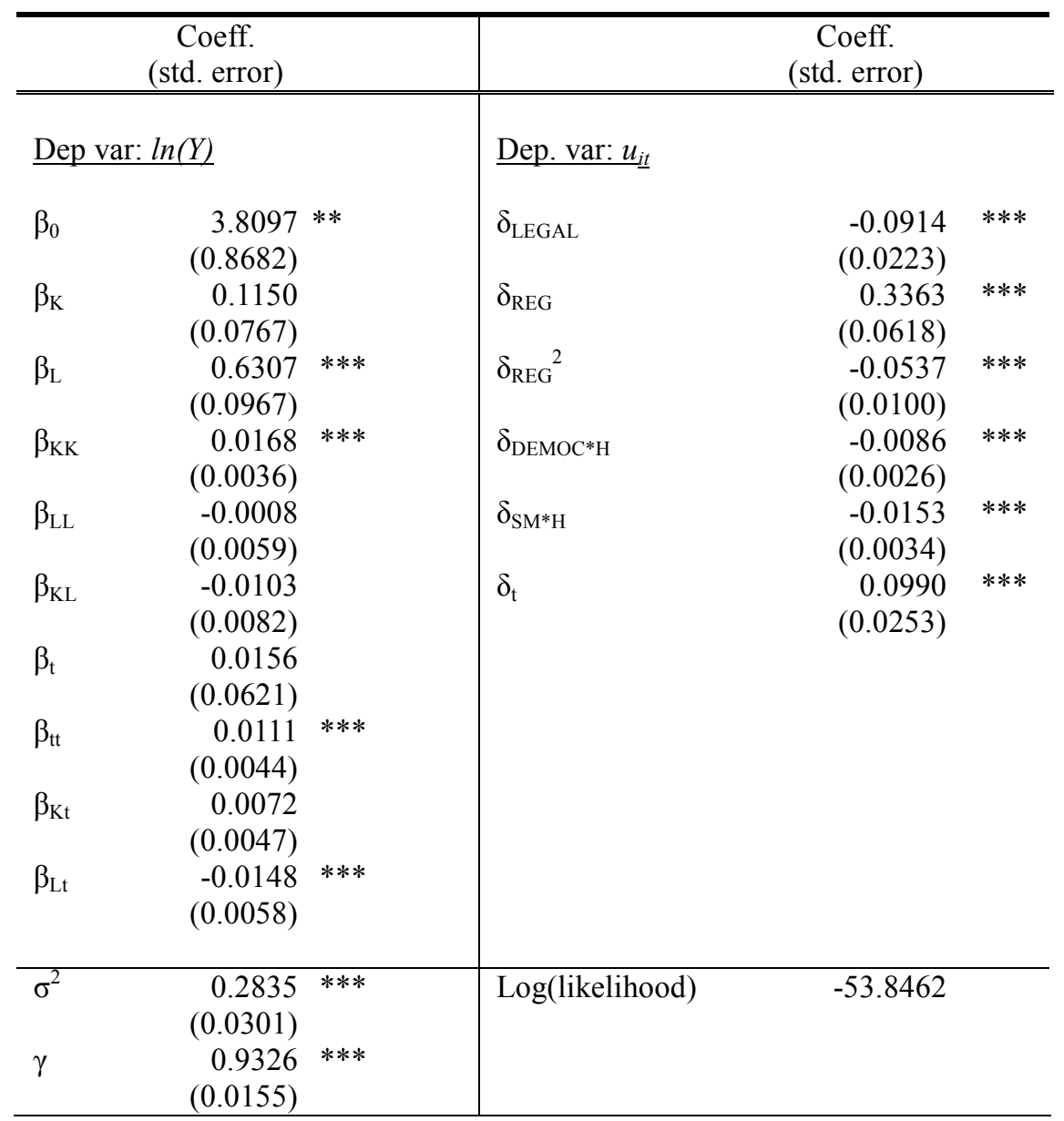

$* * *, * *$ and $*$ denote $1 \%, 5 \%$ and $10 \%$ statistical significance respectively. 
Estimation results of TE Model (3) are in Table 5.6.2-5 above. Comparing TE Models (2) without $\delta_{0}$ (with log-likelihood to be -50.5) and TE Model (3), we again carry out a LR-test in Table 5.6.2-6 to test jointly the openness parameters to be zero. The test results indicate that capital account openness and FDI are not statistically significant in explaining technical inefficiency. Henceforth, we will focus our discussion on the parameters obtained in TE Model (3).

Table 5.6.2-6: Hypothesis Testing for TE Model (2) vs. TE Model (3)

\begin{tabular}{lccc}
\hline Null Hypotheses & $\log ($ likelihood $)$ & $\chi^{2}$-stat & Decision \\
\hline \hline$\delta_{\text {KAOPEN }}=\delta_{\mathrm{FDI}}=$ & -53.85 & 6.7 & Accept $\mathrm{H}_{0}$ \\
$\delta_{\mathrm{REG} * \mathrm{H}}=0$ & & & \\
\hline
\end{tabular}

Note: The critical value of the log likelihood ratio test for degree of 3 is 7.045.

In the course of model selection through TE Models (1) to (3), generally speaking, only institutional factors survive in the final models. Other competing factors - human capital and openness - are not statistically significant in explaining the sources of cross-country technical inefficiencies. This provides empirical support to North's hypothesis - i.e. institutions are the determinant of the efficiency of production inputs, via which determine cross-country efficiency and hence economic performances. Although there are previous studies which conclude that human capital and openness in trade, foreign capital, capital account or financial integration may promote growth, we do not find such positive effects on technical efficiency. In other words, we argue that the level of technical efficiency is primarily driven by domestic market-friendly institutions rather than external forces like foreign competition brought forward by international trade or capital flow alike.

However, our final model - TE Model (3) - points out that not all clusters of institutions are directly associating with technical inefficiency. Market-creating institution, i.e. the security of property rights $(\boldsymbol{L E G \boldsymbol { A } L})$ and market-regulating institution $\left(\boldsymbol{R} \boldsymbol{E} \boldsymbol{G}\right.$ and $\left.\boldsymbol{R} \boldsymbol{E} \boldsymbol{G}^{2}\right)$ are directly associating with technical inefficiency. We obtain the negative relationship between these 
clusters of institutions and technical inefficiency as expected. Market-stabilising institution, i.e. sound monetary policy (SM), and market-legitimising institution, i.e. democratic institution (DEMOC), nonetheless have no direct and significant impact on technical inefficiency. Their interactions with human capital $(\boldsymbol{H})$ are significantly negative at the $1 \%$ level. These results may suggest that these two clusters of institutions would only improve technical efficiency given that a necessary level of human capital. That said, a democratic economy is more efficient given a minimum level of human capital is reached. Likewise, the effectiveness of stabilising monetary policy to improve efficiency of production inputs also depends on human capital. These effects are believed to be determined by human capital, which are possibly due to the effectiveness of policy execution and governance. These market-friendly institutions in turn are believed to shape the incentive structures of the society and thus affect the efficiency of production inputs.

To sum up, our final model suggests that our dataset supports a technical inefficiency story (where $\gamma$ is statistically significant at $1 \%$ level) when estimating a non-neutral translog stochastic production function. The time-varying technical inefficiency model tests three sets of explanatory factors of technical inefficiency - human capital, institutions and openness. Based on the test results of log-likelihood ratio tests, we find no direct effect of openness and human capital on technical inefficiency. However, human capital works with democracy and monetary stabilisation policy to improve technical inefficiency across countries. In contrast, better security of property rights and less regulatory environment associate with technical efficiency directly.

\subsubsection{Measures on Technical Efficiency}

Following Coelli, et al. (1998), since the SPF model can be defined as $\ln \left(y_{i t}\right)=f\left(x_{i t}, t, \beta\right)+v_{i t}-u_{i t}$, the measures of technical efficiency are essentially obtained from $T E_{i t}=E\left(\exp \left(-u_{i t}\right) \mid e_{i t}\right)$ where $e_{i t}=v_{i t}-u_{i t}$. Technical efficiency (TE) can thus be calculated for each period and compared 
to the best practice. TE represents the mean value of technical efficiency given the amount of inputs. Since the production function is assumed to be stochastic in nature, the best possible TE lies somewhere below 1 due to stochastic disturbances. A summary table of average TE over the studied period is in Table 5.6.3-1. The complete measure of TE for each cross-section and time period is presented in Table 5.6.3-2.

Over the six measured periods, USA topped the ranks of TE during 1971-75, 1976-80, 1986-90 and 1991-95. Trinidad and Tobago came first during 1981-85, possibly reflecting it as an oil-exporting economy. Ireland became the best-practice in the last measured period, i.e. 1996-2000. The mean TE of the sample is quite stable (around 0.74-0.75) over the three decades. As one can expect, the industrialised economies are among the best-practices. In contrast, the least technically efficient economies are mostly Sub-Saharan African countries.

Table 5.6.3-1: Average TE by Regions during 1971-2000

\begin{tabular}{|c|c|c|c|c|c|c|}
\hline Period & $71-75$ & $76-80$ & 81-85 & $86-90$ & 91-95 & 96-00 \\
\hline High Income Group & 0.8631 & 0.8707 & 0.8737 & 0.8933 & 0.8923 & 0.8895 \\
\hline Latin America and Caribbean & 0.8204 & 0.8363 & 0.8083 & 0.7991 & 0.8090 & 0.8048 \\
\hline Sub-Saharan Africa & 0.6006 & 0.6124 & 0.6079 & 0.6156 & 0.5928 & 0.5863 \\
\hline East Asia and Pacific & 0.7154 & 0.7453 & 0.7474 & 0.7622 & 0.8095 & 0.7774 \\
\hline Middle East and North Africa & 0.8317 & 0.8410 & 0.8371 & 0.8341 & 0.8442 & 0.8646 \\
\hline Europe and Central Asia & 0.8572 & 0.8619 & 0.8865 & 0.9093 & 0.8808 & 0.8315 \\
\hline South Asia & 0.5840 & 0.6204 & 0.6656 & 0.7141 & 0.7559 & 0.7573 \\
\hline All & 0.7393 & 0.7530 & 0.7493 & 0.7590 & 0.7586 & 0.7534 \\
\hline
\end{tabular}

Note: Average TE is calculated based on simple averages. High income group includes OECD economies and other high income groups. Regions are based on World Bank's Country Classification. Details of country coverage are at Appendix A.4.

Analysed by regions, there is a general upward trend of improvement in TE over the last three decades. Improvements are also found in the high income group even though they are amongst the best practices. However, sub-Saharan African countries indeed experienced a decline over the period. The most pronounced improvements are found in the East Asia and Pacific as well as South Asia regions, in particular starting from the 1990. Such improvements are also found in fast-growing countries like China and India during the same period. 
Table 5.6.3-2: Cross-country Technical Efficiency during 1971-2000

\begin{tabular}{|c|c|c|c|c|c|c|c|c|c|c|c|c|c|}
\hline Country & code & $\begin{array}{l}\text { Period } \\
(71-75) \\
\end{array}$ & Rank & $\begin{array}{l}\text { Period } \\
(76-80) \\
\end{array}$ & Rank & $\begin{array}{l}\text { Period } \\
(81-85) \\
\end{array}$ & Rank & $\begin{array}{l}\text { Period } \\
(86-90) \\
\end{array}$ & Rank & $\begin{array}{l}\text { Period } \\
(91-95) \\
\end{array}$ & Rank & $\begin{array}{l}\text { Period } \\
(96-00) \\
\end{array}$ & Rank \\
\hline Algeria & DZA & 0.8660 & [37] & 0.8547 & {$[42]$} & 0.8635 & [40] & 0.8396 & [47] & 0.7785 & {$[65]$} & 0.7791 & {$[65]$} \\
\hline Argentina & $\mathrm{ARG}$ & 0.8586 & [39] & 0.8507 & [44] & 0.8147 & [52] & 0.8019 & [59] & 0.8991 & [30] & 0.9250 & [20] \\
\hline Australia & AUS & 0.9120 & [17] & 0.9241 & [10] & 0.9288 & [7] & 0.9356 & [9] & 0.9379 & [13] & 0.9388 & [10] \\
\hline Austria & AUT & 0.8718 & [34] & 0.8971 & [29] & 0.8905 & [27] & 0.9024 & [29] & 0.9082 & [25] & 0.8992 & [32] \\
\hline Bangladesh & BGD & 0.4439 & [97] & 0.5310 & [94] & 0.6039 & [85] & 0.6618 & [78] & 0.7232 & [70] & 0.7304 & [70] \\
\hline Barbados & $\mathrm{BRB}$ & 0.8059 & {$[55]$} & 0.8132 & [58] & 0.7837 & [59] & 0.8849 & {$[36]$} & 0.9000 & [28] & 0.9371 & {$[12]$} \\
\hline Belgium & BEL & 0.9136 & [16] & 0.9230 & [11] & 0.9227 & {$[14]$} & 0.9328 & [12] & 0.9283 & [16] & 0.9256 & [18] \\
\hline Benin & BEN & 0.6132 & [83] & 0.5587 & [88] & 0.5515 & [89] & 0.5726 & [91] & 0.5578 & [89] & 0.5896 & [84] \\
\hline Bolivia & BOL & 0.7023 & [73] & 0.7713 & {$[66]$} & 0.7623 & {$[65]$} & 0.7563 & [69] & 0.8152 & [59] & 0.8012 & [62] \\
\hline Botswana & BWA & 0.5668 & [89] & 0.7501 & [72] & 0.8599 & [41] & 0.8972 & [31] & 0.8945 & [31] & 0.9193 & [24] \\
\hline Brazil & BRA & 0.8041 & [56] & 0.8116 & {$[60]$} & 0.7687 & [61] & 0.8208 & [54] & 0.8050 & {$[62]$} & 0.8422 & [49] \\
\hline Burki Faso & BFA & 0.4292 & [99] & 0.4526 & [99] & 0.4925 & {$[100]$} & 0.4872 & {$[101]$} & 0.4746 & [99] & 0.4591 & [98] \\
\hline Burundi & BDI & 0.6395 & [81] & 0.6542 & [78] & 0.5198 & [94] & 0.5117 & [97] & 0.4804 & [98] & 0.4002 & [103] \\
\hline Cameroon & CMR & 0.7097 & [71] & 0.8101 & [61] & 0.8491 & [44] & 0.8202 & {$[55]$} & 0.6643 & {$[77]$} & 0.7151 & {$[71]$} \\
\hline Canada & CAN & 0.9532 & {$[4]$} & 0.9560 & [3] & 0.9501 & {$[3]$} & 0.9500 & [3] & 0.9389 & {$[12]$} & 0.9373 & {$[11]$} \\
\hline Cape Verde & $\mathrm{CPV}$ & 0.3956 & {$[101]$} & 0.4166 & [102] & 0.5269 & [92] & 0.5606 & [94] & 0.5368 & [91] & 0.5393 & [87] \\
\hline Central African Republic & CAF & 0.6990 & {$[74]$} & 0.7617 & {$[68]$} & 0.7009 & {$[75]$} & 0.6833 & [73] & 0.5659 & [88] & 0.4924 & [94] \\
\hline Chad & TCD & 0.3529 & {$[103]$} & 0.4474 & {$[100]$} & 0.3798 & [104] & 0.4244 & {$[104]$} & 0.4421 & [102] & 0.4440 & [101] \\
\hline Chile & $\mathrm{CHL}$ & 0.8319 & {$[46]$} & 0.8769 & {$[37]$} & 0.8860 & {$[31]$} & 0.9148 & [19] & 0.9398 & {$[11]$} & 0.9301 & {$[16]$} \\
\hline China & $\mathrm{CHN}$ & 0.4972 & [92] & 0.5030 & [96] & 0.6108 & [84] & 0.6459 & [80] & 0.7195 & {$[72]$} & 0.7435 & [68] \\
\hline Colombia & $\mathrm{COL}$ & 0.8771 & {$[30]$} & 0.9017 & [24] & 0.8973 & {$[24]$} & 0.9082 & [24] & 0.9143 & [22] & 0.8901 & {$[37]$} \\
\hline Comoros & $\mathrm{COM}$ & 0.6608 & [78] & 0.5579 & [89] & 0.5823 & [86] & 0.6010 & [86] & 0.5042 & [94] & 0.4502 & {$[100]$} \\
\hline Congo, Dem. Rep. & ZAR & 0.6962 & {$[75]$} & 0.5648 & {$[87]$} & 0.5148 & [95] & 0.4881 & [99] & 0.3839 & [103] & 0.2183 & {$[108]$} \\
\hline Congo, Republic of & $\mathrm{COG}$ & 0.2663 & {$[106]$} & 0.3140 & {$[105]$} & 0.4191 & [103] & 0.4879 & {$[100]$} & 0.4962 & [95] & 0.4909 & [95] \\
\hline Costa Rica & CRI & 0.9239 & {$[12]$} & 0.9303 & {$[7]$} & 0.8775 & {$[35]$} & 0.8775 & [39] & 0.8537 & {$[45]$} & 0.8269 & [53] \\
\hline Cote d'Ivoire & CIV & 0.7905 & {$[60]$} & 0.8132 & [57] & 0.7512 & [68] & 0.7813 & [64] & 0.8053 & [61] & 0.8199 & {$[55]$} \\
\hline Cyprus & CYP & 0.6017 & [84] & 0.6337 & [80] & 0.7533 & {$[66]$} & 0.8534 & [43] & 0.8911 & [36] & 0.8972 & [33] \\
\hline Denmark & DNK & 0.8967 & [23] & 0.8946 & {$[30]$} & 0.8953 & {$[25]$} & 0.9177 & [18] & 0.9209 & [18] & 0.9205 & [23] \\
\hline Dominican Republic & DOM & 0.8727 & [33] & 0.8823 & {$[35]$} & 0.8831 & {$[32]$} & 0.8498 & [44] & 0.8510 & {$[46]$} & 0.9117 & [27] \\
\hline Ecuador & $\mathrm{ECU}$ & 0.6660 & [76] & 0.7972 & {$[62]$} & 0.7513 & [67] & 0.7019 & [70] & 0.7230 & [71] & 0.6472 & [79] \\
\hline Egypt & EGY & 0.9252 & [10] & 0.9043 & [21] & 0.9235 & [13] & 0.9350 & [10] & 0.9557 & [3] & 0.9630 & {$[2]$} \\
\hline El Salvador & SLV & 0.9542 & [3] & 0.9530 & [4] & 0.9068 & [19] & 0.9069 & [27] & 0.9207 & [19] & 0.9208 & [22] \\
\hline
\end{tabular}




\begin{tabular}{|c|c|c|c|c|c|c|c|c|c|c|c|c|c|}
\hline Country & code & $\begin{array}{r}\text { Period } \\
(71-75) \\
\end{array}$ & Rank & $\begin{array}{l}\text { Period } \\
(76-80) \\
\end{array}$ & Rank & $\begin{array}{l}\text { Period } \\
(81-85) \\
\end{array}$ & Rank & $\begin{array}{l}\text { Period } \\
(\mathbf{8 6 - 9 0 )}) \\
\end{array}$ & Rank & $\begin{array}{l}\text { Period } \\
(91-95) \\
\end{array}$ & Rank & $\begin{array}{l}\text { Period } \\
(\mathbf{9 6 - 0 0 )} \\
\end{array}$ & Rank \\
\hline Equatorial Guinea & GNQ & 0.9227 & [13] & 0.7299 & [74] & 0.6393 & [81] & 0.5860 & [88] & 0.4539 & {$[101]$} & 0.4557 & [99] \\
\hline Ethiopia & ETH & 0.5783 & {$[86]$} & 0.6336 & [81] & 0.6793 & [77] & 0.6746 & [77] & 0.6458 & [81] & 0.6981 & [74] \\
\hline Fiji & FJI & 0.7478 & {$[66]$} & 0.7767 & {$[65]$} & 0.7334 & {$[69]$} & 0.6996 & [71] & 0.8123 & {$[60]$} & 0.7985 & {$[64]$} \\
\hline Finland & FIN & 0.8407 & [44] & 0.8443 & [46] & 0.8799 & [33] & 0.9048 & [28] & 0.8694 & [42] & 0.9052 & [31] \\
\hline France & FRA & 0.8731 & {$[32]$} & 0.8876 & [33] & 0.8937 & [26] & 0.9071 & [26] & 0.8933 & {$[35]$} & 0.8939 & {$[35]$} \\
\hline Gabon & GAB & 0.8907 & {$[26]$} & 0.8521 & [43] & 0.7284 & {$[71]$} & 0.7933 & [61] & 0.8723 & [41] & 0.8697 & {$[42]$} \\
\hline Gambia, The & GMB & 0.7350 & {$[68]$} & 0.7277 & [76] & 0.6401 & [80] & 0.5838 & [89] & 0.4913 & [96] & 0.4439 & [102] \\
\hline Ghana & GHA & 0.4626 & [95] & 0.4411 & [101] & 0.4833 & [101] & 0.5931 & [87] & 0.6688 & {$[76]$} & 0.6911 & {$[75]$} \\
\hline Greece & GRC & 0.8108 & [53] & 0.8460 & {$[45]$} & 0.8208 & {$[51]$} & 0.8329 & [51] & 0.8328 & {$[56]$} & 0.8496 & [47] \\
\hline Guatemala & GTM & 0.9188 & {$[15]$} & 0.9333 & [6] & 0.9224 & {$[15]$} & 0.9221 & [16] & 0.9277 & [17] & 0.9234 & {$[21]$} \\
\hline Guinea & GIN & 0.4945 & [94] & 0.5455 & [90] & 0.5300 & {$[90]$} & 0.5698 & [92] & 0.6304 & [83] & 0.7043 & [72] \\
\hline Guinea-Bissau & GNB & 0.1427 & [108] & 0.2198 & [108] & 0.2336 & [107] & 0.2172 & [108] & 0.2226 & [107] & 0.2409 & [107] \\
\hline Haiti & HTI & 0.7753 & {$[63]$} & 0.7517 & {$[71]$} & 0.6818 & {$[76]$} & 0.5736 & {$[90]$} & 0.6577 & {$[78]$} & 0.9555 & [4] \\
\hline Honduras & HND & 0.7063 & [72] & 0.7549 & [70] & 0.7823 & [60] & 0.7843 & [63] & 0.7002 & [73] & 0.5991 & [82] \\
\hline Hong Kong & HKG & 0.8514 & [42] & 0.9099 & [18] & 0.9191 & {$[16]$} & 0.9370 & [8] & 0.9467 & [7] & 0.9169 & {$[25]$} \\
\hline Iceland & ISL & 0.8018 & [57] & 0.8366 & [49] & 0.8442 & [46] & 0.8779 & [38] & 0.8498 & [48] & 0.8591 & [45] \\
\hline India & IND & 0.5747 & [88] & 0.6428 & [79] & 0.7146 & [72] & 0.8056 & [58] & 0.8436 & [53] & 0.8869 & [39] \\
\hline Indonesia & IDN & 0.8525 & {$[41]$} & 0.8737 & [39] & 0.8568 & [43] & 0.8446 & [45] & 0.8446 & {$[52]$} & 0.7663 & [67] \\
\hline Iran & IRN & 0.9389 & [7] & 0.8408 & [47] & 0.7042 & [74] & 0.6806 & [75] & 0.7679 & [67] & 0.8607 & [44] \\
\hline Ireland & IRL & 0.9246 & [11] & 0.9393 & [5] & 0.9356 & [4] & 0.9400 & [7] & 0.9554 & [4] & 0.9632 & [1] \\
\hline Israel & ISR & 0.8824 & [28] & 0.8388 & [48] & 0.8665 & [37] & 0.8862 & [34] & 0.9134 & [23] & 0.8962 & [34] \\
\hline Italy & ITA & 0.8272 & [48] & 0.8702 & {$[40]$} & 0.8872 & [28] & 0.9142 & [20] & 0.9085 & {$[24]$} & 0.9073 & [29] \\
\hline Jamaica & JAM & 0.6010 & [85] & 0.5420 & [92] & 0.5248 & [93] & 0.6089 & [85] & 0.5923 & [85] & 0.5301 & [88] \\
\hline Japan & JPN & 0.8223 & {$[50]$} & 0.8327 & [51] & 0.8410 & [47] & 0.8656 & [41] & 0.8466 & [51] & 0.7988 & [63] \\
\hline Jordan & JOR & 0.8216 & [51] & 0.9287 & [8] & 0.9340 & [5] & 0.9076 & [25] & 0.8326 & [57] & 0.8353 & [51] \\
\hline Kenya & KEN & 0.4321 & [98] & 0.4777 & [98] & 0.5290 & [91] & 0.6230 & [83] & 0.6419 & [82] & 0.6535 & [78] \\
\hline Korea, Republic of & KOR & 0.7741 & {$[64]$} & 0.8117 & [59] & 0.7901 & {$[55]$} & 0.8620 & [42] & 0.8543 & [44] & 0.8176 & [58] \\
\hline Lesotho & LSO & 0.6133 & [82] & 0.6033 & [83] & 0.5084 & [97] & 0.4919 & [98] & 0.3722 & {$[105]$} & 0.3078 & [105] \\
\hline Luxembourg & LUX & 0.8964 & [24] & 0.8940 & [31] & 0.9011 & [23] & 0.9349 & [11] & 0.9445 & [9] & 0.9465 & [9] \\
\hline Madagascar & MDG & 0.8097 & {$[54]$} & 0.7925 & [63] & 0.7898 & {$[56]$} & 0.7996 & {$[60]$} & 0.7719 & {$[66]$} & 0.7770 & [66] \\
\hline Malawi & MWI & 0.2829 & {$[105]$} & 0.3053 & [106] & 0.3130 & {$[106]$} & 0.3359 & {$[106]$} & 0.3628 & [106] & 0.4698 & [96] \\
\hline Malaysia & MYS & 0.8423 & {$[43]$} & 0.8894 & {$[32]$} & 0.8871 & [29] & 0.8797 & {$[37]$} & 0.9029 & {$[27]$} & 0.8658 & {$[43]$} \\
\hline Mali & MLI & 0.4282 & {$[100]$} & 0.5429 & [91] & 0.4942 & [99] & 0.4537 & {$[103]$} & 0.4624 & {$[100]$} & 0.5280 & [90] \\
\hline Mauritania & MRT & 0.8736 & [31] & 0.9019 & [23] & 0.7675 & [62] & 0.5510 & [95] & 0.5300 & [93] & 0.4956 & [92] \\
\hline
\end{tabular}




\begin{tabular}{|c|c|c|c|c|c|c|c|c|c|c|c|c|c|}
\hline Country & code & $\begin{array}{l}\text { Period } \\
(71-75) \\
\end{array}$ & Rank & $\begin{array}{l}\text { Period } \\
(\mathbf{7 6 - 8 0 )}) \\
\end{array}$ & Rank & $\begin{array}{l}\text { Period } \\
(81-85) \\
\end{array}$ & Rank & $\begin{array}{l}\text { Period } \\
(86-90) \\
\end{array}$ & Rank & $\begin{array}{l}\text { Period } \\
(91-95) \\
\end{array}$ & Rank & $\begin{array}{l}\text { Period } \\
(96-00) \\
\end{array}$ & Rank \\
\hline Mauritius & MUS & 0.8844 & [27] & 0.9209 & [12] & 0.9279 & [8] & 0.9423 & [5] & 0.9501 & [5] & 0.9520 & [6] \\
\hline Mexico & MEX & 0.8942 & [25] & 0.9163 & [14] & 0.9030 & [21] & 0.8850 & [35] & 0.8772 & [39] & 0.8562 & [46] \\
\hline Morocco & MAR & 0.8197 & [52] & 0.7813 & [64] & 0.7627 & [64] & 0.8169 & [56] & 0.8166 & [58] & 0.8110 & [59] \\
\hline Mozambique & MOZ & 0.9467 & [5] & 0.8975 & [27] & 0.8007 & [53] & 0.7678 & {$[67]$} & 0.7908 & [64] & 0.8073 & [61] \\
\hline Nepal & NPL & 0.5782 & [87] & 0.5329 & [93] & 0.5111 & [96] & 0.5164 & [96] & 0.5340 & [92] & 0.5291 & [89] \\
\hline Netherlands & NLD & 0.9022 & [21] & 0.9139 & [15] & 0.9060 & [20] & 0.9192 & {$[17]$} & 0.9284 & {$[15]$} & 0.9334 & [13] \\
\hline New Zealand & NZL & 0.9398 & {$[6]$} & 0.9274 & [9] & 0.9279 & [9] & 0.9252 & {$[14]$} & 0.9353 & [14] & 0.9255 & [19] \\
\hline Nicaragua & $\mathrm{NIC}$ & 0.9050 & [20] & 0.8747 & [38] & 0.7304 & [70] & 0.6159 & [84] & 0.5454 & {$[90]$} & 0.4932 & [93] \\
\hline Niger & NER & 0.4958 & [93] & 0.4808 & [97] & 0.4258 & {$[102]$} & 0.4630 & [102] & 0.4813 & [97] & 0.5200 & [91] \\
\hline Nigeria & NGA & 0.7773 & [62] & 0.6074 & [82] & 0.5629 & [87] & 0.6879 & {$[72]$} & 0.6693 & {$[75]$} & 0.5960 & [83] \\
\hline Norway & NOR & 0.8004 & {$[58]$} & 0.8301 & {$[52]$} & 0.8483 & {$[45]$} & 0.8762 & [40] & 0.9000 & [29] & 0.9063 & [30] \\
\hline Pakistan & PAK & 0.4993 & [91] & 0.5813 & [85] & 0.7088 & {$[73]$} & 0.8112 & [57] & 0.8401 & [54] & 0.8196 & [56] \\
\hline Panama & PAN & 0.7241 & {$[70]$} & 0.7477 & [73] & 0.8582 & [42] & 0.8331 & [50] & 0.8474 & {$[50]$} & 0.7421 & [69] \\
\hline Papua New Guinea & PNG & 0.6635 & {$[77]$} & 0.6721 & {$[77]$} & 0.6414 & [79] & 0.6767 & {$[76]$} & 0.7639 & [68] & 0.6752 & [77] \\
\hline Paraguay & PRY & 0.8652 & [38] & 0.8994 & [26] & 0.8671 & [36] & 0.8421 & [46] & 0.8888 & {$[37]$} & 0.8487 & [48] \\
\hline Peru & PER & 0.7290 & [69] & 0.7281 & {$[75]$} & 0.6735 & [78] & 0.6612 & [79] & 0.6529 & [79] & 0.7035 & [73] \\
\hline Philippines & PHL & 0.7887 & {$[61]$} & 0.8170 & [53] & 0.7637 & [63] & 0.7687 & [66] & 0.7943 & [63] & 0.8081 & [60] \\
\hline Portugal & PRT & 0.8369 & {$[45]$} & 0.8863 & [34] & 0.8662 & [38] & 0.9000 & [30] & 0.9042 & [26] & 0.8852 & [40] \\
\hline Rwanda & RWA & 0.7676 & {$[65]$} & 0.8340 & [50] & 0.8368 & [49] & 0.7579 & [68] & 0.5966 & [84] & 0.6061 & [81] \\
\hline Senegal & SEN & 0.5521 & [90] & 0.5780 & [86] & 0.6243 & [83] & 0.6811 & [74] & 0.6470 & [80] & 0.6847 & [76] \\
\hline Sierra Leone & SLE & 0.9260 & [9] & 0.9061 & [19] & 0.9257 & [10] & 0.9129 & [21] & 0.7453 & [69] & 0.5730 & [85] \\
\hline Singapore & SGP & 0.7393 & [67] & 0.7569 & [69] & 0.7855 & [58] & 0.7859 & [62] & 0.8490 & [49] & 0.8411 & [50] \\
\hline South Africa & ZAF & 0.9215 & {$[14]$} & 0.9132 & [16] & 0.9250 & [12] & 0.9283 & [13] & 0.9411 & [10] & 0.9479 & [7] \\
\hline Spain & ESP & 0.8682 & [36] & 0.8802 & [36] & 0.8647 & [39] & 0.8883 & [32] & 0.8937 & [34] & 0.8915 & [36] \\
\hline Sri Lanka & LKA & 0.8239 & [49] & 0.8142 & [55] & 0.7897 & {$[57]$} & 0.7754 & [65] & 0.8387 & {$[55]$} & 0.8204 & {$[54]$} \\
\hline Sweden & SWE & 0.8978 & [22] & 0.9056 & [20] & 0.9138 & {$[17]$} & 0.9232 & {$[15]$} & 0.9184 & [20] & 0.9258 & [17] \\
\hline Switzerland & $\mathrm{CHE}$ & 0.9076 & [18] & 0.8975 & [28] & 0.9080 & [18] & 0.9120 & [22] & 0.8941 & [33] & 0.8717 & [41] \\
\hline Syrian Arab Republic & SYR & 0.7934 & [59] & 0.8150 & [54] & 0.8791 & [34] & 0.8217 & [53] & 0.8944 & [32] & 0.9158 & [26] \\
\hline Taiwan & TWN & 0.8781 & [29] & 0.9117 & {$[17]$} & 0.9250 & [11] & 0.9525 & {$[2]$} & 0.9576 & {$[2]$} & 0.9546 & {$[5]$} \\
\hline Tanzania & TZA & 0.2239 & {$[107]$} & 0.2433 & [107] & 0.2316 & {$[108]$} & 0.2252 & [107] & 0.2213 & [108] & 0.2557 & [106] \\
\hline Thailand & THA & 0.4527 & [96] & 0.5188 & [95] & 0.5606 & {$[88]$} & 0.6297 & {$[82]$} & 0.6810 & [74] & 0.6075 & {$[80]$} \\
\hline Togo & TGO & 0.6452 & {$[80]$} & 0.5977 & [84] & 0.6389 & [82] & 0.6442 & [81] & 0.5869 & [86] & 0.4697 & [97] \\
\hline Trinidad and Tobago & TTO & 0.9557 & {$[2]$} & 0.9605 & {$[2]$} & 0.9603 & {$[1]$} & 0.9415 & {$[6]$} & 0.9450 & {$[8]$} & 0.9327 & [14] \\
\hline Tunisia & TUN & 0.6571 & [79] & 0.7621 & [67] & 0.7930 & [54] & 0.8376 & [49] & 0.8638 & [43] & 0.8870 & [38] \\
\hline
\end{tabular}




\begin{tabular}{|c|c|c|c|c|c|c|c|c|c|c|c|c|c|}
\hline Country & code & $\begin{array}{l}\text { Period } \\
(71-75) \\
\end{array}$ & Rank & $\begin{array}{l}\text { Period } \\
(\mathbf{7 6 - 8 0 )}) \\
\end{array}$ & Rank & $\begin{array}{l}\text { Period } \\
(81-85) \\
\end{array}$ & Rank & $\begin{array}{l}\text { Period } \\
(86-90) \\
\end{array}$ & Rank & $\begin{array}{l}\text { Period } \\
(91-95) \\
\end{array}$ & Rank & $\begin{array}{l}\text { Period } \\
(96-00) \\
\end{array}$ & Rank \\
\hline Turkey & TUR & 0.8572 & [40] & 0.8619 & [41] & 0.8865 & [30] & 0.9093 & {$[23]$} & 0.8808 & [38] & 0.8315 & {$[52]$} \\
\hline Uganda & UGA & 0.8290 & {$[47]$} & 0.8142 & [56] & 0.9019 & [22] & 0.8391 & [48] & 0.8747 & [40] & 0.9107 & [28] \\
\hline United Kingdom & GBR & 0.9059 & [19] & 0.9175 & {$[13]$} & 0.9305 & {$[6]$} & 0.9439 & {$[4]$} & 0.9476 & {$[6]$} & 0.9473 & {$[8]$} \\
\hline United States of America & USA & 0.9571 & [1] & 0.9614 & [1] & 0.9572 & {$[2]$} & 0.9595 & {$[1]$} & 0.9600 & {$[1]$} & 0.9577 & [3] \\
\hline Uruguay & URY & 0.8690 & [35] & 0.9034 & {$[22]$} & 0.8392 & [48] & 0.8869 & [33] & 0.9184 & [21] & 0.9306 & {$[15]$} \\
\hline Venezuela & VEN & 0.9285 & [8] & 0.9004 & [25] & 0.8362 & [50] & 0.8304 & [52] & 0.8508 & [47] & 0.8185 & [57] \\
\hline Zambia & ZMB & 0.3100 & [104] & 0.3326 & [104] & 0.3412 & [105] & 0.3585 & [105] & 0.3816 & [104] & 0.3915 & [104] \\
\hline Zimbabwe & ZWE & 0.3787 & {$[102]$} & 0.3893 & [103] & 0.5046 & [98] & 0.5663 & [93] & 0.5685 & [87] & 0.5616 & {$[86]$} \\
\hline
\end{tabular}


Our measured period is long enough to compare the experiences of economic development in different regions. Figure 5.6-1 clearly shows that China and India rapidly caught up with the USA. The catching-up was fairly persistent for India during the studied period. China only started picking up since the early 80s, echoing her "open-door" policy. In comparison to other emerging markets like Brazil, her TE improvements were relatively gentle. We can also compare these growth experiences with that of the "East Asian Tigers" as shown in Figure 5.6-2. The latter four economies also enjoyed fast growth during the last three decades. In conjunction, they showed rapid improvements in technical efficiency in the 70 s and 80 s.

Figure 5.6-1: TE of Brazil, China and India vis-à-vis USA

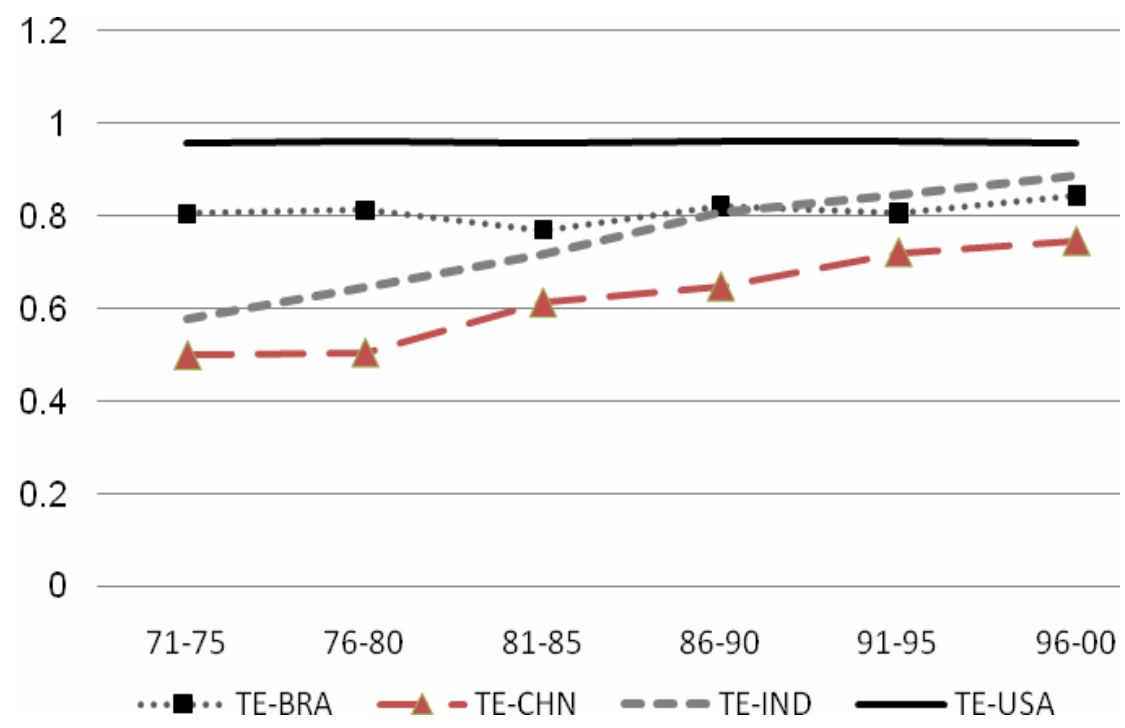


Figure 5.6-2: TE of Hong Kong, Republic of Korea, Singapore and Taiwan vis-à-vis USA

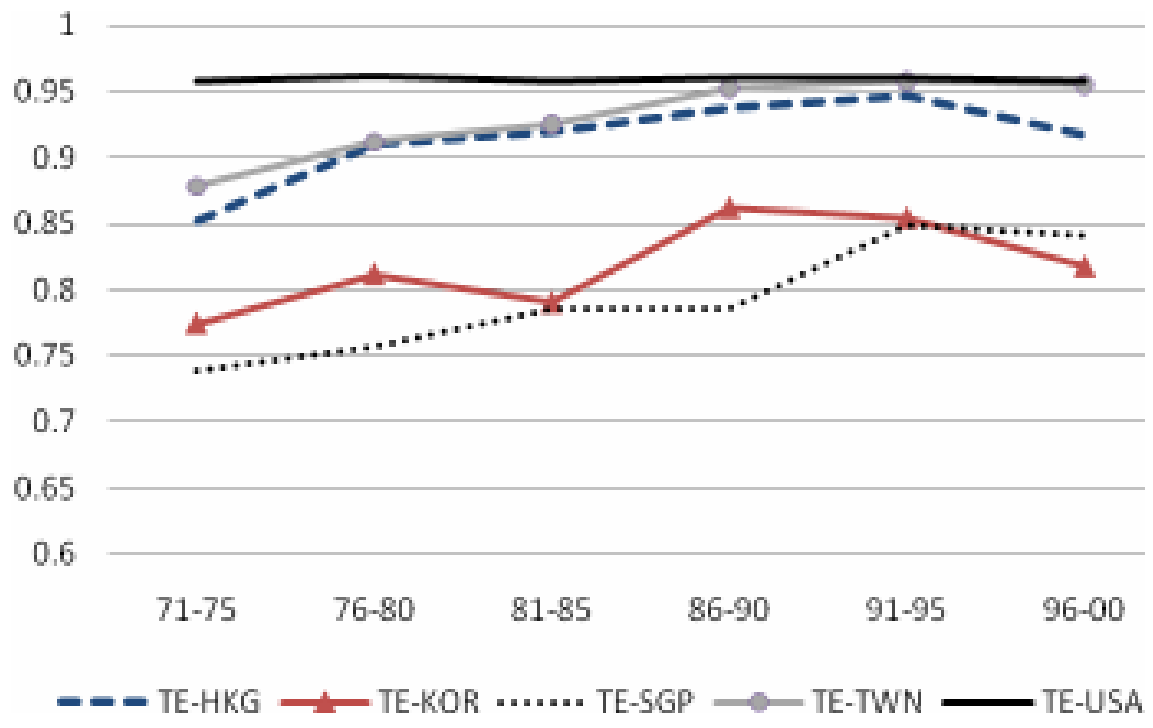

To calculate efficiency change $(\boldsymbol{E} \boldsymbol{C})$ over two periods, we can define $\boldsymbol{E} \boldsymbol{C}$ as:

Efficiency change $=T E_{i t} / T E_{i s} \quad$ from period $s$ to period $t$

Based on $\boldsymbol{E C}$ calculated, the four "Asian tigers" - Hong Kong, Singapore, South Korea and Taiwan - enjoyed an average efficiency gains of 1.5\%, 2.7\%, $1.2 \%$ and $1.7 \%$ respectively over the studied period. These figures represent above-average performances (around $0.85 \%$ for the full sample) on the global scale. This may be one underlying source of their impressive growth performances. Nevertheless, India and China show even more impressive improvements. China registered an average $8.6 \%$ efficiency change whereas India showed an even more impressive 9.1\% positive change. All these provide quantitative evidence that the rapid growth we found in these economies may not be a mere result of capital accumulation. Efficiency improvements may be their sources of growth. Figure 5.6-3-Figure 5.6-5 provide an overview of efficiency changes in other selected countries. 
Figure 5.6-3: TE of Indonesia, Malaysia, Philippines and Thailand vis-à-vis USA

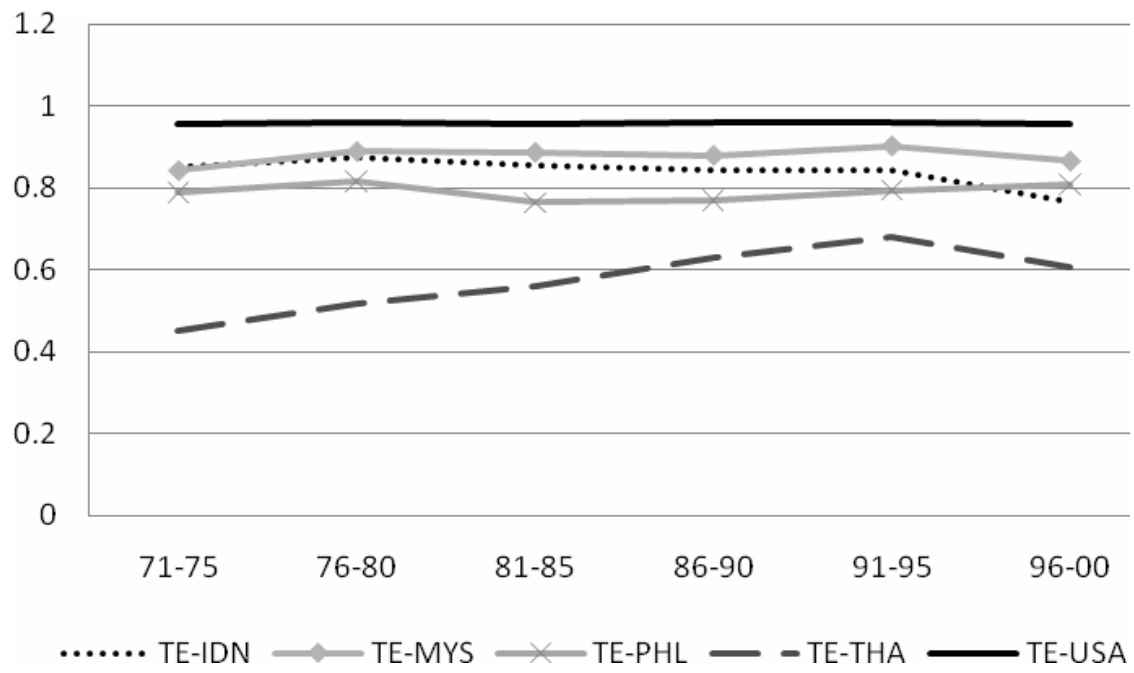

Figure 5.6-4: TE of Selected Lower Middle Income Countries in Latin America and Caribbean vis-à-vis USA

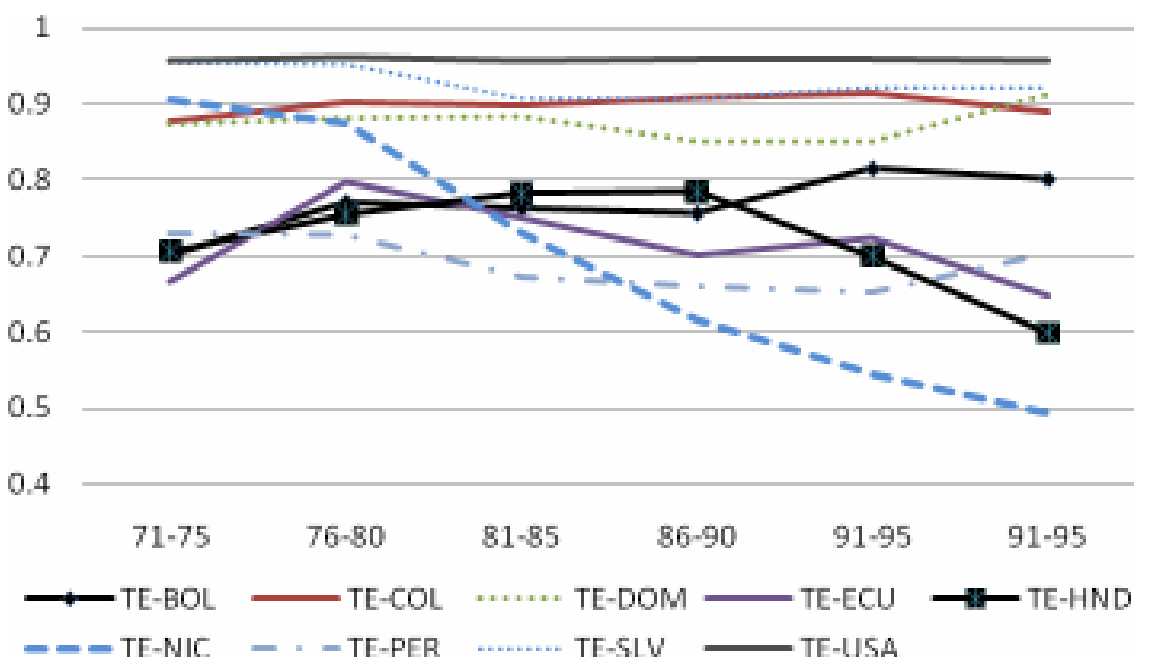

Note: Countries include Bolivia, Colombia, Dominican Republic, Ecuador, Honduras, Nicaragua, Peru and El Salvador. 
Figure 5.6-5: TE of MENA Region vis-à-vis USA

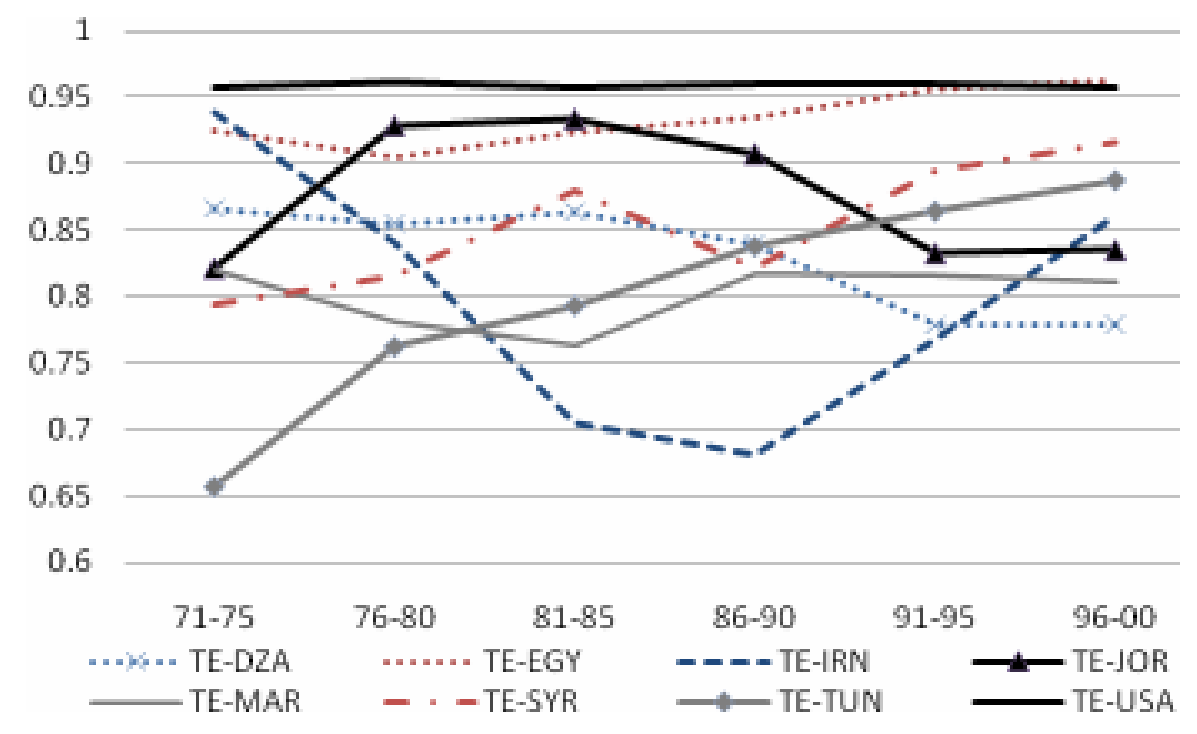

Note: Countries cover Algeria, Egypt, Iran, Jordan, Morocco, Syrian Arab Republic and Tunisia.

To better illustrate that efficiency change is possibly the source of growth, we separate the sources of growth by capital accumulation, technical change and efficiency change. As mentioned earlier in our methodology, estimating a time-varying stochastic production frontier allows us to estimate technical change (TC) and TE. Technical change is calculated based on the first partial derivative of the stochastic production frontier with respect to time. According to Coelli, et al. (1998), a geometric mean can be used to estimate the technical change index between adjacent periods $s$ and $t$ as the following:

$$
\left\{\left[1+\frac{\partial f\left(x_{i s}, s, \beta\right)}{\partial s}\right] \times\left[1+\frac{\partial f\left(x_{i t}, t, \beta\right)}{\partial t}\right]\right\}^{0.5}
$$

By definition, TFP can be obtained thereafter by summing up EC and TC as in Lee and Kim (2006). Measures of average $\boldsymbol{E} \boldsymbol{C}, \boldsymbol{T C}$ and $\boldsymbol{T F P}$ over the period of 1971-2000 are presented in Table 5.6.3-3.

Once we have decomposed growth, it also facilitates us to compare the sources of growth in developed countries as against that in developing countries. Rankings of efficiency change reveal that the sources of growth in developing countries primarily come from efficiency gains. Most of the economies 
topping the rankings of efficiency changes (i.e. with greatest efficiency gains in the sample) are low or lower middle income countries - for examples, Republic of Congo, Pakistan, Botswana, Bangladesh, India and China. In contrast, the sources of growth for high-income or developed countries come from technical changes (i.e. technological progress). For example, in terms of technical changes, Luxembourg, Iceland, Singapore, Norway and New Zealand are amongst those showing most distinct technical changes. This points out that the development strategy for developing countries mainly aims at "catching-up", whereas that of the developed countries is by means of innovations.

Since our sample is dominated by developing countries, we naturally find a strong correlation of TFP and EC. For demonstration purpose, Figure 5.6-6 shows a simple correlation plot between the rankings of TFP as against that of EC and TC of the 108 economies being studied in our sample.

The most important lesson of decomposing the sources of growth after all is not the comparison of rankings. The main point to note is that when we compare cross-country TFP growth using a standard Solow-growth accounting framework (i.e. by assuming that all factors of production are efficiently used), the results obtained may only reveal a partial picture of the sources of growth. Through estimating a stochastic production frontier, we are able to segregate the two sources conceptually. More importantly, we could identify the sources of technical inefficiency which is helpful in implying policy implications. 
Figure 5.6-6: Ranking s of EC, TC as against TFP of 108 Economies
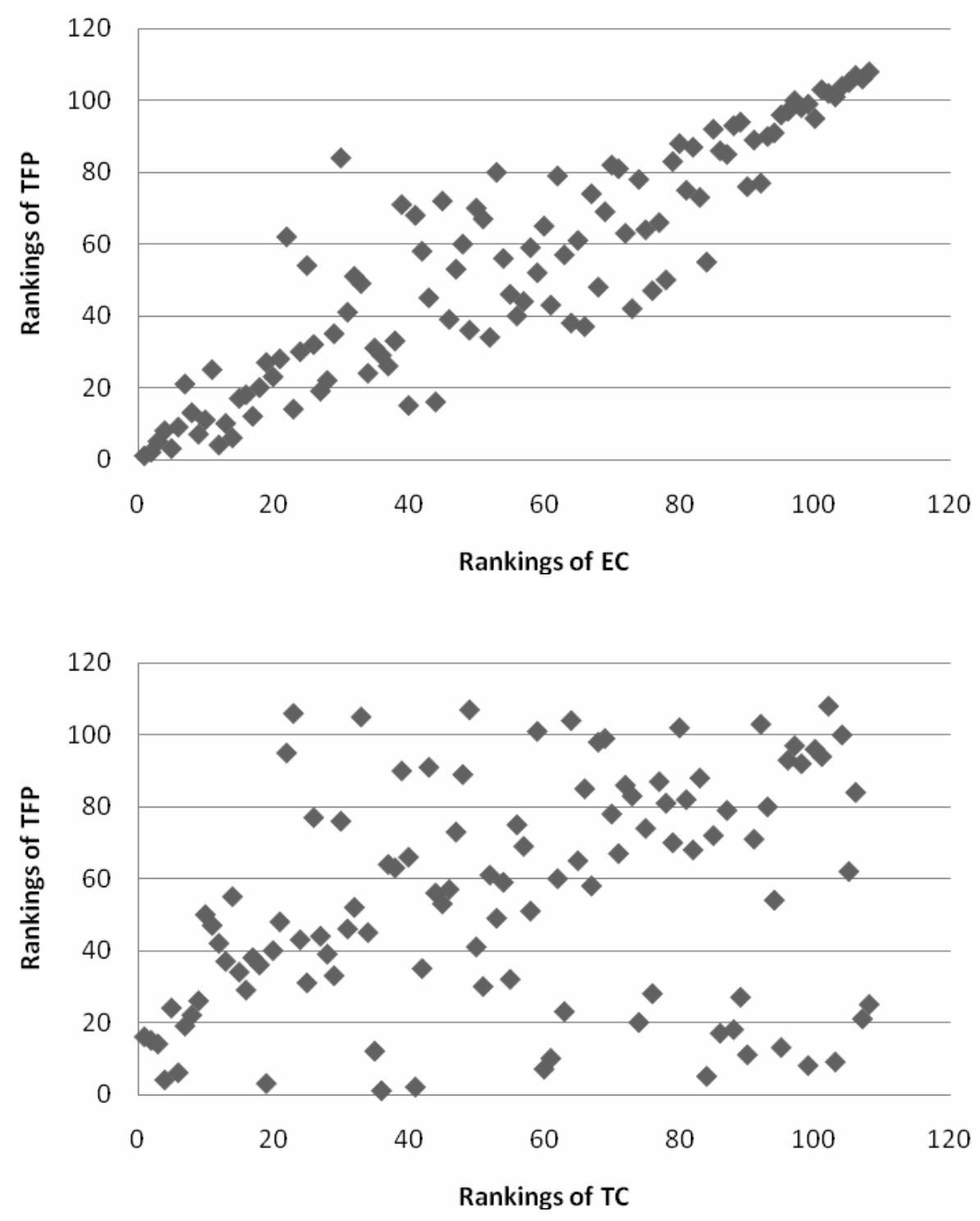
Table 5.6.3-3: Sources of Economic Growth (rate of change in \%) for the Sample Countries (1971-2000)

\begin{tabular}{|c|c|c|c|c|c|c|c|c|c|}
\hline Country & $\mathbf{Y}$ & $\mathbf{K}$ & $\mathbf{L}$ & EC & $\operatorname{Rank}[\mathrm{EC}]$ & TC & $\operatorname{Rank}[\mathrm{TC}]$ & TFP & Rank[TFP] \\
\hline Algeria & 4.195 & 5.634 & 3.743 & -2.047 & 91 & -0.066 & 48 & -2.113 & 89 \\
\hline Argentina & 2.689 & 2.904 & 1.635 & 1.656 & 33 & -0.256 & 53 & 1.400 & 49 \\
\hline Australia & 3.289 & 3.449 & 1.916 & 0.583 & 59 & 0.643 & 32 & 1.226 & 52 \\
\hline Austria & 2.77 & 3.536 & 0.59 & 0.630 & 56 & 1.240 & 20 & 1.871 & 40 \\
\hline Bangladesh & 4.335 & 3.452 & 2.324 & 10.644 & 6 & -3.417 & 103 & 7.227 & 9 \\
\hline Barbados & 4.266 & 2.084 & 1.649 & 3.204 & 23 & 3.123 & 3 & 6.328 & 14 \\
\hline Belgium & 2.449 & 2.864 & 0.534 & 0.263 & 68 & 1.189 & 21 & 1.452 & 48 \\
\hline Benin & 3.372 & 5.893 & 2.597 & -0.645 & 82 & -1.381 & 77 & -2.026 & 87 \\
\hline Bolivia & 2.855 & 2.492 & 2.389 & 2.788 & 26 & -0.331 & 55 & 2.457 & 32 \\
\hline Botswana & 10.736 & 11.891 & 3.278 & 10.759 & 5 & 1.325 & 19 & 12.084 & 3 \\
\hline Brazil & 4.992 & 5.719 & 2.975 & 1.025 & 45 & -1.700 & 85 & -0.675 & 72 \\
\hline Burkina Faso & 3.818 & 6.78 & 1.991 & 1.470 & 39 & -2.062 & 91 & -0.593 & 71 \\
\hline Burundi & 0.523 & 5.457 & 1.463 & -8.525 & 101 & -2.087 & 92 & -10.612 & 103 \\
\hline Cameroon & 4.188 & 6.03 & 2.303 & 0.842 & 50 & -1.428 & 79 & -0.586 & 70 \\
\hline Canada & 3.544 & 4.935 & 2.102 & -0.334 & 77 & 0.127 & 40 & -0.207 & 66 \\
\hline Cape Verde & 5.584 & 6.315 & 2.145 & 6.876 & 14 & 2.043 & 6 & 8.920 & 6 \\
\hline Central African Republic & -0.275 & 0.564 & 1.562 & -6.338 & 99 & -0.892 & 69 & -7.230 & 99 \\
\hline Chad & 2.649 & 0.332 & 2.486 & 5.605 & 18 & -1.121 & 74 & 4.484 & 20 \\
\hline Chile & 4.395 & 4.695 & 2.525 & 2.279 & 29 & 0.010 & 42 & 2.289 & 35 \\
\hline China & 6.759 & 8.673 & 1.954 & 8.618 & 11 & -5.134 & 108 & 3.483 & 25 \\
\hline Colombia & 4.73 & 5.718 & 3.302 & 0.311 & 67 & -1.233 & 75 & -0.923 & 74 \\
\hline Comoros & 2.158 & 3.929 & 3.063 & -6.963 & 100 & 1.183 & 22 & -5.781 & 95 \\
\hline Congo, Dem. Rep. & -3.256 & 2.151 & 2.488 & -19.478 & 108 & -3.319 & 102 & -22.797 & 108 \\
\hline Congo, Republic of & 5.905 & 3.184 & 2.733 & 13.692 & 1 & 0.283 & 36 & 13.975 & 1 \\
\hline Costa Rica & 3.879 & 5.607 & 3.522 & -2.166 & 92 & 1.021 & 26 & -1.145 & 77 \\
\hline
\end{tabular}




\begin{tabular}{|c|c|c|c|c|c|c|c|c|c|}
\hline Country & $\mathbf{Y}$ & $\mathbf{K}$ & $\mathbf{L}$ & EC & $\operatorname{Rank}[\mathrm{EC}]$ & TC & $\operatorname{Rank}[\mathrm{TC}]$ & TFP & Rank[TFP] \\
\hline Cote d'Ivoire & 3.506 & 3.638 & 3.49 & 0.827 & 51 & -1.059 & 71 & -0.231 & 67 \\
\hline Cyprus & 5.414 & 4.519 & 1.224 & 8.517 & 12 & 2.575 & 4 & 11.092 & 4 \\
\hline Denmark & 2.003 & 2.394 & 0.715 & 0.530 & 64 & 1.398 & 17 & 1.928 & 38 \\
\hline Dominican Republic & 5.719 & 7.184 & 2.983 & 0.939 & 47 & -0.018 & 45 & 0.920 & 53 \\
\hline Ecuador & 4.257 & 4.08 & 3.271 & -0.021 & 72 & 0.200 & 38 & 0.179 & 63 \\
\hline Egypt & 5.188 & 6.261 & 2.77 & 0.816 & 53 & -2.135 & 93 & -1.318 & 80 \\
\hline El Salvador & 2.145 & 3.82 & 2.701 & -0.686 & 83 & -0.041 & 47 & -0.727 & 73 \\
\hline Equatorial Guinea & 4.22 & 8.686 & 1.648 & -12.757 & 107 & 1.178 & 23 & -11.578 & 106 \\
\hline Ethiopia & 2.988 & 2.579 & 2.329 & 3.982 & 22 & -3.749 & 105 & 0.233 & 62 \\
\hline Fiji & 3.255 & 3.086 & 2.586 & 1.621 & 34 & 2.238 & 5 & 3.859 & 24 \\
\hline Finland & 2.934 & 3.047 & 0.565 & 1.534 & 36 & 1.456 & 16 & 2.991 & 29 \\
\hline France & 2.532 & 3.412 & 0.725 & 0.479 & 65 & -0.238 & 52 & 0.241 & 61 \\
\hline Gabon & 4.265 & 5.67 & 2.226 & -0.056 & 73 & 1.732 & 12 & 1.677 & 42 \\
\hline Gambia, The & 3.936 & 9.021 & 3.414 & -9.466 & 103 & -0.437 & 59 & -9.903 & 101 \\
\hline Ghana & 3.728 & 1.527 & 2.887 & 8.748 & 10 & -1.915 & 90 & 6.833 & 11 \\
\hline Greece & 2.695 & 3.122 & 1.135 & 0.969 & 46 & 0.958 & 28 & 1.928 & 39 \\
\hline Guatemala & 3.899 & 4.571 & 3.174 & 0.103 & 69 & -0.415 & 57 & -0.311 & 69 \\
\hline Guinea & 3.877 & 2.336 & 2.686 & 7.468 & 13 & -0.501 & 61 & 6.967 & 10 \\
\hline Guinea-Bissau & 6.235 & 2.643 & 2.168 & 12.794 & 2 & 0.076 & 41 & 12.870 & 2 \\
\hline Haiti & 5.175 & 5.589 & 0.847 & 6.345 & 16 & -1.732 & 88 & 4.614 & 18 \\
\hline Honduras & 3.216 & 4.793 & 3.251 & -2.877 & 94 & -0.009 & 43 & -2.886 & 91 \\
\hline Hong Kong & 7.139 & 8.016 & 2.872 & 1.543 & 35 & 1.056 & 25 & 2.600 & 31 \\
\hline Iceland & 4.034 & 3.747 & 1.971 & 1.428 & 40 & 3.711 & 2 & 5.140 & 15 \\
\hline India & 4.876 & 5.253 & 1.998 & 9.121 & 7 & -4.650 & 107 & 4.471 & 21 \\
\hline Indonesia & 6.357 & 10.9 & 2.854 & -2.030 & 89 & -3.215 & 101 & -5.245 & 94 \\
\hline Iran & 3.698 & 5.588 & 3.157 & -1.027 & 87 & -0.732 & 66 & -1.760 & 85 \\
\hline Ireland & 5.473 & 5.863 & 1.197 & 0.823 & 52 & 1.511 & 15 & 2.335 & 34 \\
\hline
\end{tabular}

$-228$ 


\begin{tabular}{|c|c|c|c|c|c|c|c|c|c|}
\hline Country & $\mathbf{Y}$ & $\mathbf{K}$ & $\mathbf{L}$ & EC & $\operatorname{Rank[EC]}$ & TC & Rank[TC] & TFP & Rank[TFP] \\
\hline Israel & 4.593 & 5.027 & 2.885 & 0.365 & 66 & 1.644 & 13 & 2.009 & 37 \\
\hline Italy & 2.779 & 3.061 & 0.637 & 1.889 & 31 & -0.164 & 50 & 1.726 & 41 \\
\hline Jamaica & 0.897 & 1.116 & 1.929 & -2.036 & 90 & 0.895 & 30 & -1.140 & 76 \\
\hline Japan & 3.45 & 5.691 & 0.834 & -0.532 & 79 & -1.087 & 73 & -1.619 & 83 \\
\hline Jordan & 6.567 & 8.299 & 4.645 & 0.568 & 61 & 1.081 & 24 & 1.649 & 43 \\
\hline Kenya & 5.572 & 4.209 & 3.573 & 8.780 & 8 & -2.201 & 95 & 6.579 & 13 \\
\hline Korea, Republic of & 7.509 & 10.461 & 2.511 & 1.222 & 42 & -0.796 & 67 & 0.426 & 58 \\
\hline Lesotho & 4.262 & 12.226 & 1.723 & -12.447 & 106 & -0.113 & 49 & -12.560 & 107 \\
\hline Luxembourg & 4.525 & 3.602 & 1.141 & 1.104 & 44 & 3.745 & 1 & 4.849 & 16 \\
\hline Madagascar & 1.42 & 1.924 & 2.625 & -0.805 & 85 & -2.608 & 98 & -3.412 & 92 \\
\hline Malawi & 5.187 & 3.272 & 2.728 & 11.054 & 3 & -1.679 & 84 & 9.375 & 5 \\
\hline Malaysia & 6.775 & 8.829 & 3.052 & 0.606 & 58 & -0.273 & 54 & 0.333 & 59 \\
\hline Mali & 3.196 & 2.761 & 1.959 & 5.142 & 19 & -1.912 & 89 & 3.230 & 27 \\
\hline Mauritania & 1.752 & 6.186 & 1.984 & -10.033 & 104 & -0.672 & 64 & -10.705 & 104 \\
\hline Mauritius & 5.599 & 5.882 & 2.408 & 1.492 & 37 & 1.801 & 9 & 3.293 & 26 \\
\hline Mexico & 4.064 & 4.905 & 3.444 & -0.849 & 86 & -1.076 & 72 & -1.926 & 86 \\
\hline Morocco & 3.931 & 5.764 & 2.741 & -0.135 & 74 & -1.019 & 70 & -1.155 & 78 \\
\hline Mozambique & 1.121 & 2.963 & 1.95 & -3.003 & 95 & -2.989 & 100 & -5.992 & 96 \\
\hline Nepal & 4.671 & 9.062 & 2.098 & -1.680 & 88 & -2.232 & 96 & -3.912 & 93 \\
\hline Netherlands & 3.003 & 3.168 & 1.438 & 0.687 & 55 & 0.806 & 31 & 1.493 & 46 \\
\hline New Zealand & 2.291 & 2.954 & 1.85 & -0.302 & 76 & 1.763 & 11 & 1.460 & 47 \\
\hline Nicaragua & 0.27 & 2.714 & 3.539 & -11.306 & 105 & 0.443 & 33 & -10.863 & 105 \\
\hline Niger & 1.715 & 1.48 & 2.75 & 1.251 & 41 & -1.537 & 82 & -0.286 & 68 \\
\hline Nigeria & 2.113 & 6.944 & 2.753 & -4.128 & 97 & -3.483 & 104 & -7.610 & 100 \\
\hline Norway & 3.633 & 3.698 & 1.249 & 2.522 & 28 & 1.815 & 8 & 4.337 & 22 \\
\hline Pakistan & 4.943 & 4.097 & 2.57 & 10.786 & 4 & -2.812 & 99 & 7.975 & 8 \\
\hline Panama & 3.776 & 5.23 & 2.849 & 0.882 & 49 & 1.340 & 18 & 2.222 & 36 \\
\hline
\end{tabular}




\begin{tabular}{|c|c|c|c|c|c|c|c|c|c|}
\hline Country & $\mathbf{Y}$ & $\mathbf{K}$ & $\mathbf{L}$ & EC & $\operatorname{Rank}[\mathrm{EC}]$ & TC & Rank[TC] & TFP & Rank[TFP] \\
\hline Papua New Guinea & 3.037 & 3.41 & 2.409 & 0.702 & 54 & -0.010 & 44 & 0.692 & 56 \\
\hline Paraguay & 4.905 & 7.849 & 3.01 & -0.298 & 75 & 0.218 & 37 & -0.080 & 64 \\
\hline Peru & 2.829 & 2.758 & 3.205 & -0.589 & 81 & -0.334 & 56 & -0.924 & 75 \\
\hline Philippines & 3.733 & 4.741 & 2.81 & 0.557 & 62 & -1.720 & 87 & -1.163 & 79 \\
\hline Portugal & 4.449 & 5.806 & 1.437 & 1.180 & 43 & 0.430 & 34 & 1.610 & 45 \\
\hline Rwanda & 3.491 & 6.401 & 2.499 & -4.025 & 96 & -2.272 & 97 & -6.298 & 97 \\
\hline Senegal & 3.131 & 2.965 & 2.526 & 4.524 & 21 & -1.334 & 76 & 3.190 & 28 \\
\hline Sierra Leone & -0.104 & 4.476 & 1.832 & -8.567 & 102 & -1.487 & 80 & -10.055 & 102 \\
\hline Singapore & 7.947 & 9.424 & 3.575 & 2.664 & 27 & 1.892 & 7 & 4.555 & 19 \\
\hline South Africa & 2.583 & 2.356 & 2.551 & 0.570 & 60 & -0.673 & 65 & -0.103 & 65 \\
\hline Spain & 3.311 & 4.238 & 1.145 & 0.543 & 63 & -0.028 & 46 & 0.515 & 57 \\
\hline Sri Lanka & 4.658 & 7.801 & 2.161 & -0.003 & 71 & -1.392 & 78 & -1.395 & 81 \\
\hline Sweden & 2.05 & 2.308 & 0.841 & 0.619 & 57 & 0.999 & 27 & 1.618 & 44 \\
\hline Switzerland & 1.261 & 1.938 & 0.915 & -0.793 & 84 & 1.537 & 14 & 0.744 & 55 \\
\hline Syrian Arab Republic & 6.954 & 6.073 & 3.604 & 3.058 & 24 & -0.177 & 51 & 2.882 & 30 \\
\hline Taiwan & 8.275 & 10.624 & 1.936 & 1.698 & 32 & -0.435 & 58 & 1.263 & 51 \\
\hline Tanzania & 2.985 & 2.481 & 2.888 & 2.979 & 25 & -2.168 & 94 & 0.811 & 54 \\
\hline Thailand & 6.282 & 7.637 & 2.365 & 6.468 & 15 & -1.706 & 86 & 4.762 & 17 \\
\hline Togo & 2.197 & 5.849 & 3.043 & -5.702 & 98 & -0.880 & 68 & -6.582 & 98 \\
\hline Trinidad and Tobago & 2.697 & 4.431 & 1.553 & -0.481 & 78 & 1.797 & 10 & 1.316 & 50 \\
\hline Tunisia & 5.621 & 3.813 & 3.16 & 6.295 & 17 & 0.348 & 35 & 6.643 & 12 \\
\hline Turkey & 4.26 & 6.599 & 2.233 & -0.551 & 80 & -1.550 & 83 & -2.101 & 88 \\
\hline Uganda & 4.701 & 6.819 & 2.697 & 2.077 & 30 & -3.792 & 106 & -1.715 & 84 \\
\hline United Kingdom & 2.332 & 2.655 & 0.514 & 0.900 & 48 & -0.611 & 62 & 0.288 & 60 \\
\hline United States of America & 3.44 & 4.79 & 1.638 & 0.013 & 70 & -1.537 & 81 & -1.524 & 82 \\
\hline Uruguay & 2.617 & 3.24 & 0.992 & 1.482 & 38 & 0.954 & 29 & 2.436 & 33 \\
\hline Venezuela & 1.031 & 2.626 & 3.742 & -2.436 & 93 & 0.175 & 39 & -2.261 & 90 \\
\hline
\end{tabular}


\begin{tabular}{l}
\hline Country \\
\hline \hline Zambia \\
Zimbabwe
\end{tabular}

Y

Y

3.871

K

K

0.088

2.656

L

2.59

2.587

EC

4.798

Rank[EC]

TC

$-0.642$

Rank[TC]

TFP

4.156

Rank[TFP]

$-0.441$

63

60

8.324 


\subsection{Concluding Remarks}

In this chapter, we point out that conventional growth empirics are not sufficient to understand diverse economic performances. Measuring technical efficiency may be more in line with the theoretical foundation of explaining cross-country economic performances. Compared to TFP measurement, using a SPF approach may help us understand the sources of growth better as this methodology also allows us to disentangle technical change and technical efficiency change. In addition, the model allows us to incorporate explanatory factors of technical inefficiency.

In terms of investigating the sources of technical efficiency, we identify three key competing views on potential sources, firstly human capital, secondly openness and last but not least institutions. In the existing literature, there is no conclusive empirical evidence showing which factors are more prominent. Effects of these deep determinants also depend on the level of economic development.

We apply the Battese and Coelli (1993) model to estimate technical efficiency and incorporate its determining factors in a single model. Using a translog stochastic production function specification, we cannot find empirical evidence to show that human capital, trade openness, financial integration and capital account openness have direct impacts on explaining cross-country technical inefficiency. In terms of institution, we find that the rule of law has a direct impact of decreasing technical inefficiency. Regulation, nevertheless, shows an optimal level. That said, only after reaching a threshold of minimum amount of regulation, too much regulation leads to technical inefficiency. Democracy and stability of monetary policy have no direct impact of technical inefficiency as our empirical results show. However, their interactions with human capital in turn are statistically significant. It implies that these two aspects of institutions only work with given level of human capital to improve technical efficiency. Our findings seem to support the view of North and Parente and Prescott's theory that to reduce the income gap between developed 
economies and developing economies, the late starters have to use resources by making improvements in its institutional quality.

Our model also shows that technical efficiency is time-varying. Based on our estimated stochastic production frontier, we can proceed with deriving cross-country efficiency changes and technical changes. As expected, the industrialised economies are among the best-practice. Comparing the performances across regions, we find that the emerging markets like China and India experienced drastic improvements in technical efficiency. Sub-Saharan African countries stayed well below the frontier over our studied period, although performances of individual countries are quite diverse. When we further segregate the sources of growth into efficiency changes and technical changes, we find that the main source of growth of developing countries is through the channel of efficiency change. In developed economies, in contrast, the source of growth primarily comes from technical change (i.e. technological progress).

Our research helps our understanding of the economic importance of institutions. Also, it attempts to quantify to what extent market-sustaining institutions could hamper economic performances. Our quantifiable indicator is the estimated mean level of technical efficiency, as compared to that of the best-practice. One of our major findings is that income disparities across countries may result from the way production inputs are allocated, rather than factor accumulation.

This study provides empirical support to demonstrate what the likely and potential benefits of structural reform are that help strengthen market-sustaining institutions. In particular for developing countries, as we find, the main source of growth comes from efficiency change, which in turn relies on institutions and their interaction with human capital. 
CHAPTER 6 : CONCLUSION 
In this thesis, we investigate the inter-relationships between institutions and development outcomes, more specifically, economic growth, economic reforms, FDI and technical efficiency. The fundamental question we are interested in is to identify the development outcomes and channels on which institutional quality has direct impacts. To this end, we use Rodrik (2005)'s taxonomy to unbundle institutions into economic and political institution, as well as macroeconomic policies. This largely follows the theoretical basis of earlier literature, arguing that these three aspects are endogenously determined. We then disentangle their individual effects on different development outcomes. Also, as institution is probably not as persistent as one may have perceived, we explore the dynamic effect of institutions. Causality relationships between institutions and macroeconomic policies and reforms are also examined. Last but not least, other than domestic institutional quality, we also consider the impact of external institutions on development outcomes.

We carry out four studies in Chapters 2 to 5 with an aim to provide empirical evidence for these interrelated themes. In the following, we will summarise the major findings in these Chapters and discuss briefly their policy implications. We will also highlight the limitations of our work and suggest some possible extensions for further research.

\subsection{Summary of Findings and Policy Implications}

In Chapter 2, we revisit the empirical evidence of institutions as the source of GDP per capita growth using dynamic panel GMM estimator. As reflected in our brief survey of institution view of growth literature, the empirical evidence is rather inconclusive. This on one hand reflects technical limitations especially endogeneity - are not adequately addressed in these empirical studies. On the other hand, a consensus of which aspect of institutions causes growth is yet to be reached. Rodrik (2005)'s taxonomy that we deployed facilitates us to test the direct partial impact of four clusters of institutions (including democracy, security of property rights, regulatory environment and sound of money) on growth. The use of panel data allows us to control for 
country-specific and time-specific effects, especially the level of development. The dynamic framework further relaxes the assumption of institutional persistence, thereby estimating the short-run effect of institutions on growth. The main technical improvement in our strategy is the attempt to tackle the endogeneity problem. The GMM estimator we used does not impose the need of "external" instruments. The frequently used "external" instruments in the existing literature, being criticised by its lack of theoretical foundation and data accuracy, are no longer presence in this case.

We first test the role of institution in an augmented Solow growth models using data for the period of 1970-2004. We show that institutions, when incorporated in traditional growth models, have a direct partial impact on economic growth. As compared to human capital, for example, the effect is more statistically significant. In our model using the four clusters of institutions, we find that democracy - our measure of political institution does not have any direct impact on growth. Neither does the regulatory environment. In contrast, market-creating institutions measured by the security of property rights and market-stabilising institutions measured by the stability of monetary and fiscal policies show direct impacts on growth. The results are robust to additional covariates, alternative measures of institutions and different sub-samples used. In the sub-samples, we also find that excessive regulation imposes significant and negative impacts, which are more pronounced in non-industrialised and low and middle income economies.

Our results refine the cross-sectional approach adopted in the previous literature to test the relationship between a broad, over-generalised measure of institution and economic growth. We particularly pin down two aspects of institutions - security of property rights and sound of money (i.e. the stability of monetary policy) - that have short-run direct partial impact on GDP per capita growth rates. This is also in line with the qualitative conclusion in the literature that security of property rights and sound money constitute the first-order economic principles of economic development. In other words, constructing a sound institutional environment to maintain productive dynamism and endow the economy with resilience to shocks could bring 
economic growth in the long term. Our dynamic analyses also imply that institutional quality could associate with faster growth even in a shorter timeframe, even after controlling for the level of development that the economy has attained and the characteristics of individual country. Besides, we find that the negative impacts of regulations are more pronounced in the low and middle income countries. It may also suggest that regulations per se are not growth-impeding or enhancing, but the capacity to execute these regulations (for example bureaucratic quality of low income countries is likely to be poorer) matters.

In Chapter 3, we use the same estimation technique as in Chapter 2 to establish a causal relationship between political institutions - i.e. democracies, and economic reforms - i.e. measures that broaden the scope of the domestic and international markets. We attempt to test if democracies, which presumably have greater accountability, lead to adopting those reform measures that are more likely to gain support from the majority. We study the economic reforms in different sectors, namely fiscal measures, trade liberalisation, credit market liberalisation, capital account openness and labour market deregulation. The reciprocal causality relationship is also studied.

Analysed by sectors, our empirical results suggest that democratisation is more likely to cause redistributive policies in the form of transfer and subsidy, trade liberalisation and credit market liberalisation. There is no causal relationship found between democracy and tax policy, capital account openness and labour market deregulation. Understandably, in a democratic society, the reform measures that are more likely to benefit the majority of population (i.e. workers) are more likely to roll out in democracies. Trade and credit market liberalisation measures lead to wider range of choices of goods and services, thereby benefitting many sectors in the economy, are also more likely to gain support. Reciprocally, redistributive policies and trade liberalisation speed up the democratisation process. However, credit market deregulation does not have such effect.

Our empirical results show how political institution and economic reforms 
interact. Our findings seem to support the "dictatorship of the workers" model (Acemoglu 2009) - i.e. policies that favour the economic interests of the workers will then be implemented. In addition, redistributive policies and liberalisation measures may also lead to more resources for the majority of people to pursue more political rights. These results may help shed light on those economies that have pursued liberalisation measures, but democratisation has yet to take place.

In Chapter 4, we explore the effects of three determinants of bilateral FDI, including natural barriers, "at-the-border" barrier (i.e. regional trade agreement) and "behind the border" barrier (i.e. domestic regulatory environment). An augmented gravity model is deployed to carry out the test for the inter-OECD and intra-OECD regions. In total, there are 60 economies being studied for the period of $1985-2006$. The main aim is to study the roles of external institution vis-à-vis domestic institution on FDI.

To test the robustness of the augmented gravity models, we perform several estimation strategies for our panel data analysis. The overall results suggest that geographical, historical and cultural proximities all explain bilateral FDI significantly, even after controlling for unobserved country-pair heterogeneity and time effect. Using a "catch-all" regulatory environment index and a dummy variable for country-pair membership of regional trade agreement (RTA), our analysis shows that lax regulatory environment and RTA are seemingly associating with FDI positively in both regions. When we consider specific type of regulation, credit market regulation is the most statistically significant determinant of FDI. The effects of labour market and business regulations are less significant.

Domestic regulatory environment and RTA impose effects with different magnitudes on intra-OECD and inter-OECD FDI. We find that for the inter-OECD region, RTA is more significantly associating with FDI than domestic regulation does. In comparison, domestic regulatory environment of the destination economy is a more significant determinant of FDI rather than membership of an RTA in the intra-OECD region. 
Our results point out that RTAs, originally designed to promote inter-regional trade, also foster FDI. This also opens up one development channel for developing countries, i.e. to attract FDI, by engaging in regional integration. Furthermore, domestic regulatory environment of the destination economy is not only essential for developing economies, but also for developed economies. In particular, credit market regulation plays a more significant role than labour market regulation and business regulation. This also helps reiterate the importance of financial development, not only to growth, but also to FDI inflows. The significant impact of domestic regulatory environment found in the intra-OECD sub-sample may also interpret as the possibility that institutional difference could also be a form of comparative advantage. In the intra-OECD region, the comparative advantages of the economies may not be production costs or productivity differences, institutional strengths on the other hand turn out to be essential in affecting investors' decisions. This also helps point out that institutional difference is a key determinant of bilateral FDI flows pattern between economies with comparable level of developments.

In Chapter 5, we argue that differences in technical inefficiency (i.e. the inefficient allocation of production inputs) explain the diverse cross-country economic performances. By means of estimating a "global" stochastic production frontier, we can then compare the mean level of technical inefficiency for each country to the best practice in each period.

We estimate a translog production frontier using Battese and Coelli (1993)'s model. The model allows us to estimate the sources of technical efficiency in an one-stage estimation. In our specification, we consider three dimensions of variables - human capital, openness and institutions. We find that human capital, trade and financial openness are not statistically significant. By contrast, institutions are more fundamental to the sources of technical inefficiency. More specifically, the rule of law has a direct impact of improving technical efficiency. Democracy and sound money, nevertheless, do not have direct impact on technical efficiency. However, their interactions with human capital are statistically significant. It points out a possibility that 
a minimum level of human capital matters for these two aspects of institutions to have any impact on technical efficiency. Regulation, on the other hand, shows a threshold effect. That said, after reaching a threshold level of regulation, excessive regulation leads to technical inefficiency.

All these empirical findings support the view of North and Parente and Prescott's theory that to reduce the income gap between developed economies and developing economies, the late starters have to use resources by making improvements in its policies and institutions. Our estimations also allow us to decompose the sources of growth into efficiency gains (i.e. changes in technical efficiency) as well as technical change (technological progress). We furthermore find that developing countries generally enjoy efficiency changes which are their major source of economic growth. For developed economies, the source of growth comes from technical change (i.e. technological progress). Our regional analysis shows that the East Asia and Pacific and South Asia regions, due to the dominating effects of China and India, caught up with the best-practice rapidly over the last three decades. However, for Sub-Saharan African countries, the performances are quite diverse across countries.

These empirical studies facilitate the understanding of the economic importance of institutions, with an attempt to quantify to what extent market-sustaining institutions could hamper economic performances. The results also help imply the likely pay-off and the potential benefits of reforming market-sustaining institutions.

\subsection{Limitations of the Study}

Our contributions to the literature help reduce the over-generalised effect of institutions on economic development. Our work can be categorised into 2 ambits: (i) identify the development outcomes and unbundle the specific aspects of institutions, and (ii) develop their richer interrelationships between institutions and economic development by econometrics. 
However, like other macroeconomic studies, our work intends to investigate a "common" pattern across economies. This inevitably masks cross-sectional heterogeneity. The taxonomy of institution we used although facilitates the understanding of the specific types of institutions, there are many other country-specific characteristics that do not fall under such classification. In our estimations, we treat country-specific characteristics as unobserved. In fact, understanding the country-specific situation is important for designing growth strategies.

Secondly, data limitation is also a major problem. On one hand, all the institutional variables are actually measuring the macroeconomic environment, without specific reference to particular sectors or industries. Variables with particular focus at the micro-level may help strengthen further how development outcomes interact with the institutional arrangement. However, these are not readily available at this stage. On the other hand, so far, we only have three decades of institutional variables. Over time, when more data come up from different sources, more studies in respect to institutional change can be undertaken for checking robustness and sensitivity.

Thirdly, our work does not tie closely with a particular theoretical model. Although theoretical foundations suggesting the interrelationship between the choices of economic institution and political institutions are available in the literature, models that provide a link between how specific aspects of economic/political institution affect a particular development outcome (say, FDI) are far from unified. This gives an impression that a coherent theoretical model to explain our results is absent.

Despite all these limitations, our research provides empirical basis to identify the channels of particular aspects of institutions. It also helps pin down the over-generalised analysis of the relationship between institutions and economic development in a more robust manner. 


\subsection{Further Research}

In the light of our empirical results and limitations aforementioned, we propose the following dimensions for further investigation and for polishing our work:

- Firstly, we could consider a micro-level analysis investigating how firm- or sector-level development relates to institutional change. Such kind of micro-level investigation has been started in recent years. However, most of these work relate to qualitative analysis on one hand and mostly land reform on the other (see Nunn (2009)). Empirical work in respect to the manufacturing and services sectors remain limited. As institutional measures are largely macro in nature, case studies for specific data needs at sectoral-level may have to be built up. Alternatively, we could also investigate how macro institutional arrangement could be differently felt by sectors and industries.

- Secondly, a theoretical model to incorporate the bilateral causal relationship between democracy and economic reforms may need to be considered. How and why economic reforms are more likely to be implemented in democracy have been previously studied in the literature. However, a model to explain the reverse causality is perhaps more interesting, especially with reference to the experiences of emerging markets like China, where economic reforms have taken place but democratisation progress has been slow.

- The third is how to formalise institutional quality - regulatory environment in particular - as a source of comparative advantage which ultimately determines the pattern of capital flow. Models relating institutional quality and trade have been built up by Levchenko (2007) and Levchenko (2008). Models in regard to capital flow are rare. How these institutional differences could be reduced (or institutional convergence) after closer market integration 
could also be empirically tested.

- Finally, on estimating the stochastic production frontier, there is considerable merit to extend the measurement beyond 2000. For monitoring international development, we could ideally extract continuous information on cross-country economic performances in respect to their efficiency change and TFP growth from these measurements. 
APPENDICES

$-244-$ 


\section{A.1 Summary Table of Institution and Growth Literature}

To summarise the key empirical results, Pande and Udry (2006) provide an overview of recent empirical work of institution and growth. We combine it with De Haan, et al. (2006)'s survey on the empirical work on the same subject using the Fraser Institute's economic freedom index (i.e. Gwartney, et al. (2008)), and augment the list further ${ }^{(1)}$ below for easy reference. Selection criteria is described in Pande and Udry (2006).

\begin{tabular}{|c|c|c|c|}
\hline Article & Dependent variable ${ }^{(2)}$ & Measure of Institution & Instrumental variables \\
\hline \multicolumn{4}{|l|}{ (I) CORE PAPERS } \\
\hline $\begin{array}{l}\text { Acemoglu, et al. } \\
(2001)\end{array}$ & $\begin{array}{l}\text { Log GDP per capita } \\
(1995)\end{array}$ & $\begin{array}{l}\text { Protection against } \\
{\text { expropriation } \text { risk }^{1}}_{(1985-1995)}\end{array}$ & Settler mortality ${ }^{1}$ \\
\hline $\begin{array}{l}\text { Hall and Jones } \\
\text { (1999) }\end{array}$ & $\begin{array}{l}\text { Log output per } \\
\text { worker }^{1}(1988)\end{array}$ & $\begin{array}{l}\text { Index of social } \\
\text { infrastructure }{ }^{2} \text { which } \\
\text { combines: } \\
\text { i. index of government } \\
\text { antidiversion } \\
\text { policies }^{3} \\
\text { ii. index of country's } \\
\text { openness } \\
\end{array}$ & $\begin{array}{l}\text { I. Distance from } \\
\text { equator }^{2} \\
\text { II. English speakers } \\
\text { III. European-language } \\
\text { speakers } \\
\text { IV. Predicted trade } \\
\text { share }^{5}\end{array}$ \\
\hline $\begin{array}{l}\text { Knack and } \\
\text { Keefer (1995) }\end{array}$ & $\begin{array}{l}\text { I. Annual GDP per } \\
\text { capita growth } \\
\text { (1974-1989) } \\
\text { II. Private } \\
\text { investment/GDP } \\
\text { (1974-1989) (all } \\
\text { averages) }\end{array}$ & $\begin{array}{l}\text { I. ICRG index }{ }^{5} \\
\text { II. BERI index }\end{array}$ & No IV estimates \\
\hline $\begin{array}{l}\text { La Porta, } \\
\text { Lopez-de-Silanes, } \\
\text { Shleifer, et al. } \\
\text { (1999) }\end{array}$ & $\begin{array}{l}\text { Dependent variables } \\
\text { are classified in five } \\
\text { groups (data from } \\
\text { 1990s): } \\
\text { I. Interference with } \\
\text { private sector } \\
\text { II. Efficiency } \\
\text { III. Output of public } \\
\text { goods } \\
\text { IV. Size of public } \\
\text { sector } \\
\text { V. Political freedom }\end{array}$ & $\begin{array}{l}\text { I. Ethnolinguistic } \\
\text { fractionalization } \\
\text { II. Legal origin } \\
\text { III. Religion }\end{array}$ & No IV estimates \\
\hline
\end{tabular}

\footnotetext{
(1) Separately, Acemoglu, et al. (2005) provide a survey of historical account of the effect of institution on development.

${ }^{(2)}$ Footnotes on outcome variables and institution measures are on separate pages at the end of the table.
} 


\begin{tabular}{|c|c|c|c|}
\hline Article & Dependent variable ${ }^{(2)}$ & Measure of Institution & Instrumental variables \\
\hline Mauro (1995) & $\begin{array}{l}\text { I.GDP per capita } \\
\text { growth (1960-1985) } \\
\text { II. Investment/GDP } \\
(1960-1985) \\
\text { III. Investment/GDP } \\
\text { (1980-1985) (all } \\
\text { averages) }\end{array}$ & $\begin{array}{l}\text { I. Index of institutional } \\
\text { efficiency } \\
\text { II. Index of } \\
\text { bureaucratic efficiency }^{8}\end{array}$ & $\begin{array}{l}\text { Ethnolinguistic } \\
\text { fractionalization }^{6} \\
(1960)\end{array}$ \\
\hline
\end{tabular}

\section{(II)PAPERS EMPLOYING CROSS-SECTIONAL ESTIMATIONS}

\begin{tabular}{|c|c|c|c|}
\hline $\begin{array}{l}\text { Acemoglu, et al. } \\
(2002)\end{array}$ & $\begin{array}{l}\text { I. Log GDP per } \\
\text { capita (1995) } \\
\text { II. Urbanization }{ }^{2} \\
\text { (1995) }\end{array}$ & $\begin{array}{l}\text { I. Current institutions: } \\
\text { i. protection against } \\
\text { expropriation risk } \\
\text { ii. executive constraints } \\
\text { in } 1990^{9} \\
\text { II. Early institutions: } \\
\text { i. executive constraints } \\
\text { in } 1900 \\
\text { ii. initial executive } \\
\text { constraints }\end{array}$ & Settler mortality \\
\hline $\begin{array}{l}\text { Acemoglu and } \\
\text { Johnson }(2005)\end{array}$ & $\begin{array}{l}\text { I. Log GDP per } \\
\text { capita (1995) } \\
\text { II. Average } \\
\text { investment/GDP } \\
(1990 \text { s) } \\
\text { III. Private } \\
\text { credit/GDP (1998) } \\
\text { IV. Average stock } \\
\text { market } \\
\text { capitalization }{ }^{3} / \mathrm{GDP} \\
(1990-1995)\end{array}$ & $\begin{array}{l}\text { I. Contracting } \\
\text { institutions: } \\
\text { i. legal formalism }{ }^{11} \\
\text { II. Property rights } \\
\text { institutions: } \\
\text { i. executive constraints } \\
\text { ii. protection against } \\
\text { expropriation risk }\end{array}$ & $\begin{array}{l}\text { I. Settler mortality } \\
\text { II. Log of indigenous } \\
\text { population } \\
\text { density in } 1500^{7} \\
\text { III. legal origin }^{8}\end{array}$ \\
\hline $\begin{array}{l}\text { Aghion, et al. } \\
(2005)\end{array}$ & $\begin{array}{l}\text { Average growth rate } \\
\text { of GDP per capita } \\
\text { (1960-1995) relative } \\
\text { to the United States }\end{array}$ & $\begin{array}{l}\text { I. Private } \text { credit }^{12} \\
\text { II. Liquid liabilities } \\
\text { III. Bank assets } \\
{ }^{14} \\
\text { IV. Commercial-central } \\
\text { bank }^{15}\end{array}$ & $\begin{array}{l}\text { I. Legal origin } \\
\text { II. Settler mortality }\end{array}$ \\
\hline $\begin{array}{l}\text { Ciccone and } \\
\text { Alcala (2004) }\end{array}$ & $\begin{array}{l}\text { Log GDP per capita } \\
\text { (1995) }\end{array}$ & $\begin{array}{l}\text { Index of institutional } \\
\text { quality }^{16}\end{array}$ & $\begin{array}{l}\text { I. Settler mortality } \\
\text { II. European-language } \\
\text { speakers } \\
\text { III. Predicted trade } \\
\text { share }^{12}\end{array}$ \\
\hline $\begin{array}{l}\text { Bockstette, } \\
\text { Chanda, and } \\
\text { Putterman (2002) }\end{array}$ & $\begin{array}{l}\text { I. Log output per } \\
\text { worker (1988) } \\
\text { II. Average GDP per } \\
\text { capita growth } \\
(1960-1995)\end{array}$ & $\begin{array}{l}\text { I. Index of social } \\
\text { infrastructure } \\
\text { II. ICRG index }\end{array}$ & $\begin{array}{l}\text { I. Distance from } \\
\text { equator } \\
\text { II. English speakers } \\
\text { III. European-language } \\
\text { speakers } \\
\text { IV. Log predicted trade } \\
\text { share } \\
\text { V. State antiquity }\end{array}$ \\
\hline
\end{tabular}




\begin{tabular}{|c|c|c|c|}
\hline Article & Dependent variable ${ }^{(2)}$ & Measure of Institution & Instrumental variables \\
\hline $\begin{array}{l}\text { Clague, Keefer, } \\
\text { Knack, et al. } \\
\text { (1999) }\end{array}$ & $\begin{array}{l}\text { I. Annual per capita } \\
\text { GDP growth } \\
\text { (1970-1992) } \\
\text { II. Output per worker } \\
\text { (1988) } \\
\text { III. Capital per } \\
\text { worker (1988) } \\
\text { IV. Years schooling } \\
\text { per worker (1985) } \\
\text { V.TFP (1988) }\end{array}$ & $\begin{array}{l}\text { I. Contract-intensive } \\
\text { money }^{17} \\
\text { II. ICRG index } \\
\text { III. BERI index }\end{array}$ & $\begin{array}{l}\text { I. Colonial origin }^{10} \\
\text { II. Ethnolinguistic } \\
\text { homogeneity }^{11}\end{array}$ \\
\hline $\begin{array}{l}\text { Djankov, et al. } \\
(2002)\end{array}$ & $\begin{array}{l}\text { I. Deaths from } \\
\text { (i)intestinal infection } \\
\text { (ii)accidental } \\
\text { poisoning } \\
\text { II. Quality standards } \\
\text { (no. ISO 9000 } \\
\text { certifications) } \\
\text { III. Water pollution } \\
\text { IV. Unofficial } \\
\text { economy:(i) size/ } \\
\text { GDP (ii) employment } \\
\text { V. Product market } \\
\text { competition }\end{array}$ & $\begin{array}{l}\text { Number of different } \\
\text { procedures that a } \\
\text { start-up has to comply } \\
\text { with in order to obtain } \\
\text { a legal status, i.e. to } \\
\text { start operating as a } \\
\text { legal entity. }\end{array}$ & No IV estimates. \\
\hline $\begin{array}{l}\text { Esfahani and } \\
\text { Ramirez (2003) }\end{array}$ & $\begin{array}{l}\text { I. Growth of GDP per } \\
\text { capita } \\
\text { II. Growth rates of } \\
\text { telephones and power } \\
\text { production per capita }\end{array}$ & $\begin{array}{l}\text { I. Adverseness of } \\
\text { policy environment }^{18} \\
\text { II. Indices of } \\
\text { democracy and } \\
\text { centralization }^{19} \\
\text { III. Indices of contract } \\
\text { repudiation, } \\
\text { bureaucratic quality } \\
\text { and corruption }{ }^{20} \\
\text { IV. Ethnolinguistic } \\
\text { fractionalization }\end{array}$ & No IV estimates. \\
\hline $\begin{array}{l}\text { Glaeser, et al. } \\
(2004)\end{array}$ & $\begin{array}{l}\text { I. Log GDP per } \\
\text { capita (2000) } \\
\text { II. Growth rates of } \\
\text { GDP per capita } \\
\text { 1960-2000, overall } \\
\text { and by decade } \\
\text { III. Years schooling } \\
\text { IV. Political } \\
\text { institutions } \\
\text { (III and IV are 5-year } \\
\text { change) }\end{array}$ & Executive constraints & $\begin{array}{l}\text { I. Settler mortality } \\
\text { II. Legal origin } \\
\text { III. Log indigenous } \\
\text { population } \\
\text { density in } 1500\end{array}$ \\
\hline $\begin{array}{l}\text { Knack and } \\
\text { Keefer (1997) }\end{array}$ & $\begin{array}{l}\text { I. Average annual } \\
\text { growth in per capita } \\
\text { income (1980-1992) } \\
\text { II. Investment/GDP } \\
(1980-1992)\end{array}$ & $\begin{array}{l}\text { I. Trust }{ }^{23} \\
\text { II. Civic norms (civic } \\
\text { cooperation) }\end{array}$ & $\begin{array}{l}\text { I. Ethnolinguistic } \\
\text { homogeneity } \\
\text { II. \% Law students } \\
1963\end{array}$ \\
\hline
\end{tabular}




\begin{tabular}{|c|c|c|c|}
\hline Article & Dependent variable ${ }^{(2)}$ & Measure of Institution & Instrumental variables \\
\hline Kogel (2005) & $\begin{array}{l}\text { Annual average } \\
\text { growth rate of TFP } \\
\text { (1965-1990, panel } \\
\text { data of 5-year } \\
\text { averages) }\end{array}$ & $\begin{array}{l}\text { Index of social } \\
\text { infrastructure }\end{array}$ & $\begin{array}{l}\text { I. English speakers } \\
\text { II. European-language } \\
\text { speakers } \\
\text { III. Predicted trade } \\
\text { shares } \\
\text { IV. Distance from } \\
\text { equator } \\
\text { V. State antiquity }\end{array}$ \\
\hline $\begin{array}{l}\text { Masters and } \\
\text { McMillan (2001) }\end{array}$ & $\begin{array}{l}\text { Log output per } \\
\text { worker (1988) }\end{array}$ & $\begin{array}{l}\text { Index of social } \\
\text { infrastructure }\end{array}$ & $\begin{array}{l}\text { I. Distance from } \\
\text { equator } \\
\text { II. Predicted trade } \\
\text { share } \\
\text { III. English speakers } \\
\text { IV. European-language } \\
\text { speakers }\end{array}$ \\
\hline Rodrik (1999) & $\begin{array}{l}\text { Average dollar wages } \\
\text { in manufacturing } \\
(1985-1989)\end{array}$ & $\begin{array}{l}\text { I. Political institutions: } \\
\text { i. two rule of law } \\
\text { indicators } \\
\text { ii } \\
\text { ii. two democracy } \\
\text { indicators }{ }^{25} \\
\text { II. Labor market } \\
\text { institutions: } \\
\text { i. unionization rate ii. } \\
\text { number ILO workers' } \\
\text { rights conventions } \\
\text { ratified }\end{array}$ & $\begin{array}{l}\text { I. Dummy for oil } \\
\text { exporter } \\
\text { II. Colonial origins } \\
\text { III. Each measure of } \\
\text { democracy } \\
\text { as an instrument for } \\
\text { the other }\end{array}$ \\
\hline $\begin{array}{l}\text { Rodrik, et al. } \\
(2004)\end{array}$ & $\begin{array}{l}\text { Same as Clague, } \\
\text { Keefer, Knack and } \\
\text { Olson (1999), except } \\
\text { they use GDP per } \\
\text { capita (1995) }\end{array}$ & Rule of law index ${ }^{26}$ & $\begin{array}{l}\text { I. Settler mortality } \\
\text { II. European-language } \\
\text { speakers } \\
\text { III. Predicted trade } \\
\text { shares }\end{array}$ \\
\hline \multicolumn{4}{|c|}{$\begin{array}{l}\text { (III) PAPERS EMPLOYING PANEL ESTIMATIONS USING } \\
\text { ECONOMIC FREDOM INDICIES (EF) }\end{array}$} \\
\hline Dawson (1998) & $\begin{array}{l}\text { GDP per capita } \\
\text { growth }(1975-1990)\end{array}$ & $\begin{array}{l}\text { Aggregate Economic } \\
\text { Freedom Index }\end{array}$ & $\begin{array}{l}\text { Fixed effects model/ } \\
\text { No IV estimation }\end{array}$ \\
\hline $\begin{array}{l}\text { Nelson and Singh } \\
\text { (1998) }\end{array}$ & $\begin{array}{l}\text { GDP per capita } \\
\text { growth }(1970-1989)\end{array}$ & $\begin{array}{l}\text { Aggregate Economic } \\
\text { Freedom Index }\end{array}$ & $\begin{array}{l}\text { Fixed effects model/ } \\
\text { No IV estimation }\end{array}$ \\
\hline $\begin{array}{l}\text { Paldam, Wurtz, } \\
\text { and Gorgens } \\
(2003)\end{array}$ & $\begin{array}{l}\text { GDP per capita } \\
\text { growth }(1970-1999)\end{array}$ & $\begin{array}{l}\text { Aggregate Economic } \\
\text { Freedom Index }\end{array}$ & $\begin{array}{l}\text { Fixed effects model/ } \\
\text { No IV estimation }\end{array}$ \\
\hline $\begin{array}{l}\text { Bengoa and } \\
\text { Sanchez-Robles } \\
(2003)\end{array}$ & $\begin{array}{l}\text { I. GDP per capita } \\
\text { growth (1970-1999) } \\
\text { II. FDI }\end{array}$ & $\begin{array}{l}\text { Aggregate Economic } \\
\text { Freedom Index }\end{array}$ & $\begin{array}{l}\text { Fixed effects model/ } \\
\text { No IV estimation }\end{array}$ \\
\hline $\begin{array}{l}\text { Bhattacharyya } \\
(2009)\end{array}$ & $\begin{array}{l}\text { GDP per capita } \\
\text { growth }(1970-2004)\end{array}$ & $\begin{array}{l}\text { Four components of } \\
\text { Economic Freedom } \\
\text { Index }\end{array}$ & $\begin{array}{l}\text { System GMM } \\
\text { instruments }\end{array}$ \\
\hline
\end{tabular}

(IV) OTHER PAPER EMPLOYING PANEL ESTIMATIONS 


\begin{tabular}{|c|c|c|c|}
\hline Article & Dependent variable ${ }^{(2)}$ & Measure of Institution & Instrumental variables \\
\hline $\begin{array}{l}\text { Law and } \\
\text { Bany-Ariffin } \\
(2008)\end{array}$ & $\begin{array}{l}\text { GDP per capita } \\
\text { growth } \\
(1980-2001)\end{array}$ & $\begin{array}{l}\text { ICRG's } 5 \text { indicators: } \\
\text { (1) corruption; (2) rule } \\
\text { of law; (3) bureaucratic } \\
\text { quality; (4) government } \\
\text { repudiation of } \\
\text { contracts, and (5) risk } \\
\text { of expropriation }\end{array}$ & $\begin{array}{l}\text { Difference GMM } \\
\text { instruments and pooled } \\
\text { mean group estimation }\end{array}$ \\
\hline
\end{tabular}

Source: Pande and Udry (2006), De Haan, et al. (2006) and author's augmentation.

\section{Footnotes}

Notes on Outcome Variables:

1) Output per worker: Output calculated as GDP minus value added in the mining industry (which includes oil and gas).

2) Urbanization:\% of population living in urban areas with a population of at least 5,000 in 1995. Source: World Bank, World Development Indicators.

3) Stock market capitalization : Market value of all traded stocks as a \% of GDP, average over 1990-95. Source: Beck, Demirguc-Kunt, and Levine (2003b)

\section{Notes on Institution Measures:}

1) Protection against expropriation risk: A measure of risk of expropriation of foreign private investment by government, from 0 to 10, where a higher score indicates less risk. Originally used by Knack and Keefer (1995). Source: ICRG, Political Risk Services

2) Index of social infrastructure: Institutions and government policies that provide incentives for individuals and firms in an economy.

3) Index of government antidiversion policies: Created by averaging five indicators following Knack and Keefer (1995) for 1986-1995. Two categories relate to government's role in protecting against private diversion: (i) law and order, and (ii) bureaucratic quality. Three categories relate to government's possible role as a diverter: (i)corruption, (ii) risk of expropriation, and (iii) government repudiation of contracts. The index takes values from 0 to 1 (higher is better). Source: ICRG, Political Risk Services.

4) Index of country's openness: Sachs-Warner index which measures fraction years between 1950 to 1994 that the economy has been open, measured on a 0-1scale. A country is open if it satisfies the following criteria: (i) nontariff barriers cover less than $40 \%$ of trade, (ii) average tariff rates are less than $40 \%$, (iii) any black market premium was less than $20 \%$ during 1970s and 1980s, (iv) country is not classified as socialist by Kornai (1992), and (v) government does not monopolize major exports. Source: Sachs and Warner (1995).

5) ICRG index: Combines (i) protection against expropriation risk, (ii) rule of law, (iii) repudiation of contracts by government, (iv)corruption in government, and (v) quality of bureaucracy. Source: ICRG, Political Risk Services.

6) Business Environmental Risk Intelligence (BERI) index: Combines (i)contract enforceability, (ii) infrastructure quality, (iii) nationalization potential, (iv) bureaucratic delays.

7) Index of institutional efficiency: Combines nine indices of institutional efficiency: political change, political stability, probability of opposition group takeover, stability of labor, relationship with neighboring countries, terrorism, legal system, red tape, and corruption. Indices are integers between $0-10$, higher values indicates that country has "good" institutions. All indices are simple country averages for the period 1980-1983. Source: Economist Intelligence Unit.

8) Index of bureaucratic efficiency: Combines three indices used for institutional efficiency measure: judiciary system, red tape and corruption indices.

9) Executive constraints: 1-7 category scale, higher score means more constraints on the executive. Equals one if country not independent. Source: Gurr (1997)'s Polity III data set

10) Initial executive constraints: Executive constraints in the first year that country appears in the Gurr (1997)'s Polity III data set. Source: Polity III data set

11) Legal formalism: Measures number of formal legal procedures necessary to resolve a simple case of collecting on an unpaid check or evicting a non-paying tenant (from 1 to 7). "Check measure" and "Eviction measure" from Djankov, Glaeser, Porta, et al. (2003a). Source: Djankov, et al. (2002) and Djankov, et al. (2003a).

12) Private credit: Value of credits by financial intermediaries to the private sector, divided by GDP.

13) Liquid liabilities: Currency plus demand and interest-bearing liabilities of banks and non-bank financial intermediaries, divided by GDP

14) Bank Assets: Ratio of all credits by banks (but not other financial intermediaries) to GDP

15) Commercial-central bank: Ratio of commercial bank assets to the sum of commercial plus central bank assets, which has been used by others.

16) Institutional Quality: Combines bureaucratic quality, law/order, and property rights protection indices. Source: Political Risk Services (similar to Knack and Keefer (1995), Hall and Jones (1999)).

17) Contract-intensive money: Ratio of noncurrency money to total money supply. An objective measure of enforceability of contracts and the security of property rights based on the citizens' decisions regarding the form in which they choose to hold their financial assets.

18) Adverseness of policy environment: Measured by black market premium on the foreign exchange rate. (Barro and 
Lee (1994)).

19) Index of democracy: Average of 8 indicators ranking policymaker selection process and the constraints on them. Index of centralization: Geographic devolution of state decision-making authority, values of 1 and 3 assigned to federal and unitary systems, respectively, and 2 to intermediate categories. Gurr (1997)'s Polity III data set.

20) Index of contract repudiation: risk of a modification in a contract taking the form of repudiation, postponement, or scaling down due to budget cutbacks, indigenization pressure, a change in government, or a change in government economic and social policies. Higher scores indicate lower risks. Index of bureaucratic quality: autonomy from political pressure and strength and expertise to govern without drastic changes in policy or interruption in government services as well as the existence of an established mechanism for recruiting and training. Higher scores indicate higher quality. Index of corruption: indicator of the degree of "improper practices" in the government. The higher the indicator, the lower the degree of corruption. Source: International Country Risk Guide (ICRG) dataset, Political Risk Services.

21) Index of institutional quality: Measured by scores for corruption, law and order, and bureaucracy for 1990 . Three different measures are scaled from 1 (worst) through 6 (best). They have followed Rodrik in employing a rescaled unweighted average of the three measures. Source: International Country Risk Guide (ICRG) dataset, Political Risk Services.

22) Index of democratization: Measured using the "polity" variable in the Polity IV dataset. Autocrats are defined as having a polity score less than or equal to 0 . Democrats are those leaders with a polity score greater than 0 .

23) Trust: The question used to assess trust in a society is: "Generally speaking, would you say that most people can be trusted, or that you can't be too careful in dealing with people? Trust indicator used by the authors is the percentage of respondents in each nation replying "most people can be trusted" (after deleting the "don't know" responses).

24) These indicators are: (i) ICRG from Knack and Keefer (1995) (ii) bureaucratic efficiency from (Mauro (1995).

25) These indicators are: (i) Freedom House Index (a composite index of democracy for the 1970s, constructed from the indicators of political rights and civil liberties with a scale from 0 to 1 where 1 indicates a fully democratic system) (ii) Polity III (Gurr (1997))

26) Rule of law index: Composite indicator of multiple elements that capture the protection afforded to property rights and the strength of the rule of law. This is a standardized measure with range -2.5 (weakest institutions) and 2.5 (strongest institutions). Approximates for 1990's institutions. Source: Kaufmann, Kraay, and Zoido-Lobatón (2002)

27) Fraser Institue's Economic Freedom Index. Source: Gwartney, et al. (2008)

\section{Notes on Instruments:}

1) Settler Mortality: Log estimated mortality for European settlers during European colonization (before 1850). It is calculated from the mortality rates of European-born soldiers, sailors and bishops when stationed in colonies. It measures the effects of local diseases on people without inherited or acquired immunities. Source: Curtin (1989).

2) Distance from equator: Center of county or province within a country that contains the most people. Source: Global Demography Project, University of California, Santa Barbara.

3) English speakers: Fraction of the population speaking English at birth.

4) European-language speakers: Fraction of the population speaking one of the five principal languages of Europe (English, French, German, Portuguese, or Spanish) at birth.

5) Predicted trade share: Log value, based on a gravity trade model that only uses a country's population and geographical features. Source: Frankel and Romer (1999).

6) Ethnolinguistic fractionalization: Measures probability that two randomly selected persons from a given country will not belong to the same ethnolinguistic group. Source: Taylor and Hudson, World Handbook of Political and Social Indicators, 1972

7) Indigenous population density: Population density is calculated as total population divided by land area usable for agriculture. Source: McEvedy and Jones (1978)

8) Legal Origin: Legal origin of the company law or commercial code of each country (French Commercial Code versus English Common Law Origin) Source: La Porta, et al. (1999).

9) State antiquity: Index for the depth of experience with state-level institutions. Scales from 0 to 1

10) Colonial Origin: Dummy variable indicating whether country was a British, French, German, Spanish, Italian, Belgian, Dutch or Portuguese colony. Source: La Porta, et al. (1999)

11) Ethnolinguistic homogeneity: Percentage of a country's population belonging to the largest ethnic group. Each ethnolinguistic group is identified by religion, race, or language depending on which of this appears to be the most important cleavage in the given community. Source: Sullivan (1991).

12) Predicted trade share: A geography-based instrument for trade. They used exactly the same approach with Frankel and Romer (1999), except that they employ more bilateral trade data than Frankel and Romer (1999). 


\section{A.2 Data Description and Sources}

\section{i. Variables Used in Chapter 2, 3 and 5}

The following table intends to summarise the detailed description of the variables used in Chapters 2, 3 and 5, which were briefly discussed in the respective Chapters before. The variables hereby presented are in alphabetical order.

\begin{tabular}{|c|c|c|}
\hline Variable & Description & Source \\
\hline ca_open & Index for openness to capital account transactions & Chinn and Ito (2006) \\
\hline CREDIT & $\begin{array}{l}\text { Index of credit market regulation, ranging from } 0 \\
\text { to } 10 \text {. Higher scores mean less credit market } \\
\text { control. }\end{array}$ & $\begin{array}{l}\text { Fraser Institute 's } \\
\text { Economic Freedom } \\
\text { of the World Report } \\
\text { Gwartney, et al. } \\
(2008)\end{array}$ \\
\hline DEMOC & $\begin{array}{l}\text { The Democracy indicator is an additive } \\
\text { eleven-point scale }(0-10) \text {. Democracy is } \\
\text { conceived as three essential interdependent } \\
\text { elements. One is the presence of institutions and } \\
\text { procedures through which citizens can express } \\
\text { effective preferences about alternative policies } \\
\text { and leaders. Second is the existence of } \\
\text { institutionalized constraints on the exercise of } \\
\text { power by the executive. Third is the guarantee of } \\
\text { civil liberties to all citizens in their daily lives and } \\
\text { in acts of political participation. }\end{array}$ & $\begin{array}{l}\text { Polity IV Project } \\
\text { Marshall and Jaggers } \\
\text { (2009) }\end{array}$ \\
\hline$E F$ & $\begin{array}{l}\text { Index of economic freedom, ranging from } 0 \text { to } \\
10 . \text { Higher scores mean more economic free. }\end{array}$ & $\begin{array}{l}\text { Fraser Institute 's } \\
\text { Economic Freedom } \\
\text { of the World Report } \\
\text { Gwartney, et al. } \\
(2008)\end{array}$ \\
\hline ER & Real exchange rate (against USD). & $\begin{array}{l}\text { Penn World Table } \\
\text { ver } 6.2\end{array}$ \\
\hline$f d i \_g d p$ & $\begin{array}{l}\text { Foreign direct investment (net) as percentage of } \\
\text { GDP }\end{array}$ & WDI \\
\hline$F I N$ & (see variable fin_open) & \\
\hline fin_open & $\begin{array}{l}\text { Volume-based measure of international financial } \\
\text { integration, calculated by the sum of stock of } \\
\text { external assets and liabilities as percentage of } \\
\text { GDP }\end{array}$ & $\begin{array}{l}\text { Lane and } \\
\text { Milesi-Ferretti (2006) }\end{array}$ \\
\hline FREE TRADE & $\begin{array}{l}\text { Index of freedom to trade internationally, ranging } \\
\text { from } 0 \text { to } 10 \text {. Higher scores mean more open to } \\
\text { trade. }\end{array}$ & $\begin{array}{l}\text { Fraser Institute 's } \\
\text { Economic Freedom } \\
\text { of the World Report } \\
\text { Gwartney, et al. } \\
(2008)\end{array}$ \\
\hline gcon_gdp & $\begin{array}{l}\text { Government consumption as percentage of GDP } \\
(\%)\end{array}$ & $\begin{array}{l}\text { Penn World Table } \\
\text { ver } 6.2\end{array}$ \\
\hline GDPPC_gr & $\begin{array}{l}\text { Growth rate of real GDP per capita } \\
\text { (PPP-adjusted) }\end{array}$ & WDI \\
\hline
\end{tabular}




\begin{tabular}{|c|c|c|}
\hline Variable & Description & Source \\
\hline GOVTC & $\begin{array}{l}\text { Index of government consumption spending as a } \\
\text { percentage of total consumption, ranging from } 0 \\
\text { to } 10 \text {. Higher scores mean less government } \\
\text { consumption. }\end{array}$ & $\begin{array}{l}\text { Fraser Institute 's } \\
\text { Economic Freedom } \\
\text { of the World Report } \\
\text { Gwartney, et al. } \\
(2008)\end{array}$ \\
\hline $\boldsymbol{H}$ & Average years of Schooling of aged 15 or above & Barro and Lee (2001) \\
\hline IPOLITY2 & $\begin{array}{l}\text { Scale ranges from } 0-10 \text { where } 0 \text { is least } \\
\text { democratic and } 10 \text { most democratic. Average of } \\
\text { Freedom House's political rights and civil } \\
\text { liberties indices and Polity IV's DEMOC (as } \\
\text { defined above). }\end{array}$ & Teorell, et al. (2009) \\
\hline $\boldsymbol{K} \_A C$ & $\begin{array}{l}\text { Index of international capital market controls, } \\
\text { ranging from } 0 \text { to } 10 . \text { Higher scores mean less } \\
\text { capital market controls. }\end{array}$ & $\begin{array}{l}\text { Fraser Institute 's } \\
\text { Economic Freedom } \\
\text { of the World Report } \\
\text { Gwartney, et al. } \\
(2008)\end{array}$ \\
\hline KAOPEN & (see variable ca_open) & \\
\hline$L A B O R$ & $\begin{array}{l}\text { Index of labour market regulation, ranging from } 0 \\
\text { to } 10 . \text { Higher score means less labour market } \\
\text { controls. }\end{array}$ & $\begin{array}{l}\text { Fraser Institute 's } \\
\text { Economic Freedom } \\
\text { of the World Report } \\
\text { Gwartney, et al. } \\
(2008)\end{array}$ \\
\hline$L E G A L$ & $\begin{array}{l}\text { The index ranges from } 0-10 \text { where } 0 \text { corresponds } \\
\text { to 'no judicial independence', 'no trusted legal } \\
\text { framework exists', 'no protection of intellectual } \\
\text { property', 'military interference in rule of law', } \\
\text { and 'no integrity of the legal system' and vice } \\
\text { versa. } \\
\text { The index consists of the following indicators: } \\
\text { - Judicial independence: The judiciary is } \\
\text { independent and not subject to interference by the } \\
\text { government or parties in dispute } \\
\text { - Impartial courts: A trusted legal framework } \\
\text { exists for private businesses to challenge the } \\
\text { legality of government actions or regulations } \\
\text { - Protection of intellectual property } \\
\text { - Military interference in rule of law and the } \\
\text { political process } \\
\text { - Integrity of the legal system }\end{array}$ & $\begin{array}{l}\text { Fraser Institute 's } \\
\text { Economic Freedom } \\
\text { of the World Report } \\
\text { Gwartney, et al. } \\
(2008)\end{array}$ \\
\hline Lliab_gdp & Total liquid liabilities as percentage of GDP. & Beck, et al. (2009) \\
\hline $\ln (G D P P C)$ & Natural log of GDP per capita. & WDI \\
\hline In(invest_gdp) & Investment as percentage of GDP (ln) & $\begin{array}{l}\text { Penn World Table } \\
\text { ver } 6.2\end{array}$ \\
\hline In(trade_gdp) & Total trade as percentage GDP $(\ln )$ & WDI \\
\hline POP & Natural log of population. & WDI \\
\hline pop_gr & Population growth rate & WDI \\
\hline$Q O G$ & $\begin{array}{l}\text { The mean value of the ICRG variables of } \\
\text { "Corruption", "Law and Order" and } \\
\text { "Bureaucracy Quality", scaled 0-1. Higher } \\
\text { values indicate higher quality of government. }\end{array}$ & Teorell, et al. (2009) \\
\hline
\end{tabular}




\begin{tabular}{|c|c|c|}
\hline Variable & Description & Source \\
\hline$R E G$ & $\begin{array}{l}\text { The index ranges from } 0 \text { - } 10 \text { where } 0 \text { is the most } \\
\text { regulated. The index consists of the following } \\
\text { indicators: } \\
\text { - Credit Market Regulations: corresponds to 'low } \\
\text { percentage of deposits held in privately owned } \\
\text { banks', 'high foreign bank license denial rate', } \\
\text { 'private sector's share of credit is close to the } \\
\text { base-year-minimum', 'deposit and lending rates } \\
\text { is fixed by the government and real rates is } \\
\text { persistently negative'. } \\
\text { - Labor Market Regulations: corresponds to 'high } \\
\text { impact of minimum wage'. } \\
\text { - Business Regulations: corresponds to } \\
\text { 'widespread use of price controls throughout } \\
\text { various sectors of the economy', and 'starting a } \\
\text { new business is generally complicated'. }\end{array}$ & $\begin{array}{l}\text { Fraser Institute 's } \\
\text { Economic Freedom } \\
\text { of the World Report } \\
\text { Gwartney, et al. } \\
(2008)\end{array}$ \\
\hline SCHOOLING & $\begin{array}{l}\text { Average schooling years in the total population } \\
\text { aged } 25 \text { and over. }\end{array}$ & Barro and Lee (2001) \\
\hline$S M$ & $\begin{array}{l}\text { The index ranges from } 0 \text { - } 10 \text { where } 0 \text { corresponds } \\
\text { to 'high annual money growth', 'high variation in } \\
\text { the annual rate of inflation', 'high inflation rate', } \\
\text { and 'restricted foreign currency bank accounts' } \\
\text { and vice versa. The index consists of the } \\
\text { following indicators: } \\
\text { - Average annual growth of the money supply in } \\
\text { the last five years minus average annual growth } \\
\text { of real GDP in the last ten years } \\
\text { - Standard inflation variability in the last five } \\
\text { years } \\
\text { - Recent inflation rate } \\
\text { - Freedom to own foreign currency bank accounts } \\
\text { domestically and abroad }\end{array}$ & $\begin{array}{l}\text { Fraser Institute 's } \\
\text { Economic Freedom } \\
\text { of the World Report } \\
\text { Gwartney, et al. } \\
(2008)\end{array}$ \\
\hline $\boldsymbol{T A X}$ & $\begin{array}{l}\text { Index of top marginal tax rate, ranging from } 0 \text { to } \\
10 . \quad \text { Higher score means lower tax rates. }\end{array}$ & $\begin{array}{l}\text { Fraser Institute 's } \\
\text { Economic Freedom } \\
\text { of the World Report } \\
\text { Gwartney, et al. } \\
(2008)\end{array}$ \\
\hline TRANSFER & $\begin{array}{l}\text { Index of transfer and subsidies as percentage of } \\
\text { GDP, ranging from } 0 \text { to } 10 \text {. Higher scores mean } \\
\text { less transfer and subsidies. }\end{array}$ & $\begin{array}{l}\text { Fraser Institute 's } \\
\text { Economic Freedom } \\
\text { of the World Report } \\
\text { Gwartney, et al. } \\
\text { (2008) }\end{array}$ \\
\hline$T R A D E$ & Total trade (exports and imports) to GDP & WDI \\
\hline XCONST & $\begin{array}{l}\text { Constraint on Chief Executive. Index ranges } \\
\text { from } 0-10 \text {. Higher Score means more } \\
\text { constraints, implying better protection of private } \\
\text { property rights. }\end{array}$ & $\begin{array}{l}\text { Polity IV Project } \\
\text { Marshall and Jaggers } \\
(2009)\end{array}$ \\
\hline
\end{tabular}




\section{ii. Variables Used in Chapter 4}

\begin{tabular}{|c|c|c|}
\hline Variable & Description & Source \\
\hline \multicolumn{3}{|l|}{ Dependent Variable } \\
\hline $\operatorname{lnfdi}$ & $\begin{array}{l}\text { Natural log of (FDI outward stock }+0.3) . \quad \text { FDI is } \\
\text { expressed in current million USD. }\end{array}$ & $\begin{array}{l}\text { OECD International } \\
\text { Direct Investment } \\
\text { Statistics }\end{array}$ \\
\hline \multicolumn{3}{|c|}{ Independent Variables } \\
\hline Border & Dummy for having common border. & Rose (2004) \\
\hline Business reg & $\begin{array}{l}\text { Economic Freedom Index of business regulation, } \\
0-10, \text { higher score denotes less burdensome } \\
\text { business environment }\end{array}$ & $\begin{array}{l}\text { Fraser Institute 's } \\
\text { Economic Freedom } \\
\text { of the World Report } \\
\text { Gwartney, et al. } \\
\text { (2008) }\end{array}$ \\
\hline Colony $_{i j}$ & Dummy for the pair ever in colonial relationship. & Rose (2004) \\
\hline Common coloniser & Dummy for the pair even had common colonizer. & Rose (2004) \\
\hline Common lang & Dummy for having common language. & Rose (2004) \\
\hline Credit reg & $\begin{array}{l}\text { Economic Freedom Index of credit regulation, } \\
0-10, \text { higher score denotes less regulatory burden } \\
\text { on the credit market }\end{array}$ & $\begin{array}{l}\text { Fraser Institute 's } \\
\text { Economic Freedom } \\
\text { of the World Report } \\
\text { Gwartney, et al. } \\
(2008)\end{array}$ \\
\hline $\begin{array}{l}G D P_{i} \\
G D P_{j}\end{array}$ & $\begin{array}{l}\text { GDP (constant } 2000 \text { US\$) of economy } \mathrm{i} \text { and } \mathrm{j} \\
\text { respectively. }\end{array}$ & WDI \\
\hline Island & No. of island nations in the pair. & Rose (2004) \\
\hline Labor reg & $\begin{array}{l}\text { Economic Freedom Index of labour regulation, } \\
0-10 \text {, higher score denotes less regulatory burden } \\
\text { on the labour market }\end{array}$ & $\begin{array}{l}\text { Fraser Institute 's } \\
\text { Economic Freedom } \\
\text { of the World Report } \\
\text { Gwartney, et al. } \\
(2008)\end{array}$ \\
\hline Landlock & $\begin{array}{l}\text { Dummy for the number of economy in the pair is } \\
\text { landlocked }(0 / 1 / 2) \text {. }\end{array}$ & Rose (2004) \\
\hline $\ln \left(\right.$ Area $\left._{i j}\right)$ & Log product of land areas of the pair. & Rose (2004) \\
\hline $\ln (D i s t)$ & $\begin{array}{l}\text { Log of geographical distance between the capital } \\
\text { cities of the two economies. }\end{array}$ & Rose (2004) \\
\hline $\begin{array}{l}\boldsymbol{P O P}_{i} \\
\boldsymbol{P O P}_{j}\end{array}$ & Population of economy $i$ and $j$ respectively & WDI \\
\hline$R E G$ & $\begin{array}{l}\text { Economic Freedom Index of regulation, } 0-10 \text {, } \\
\text { higher score denotes less regulatory burden. }\end{array}$ & $\begin{array}{l}\text { Fraser Institute 's } \\
\text { Economic Freedom } \\
\text { of the World Report } \\
\text { Gwartney, et al. } \\
(2008)\end{array}$ \\
\hline RTA & $\begin{array}{l}\text { Dummy for bilateral regional trade agreement. } 1 \\
=\text { yes, } 0 \text { otherwise. }\end{array}$ & $\begin{array}{l}\text { Rose }(2004) \text { and } \\
\text { WTO }\end{array}$ \\
\hline
\end{tabular}




\section{iii. Components of the Regulation Index (REG) of the Fraser Institute's Economic Freedom of the World Report}

A. Credit market regulations (Credit Reg)

i. Ownership of banks: percentage of deposits held in privately owned banks

ii. Competition: domestic banks face competition from foreign banks

iii. Extension of credit: percentage of credit extended to private sector iv. Avoidance of interest rate controls and regulations that lead to negative real interest rates

\section{B. Labor market regulations (Labour Reg)}

i. Impact of minimum wage: the minimum wage, set by law, has little impact on wages because it is too low or not obeyed

ii. Hiring and firing practices: hiring and firing practices of companies are determined by private contract

iii. Share of labor force whose wages are set by centralized collective bargaining iv. Mandated cost of hiring

v. Mandated cost of worker dismissal

vi. Use of conscripts to obtain military personnel

\section{Business regulations (Business Reg)}

i. Price controls: extent to which businesses are free to set their own prices ii. Administrative conditions and new businesses: administrative procedures are an important obstacle to starting a new business

iii. Time with government bureaucracy: senior management spends a substantial amount of time dealing with government bureaucracy iv. Starting a new business: starting a new business is generally easy v. Extra payments/bribes: irregular, additional payments connected with import and export permits, business licenses, exchange controls, tax assessments, police protection or loan applications are very rare

vi. Licensing restrictions: Time in days and monetary costs required to obtain a license to construct a standard warehouse vii. Cost of tax compliance: Time required per year for a business to prepare, file, and pay taxes on corporate income, value added or sales taxes, and taxes on labor.

Source: Gwartney, et al. (2008) 


\section{A.3 Descriptive Statistics and Correlation Matrices}

The following is the descriptive statistics and correlation matrices of key variables used in each Chapter. Descriptive statistics of the same variables may differ due to different sample size.

\section{i. Chapter 2 Data}

\begin{tabular}{|c|c|c|c|c|c|}
\hline Variable & Obs & Mean & Std. Dev. & Min & Max \\
\hline \multicolumn{6}{|l|}{ Key Variables } \\
\hline GDPPC_gr & 1101 & 0.0163 & 0.0458 & -0.4288 & 0.3237 \\
\hline DEMOC & 986 & 3.9782 & 4.1208 & 0 & 10 \\
\hline$L E G A L$ & 664 & 5.3639 & 1.9251 & 1.1500 & 9.3340 \\
\hline IPOLITY2 & 1189 & 5.3734 & 3.4537 & 0 & 10 \\
\hline$Q O G$ & 625 & 0.5488 & 0.2351 & 0.0556 & 1.0000 \\
\hline XCONST & 1006 & 0.1601 & 14.2511 & -88.0000 & 7.0000 \\
\hline$R E G$ & 699 & 5.4414 & 1.1096 & 2.4700 & 8.7600 \\
\hline$S M$ & 800 & 6.5251 & 2.2143 & 0.0000 & 9.8633 \\
\hline SCHOOLING & 715 & 4.7890 & 2.9261 & 0.0420 & 12.2470 \\
\hline \multicolumn{6}{|l|}{ Control Variables } \\
\hline$f d i \_g d p$ & 956 & 0.0303 & 0.1276 & -0.0528 & 3.5772 \\
\hline pop_gr & 1375 & 0.0181 & 0.0165 & -0.1605 & 0.1773 \\
\hline fin_open & 865 & 1.7679 & 6.5469 & 0.1195 & 179.2779 \\
\hline ca_open & 1037 & -0.0657 & 1.4480 & -1.8081 & 2.5408 \\
\hline$l l i a b \_g d p$ & 840 & 0.4439 & 0.3376 & 0.0084 & 3.0226 \\
\hline gcon_gdp & 1143 & 23.5662 & 11.3795 & 2.5525 & 79.5660 \\
\hline In(trade_gdp) & 1075 & 4.1823 & 0.6104 & 0.8215 & 5.9644 \\
\hline In(invest_gdp) & 1143 & 2.4376 & 0.6801 & -0.0657 & 4.5148 \\
\hline
\end{tabular}




\begin{tabular}{lccccccccc}
\hline & GDPPC_gr & DEMOC & LEGAL & IPOLITY2 & QOG & XCONST & REG & SM & SCHOOLING $\begin{array}{c}\text { Lagged } \\
\text { In(GDPPC) }\end{array}$ \\
\hline \hline GDPPC_gr & 1 & & & & & & & & \\
DEMOC & 0.0627 & 1 & & & & & & & \\
LEGAL & 0.2585 & 0.5181 & 1 & & & & & & \\
IPOLITY2 & 0.0713 & 0.9717 & 0.5463 & 1 & & & & \\
QOG & 0.2014 & 0.5742 & 0.8768 & 0.5767 & 1 & & & \\
XCONST & 0.1616 & 0.2917 & 0.3219 & 0.2609 & 0.367 & 1 & & & \\
REG & 0.2321 & 0.3741 & 0.4496 & 0.4165 & 0.4159 & 0.1684 & 1 & & \\
SM & 0.1725 & 0.2457 & 0.4578 & 0.2541 & 0.4351 & 0.1707 & 0.4611 & 1 \\
SCHOOLING & 0.1479 & 0.6487 & 0.7006 & 0.6767 & 0.7633 & 0.2917 & 0.4132 & 0.3771 & \\
Lagged & 0.0507 & 0.5626 & 0.6907 & 0.5373 & 0.7403 & 0.2505 & 0.436 & 0.4232 & 0.8356 \\
In(GDPPC) & & & & & & & & & 1
\end{tabular}




\section{ii. Chapter 3 Data}

\begin{tabular}{|c|c|c|c|c|c|}
\hline Variable & Obs & Mean & Std. Dev. & Min & Max \\
\hline DEMOC & 1283 & 4.0748 & 4.1998 & 0 & 10 \\
\hline IPOLITY2 & 1193 & 5.5610 & 3.4911 & 0 & 10 \\
\hline$E F$ & 688 & 5.7346 & 1.1754 & 2.30 & 8.78 \\
\hline $\ln (G D P P C)$ & 1254 & 7.5600 & 1.5562 & 4.03 & 10.85 \\
\hline GOVTC & 934 & 6.1040 & 2.2231 & 0 & 10 \\
\hline TRANSFER & 736 & 7.6944 & 2.2268 & 0 & 10 \\
\hline$T A X$ & 657 & 4.4072 & 3.0687 & 0 & 10 \\
\hline FREE TRADE & 871 & 6.1158 & 1.6058 & 1.35 & 9.78 \\
\hline$K_{-} A C$ & 852 & 3.3595 & 3.2159 & 0 & 10 \\
\hline$\overline{C R E I D T}$ & 938 & 6.2549 & 2.6917 & 0 & 10 \\
\hline$L A B O R$ & 390 & 5.2107 & 1.4963 & 1.84 & 8.92 \\
\hline SCHOOLING & 907 & 4.4722 & 2.9035 & 0.04 & 12.25 \\
\hline gcon_gdp & 1320 & 22.5158 & 11.2597 & 2.97 & 76.14 \\
\hline$E R$ & 1496 & 653.25 & 16237.44 & 0 & 625218.5 \\
\hline POP & 1571 & 15.1253 & 2.1114 & 9.91 & 20.99 \\
\hline
\end{tabular}




\begin{tabular}{|c|c|c|c|c|c|c|c|c|}
\hline & DEMOC & IPOLITY2 & $E F$ & $\ln (G D P P C)$ & GOVTC & TRANSFER & $T A X$ & \\
\hline DEMOC & 1 & & & & & & & \\
\hline IPOLITY2 & 0.9715 & 1 & & & & & & \\
\hline$E F$ & 0.4582 & 0.4867 & 1 & & & & & \\
\hline $\ln (G D P P C)$ & 0.5557 & 0.5353 & 0.6229 & 1 & & & & \\
\hline GOVTC & -0.1812 & -0.1756 & -0.1866 & -0.4758 & 1 & & & \\
\hline TRANSFER & -0.5379 & -0.5095 & -0.2276 & -0.5897 & 0.4276 & 1 & & \\
\hline$T A X$ & -0.1157 & -0.1191 & 0.313 & -0.0139 & 0.0997 & 0.3478 & 1 & \\
\hline FREE TRADE & 0.4669 & 0.4521 & 0.7742 & 0.6088 & -0.3633 & -0.3815 & 0.2061 & \\
\hline $\boldsymbol{K} \_A C$ & 0.5266 & 0.5037 & 0.7026 & 0.5593 & -0.1921 & -0.3391 & 0.269 & \\
\hline CREIDT & 0.4809 & 0.5187 & 0.7536 & 0.4749 & -0.1469 & -0.1014 & 0.2895 & \\
\hline$L A B O R$ & -0.0207 & -0.0079 & 0.3288 & -0.0011 & 0.0616 & 0.3601 & 0.3116 & \\
\hline SCHOOLING & 0.6391 & 0.6617 & 0.5936 & 0.8311 & -0.3899 & -0.6148 & -0.0719 & \\
\hline gcon_gdp & -0.1251 & -0.0529 & -0.2243 & -0.2052 & -0.2168 & -0.0857 & 0.0094 & \\
\hline$E R$ & 0.0303 & 0.0077 & -0.0011 & 0.0089 & 0.0206 & 0.0325 & 0.0153 & \\
\hline \multirow[t]{2}{*}{ POP } & 0.1068 & -0.0995 & -0.1221 & -0.1345 & 0.2145 & -0.1117 & -0.1576 & \\
\hline & $\begin{array}{c}\text { FREE } \\
\text { TRADE } \\
\end{array}$ & $K_{-} A C$ & CREIDT & $L A B O R$ & SCHOOLING & gcon_gdp & $E R$ & POP \\
\hline $\begin{array}{l}\text { FREE } \\
\text { TRADE }\end{array}$ & 1 & & & & & & & \\
\hline$K_{-} A C$ & 0.7597 & 1 & & & & & & \\
\hline CREIDT & 0.5699 & 0.5297 & 1 & & & & & \\
\hline$L A B O R$ & 0.1132 & 0.2166 & 0.2674 & 1 & & & & \\
\hline SCHOOLING & 0.5916 & 0.5968 & 0.4057 & 0.2161 & 1 & & & \\
\hline gcon_gdp & -0.0692 & -0.1446 & -0.1301 & -0.0142 & -0.1137 & 1 & & \\
\hline$E R$ & 0.0285 & 0.0326 & 0.0094 & -0.0218 & 0.0009 & -0.0158 & 1 & \\
\hline POP & -0.0897 & 0.014 & -0.2005 & -0.0797 & 0.0357 & -0.3062 & 0.0489 & 1 \\
\hline
\end{tabular}




\section{iii. Chapter 4 Data}

\begin{tabular}{|c|c|c|c|c|c|}
\hline Variable & Obs & Mean & Std. Dev. & Min & Max \\
\hline \multicolumn{6}{|l|}{$\underline{\underline{\text { Key Variables }}}$} \\
\hline Infdi & 16183 & 4.74018 & 3.538921 & -1.20397 & 12.80514 \\
\hline $\ln \left(G D P_{i}\right)$ & 38350 & 26.12662 & 1.566639 & 22.47594 & 30.05582 \\
\hline $\ln \left(G D P_{j}\right)$ & 38170 & 25.44979 & 1.572495 & 22.13669 & 30.05582 \\
\hline $\ln \left(P O P_{i}\right)$ & 38940 & 16.49722 & 1.525094 & 12.39255 & 19.51595 \\
\hline $\ln \left(P O P_{j}\right)$ & 38940 & 16.78246 & 1.685671 & 12.39255 & 20.99329 \\
\hline $\ln ($ Dist) & 34869 & 7.882756 & 1.03274 & 4.764804 & 9.416901 \\
\hline Landlock & 34869 & 0.258625 & 0.467534 & 0 & 2 \\
\hline Colony $_{i j}$ & 34869 & 0.028048 & 0.165112 & 0 & 1 \\
\hline Common Lang & 34869 & 0.113855 & 0.317639 & 0 & 1 \\
\hline Common Coloniser & 34869 & 0.000803 & 0.028326 & 0 & 1 \\
\hline Island & 34869 & 0.263386 & 0.473608 & 0 & 2 \\
\hline Border & 34869 & 0.043649 & 0.204316 & 0 & 1 \\
\hline $\ln \left(\right.$ Area $\left._{i j}\right)$ & 34869 & 24.90223 & 2.657506 & 14.33099 & 32.76884 \\
\hline $\boldsymbol{R T A}$ & 38940 & 0.093452 & 0.291068 & 0 & 1 \\
\hline$R E G$ & 17193 & 6.128058 & 1.150347 & 2.4732 & 8.764566 \\
\hline Credit Reg & 17282 & 7.495658 & 2.006974 & 0 & 10 \\
\hline Labour Reg & 15255 & 5.285696 & 1.336855 & 1.837167 & 8.9195 \\
\hline Business Reg & 13472 & 5.921909 & 1.404228 & 3 & 9 \\
\hline \multicolumn{6}{|c|}{ Instrumental Variables } \\
\hline religion $_{j}$ & 35024 & .4077816 & .2312489 & .0035 & .8603 \\
\hline ethnic $_{i}$ & 35024 & .3389358 & .2269986 & .0119 & .8505 \\
\hline longitude $_{j}$ & 36960 & 22.07841 & 63.03241 & -112.103 & 172.8989 \\
\hline UK legal origin $_{j}$ & 38940 & .2677966 & .4428167 & 0 & 1 \\
\hline
\end{tabular}




\begin{tabular}{|c|c|c|c|c|c|c|c|c|c|c|c|c|}
\hline & $\operatorname{lnfdi}$ & $\ln \left(G D P_{i}\right)$ & $\ln \left(G D P_{j}\right)$ & $\ln \left(P O P_{i}\right)$ & $\ln \left(P O P_{j}\right)$ & $\ln ($ Dist $)$ & Landlock & Colony $_{i j}$ & $\begin{array}{c}\text { Common } \\
\text { Lang }\end{array}$ & $\begin{array}{l}\text { Common } \\
\text { Coloniser }\end{array}$ & Island & Border \\
\hline$\overline{\overline{l n f d i}}$ & 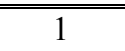 & & & & & & & & & & & \\
\hline $\ln \left(G D P_{i}\right)$ & 0.5672 & 1 & & & & & & & & & & \\
\hline $\ln \left(G D P_{j}\right)$ & 0.3662 & -0.0054 & 1 & & & & & & & & & \\
\hline $\ln \left(P O P_{i}\right)$ & 0.3907 & 0.8921 & -0.0123 & 1 & & & & & & & & \\
\hline $\ln \left(P O P_{j}\right)$ & 0.1428 & -0.0103 & 0.6561 & -0.0144 & 1 & & & & & & & \\
\hline $\ln ($ Dist) & -0.1249 & 0.1075 & 0.0684 & 0.1081 & 0.2544 & 1 & & & & & & \\
\hline Landlock & -0.1916 & -0.2920 & -0.0720 & -0.2426 & -0.1552 & -0.3075 & 1 & & & & & \\
\hline Colony $_{i j}$ & 0.1698 & 0.0826 & 0.0290 & 0.0752 & 0.0171 & -0.0247 & -0.0695 & 1 & & & & \\
\hline Common Lang & 0.2177 & 0.1069 & 0.0771 & 0.0703 & 0.0692 & 0.0856 & -0.1218 & 0.3175 & 1 & & & \\
\hline Common Coloniser & 0.0076 & -0.0369 & -0.0233 & -0.0145 & -0.0170 & -0.0716 & 0.1056 & -0.0048 & -0.0102 & 1 & & \\
\hline Island & -0.0755 & -0.0916 & -0.0772 & -0.1596 & -0.1818 & 0.3586 & -0.1544 & -0.0219 & 0.0691 & -0.0158 & 1 & \\
\hline Border & 0.1914 & 0.0171 & 0.0877 & 0.0246 & -0.0096 & -0.4215 & 0.1376 & 0.1329 & 0.1320 & 0.1327 & -0.1188 & 1 \\
\hline $\ln \left(\right.$ Area $\left._{i j}\right)$ & 0.2182 & 0.3435 & 0.3477 & 0.3614 & 0.5613 & 0.3930 & -0.3593 & 0.0209 & 0.1030 & -0.0302 & -0.0092 & -0.0434 \\
\hline$R T A$ & 0.2861 & 0.0907 & 0.2123 & 0.0484 & -0.0197 & -0.3665 & -0.1095 & 0.0250 & 0.0076 & -0.0097 & -0.1567 & 0.1847 \\
\hline$R E G$ & 0.1412 & 0.0445 & 0.1039 & 0.0141 & -0.3280 & -0.0013 & 0.0870 & 0.0278 & 0.1003 & -0.0011 & 0.1588 & 0.0038 \\
\hline Credit Reg & 0.1379 & 0.0421 & 0.0795 & 0.0122 & -0.3109 & -0.0825 & 0.0711 & 0.0194 & 0.0518 & 0.0013 & 0.1120 & 0.0406 \\
\hline Labour Reg & 0.0654 & 0.0125 & 0.0203 & 0.0041 & -0.0456 & 0.2162 & 0.0337 & 0.0381 & 0.1396 & 0.0011 & 0.1750 & -0.0880 \\
\hline Business Reg & 0.1268 & 0.0021 & 0.0644 & 0.0054 & -0.4929 & -0.0939 & 0.0558 & 0.0209 & 0.0694 & -0.0139 & 0.1662 & 0.0283 \\
\hline
\end{tabular}

\begin{tabular}{|c|c|c|c|c|c|c|}
\hline & $\ln \left(\right.$ Area $\left._{i j}\right)$ & RTA & $R E G$ & Credit Reg & Labour Re & Business Reg \\
\hline$\overline{\ln \left(\text { Area }_{i j}\right)}$ & 1 & & & & & \\
\hline$R T A$ & -0.1034 & 1 & & & & \\
\hline$R E G$ & -0.2328 & 0.1344 & 1 & & & \\
\hline Credit Reg & -0.2164 & 0.1707 & 0.8225 & 1 & & \\
\hline Labour Reg & -0.0643 & -0.1233 & 0.6743 & 0.3028 & 1 & \\
\hline Business Reg & -0.2693 & 0.1778 & 0.8113 & 0.5538 & 0.2957 & 1 \\
\hline
\end{tabular}


iv. Chapter 5 Data

\begin{tabular}{|c|c|c|c|c|c|}
\hline Variable & Obs & Mean & Std. Dev. & Min & Max \\
\hline $\ln (Y)$ & 648 & 17.3428 & 1.9759 & 12.6472 & 22.9634 \\
\hline $\ln (K)$ & 648 & 17.6750 & 2.3077 & 11.7310 & 23.7777 \\
\hline $\ln (L)$ & 648 & 15.1636 & 1.6502 & 11.4135 & 20.4427 \\
\hline$Q O G$ & 368 & 0.5749 & 0.2488 & 0.0556 & 1 \\
\hline$L E G A L$ & 520 & 5.3408 & 1.9411 & 1.1500 & 9.6200 \\
\hline$L E G A L * H$ & 473 & 34.4196 & 26.2418 & 0.9831 & 111.2123 \\
\hline$R E G$ & 543 & 5.5105 & 1.0569 & 2.5900 & 8.7600 \\
\hline$R E G 2$ & 543 & 31.4804 & 11.6833 & 6.7081 & 76.7376 \\
\hline$R E G^{*} H$ & 495 & 32.4934 & 19.6351 & 2.4780 & 100.6699 \\
\hline$S M$ & 582 & 6.3968 & 2.3054 & 0 & 9.8430 \\
\hline$S M * H$ & 532 & 37.9806 & 28.2863 & 0 & 117.8021 \\
\hline DEMOC & 613 & 4.4928 & 4.1925 & 0 & 10 \\
\hline DEMOC * H & 538 & 33.9340 & 36.1709 & 0 & 120.4900 \\
\hline $\boldsymbol{H}$ & 551 & 5.3354 & 2.8176 & 0.2610 & 12.0490 \\
\hline FINOPEN & 576 & 1.4912 & 6.2675 & 0.1422 & 147.5670 \\
\hline$T R A D E$ & 617 & 64.4729 & 37.4159 & 7.9800 & 270.7900 \\
\hline KAOPEN & 615 & -0.2430 & 1.3212 & -1.8081 & 2.5408 \\
\hline FDI & 598 & 1.6521 & 3.4464 & -5.3796 & 51.4763 \\
\hline
\end{tabular}




\begin{tabular}{|c|c|c|c|c|c|c|c|c|c|c|c|c|c|c|c|}
\hline & $Q O G$ & $L E G A L$ & $\begin{array}{c}L E G A L * \\
H\end{array}$ & $R E G$ & $R E G 2$ & $\begin{array}{c}R E G^{*} \\
H\end{array}$ & $\boldsymbol{H}$ & DEMOC & $\begin{array}{c}\text { DEMOC } \\
{ }^{*} H\end{array}$ & FINOPEN & $T R A D E$ & KAOPEN & $F D I$ & $S M$ & $S M * H$ \\
\hline$Q O G$ & 1.000 & & & & & & & & & & & & & & \\
\hline$L E G A L$ & 0.889 & 1.000 & & & & & & & & & & & & & \\
\hline$L E G A L * H$ & 0.857 & 0.886 & 1.000 & & & & & & & & & & & & \\
\hline$R E G$ & 0.501 & 0.534 & 0.559 & 1.000 & & & & & & & & & & & \\
\hline$R E G 2$ & 0.519 & 0.549 & 0.587 & 0.990 & 1.000 & & & & & & & & & & \\
\hline$R E G^{*} H$ & 0.747 & 0.735 & 0.930 & 0.693 & 0.721 & 1.000 & & & & & & & & & \\
\hline $\boldsymbol{H}$ & 0.736 & 0.708 & 0.924 & 0.470 & 0.494 & 0.949 & 1.000 & & & & & & & & \\
\hline DEMOC & 0.596 & 0.584 & 0.649 & 0.476 & 0.475 & 0.650 & 0.636 & 1.000 & & & & & & & \\
\hline DEMOC * H & 0.761 & 0.720 & 0.878 & 0.510 & 0.524 & 0.865 & 0.862 & 0.880 & 1.000 & & & & & & \\
\hline FINOPEN & 0.112 & 0.128 & 0.269 & 0.135 & 0.148 & 0.316 & 0.272 & 0.143 & 0.208 & 1.000 & & & & & \\
\hline$T R A D E$ & 0.215 & 0.255 & 0.174 & 0.394 & 0.410 & 0.257 & 0.193 & 0.140 & 0.152 & 0.347 & 1.000 & & & & \\
\hline KAOPEN & 0.543 & 0.562 & 0.616 & 0.557 & 0.579 & 0.625 & 0.510 & 0.398 & 0.521 & 0.386 & 0.226 & 1.000 & & & \\
\hline$F D I$ & 0.223 & 0.252 & 0.247 & 0.341 & 0.357 & 0.285 & 0.192 & 0.080 & 0.164 & 0.368 & 0.425 & 0.189 & 1.000 & & \\
\hline$S M$ & 0.500 & 0.502 & 0.520 & 0.497 & 0.508 & 0.532 & 0.447 & 0.336 & 0.443 & 0.102 & 0.245 & 0.620 & 0.254 & 1.000 & \\
\hline$S M * H$ & 0.754 & 0.743 & 0.908 & 0.578 & 0.604 & 0.919 & 0.892 & 0.600 & 0.825 & 0.327 & 0.243 & 0.685 & 0.286 & 0.754 & 1.000 \\
\hline
\end{tabular}


A.4 List of Economies

\section{i. Country Coverage of the Fraser Institute's Economic Freedom of the World Report in Chapter 2}

\begin{tabular}{|c|c|c|c|}
\hline Albania & Denmark & Latvia & Romania \\
\hline Algeria & Dominican Rep. & Lesotho & Russia \\
\hline Angola & Ecuador & Lithuania & Rwanda \\
\hline Argentina & Egypt & Luxembourg & Senegal \\
\hline Armenia & El Salvador & Macedonia & Serbia \\
\hline Australia & Estonia & Madagascar & Sierra Leone \\
\hline Austria & Ethiopia & Malawi & Singapore \\
\hline Azerbaijan & Fiji & Malaysia & Slovak Rep \\
\hline Bahamas & Finland & Mali & Slovenia \\
\hline Bahrain & France & Malta & South Africa \\
\hline Bangladesh & Gabon & Mauritania & South Korea \\
\hline Barbados & Georgia & Mauritius & Spain \\
\hline Belgium & Germany & Mexico & Sri Lanka \\
\hline Belize & Ghana & Moldova & Sweden \\
\hline Benin & Greece & Mongolia & Switzerland \\
\hline Bolivia & Guatemala & Montenegro & Syria \\
\hline Bosnia and Herzegovina & Guinea-Bissau & Morocco & Taiwan \\
\hline Botswana & Guyana & Mozambique & Tanzania \\
\hline Brazil & Haiti & Myanmar & Thailand \\
\hline Bulgaria & Honduras & Namibia & Togo \\
\hline Burkina Faso & Hong Kong & Nepal & $\begin{array}{l}\text { Trinidad \& } \\
\text { Tobago }\end{array}$ \\
\hline Burundi & Hungary & Netherlands & Tunisia \\
\hline Cameroon & Iceland & New Zealand & Turkey \\
\hline Canada & India & Nicaragua & Uganda \\
\hline Central Afr. Rep. & Indonesia & Niger & Ukraine \\
\hline Chad & Iran & Nigeria & Unit. Arab Em. \\
\hline Chile & Ireland & Norway & United Kingdom \\
\hline China & Israel & Oman & United States \\
\hline Colombia & Italy & Pakistan & Uruguay \\
\hline Congo, Dem. R. & Jamaica & Panama & Venezuela \\
\hline Congo, Rep. Of & Japan & Pap. New Guinea & Vietnam \\
\hline Costa Rica & Jordan & Paraguay & Zambia \\
\hline Cote d'Ivoire & Kazakhstan & Peru & Zimbabwe \\
\hline Croatia & Kenya & Philippines & \\
\hline Cyprus & Kuwait & Poland & \\
\hline Czech Rep. & Kyrgyz Republic & Portugal & \\
\hline
\end{tabular}




\section{ii. Country Coverage in Chapter 3}

\begin{tabular}{|c|c|c|c|c|}
\hline $\begin{array}{c}\text { All-time } \\
\text { Democracy }\end{array}$ & $\begin{array}{l}\text { All-time } \\
\text { Autocracy }\end{array}$ & $\begin{array}{c}\text { More } \\
\text { democratic }\end{array}$ & $\begin{array}{c}\text { More } \\
\text { autocratic }\end{array}$ & $\begin{array}{l}\text { Regime } \\
\text { changes }\end{array}$ \\
\hline Armenia & Unit. Arab Em. & Albania & Zimbabwe & Argentina \\
\hline Australia & Azerbaijan & Benin & & Central Africa. Rep. \\
\hline Austria & Burundi & Bangladesh & & Chile \\
\hline Belgium & Bahrain & Bulgaria & & Congo, Rep. Of \\
\hline Botswana & China & Bolivia & & Ghana \\
\hline Canada & Cameroon & Brazil & & Guinea-Bissau \\
\hline Switzerland & Algeria & Cote d'Ivoire & & Haiti \\
\hline Colombia & Egypt & Ecuador & & Malaysia \\
\hline Costa Rica & Gabon & Spain & & Nigeria \\
\hline Cyprus & Iran & Greece & & Nepal \\
\hline Czech Rep. & Jordan & Guatemala & & Pakistan \\
\hline Germany & Kuwait & Guyana & & Peru \\
\hline Denmark & Morocco & Croatia & & Turkey \\
\hline Dominican Rep. & Myanmar & Hungary & & Zambia \\
\hline Estonia & Oman & Indonesia & & \\
\hline Finland & Rwanda & Kenya & & \\
\hline Fiji & Singapore & South Korea & & \\
\hline France & Syria & Madagascar & & \\
\hline United Kingdom & Chad & Mexico & & \\
\hline Georgia & Togo & Mali & & \\
\hline Honduras & Tunisia & Malawi & & \\
\hline Ireland & Tanzania & Niger & & \\
\hline India & Uganda & Nicaragua & & \\
\hline Israel & Vietnam & Panama & & \\
\hline Italy & Congo, Dem. Rep. & Philippines & & \\
\hline Jamaica & & Poland & & \\
\hline Japan & & Portugal & & \\
\hline Sri Lanka & & Paraguay & & \\
\hline Lithuania & & Romania & & \\
\hline Latvia & & Senegal & & \\
\hline Macedonia & & Sierra Leone & & \\
\hline Mongolia & & Thailand & & \\
\hline Mozambique & & Taiwan & & \\
\hline Mauritius & & Uruguay & & \\
\hline \multicolumn{5}{|l|}{ Namibia } \\
\hline \multicolumn{5}{|l|}{ Netherlands } \\
\hline \multicolumn{5}{|l|}{ Norway } \\
\hline \multicolumn{5}{|l|}{ New Zealand } \\
\hline \multicolumn{5}{|l|}{ Pap. New Guinea } \\
\hline \multicolumn{5}{|l|}{ Russia } \\
\hline \multicolumn{5}{|l|}{ El Salvador } \\
\hline \multicolumn{5}{|l|}{ Slovak Rep } \\
\hline \multicolumn{5}{|l|}{ Slovenia } \\
\hline \multicolumn{5}{|l|}{ Sweden } \\
\hline \multicolumn{5}{|c|}{ Trinidad \& Tobago } \\
\hline \multicolumn{5}{|l|}{ Ukraine } \\
\hline \multicolumn{5}{|l|}{ United States } \\
\hline \multicolumn{5}{|l|}{ Venezuela } \\
\hline South Africa & & & & \\
\hline
\end{tabular}

Notes:

Economies are classified as all-time democracy (autocracy) if they continuously score 5 or above (less than 5) in $\boldsymbol{D E M O C}$ during the sample period.

Economies are classified as more democratic (autocratic) if they switched from autocracy (democracy) to democracy (autocracy) during the sample period, i.e. from scores of less than 5 
to 5 or above (from scores of 5 or above to less than 5 ).

Economies are classified as regime changes if they experienced more than one switch of political regime during the sample period. 


\section{iii. Country Coverage in Chapter 4}

\section{OECD Economies (as Destination and/or Source Economies)}

\begin{tabular}{lllll}
\hline \hline Australia & Finland & Ireland & New Zealand & Spain \\
Austria & France & Italy & Norway & Sweden \\
Belgium & Germany & Japan & Poland & Switzerland \\
Canada & Greece & Luxembourg & Portugal & Turkey \\
Czech Republic & Hungary & Mexico & Republic of Korea & United Kingdom \\
Denmark & Iceland & Netherlands & Slovakia & United States of America
\end{tabular}

Non-OECD Economies (as Destination Economies)

\begin{tabular}{lllll}
\hline \hline Argentina & Costa Rica & India & Morocco & Russian Federation \\
Brazil & Croatia & Indonesia & Nigeria & Singapore \\
Bulgaria & Cyprus & Israel & Pakistan & South Africa \\
Chile & Egypt & Latvia & Peru & Thailand \\
China & Estonia & Lithuania & Philippines & Ukraine \\
Colombia & Hong Kong & Malaysia & Romania & Viet Nam \\
\hline
\end{tabular}




\section{iv. Country Coverage in Chapter 5}

\begin{tabular}{|c|c|c|}
\hline Economy & Code $^{\wedge}$ & ${\text { Income } \text { group }^{\wedge}}^{\wedge}$ \\
\hline \multicolumn{3}{|l|}{ OECD Economies } \\
\hline Australia & AUS & High income \\
\hline Austria & AUT & High income \\
\hline Belgium & BEL & High income \\
\hline Canada & CAN & High income \\
\hline Switzerland & $\mathrm{CHE}$ & High income \\
\hline Denmark & DNK & High income \\
\hline Spain & ESP & High income \\
\hline Finland & FIN & High income \\
\hline France & FRA & High income \\
\hline United Kingdom & GBR & High income \\
\hline Greece & GRC & High income \\
\hline Ireland & IRL & High income \\
\hline Iceland & ISL & High income \\
\hline Italy & ITA & High income \\
\hline Japan & JPN & High income \\
\hline Korea, Republic of & KOR & High income \\
\hline Luxembourg & LUX & High income \\
\hline Netherlands & NLD & High income \\
\hline Norway & NOR & High income \\
\hline New Zealand & NZL & High income \\
\hline Portugal & PRT & High income \\
\hline Sweden & SWE & High income \\
\hline United States of America & USA & High income \\
\hline \multicolumn{3}{|l|}{ East Asia and Pacific } \\
\hline China & $\mathrm{CHN}$ & Lower middle income \\
\hline Fiji & FJI & Upper middle income \\
\hline Indonesia & IDN & Lower middle income \\
\hline Malaysia & MYS & Upper middle income \\
\hline Philippines & PHL & Lower middle income \\
\hline Papua New Guinea & PNG & Low income \\
\hline Thailand & THA & Lower middle income \\
\hline Taiwan & TWN & High income \\
\hline \multicolumn{3}{|c|}{ Latin America and Caribbean } \\
\hline Argentina & ARG & Upper middle income \\
\hline Bolivia & BOL & Lower middle income \\
\hline Brazil & BRA & Upper middle income \\
\hline Chile & $\mathrm{CHL}$ & Upper middle income \\
\hline Colombia & $\mathrm{COL}$ & Lower middle income \\
\hline Costa Rica & CRI & Upper middle income \\
\hline Dominican Republic & DOM & Lower middle income \\
\hline Ecuador & ECU & Lower middle income \\
\hline Guatemala & GTM & Lower middle income \\
\hline Honduras & HND & Lower middle income \\
\hline Haiti & HTI & Low income \\
\hline Jamaica & JAM & Upper middle income \\
\hline Mexico & MEX & Upper middle income \\
\hline Nicaragua & NIC & Lower middle income \\
\hline Panama & PAN & Upper middle income \\
\hline
\end{tabular}




\begin{tabular}{lcc}
\hline \multicolumn{1}{c}{ Economy } & Code $^{\wedge}$ & Income $^{\text {group }}{ }^{\wedge}$ \\
\hline \hline Peru & PER & Lower middle income \\
Paraguay & PRY & Lower middle income \\
El Salvador & SLV & Lower middle income \\
Uruguay & URY & Upper middle income \\
Venezuela & VEN & Upper middle income
\end{tabular}

Sub-Saharan Africa

\begin{tabular}{|c|c|c|}
\hline Burundi & BDI & Low income \\
\hline Benin & $\mathrm{BEN}$ & Low income \\
\hline Burkina Faso & BFA & Low income \\
\hline Botswana & BWA & Upper middle income \\
\hline Central African Republic & CAF & Low income \\
\hline Cote d'Ivoire & CIV & Low income \\
\hline Cameroon & CMR & Lower middle income \\
\hline Congo, Republic of & $\mathrm{COG}$ & Lower middle income \\
\hline Comoros & $\mathrm{COM}$ & Low income \\
\hline Cape Verde & CPV & Lower middle income \\
\hline Ethiopia & ETH & Low income \\
\hline Gabon & GAB & Upper middle income \\
\hline Ghana & GHA & Low income \\
\hline Guinea & GIN & Low income \\
\hline Gambia, The & GMB & Low income \\
\hline Guinea-Bissau & GNB & Low income \\
\hline Kenya & KEN & Low income \\
\hline Lesotho & LSO & Lower middle income \\
\hline Madagascar & MDG & Low income \\
\hline Mali & MLI & Low income \\
\hline Mozambique & MOZ & Low income \\
\hline Mauritania & MRT & Low income \\
\hline Mauritius & MUS & Upper middle income \\
\hline Malawi & MWI & Low income \\
\hline Niger & NER & Low income \\
\hline Nigeria & NGA & Low income \\
\hline Rwanda & RWA & Low income \\
\hline Senegal & SEN & Low income \\
\hline Sierra Leone & SLE & Low income \\
\hline Chad & $\mathrm{TCD}$ & Low income \\
\hline Togo & TGO & Low income \\
\hline Tanzania & TZA & Low income \\
\hline Uganda & UGA & Low income \\
\hline South Africa & ZAF & Upper middle income \\
\hline Congo, Dem. Rep. & ZAR & Low income \\
\hline Zambia & $\mathrm{ZMB}$ & Low income \\
\hline Zimbabwe & ZWE & Low income \\
\hline \multicolumn{3}{|l|}{ South Asia } \\
\hline Bangladesh & BGD & Low income \\
\hline India & IND & Lower middle income \\
\hline Sri Lanka & LKA & Lower middle income \\
\hline Nepal & NPL & Low income \\
\hline Pakistan & PAK & Low income \\
\hline \multicolumn{3}{|c|}{ Middle East and North Africa } \\
\hline Algeria & DZA & Lower middle income \\
\hline Egypt & EGY & Lower middle income \\
\hline Iran & IRN & Lower middle income \\
\hline Jordan & JOR & Lower middle income \\
\hline Morocco & MAR & Lower middle income \\
\hline
\end{tabular}




\begin{tabular}{lll}
\hline \multicolumn{1}{c}{ Economy } & Code $^{\wedge}$ & \multicolumn{1}{c}{${\text { Income } \text { group }^{\wedge}}^{\wedge}$} \\
\hline $\begin{array}{l}\text { Syrian Arab Republic } \\
\text { Tunisia }\end{array}$ & SYR & $\begin{array}{l}\text { Lower middle income } \\
\text { Lower middle income }\end{array}$ \\
Europe and Central Asia & & \\
\hline Turkey & TUR & Upper middle income \\
Others & & \\
\hline Barbados & & \\
Cyprus & BRB & High income \\
$\begin{array}{l}\text { Equatorial Guinea } \\
\text { Hong Kong }\end{array}$ & CYP & High income \\
$\begin{array}{l}\text { Israel } \\
\text { Singapore } \\
\text { Trinidad and Tobago }\end{array}$ & GNQ & High income \\
& HKG & High income \\
& ISR & High income \\
& SGP & High income \\
TTO & High income
\end{tabular}

Note $^{\wedge}$ : Country code and income group classifications are based on World Bank Country Classification. 


\section{A.5 List of Regional Trade Agreements (RTA)}

\begin{tabular}{|c|c|c|}
\hline Abbreviation & Name of RTA ${ }^{(3)}$ & $\begin{array}{c}\text { Member countries } \\
\text { (Date of Entry into Force) } \\
\end{array}$ \\
\hline AZCERTA & $\begin{array}{l}\text { Australia - New Zealand } \\
\text { Closer Economic Relations } \\
\text { Trade Agreement }\end{array}$ & $\begin{array}{l}\text { Australia, New Zealand } \\
\text { (1983) }\end{array}$ \\
\hline EEC/EC & European Union & $\begin{array}{l}\text { Austria, Belgium, Denmark, } \\
\text { Finland, France, Germany, } \\
\text { Greece, Luxembourg, Ireland, } \\
\text { Italy, Netherlands, Portugal, } \\
\text { Spain, Sweden, United Kingdom. } \\
\text { (1994) }\end{array}$ \\
\hline NAFTA & $\begin{array}{l}\text { Canada-US Free Trade } \\
\text { Arrangement / North } \\
\text { America Free Trade } \\
\text { Agreement }\end{array}$ & $\begin{array}{l}\text { Canada, United States, Mexico. } \\
\text { (1994) }\end{array}$ \\
\hline SPARTECA & $\begin{array}{l}\text { South Pacific Regional } \\
\text { Trade and Economic } \\
\text { Cooperation Agreement }\end{array}$ & $\begin{array}{l}\text { Covers trade relations between the } \\
\text { Cook Islands, Fiji, Kiribati, } \\
\text { Micronesia, Nauru, Niue, Palau, } \\
\text { Papua, Papua-New Guinea, } \\
\text { Salomon Islands, Samoa, Tonga, } \\
\text { Tuvalu, Vanuatu, on the one hand, } \\
\text { and Australia and New Zealand on } \\
\text { the other. } \\
(1981)\end{array}$ \\
\hline APTA - China & $\begin{array}{l}\text { Asia Pacific Trade } \\
\text { Agreement - Accession of } \\
\text { China }\end{array}$ & $\begin{array}{l}\text { Korea, China } \\
(2002)\end{array}$ \\
\hline EFTA - Mexico & & $\begin{array}{l}\text { Austria, Denmark, Norway, } \\
\text { Portugal, Sweden, Switzerland, } \\
\text { United Kingdom, Mexico } \\
(2001)\end{array}$ \\
\hline $\begin{array}{l}\text { New Zealand - } \\
\text { Singapore }\end{array}$ & & $\begin{array}{l}\text { New Zealand, Singapore } \\
(2001)\end{array}$ \\
\hline EFTA - Croatia & & $\begin{array}{l}\text { Austria, Denmark, Norway, } \\
\text { Portugal, Sweden, Switzerland, } \\
\text { United Kingdom, Croatia } \\
(2002)\end{array}$ \\
\hline Japan - Singapore & & $\begin{array}{l}\text { Japan, Singapore } \\
(2002)\end{array}$ \\
\hline CEFTA-Croatia & $\begin{array}{l}\text { Central European Free } \\
\text { Trade Agreement - } \\
\text { Accession of Croatia }\end{array}$ & $\begin{array}{l}\text { Czech Republic, Hungary, Poland, } \\
\text { Slovak Republic, Croatia } \\
(2003)\end{array}$ \\
\hline EFTA - Singapore & & $\begin{array}{l}\text { Austria, Denmark, Norway, } \\
\text { Portugal, Sweden, Switzerland, } \\
\text { United Kingdom, Singapore } \\
(2003)\end{array}$ \\
\hline Singapore - Australia & & $\begin{array}{l}\text { Singapore, Australia } \\
(2003)\end{array}$ \\
\hline Turkey - Croatia & & $\begin{array}{l}\text { Turkey, Croatia } \\
\text { (2003) }\end{array}$ \\
\hline
\end{tabular}

${ }^{(3)}$ RTA also includes bilateral trade agreement here. 


\begin{tabular}{|c|c|c|}
\hline Abbreviation & Name of RTA ${ }^{(3)}$ & $\begin{array}{c}\text { Member countries } \\
\text { (Date of Entry into Force) }\end{array}$ \\
\hline EFTA - Chile & & $\begin{array}{l}\text { Austria, Denmark, Norway, } \\
\text { Portugal, Sweden, Switzerland, } \\
\text { United Kingdom, Chile } \\
(2004)\end{array}$ \\
\hline $\begin{array}{l}\text { Republic of Korea - } \\
\text { Chile }\end{array}$ & Republic of Korea - Chile & $\begin{array}{l}\text { Korea, Chile } \\
\text { (2004) }\end{array}$ \\
\hline US - Chile & & $\begin{array}{l}\text { United States of America, Chile } \\
\text { (2004) }\end{array}$ \\
\hline US - Singapore & & $\begin{array}{l}\text { United States of America, } \\
\text { Singapore } \\
(2004)\end{array}$ \\
\hline Japan - Mexico & & $\begin{array}{l}\text { Japan, Mexico } \\
(2005)\end{array}$ \\
\hline Thailand - Australia & & $\begin{array}{l}\text { Thailand, Australia } \\
\text { (2005) }\end{array}$ \\
\hline US -Australia & & $\begin{array}{l}\text { United States of America, } \\
\text { Australia } \\
(2005)\end{array}$ \\
\hline $\begin{array}{l}\text { EFTA - Republic of } \\
\text { Korea }\end{array}$ & EFTA - Republic of Korea & $\begin{array}{l}\text { Austria, Denmark, Norway, } \\
\text { Portugal, Sweden, Switzerland, } \\
\text { United Kingdom, Korea } \\
(2006)\end{array}$ \\
\hline Japan - Malaysia & & $\begin{array}{l}\text { Japan, Malaysia } \\
\text { (2006) }\end{array}$ \\
\hline $\begin{array}{l}\text { Republic of Korea - } \\
\text { Singapore }\end{array}$ & $\begin{array}{l}\text { Republic of Korea - } \\
\text { Singapore }\end{array}$ & $\begin{array}{l}\text { Korea, Singapore } \\
(2006)\end{array}$ \\
\hline
\end{tabular}

Source: WTO 


\section{A.6 Diagnostic Tests for Estimations in Chapter 4}

\section{i. F-test for FE vs. OLS Estimations}

An F-test is used to test for the existence of individual effects. Test for the two-way error component model is similar to the one-way model. Given time effects, the null hypothesis assumes

$$
H_{0}: u_{1}=\ldots=u_{N-1}=0 \quad \text { given } \delta_{t} \neq 0 \text { for } t=1, \ldots T-1
$$

The unrestricted residual sum of squares (URSS) is the Within residual sum of squares. However, the restricted residual sum of squares (RRSS) is based on the regression

$$
\left(y_{i t}-\bar{y}_{. t}\right)=\left(x_{i t}-\bar{x}_{. t}\right) \beta+\left(v_{i t}-\bar{v}_{. t}\right) \quad \text { where } v_{i t}=u_{i}+\delta_{t}+\varepsilon_{i t} .
$$

The F-ratio used for the test is

$$
F(N-1, N T-N-k)=\frac{(R R S S-U R S S) /(N-1)}{(U R S S) /(N T-N-k)}
$$

where $k$ is the number of regressors. F-test results of our FE models are presented below:

\begin{tabular}{c|c|c|c|c}
\hline Model & FE(1) & FE(2) & FE(3) & FE(4) \\
\hline \hline F-stat & $\mathrm{F}(1516,7678)$ & $\mathrm{F}(1516,7679)$ & $\mathrm{F}(1511,7440)$ & $\mathrm{F}(1562,7001)$ \\
& $=32.15$ & $=33.05$ & $=33.60$ & $=36.14$ \\
Prob $>F$ & 0.0000 & 0.0000 & 0.0000 & 0.0000 \\
Conclusion & Reject OLS & Reject OLS & Reject OLS & Reject OLS \\
\hline
\end{tabular}

Note: Conclusion does not change when using inter-OECD and intra-OECD samples.

\section{ii. Breusch and Pagan test for RE vs. OLS Estimations}

Breusch and Pagan. (1980) have devised a Lagrange multiplier test for RE model based on the OLS residuals. The test hypothesis is 


$$
\begin{aligned}
& H_{0}: \delta_{u}^{2}=0 \\
& H_{1}: \delta_{u}^{2} \neq 0
\end{aligned}
$$

The test statistic is described below. Under the null hypothesis, the limiting distribution of $L M$ is chi-squared with one degree of freedom.

$$
\begin{aligned}
L M & =\frac{n T}{2(T-1)}\left[\frac{\sum_{i j=1}^{n}\left[\sum_{i=1}^{T} \varepsilon_{i j t}\right]^{2}}{\sum_{i j=1}^{n} \sum_{t=1}^{T} \varepsilon_{i j t}^{2}}-1\right]^{2} \\
& =\frac{n T}{2(T-1)}\left[\frac{\sum_{i j=1}^{n}\left(T \bar{\varepsilon}_{i j}\right)^{2}}{\sum_{i=1}^{n} \sum_{i=1}^{T} \varepsilon_{i j t}^{2}}-1\right]^{2}
\end{aligned}
$$

Breusch and Pagan test results on the RE models are show below:

\begin{tabular}{c|c|c|c|c}
\hline Model & RE(1) & RE(2) & RE(3) & RE(4) \\
\hline \hline chi2(1) & 13088.37 & 13476.41 & 12523.16 & 12246.28 \\
Prob > chi2 & 0.0000 & 0.0000 & 0.0000 & 0.0000 \\
Conclusion & Reject OLS & Reject OLS & Reject OLS & Reject OLS \\
\hline
\end{tabular}

Note: Conclusion does not change when using inter-OECD and intra-OECD samples.

\section{iii. Hausman Specification Test}

The specification test devised by Hausman (1978) is used to test for orthogonality of the common effects and the regressors. The test is based on the hypothesis of no correlation. Under the null hypothesis, both OLS estimations in the FE model and GLS in the RE model are consistent, but OLS is inefficient. Under the alternative, OLS is consistent, but GLS is not. Therefore, under the null hypothesis, the two estimates should not differ systematically. The covariance matrix of the difference vector $[b-\hat{\beta}]$ is

$$
\operatorname{var}[b-\hat{\beta}] \quad=\operatorname{var}[b]+\operatorname{var}[\hat{\beta}]-\operatorname{cov}[b, \hat{\beta}]-\operatorname{cov}[\hat{\beta}, b]
$$

where $\mathrm{b}$ and $\hat{\beta}$ are estimates obtained from OLS and RE respectively. 
Hausman's result is that the covariance of an efficient estimator with its difference from an inefficient estimator is zero, which implies

$$
\begin{array}{rll}
\operatorname{cov}[(b-\hat{\beta}), \hat{\beta}] & =\operatorname{cov}[b, \hat{\beta}]-\operatorname{var}[\hat{\beta}] & =0 \\
\text { That said, } \operatorname{var}[b-\hat{\beta}] & =\operatorname{var}[b]-\operatorname{var}[\hat{\beta}] & =\psi
\end{array}
$$

The chi-squared test is based on the Wald's criterion:

$$
W=\chi^{2}[K-1] \quad=[b-\hat{\beta}]^{\prime} \hat{\psi}^{-1}[b-\hat{\beta}]
$$

For $\hat{\psi}$, one can use the estimated covariance matrices of the slope estimator in the FE model and the estimated covariance matrix in the RE model, excluding the constant term. Under the null hypothesis, $W$ has a limiting chi-sq. distribution with $K-1$ degrees of freedom. Hausman specification test results on the four key baseline panel models are as shown below:

\begin{tabular}{l|c|c|c|c}
\hline Models & FE(1) vs. RE(1) & FE(2) vs. RE(2) & FE(3) vs. RE(3) & FE(4) vs. RE(4) \\
\hline \hline Wald chi2 (15) & 249.21 & 251.73 & 203.89 & 235.96 \\
Prob $>$ chi2 & 0.0000 & 0.0000 & 0.0000 & 0.0000 \\
Conclusion & Prefer FE & Prefer FE & Prefer FE & Prefer FE \\
\hline
\end{tabular}

Note: Conclusion does not change when using inter-OECD and intra-OECD samples.

For IV estimation, Hausman specification test can also used to test whether $\boldsymbol{R E} \boldsymbol{G}$ is endogenous, i.e. correlated with the disturbance term in our model. Under the null hypothesis, there is no correlation between the two. If this is the case, estimators of both least squares and IV are consistent. Under the alternative hypothesis, only the IV estimator is consistent.

\begin{tabular}{l|c|c|c|c}
\hline Models & IV(1) vs. RE(1) & IV(2) vs. RE(2) & IV(3) vs. RE(3) & IV(4) vs. RE(4) \\
\hline \hline Wald chi2 (28) & 26.61 & 104.65 & 4.13 & 71.29 \\
Prob $>$ chi2 & 0.5396 & 0.0000 & 1.000 & 0.0000 \\
Conclusion & cannot reject $\mathrm{H}_{0}$ & reject $\mathrm{H}_{0}$ & cannot reject $\mathrm{H}_{0}$ & reject $\mathrm{H}_{0}$ \\
\hline
\end{tabular}

\section{iv. Test for Autocorrelation}


In a linear panel model framework, Wooldridge (2000) proposes to use the residuals from a regression in first-differences. While first-differencing the data in the model removes the individual-level effect, the term based on the time-invariant covariates and the constant becomes

$$
\begin{gathered}
y_{i t}-y_{i t-1}=\left(\mathrm{X}_{i t}-\mathrm{X}_{i t-1}\right) \beta_{1}+\varepsilon_{i t}-\varepsilon_{i t-1} \\
\Delta y_{i t}=\Delta \mathrm{X}_{i t} \beta_{1}+\Delta \varepsilon_{i t}
\end{gathered}
$$

where $\Delta$ is the first-difference operator.

Wooldridge's procedure begins by estimating the parameters $\beta_{1}$ by regressing $\Delta \mathrm{y}_{\mathrm{it}}$ on $\Delta \mathrm{X}_{i t}$ and obtaining the residuals $\hat{\mathrm{e}}_{i t}$. If the $\varepsilon_{i t}$ are not serially correlated, then $\operatorname{Corr}\left(\Delta \varepsilon_{i t}, \Delta \varepsilon_{i t-1}\right)=-0.5$. Given this, the procedure regresses the residuals $\hat{\mathrm{e}}_{i t}$ from the regression with first-differenced variables on their lags and tests that the coefficient on the lagged residuals is equal to -0.5 by using F-test. Our test results are at below. The null hypothesis of no serial correlation is strongly rejected.

\begin{tabular}{l|c|c|c|c}
\hline Model & $\underline{\text { RE(1) }}$ & $\underline{\text { RE(2) }}$ & $\underline{\text { RE(3) }}$ & $\underline{\text { RE(4) }}$ \\
\hline \hline F-stat & $\mathrm{F}(1,1248)=141.397$ & $\mathrm{~F}(1,1248)=140.798$ & $\mathrm{~F}(1,1244)=133.776$ & $\mathrm{~F}(1,1244)=133.620$ \\
Prob $>F$ & 0.0000 & 0.0000 & 0.0000 & 0.0000 \\
Conclusion & Reject $\mathrm{H}_{0}$ & Reject $\mathrm{H}_{0}$ & Reject $\mathrm{H}_{0}$ & Reject $\mathrm{H}_{0}$ \\
\hline
\end{tabular}

Note: Standard errors account for clustering within the panels. Conclusion does not change when using inter-OECD and intra-OECD samples.

\section{v. Sargan-Hansen Test on Instruments Validity}

A Sargan-Hansen test of over-identification restrictions is used to test the exogeneity of the instruments, i.e. the instruments are uncorrelated with the error term, and the excluded instruments are correctly excluded from the estimated equation. In short, under the null hypothesis, the instruments are valid. The test results are shown in the IV estimation results table at Table 4.5.3-1 - Table 4.5.3-3. The test results conclude that we cannot reject the exogeneity of the instruments. 
A.7 Summary Table of Time-Varying Technical Efficiency Models

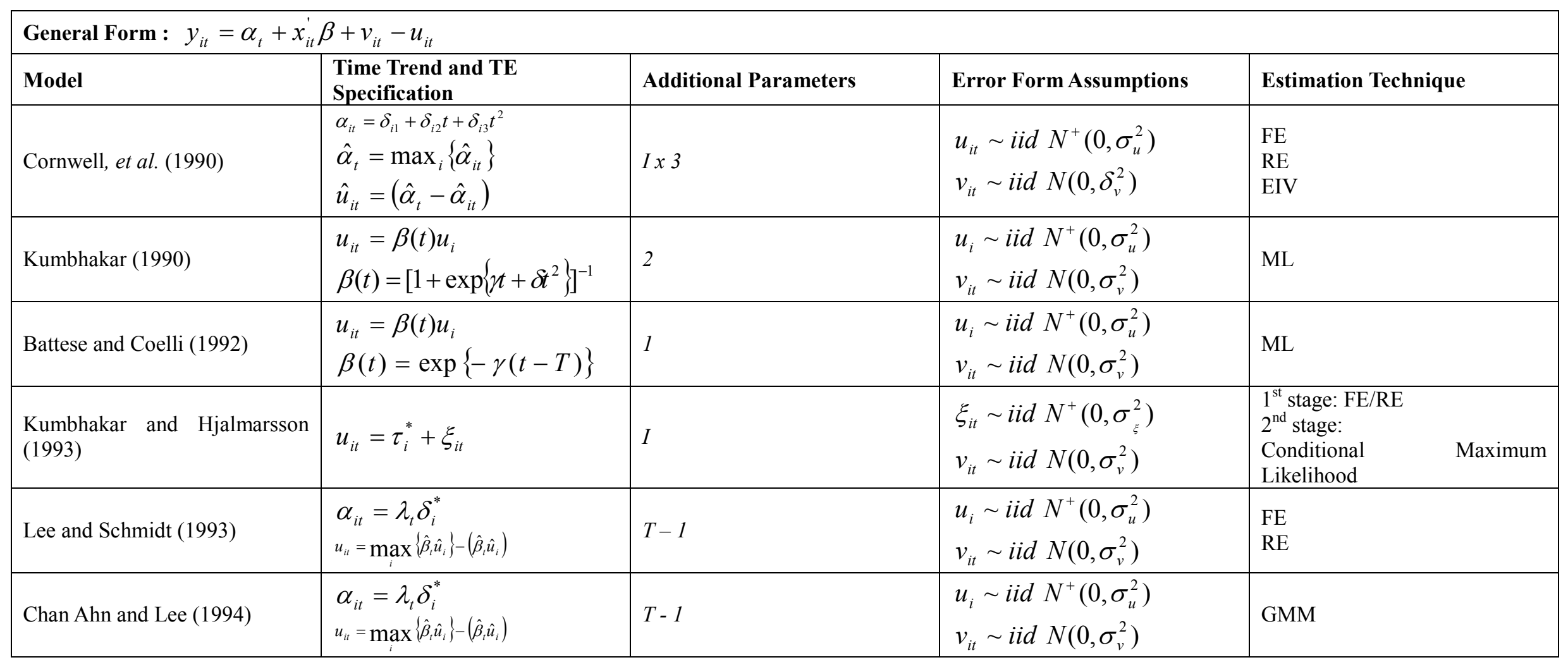




\section{BIBLIOGRAPHY}

Abiad, A. and A. Mody. 2005. "Financial Reform: What Shakes it? What Shapes it?" American Economic Review, 95:1, pp. 66-88.

Acemoglu, D. 2006. "A Simple Model of Inefficient Institutions." Scandinavian Journal of Economics, 108:4, pp. 515-46.

Acemoglu, D. 2009. Introduction to Modern Economic Growth. Cambridge, M.A.: Princeton University Press.

Acemoglu, D., P. Aghion, and F. Zilibotti. 2006. "Distance to Frontier, Selection, and Economic Growth." Journal of the European Economic Association, 4:1, pp. 37-74.

Acemoglu, D. and S. Johnson. 2005. "Unbundling Institutions." Journal of Political Economy, 113:5, pp. 949-95.

Acemoglu, D., S. Johnson, and J. Robinson. 2001. "The Colonial Origins of Comparative Development: An Empirical Investigation." American Economic Review, 91:5, pp. 1369-401.

Acemoglu, D., S. Johnson, and J. Robinson. 2002. "Reversal of Fortune: Geography and Institutions in the Making of the Modern World Income Distribution." Quarterly Journal of Economics, 117:4, pp. 1231-94.

Acemoglu, D., S. Johnson, and J. Robinson. 2003. "Disease and Development in Historical Perspective." Journal of the European Economic Association, 1:2-3, pp. 397-405.

Acemoglu, D., S. Johnson, and J. Robinson. 2005. "Institutions as a Fundamental Cause of Long-Run Growth," in Handbook of Economic Growth. Philippe Aghion and Steve Durlauf eds. Amsterdam: Elsevier, pp. 385-472.

Acemoglu, D., S. Johnson, J. Robinson, and P. Yared. 2008. "Income and Democracy." American Economic Review, 98:3 (Jun), pp. 808-42.

Acemoglu, D. and J. Robinson. 2006. "De Facto Political Power and Institutional Persistence." American Economic Review, 96:2, pp. 325-30.

Adkins, L. C., R. L. Moomaw, and A. Savvides. 2002. "Institutions, Freedom, and Technical Efficiency." Southern Economic Journal, 69:1, pp. 92-108.

Aghion, P., P. Howitt, and D. Mayer-Foulkes. 2005. "The Effect of Financial Development on Convergence: Theory and Evidence." Quarterly Journal of Economics, 120:1, pp. 173-222. 
Aidt, T. S. and M. Gassebner. 2007. "Do Autocratic States Trade Less?" Cambridge Working Papers in Economics, No. 0742.

Aigner, D., C. A. K. Lovell, and P. Schmidt. 1977. "Formulation and Estimation of Stochastic Frontier Production Function Models." Journal of Econometrics, 6:1, pp. 21-37.

Aitken, B. and A. Harrison. 1999. "Do domestic firms benefit from foreign direct investment? Evidence from Venezuela." American Economic Review, 89:3, pp. 605-18.

Aizenman, J. and M. Spiegel. 2004. "Institutional efficiency, monitoring costs, and the share of FDI." Review of International Economics, 14:4 September, pp. 683-97.

Albouy, D. Y. 2008. "The Colonial Origins of Comparative Development: An Investigation of the Settler Mortality Data." NBER Working Paper, No. 14130.

Albuquerque, R. 2003. "The composition of international capital flows: risk sharing through foreign direct investment." Journal of International Economics, 61:2, pp. 353-83.

Alcalá, F. and A. Ciccone. 2004. "Trade and Productivity." Quarterly Journal of Economics, 119:2, pp. 613-46.

Alchian, A. A. 1950. "Uncertainty, Evolution, and Economic Theory." The Journal of Political Economy, 58:3, pp. 211-21.

Alesina, A., S. Ardagna, and F. Trebbi. 2006. "Who Adjusts and When? The Political Economy of Reforms." IMF Staff Papers:53.

Alesina, A., A. Devlieeschauwer, W. Easterly, S. Kurlat, and R. Wacziarg. 2003. "Fractionalization." Journal of Economic Growth, 8:2, pp. 155-94.

Alfaro, L., A. Chanda, S. Kalemli-Ozcan, and S. Sayek. 2004. "FDI and Economic Growth: The Role of Local Financial Market." Journal of International Economics, 64:1, pp. 89-112.

Almeida, R. and C. P. 2005. "Enforcement of Regulation, Informal Labor and Firm Performance." Discussion Paper 1759.

Amin, M. and S. Djankov. 2009. "Natural Resources and Reforms." Policy Research Working Paper, No. 4882.

Anderson, J. E. 1979. "A Theoretical Foundation for Gravity Equation." The American Economic Review, 69:1, pp. 106-16.

Anderson, J. E. and E. v. Wincoop. 2003. "Gravity with Gravitas: A Solution to the Border Puzzle." American Economic Review, 93:1, pp. 170-92. 
Andreski, S. 1969. Parasitism and Subversion -- The Case of Latin America. New York: Schocken.

Arellano, M. and S. Bond. 1991. "Some Tests of Specification for Panel Data: Monte Carlo Evidence and Application to Employment Equations." The Review of Economic Studies, 58:2, pp. 277-97.

Arellano, M. and O. Bover. 1995. "Another look at the instrumental variable estimation of error-components models." Journal of Econometrics, 68:1, pp. 29-51.

Arezki, R. and F. v. d. Ploeg. 2007. "Can the Natural Resource Curse Be Turned Into a Blessing? The Role of Trade Policies and Institutions." IMF Working Paper, No. 07/55.

Autor, D. H., W. R. Kerr, and A. D. Kugler. 2007. "Do Employment Protections Reduce Productivity? Evidence from U.S. States." NBER Working Paper, No. 12860.

Ayal, E. B. and G. Karras. 1998. "Components of Economic Freedom and Growth: An Empirical Study." Journal of Developing Areas, 32:3, pp. 327-38.

Balasubramanyam, V. N., M. Salisu, and D. Sapsford. 1996. "Foreign Direct Investment and Growth in EP and IS Countries." Economic Journal, 106, pp. 92-105.

Baltagi, B. H. 1981. "Simultaneous Equations with Error Components." Journal of Econometrics, 17, pp. 189-200.

Baltagi, B. H. 2001. Econometric Analysis of Panel Data. New York ; Chichester: Wiley.

Barro, R. J. 1990. "Government Spending in a Simple Model of Endogenous Growth." The Journal of Political Economy, 98:5(2), pp. S103-25.

Barro, R. J. and J. W. Lee. 2001. "International Data on Educational Attainment: Updates and Implications." Oxford Economic Papers, 53:3 (Jul), pp. 541-63.

Barro, R. J. and J.-W. Lee. 1994. "Data Set for a Panel of 138 Countries." Available at http://www.nber.org/pub/barro lee/readme.txt.

Barro, R. J. and X. Sala-i-Martin. 1997. Economic Growth. Cambridge, Mass: MIT.

Bastos, F. and J. Nasir. 2004. "Productivity and the Investment Climate: What Matters Most." World Bank Policy Research Paper, No.3335.

Battese, G. E. and T. Coelli. 1992. "Frontier Production Functions, Technical Efficiency and Panel Data: With Application to Paddy Farmers in India." Journal of Productivity Analysis, 3, pp. 153-69. 
Battese, G. E. and T. Coelli. 1993. "A Stochastic Frontier Production Function Incorporating a Model for Technical Inefficiency Effects." Econometrics and Applied Statistics, Department of Econometrics, University of New England, Armidale Working Paper, No. 69.

Battese, G. E. and T. Coelli. 1995. "A Model of Technical Inefficiency Effects in a Stochastic Frontier Production Function for Panel Data." Empirical Economics, 20:2, pp. 325-32.

Beck, T., A. Demirguc-Kunt, and R. Levine. 2001. "Law, Politics, and Finance." World Bank Policy Research Working Paper, No. 2585.

Beck, T., A. Demirguc-Kunt, and R. Levine. 2003a. "Law and Finance: Why Does Legal Origin Matter?" Journal of Comparative Economics, 31:4, pp. 653-75.

Beck, T., A. Demirguc-Kunt, and R. Levine. 2003b. "Law, Endowments, and Finance." Journal of Financial Economics, 70:2, pp. 137-81.

Beck, T., A. Demirguc-Kunt, and R. Levine. 2009. "Financial institutions and markets across countries and over time - data and analysis." World Bank Policy Research Working Paper, No. WPS 4943.

Beck, T., A. Demirguc-Kunt, and V. Maksimovic. 2005. "Financial and Legal Constraints to Growth: Does Firm Size Matter?" Journal of Financial, 60:1, pp. 131-77.

Beck, T. and R. Levine. 2004. "Legal Institutions and Financial Development." NBER Working Paper, No. 10417.

Becker, G. S. 1983. "A Theory of Competition Among Pressure Groups for Political Influence'." The Quarterly Journal of Economics, 98:3, pp. 371-400.

Bénassy-Quéré, A., M. Coupet, and T. Mayer. 2007. "Institutional Determinants of Foreign Direct Investment." World Economy, 30:5, pp. 764 -82 .

Bengoa, M. and B. Sanchez-Robles. 2003. "Foreign Direct Investment, Economic Freedom and Growth: New Evidence from Latin America." European Journal of Political Economy, 19:3, pp. 529-45.

Benhabib, J. and M. Spiegel. 2005. "Human Capital and Technology Diffusion," in Handbook of Economic Growth. Philippe Aghion and Steven Durlauf eds: Elsevier, pp. 935-66.

Benhabib, J. and M. M. Spiegel. 1994. "The Role of Human Capital in Economic Development: Evidence from Aggregate Cross-Country Data." Journal of Monetary Economics, 34:2, pp. 143-73. 
Benhabib, J. and M. M. Spiegel. 1997. "Cross-Country Growth Regressions." C.V. Starr Center for Applied Economics, New York University Working Papers, No. 97-20.

Benhabib, J. and M. M. Spiegel. 2000. "The role of financial development in growth and investment." Journal of Economic Growth, 5:4, pp. 341-60.

Besley, T. and R. Burgess. 2004. "Can Labor Regulation Hinder Economic Performance? Evidence from India." Quarterly Journal of Economics, 119:1, pp. 91-134.

Bhattacharyya, A., A. Bhattacharyya, and K. Mitra. 1997. "Decomposition of Technological Change and Factor Bias in Indian Power Sector: An Unbalanced Panel Data Approach." Journal of Productivity Analysis, 8, pp. 35-52.

Bhattacharyya, S. 2009. "Unbundled Institutions, Human Capital and Growth." Journal of Comparative Economics, forthcoming.

Blomstrom, M. and A. Kokko. 1997. "Regional Integration and Foreign Direct Investment." NBER Working Paper, No. 6019.

Blonigen, B. A. 1997. "Firm-specific Assets and the link between Exchange Rates and Foreign Direct Investment." American Economic Review, 87:3, pp. 447-65.

Blonigen, B. A. 2005. "A Review of the Empirical Literature on FDI Determinants." Atlantic Economic Journal, 33:4, pp. 383-403.

Bloom, D. E. and J. D. Sachs. 1998. "Geography, Demography, and Economic Growth in Africa." Brookings Papers on Economic Activity, 29:1998-2, pp. 207-96.

Blundell, R. and S. Bond. 1998. "Initial conditions and moment restrictions in dynamic panel data models." Journal of Econometrics, 87:1, pp. 115-43.

Bockstette, V., A. Chanda, and L. Putterman. 2002. "States and Markets: The Advantage of an Early Start." Journal of Economic Growth, 7:4, pp. 347-69.

Bond, S. 2002. "Dynamic Panel Data Models: A Guide To Micro Data Methods and Practice." The Institute for Fiscal Studies Department of Economics, UCL, Cemmap Working Paper, cwp09/02.

Bond, S. R., A. Hoeffler, and J. Temple. 2001. "GMM Estimation of Empirical Growth Models." CEPR Discussion Papers, No. 3048.

Borensztein, E., J. De Gregorio, and J.-W. Lee. 1998. "How does Foreign Direct Investment Affect Economic Growth?" Journal of International Economics, 45:1, pp. 115-35.

Bosworth, B. P. and S. M. Collins. 2003. "The Empirics of Growth: An 
Update." mimeo, Brookings Institution, Washington, DC.

Botero, J., S. Djankov, R. La Porta, and F. C. Lopez-De-Silanes. 2004. "The Regulation of Labor." The Quarterly Journal of Economics, 119:4 (Nov), pp. 1339-82.

Botero, J., S. Djankov, R. L. Porta, F. Lopez-de-Silanes, and A. Shleifer. 2003. "The Regulation of Labor." The Quarterly Journal of Economics.

Breusch, T. and A. Pagan. 1980. "The LM Test and Its Applications to Model Specification in Econometrics." Review of economic studies, 47, pp. 239-54.

Busse, M. and J. L. Groizard. 2006. "Foreign Direct Investment, Regulations, and Growth." World Bank Policy Research Working Paper, No. 3882.

Caselli, F., G. Esquivel, and F. Lefort. 1996. "Reopening the convergence debate: a new look at cross country growth empirics." Journal of Economic Growth, 1, pp. 363-89.

Chan Ahn, S. and Y. H. Lee. 1994. "GMM Estimation of a Panel Data Regression Model with Time-Varying Individual Effects." Michigan State University, Department of Economics Working Paper Series, No. 9401.

Chang, R., L. Kaltani, and N. Loayaza. 2005. "Openness Can Be Good for Growth: The Role of Policy Complementarities." NBER Working Paper, No. 11787.

Cheng, I.-H. and H. J. Wall. 2005. "Controlling for Heterogeneity in Gravity models of Trade and Integration." Federal Reserve Bank of St. Louis Review, 87:1, pp. 49-63.

Chinn, M. D. and H. Ito. 2006. "What Matters for Financial Development? Capital Controls, Institutions, and Interactions." Journal of Development Economics, 81:1, pp. 163-92.

Chong, A. and C. Calderon. 2000. "Causality and Feedback between Institutional Measures and Economic Growth." Economic and Politics, 12:1, pp. 69-81.

Christensen, L. R., D. W. Jorgenson, and L. J. Lau. 1973. "Transcendental Logarithmic Production Frontier." The Review of Economic Statistics, 55:1, pp. $28-45$.

Ciccone, A. and F. Alcala. 2004. "Trade and Productivity." Quarterly Journal of Economics, 119:2, pp. 612-45.

Clague, C., P. Keefer, S. Knack, and M. J. Olson. 1999. "Contract-Intensive Money: Contract Enforcement, Property rights, and Economic Performance." Journal of Economic Growth, 4:2, pp. 185-211. 
Coelli, T. 1996. "A Guide to FRONTIER Version 4.1: A Computer Program for Stochastic Frontier Production and Cost Function Estimation." Centre for Efficiency and Productivity Analysis (CEPA), University of New England Working Paper, No. 96/07.

Coelli, T., D. S. P. Rao, and G. E. Battese. 1998. An Introduction to Efficiency and Productivity Analysis. Boston: Kluwer Academic Publishers.

Cornwell, C. and P. Schmidt. 1996. "Production Frontiers and Efficiency Measurement," in The Econometrics of Panel Data -- A Handbook of the Theory with Applications. László Mátyás and Patrick Sevestre eds. London: Dordrecht : Kluwer Academic, pp. 845-78.

Cornwell, C., P. Schmidt, and R. C. Sickles. 1990. "Production Frontiers with Cross-Sectional and Time-Series Variation in Efficiency Levels." Journal of Econometrics, 46:1/2, pp. 185-200.

Coviello, D. and R. Islam. 2006. "Does Aid Help Improve Economic Institutions?" World Bank Policy Research Working Paper, No. 3990.

Crafts, N. 2006. "Regulation and Productivity Performance." Oxford Review of Economic Policy, 22:2, pp. 186-202.

Curtin, P. D. 1989. Death by Migration: Europe's Encounter with the Tropical World in the 19th Century. New York: Cambridge University Press.

Dailami, M. 2000. "Financial Openness, Democracy and Redistributive Policy." World Bank Policy Research Paper, No. 2372.

Daude, C. and E. Stein. 2004. "The Quality of Institutions and Foreign Direct Investment." mimeo.

Dawson, J. W. 1998. "Institutions, Investment, and Growth: New Cross-Country and Panel Data Evidence." Economic inquiry, 36:4, pp. 603-19.

Dawson, J. W. 2003. "Causality in the Freedom-Growth Relationship." European Journal of Political Economy, 19:3, pp. 479-95.

De Haan, J., S. Lundstrom, and J.-E. Sturm. 2006. "Market-oriented institutions and policies and economic growth: A critical survey." Journal of Economic Surveys, 20:2, pp. 157-91.

De Haan, J. and J.-E. Sturm. 2003. "Does more Democracy lead to Greater Economic Freedom? New Evidence for Developing Countries." European Journal of Political Economy, 19:3, pp. 547-63.

De Vanssay, X. and Z. A. Spindler. 1994. "Freedom and Growth: Do Constitutions Matter?" Public Choice, 78:3-4, pp. 359-72.

Demirguc-Kunt, A. and V. Maksimovic. 1998. "Law, Finance and Firm 
Growth." Journal of Financial, 53:6, pp. 2107-37.

Dethier, J.-J., H. Ghanem, and E. Zoli. 1999. "Does democracy facilitate the economic transition : an empirical study of Central and Eastern Europe and the Former Soviet Union." World Bank Policy Research Working Paper, No. 2194.

Diamond, J. M. 1997. Guns, Germs and Steel: The Fate of Human Societies. New York: W.W. Norton \& Co.

Djankov, S., E. Glaeser, R. L. Porta, F. Lopez-de-Silanes, and A. Shleifer. 2003a. "The New Comparative Economics." Journal of Comparative Economics, 31, pp. 595-619.

Djankov, S., R. L. Porta, F. Lopez-de-Silane, A. Shleifer, and J. Botero. 2003b. "The Regulation of Labor." NBER Working Paper, 9756.

Djankov, S., R. L. Porta, F. Lopez-de-Silanes, and A. Shleifer. 2002. "The Regulation of Entry." Quarterly Journal of Economics, 117:1, pp. 1-37.

Dollar, D. and A. Kraay. 2003. "Institutions, Trade, and Growth: Revisiting the Evidence." World Bank Policy Research Working Paper, No. 3004.

Easterly, W., M. Kremer, L. Prichett, and L. Summers. 1993. "Good Policy or Good Luck? Country Growth Performance and Temporary Shocks." Journal of Monetary Economics, 32, pp. 459-84.

Easterly, W. and R. Levine. 2003. "Tropics, germs, and crops: how endowments influence economic development." Journal of Monetary Economics, 50:1 (Jan), pp. 3-39.

Easterly, W., N. V. Loayza, and P. Montiel. 1997. "Has Latin America's post-reform growth been disappointing?" Journal of International Economics, 43:3-4, pp. 287-311.

Easton, S. T. and M. A. Walker. 1997. "Income, Growth, and Economic Freedom." The American Economic Review, 87:2, pp. 328-32.

Eggertsson, T. 1990. Economic Behavior and Institutions. Cambridge: Cambridge University Press.

Eichengreen, B. and D. Leblang. 2006. "Democracy and Globalisation." BIS Working Papers, No. 219.

Eicher, T. S. and C. Henn. 2009. "In Search of WTO Trade Effects: Preferential Trade Agreements Promote Trade Strongly, But Unevenly." IMF Working Paper, No. 09/31.

Engerman, S. L. and K. L. Sokoloff. 1997. "Factor Endowments, Institutions, and Differential Growth Paths among New World Economies," in How Latin America Fell Behind? Stephen Haber ed. Stanford, CA: Stanford University 
Press.

Esfahani, H. S. and M. T. Ramirez. 2003. "Institutions, Infrastructure, and Economic Growth." Journal of Development Economics, 70:2, pp. 443-77.

Farr, W. K., R. A. Lord, and J. L. Wolfenbarger. 1998. "Economic Freedom, Political Freedom, and Economic Well-being: A Causality Analysis." Cato Journal, 18:2, pp. 247-63.

Farrell, M. J. 1957. "The Measurement of Productive Efficiency." Journal of the Royal Statistical Society, 120:3, pp. 253-90.

Fidrmue, J. 2003. "Economic Reform, Democracy and Growth During Post-Communist Transition." European Journal of Political Economy, 19:3, pp. 583-604.

Fisman, R. and I. Love. 2004. "Financial Development and Growth in the Short and Long Run." NBER Working Paper, No. 10236.

Forbes, K. J. 2000. "A reassessment of the relationship between inequality and growth." American Economic Review, 90:4, pp. 869-87.

Førsund, F. R., C. A. K. Lovell, and P. Schmidt. 1980. "A Survey of Frontier Productions and of their Relationship to Efficiency Measurement." Journal of Econometrics, 13:1, pp. 5-25.

Frankel, J. A. and D. Romer. 1999. "Does Trade Cause Growth?" American Economic Review, 89:3, pp. 379-99.

Friedman, M. 1962. Capitalism and freedom. Chicago: University of Chicago Press.

Froot, K. A. and J. C. Stein. 1991. "Exchange Rates and Foreign Direct Investment -- An Imperfect Markets Approach." The Quarterly Journal of Economics, 106:4, pp. 1191-217.

Galindo, A. and A. Micco. 2005. "Bank Credit to Small and Medium-Sized Enterprises: The Role of Creditor Protection." Central Bank of Chile Working Papers, No. 347.

Gallup, J. L., J. D. Sachs, and A. D. Mellinger. 1998. "Geography and Economic Development." NBER Working Paper, No. 6849.

Giannakas, K., K. Tran, and V. Tzouvelekas. 2003. "Predicting Technical Efficiency in Stochastic Frontier Production Models in the Presence of Misspecification: A Monte Carlo Analysis." Applied Economics, 35:2, pp. 153-61.

Giavazzi, F. and G. Tabellini. 2005. "Economic and Political Liberalizations." Journal of Monetary Economics, 52:7, pp. 1297-330. 
Giuliano, P., P. Mishra, and A. Spilimbergo. 2009. "Democracy and Reforms." IZA Discussion Papers, No. 4032.

Glaeser, E. L., R. L. Porta, F. Lopez-de-Silanes, and A. Shleifer. 2004. "Do Institutions Cause Growth?" Journal of Economic Growth, 9:3, pp. 271-303.

Glaeser, E. L. and A. Shleifer. 2002. "Legal Origins." The Quarterly Journal of Economics, 117:4, pp. 1193-229.

Granér, M. and A. Isaksson. 2001. "Export Performance," in Structure and Performance of Manufacturing in Kenya. Arne Bigsten and Peter Kimuyu eds. London: Palgrave Macmillan.

Greene, W. H. 1990. "A Gamma-Distributed Stochastic Frontier Model." Journal of Econometrics, 46:1/2, pp. 141-64.

Greene, W. H. 2008. Econometric Analysis. New York: Prentice Hall.

Greenwood, J. and B. Jovanovic. 1990. "Financial Development, Growth, and the Distribution of Income." The Journal of Political Economy, 98:5, Pt I, pp. 1076-107.

Gwartnet, J. D., R. Lawson, and W. Block. 1996. Economic Freedom in the World, 1975-1995. Vancouver: Fraser Institute.

Gwartney, J. D., R. Lawson, and S. Norton. 2008. "Economic Freedom of the World: 2008 Annual Report." Economic Freedom Network.

Hadenius, A. and J. Teorell. 2005. "Assessing Alternative Indices of Democracy." Political Concepts Committee on Concepts and Methods Working Paper Series, No. 6.

Hall, R. E. and C. I. Jones. 1999. "Why Do Some Countries Produce so Much More Output Per Worker Than Others?" Quarterly Journal of Economics, 114:1, pp. 83-116.

Haltiwanger, E., S. Scarpetta, and H. Schweiger. 2006. "Assessing Job Flows across Economies: The Role of Industry, Firm Size, and Regulations." World Bank Policy Research Working Paper, No. 4070.

Hansen, L. 1982. "Large sample properties of generalized method of moments estimators." Econometrica, 50:3, pp. 1029-54.

Hanson, G. 2001. "Should Countries Promote Foreign Direct Investment?" United Nations Conference on Trade and Development Series G-24 Discussion Paper, No. 9.

Harper, D. A. 2003. Foundations of Entrepreneurship and Economic Development. London; New York: Routledge. 
Harrison, A. 1996. "Openness and Growth: A Time-series, Cross-country Analysis for Developing Countries." Journal of Development Economics, 48:2, pp. 419-47.

Harrison, P., O. Sussman, and J. Zeira. 1999. "Finance and Growth: Theory and New Evidence." Federal Reserve Board Finance and Economics Discussion Paper, No. 35.

Hattari, R. and R. S. Rajan. 2008. "Trends and Drivers of Bilateral FDI Flows in Developing Asia." HKIMR Working Paper, No. 11/2008.

Hausman, J. A. 1978. "Specification Tests in Econometrics." Econometrica, 46:6, pp. 1251-71.

Hausman, J. A. and W. E. Taylor. 1981. "Panel Data and Unobservable Individual Effects." Econometrica, 49:6, pp. 1377-98.

Hayek, F. A. 1944. The Road to Serfdom. London: Routledge.

Hayek, F. A. 1945. "The Use of Knowledge in Society." American Economic Review, 35:4, pp. 519-30.

Hayek, F. A. 1960. The Constitution of Liberty. London: Routledge and Kegan.

Heritage Foundation. 2009. 2009 Index of Economic Freedom. Washington, D.C.: Heritage Foundation.

Hermes, N. and R. Lensink. 2003. "Foreign Direct Investment, Financial Development and Economic Growth." Journal of Development Studies, 40:1, pp. 142-63.

Heston, A., R. Summers, and B. Aten. 2002. "Penn World Table Version 6.1." Center for International Comparisons at the University of Pennsylvania (CICUP).

Heston, A., R. Summers, and B. Aten. 2006. "Penn World Table Version 6.2." Center for International Comparisons of Production, Income and Prices at the University of Pennsylvania.

Holtz-Eakin, D., W. Newey, and H. S. Rosen. 1988. "Estimating Vector Autoregressions with Panel Data." Econometrica, 56:6, pp. 1371-95.

Hultberg, P. T., M. I. Nadiri, and R. C. Sickles. 1999. "An International Comparison of Technology Adoption and Efficiency: A Dynamic Panel Model." Annales D'Economie et de Statistique, 0:55-56, pp. 449-74.

IMF. 2005. "Chapter 3: Building Institutions," in World Economic Outlook. Washington D.C.: IMF. 
IMF. 2008. "Structural Reforms and Economic Performance in Advanced and Developing Countries." IMF Occasional Paper, forthcoming.

Isaksson, A. 2001. "The Importance of Human Capital for the Trade-Growth Link." UNIDO Working Paper No.2, Vienna, pp. UNIDO.

Isaksson, A. 2002. "Human Capital and Economic Growth: A Survey of the Empirical Literature from 1990 to the Present." mimeo, Vienna: UNIDO.

Isaksson, A. 2007a. "Determinants of Total Factor Productivity: A Literature Review." mimeo, Vienna: UNIDO.

Isaksson, A. 2007b. "World Productivity Database: a technical description." UNIDO Research and Statistics Branch Staff Working Paper, 10/2007.

Isaksson, A. 2009. "The UNIDO World Productivity Database: An Overview." International Productivity Monitor, 18:Spring, pp. 38-50.

Isham, J., D. Kaufmann, and L. H. Pritchett. 1997. "Civil Liberties, Democracy, and the Performance of Government Projects." World Bank Economic Review, 11:2, pp. 219-42.

Islam, N. 1995. "Growth Empirics: A Panel Data Approach." The Quarterly Journal of Economics, 110:4, pp. 1127-70.

Jaumotte, F. 2004. "Foreign Direct Investment and Regional Trade Agreements: The Market Size Effect Revisited." IMF Working Paper, WP/04/206.

Kangur, A. 2008. "What rules in the 'deep' determinants of comparative development?" University of Oxford, Department of Economics, Economics Series Working Papers, No. 386.

Kaufmann, D. and A. Kraay. 2002. "Growth Without Governance." World Bank Policy Research Working Paper, No. 2928.

Kaufmann, D., A. Kraay, and M. Mastruzzi. 2005. "Governance Matter IV: Governance Indicators for 1996 to 2004." World Bank Policy Research Working Paper, No. 3630.

Kaufmann, D., A. Kraay, and P. Zoido-Lobatón. 2002. "Governance Matters II: Updated Indicators for 2000/01." World Bank Policy Research Department Working Paper, No. 2772.

Keller, W. 2004. "International Technology Diffusion." Journal of Economic Literature, 42:3, pp. 752-82.

King, R. G. and R. Levine. 1993. "Finance and Growth: Schumpeter Might be Right." The Quarterly Journal of Economics, 108:3, pp. 717-37.

King, R. J. and R. Levine. 1994. "Capital Fundamentalism Economic 
Development and Economic Growth." Carneige-Rochester Conference Series on Public Policy, 40:Jun, pp. 259-92.

Kirzner, I. M. 1973. Competition and entrepreneurship. Chicago: University of Chicago Press.

Klein, P. G. and H. Luu. 2003. "Politics and Productivity." Economic Inquiry, 41:3, pp. 433-47.

Knack, S. and P. Keefer. 1995. "Institutions and Economic Performance: Cross-Country Tests Using Alternative Institutional Measures." Economics \& Politics, 7:3, pp. 207-27.

Knack, S. and P. Keefer. 1997. "Does Social Capital Have an Economic Payoff? A Cross-Country Investigation." Quarterly Journal of Economics, 112:4, pp. 1251-88.

Kodde, D. A. and F. C. Palm. 1986. "Wald Criteria for Jointly Testing Equality and Inequality Restrictions." Econometrica, 54:5, pp. 1243-48.

Kogel, T. 2005. "Youth Dependency and Total Factor Productivity." Journal of Development Economics, 76:1, pp. 147-73.

Koop, G., J. Osiewalski, and M. F. J. Steel. 1999. "The Components of Output Growth: A Stochastic Frontier Analysis." Oxford Bulletin of Economics and Statistics, 61:4, pp. 455-87.

Koop, G., J. Osiewalski, and M. F. J. Steel. 2000. "A Stochastic Frontier Analysis of Output Level and Growth in Poland and Western Economies." Economic Change and Restructuring, 33:3, pp. 185-202.

Kornai, J. 1992. "The Postsocialist Transition and the State: Reflections in the Light of Hungarian Fiscal Problems." American Economic Review, 82:2, pp. $1-21$.

Kose, M. A., E. Prasad, and M. Terrones. 2008. "Does Openness to International Financial Flows Contribute to Productivity Growth?" IZA Discussion Papers, No. 3634.

Kruger, J. J., U. Canter, and H. Hanusch. 2000. "Total Factor Productivity, the East Asian miracle, and the World Production Frontier." Weltwirtschaftliches Archiv, 136:1, pp. 111-36.

Kumbhakar, S. C. 1990. "Production Frontiers, Panel Data, and Time-Varying Technical Inefficiency." Journal of Econometrics, 46:1-2, pp. 201-11.

Kumbhakar, S. C. and L. Hjalmarsson. 1993. "Technical Efficiency and Technical Progress in Swedish Dairy Farms," in The Measurement of Productive Efficiency: Techniques and Applications. H. O. Fried, C. A. K. Lovell and S. S. Schmidt eds. New York: Oxford University Press. 
Kumbhakar, S. C. and C. A. K. Lovell. 2000. Stochastic Frontier Analysis. Cambridge: Cambridge University Press.

La Porta, R., F. Lopez-De-Silanes, and A. Shleifer. 2008. "The Economic Consequences of Legal Origins." Journal of Economic Literature, 46:2 (Jun), pp. 285-332.

La Porta, R., F. Lopez-de-Silanes, A. Shleifer, and R. W. Vishny. 1997. "Legal Determinants of External Finance." NBER Working Paper, No. 5879.

La Porta, R., F. Lopez-de-Silanes, A. Shleifer, and R. W. Vishny. 1998. "Law and Finance." Journal of Political Economy, 106:6, pp. 1113-55.

La Porta, R., F. Lopez-de-Silanes, A. Shleifer, and R. W. Vishny. 1999. "The Quality of Government." Journal of Law, Economics and Organization, 15:1, pp. 222-79.

Lane, P. R. and G. M. Milesi-Ferretti. 2006. "The External Wealth of Nations Mark II: Revised and Extended Estimates of Foreign Assets and Liabilities, 1970-2004." IMF Working Paper, WP/06/69.

Law, S. H. and A. N. Bany-Ariffin. 2008. "Institutional Infrastructure and Economic Performance: Dynamic Panel Data Evidence." Transition Studies Review, 15:3, pp. 542-57.

Lee, Y. H. and S. Kim. 2006. "The Productivity Debate of East Asia Revisited: A Stochastic Frontier Approach." Applied Economics, 38:14 (Aug), pp. 1697-706.

Lee, Y. H. and P. Schmidt. 1993. "A Production Frontier Model with Flexible Temporal Variation in Technical Inefficiency," in The Measurement of Productive Efficiency: Techniques and Applications. H. O. Fried, C. A. K. Lovell and S. S. Schmidt eds. New York: Oxford University Press.

Levchenko, A. A. 2007. "Institutional Quality and International Trade." Review of Economic Studies, 74, pp. 791-819.

Levchenko, A. A. 2008. "International Trade and Institutional Change." Research Seminar in International Economics, Gerald R. Ford School of Public Policy, The University of Michigan, Ann Arbor, Discussion Paper No. 579.

Levine, R. 1997. "Financial Development and Economic Growth: Views and Agenda." Journal of Economic Literature, 35:2, pp. 688-729.

Levine, R., N. V. Loayza, and T. Beck. 2000. "Financial intermediation and growth: causality and causes." Journal of Monetary Economics, 46:1, pp. $31-77$. 
Li, Q. and R. Reuveny. 2003. "Economic Globalization and Democracy: An Empirical Analysis." Penn State and Indiana University, mimeo.

Li, X. and X. Liu. 2005. "Foreign Direct Investment and Economic Growth: An Increasingly Endogenous Relationship." World Development, 33:3, pp. 393-407.

Lim, E.-G. 2001. "Determinants of, and the Relation Between, Foreign Direct Investment and Growth: A Summary of the Recent Literature." IMF Working Paper, WP/01/175.

Limam, Y. R. and S. M. Miller. 2004. "Explaining Economic Growth: Factor Accumulation, Total Factor Productivity Growth and Production Efficiency Improvement." University of Connecticut Department of Economics Working Paper, No. 2004-20.

Lipset, S. M. 1959. "Some Social Requisites of Democracy: Economic Development and Political Legitimacy." The American Political Science Review, 53:1, pp. 69-105.

Liu, G. S., X. Liu, and Y. Wei. 2001. "Openness and Efficiency of India and China Relative to the World Economy: A Comparative Study." Economics and Finance Section, School of Social Sciences, Brunel University, Public Policy Discussion Papers, No. 02-18.

Liu, L.-g., K. Chow, and U. Li. 2006. "Determinants of Foreign Direct Investment in East Asia: Did China Crowd Out FDI from Her Developing East Asian Neighbours?" Research Memorandum Hong Kong Monetary Authority, $17 / 2006$.

Loayza, N. V., A. M. Oviedo, and L. Servén. 2004. "Regulation and Macroeconomic Performance." World Bank Working Paper, No. 3469.

Loko, B. and M. A. Diouf. 2009. "Revisiting the Determinants of Productivity Growth: What's New?" IMF Working Paper, WP/09/225.

Lopez-Cordova, E. and C. Meissner. 2005. "The Globalization of Trade and Democracy, 1870-2000." NBER Working Paper, No. 11117.

Lucas, R. E., Jr. 1988. "On the Mechanics of Economic Development." Journal of Monetary Economics, 22:1, pp. 3-42.

Lundstrom, S. 2003. "On institutions, economic growth and the environment." Goteborg University, Department of Economics, Economic Studies:No. 123.

Maddison, A. 2001. The World Economy: A Millennial Perspective. Paris: OECD.

Mahadevan, R. 2002. "A Frontier Approach to Measuring Total Factor Productivity Growth in Singapore's Services Sector." Journal of Economic 
Studies, 29:1, pp. 48-58.

Mahoney, P. 2001. "The Common Law and Economic Growth: Hayek Might Be Right." Journal of Legal Studies, 30:2, pp. 503-25.

Mankiw, N. G., D. Romer, and D. N. Weil. 1992. "A Contribution to the Empirics of Economic Growth." The Quarterly Journal of Economics, 107:2, pp. 407-37.

Marshall, M. G. and K. Jaggers. 2009. Polity IV Project - Political Regime Characteristics and Transitions, 1800-2007: Centre for Systemic Peace.

Masters, W. A. and M. S. McMillan. 2001. "Climate and Scale in Economic Growth." Journal of Economic Growth, 6:3, pp. 167-86.

Mauro, P. 1995. "Corruption and Growth." Quarterly Journal of Economics, 110:3, pp. 681-712.

Mayer, J. 2001. "Technology Diffusion, Human Capital and Economic Growth in Developing Countries." United Nations Conference on Trade and Development UNCTAD Discussion Papers Series, No. 154.

McArthur, J. W. and J. D. Sachs. 2001. "Institutions and Geography: Comment on Acemoglu, Johnson and Robinson (2000)." NBER Working Paper, No. 8114.

McEvedy, C. and R. Jones. 1978. Atlas of World Population History. New York: Facts on File.

Meeusen, W. and J. v. d. Broeck. 1977. "Efficiency Estimation from Cobb-Douglas Production Functions with Composed Error." International Economic Review, 18:2, pp. 435-44.

Miller, S. M. and M. P. Upadhyay. 2000. "The Effects of Openness, Trade Orientation, and Human Capital on Total Factor Productivity." Journal of Development Economics, 63:2, pp. 399-423.

Milner, H. V. and K. Kubota. 2005. "Why the Move to Free Trade? Democracy and Trade Policy in the Developing Countries." International Organization, 59:01, pp. 107-43.

Mises, L. v. 1947. Planned Chaos. Irving-on-Hudson, New York: Foundation for Economic Education.

Mises, L. v. 1951. Socialism. New Haven, C. T.: Yale University Press.

Mishkin, F. S. 2006. The Next Great Globalization: How Disadvantaged Nations Can Harness Their Financial Systems to Get Rich. Princeton, N.J.: Princeton University Press. 
Mishra, A. and K. Daly. 2007. "Effect of Quality of Institutions on Outward Foreign Direct Investment." Journal of International Trade and Economic Development, 16:2, pp. 231-44.

Moroney, J. R. and C. A. K. Lovell. 1997. "The Relative Efficiencies of Market and Planned Economies." Southern Economic Journal, 63:4, pp. 1084-93.

Nelson, M. A. and R. D. Singh. 1998. "Democracy, Economic Freedom, Fiscal Policy, and Growth in LDCs: A Fresh Look." Economic Development \& Cultural Change, 46:4, pp. 677-96.

Nickell, S. J. 1981. "Biases in Dynamic Models with Fixed Effects." Econometrica, 49:6, pp. 1417-26.

North, D. C. 1981. Structure and Change in Economic History. New York: W. W. Norton \& Co.

North, D. C. 1990. Institutions, Institutional Change and Economic Performance. New York: Cambridge University Press.

North, D. C. and R. P. Thomas. 1973. The Rise of the Western World -- A New Economic History. Cambridge: Cambridge University Press.

Nourzad, F. 2008. "Openness and the Efficiency of FDI: A Panel Stochastic Production Frontier Study." International Advances in Economic Research, $14: 1$, pp. 25-35.

Nunn, N. 2009. "The Importance of History for Economic Development." NBER Working Paper, No. 14899.

Olson, M. J. 1993. "The Political Economy of Comparative Growth Rates," in The Political Economy of Growth. D. C. Mueller ed. New Haven, Conn: Yale University Press.

Olson, M. J. 1996. "Distinguished Lecture on Economics in Government: Big Bills Left on the Sidewalk: Why Some Nations are Rich, and Others Poor." The Journal of Economic Perspectives, 10:2, pp. 3-24.

Paldam, M., A. Wurtz, and T. Gorgens. 2003. "The big bend. Economic freedom and growth." University of Aarhus, mimeo.

Pande, R. and C. Udry. 2006. "Institutions and Development: A View from Below," in Advance in Economics and Econometrics - Theory and Applications, Ninth World Congress, Vol II. Richard Blundell, Whiteney K. Newey and Torsten Persson eds.

Papaioannou, E. and G. Siourounis. 2008. "Economic and Social Factors Driving the Third Wave of Democratization." Journal of Comparative Economics, 36:3, pp. 365-87. 
Parente, S. L. and E. C. Prescott. 2005. "A Unified Theory of the Evolution of International Income Levels," in Handbook of Economic Growth. Philippe Aghion and Steven Durlauf eds: Elsevier, pp. 1372-416.

Paul, C. J. M., W. E. Johnson, and G. A. G. Frengley. 2000. "Efficiency in New Zealand Sheep and Beef Farming: The Impacts of Regulatory Reform." The Review of Economics and Statistics, 82:2, pp. 325-37.

Penalosa, C. G. and U. Teksoz. 2006. "How Do Institutions Lead Some Countries to Produce So Much More Output per Worker than Others?," in Institutions, Development, and Economic Growth. Theo Eicher and Cecilia Garcia Penalosa eds. Cambridge, M.A.: MIT Press, pp. 65-80.

Persson, T. 2005. "Forms of Democracy, Policy and Economic Development." NBER Working Paper, No. 11171.

Petrin, A. and J. Sivadasan. 2006. "Job Security Does Affect Economic Efficiency : Theory, A New Statistic, and Evidence from Chile." NBER Working Paper, No. 12757.

Pitlik, H. and S. Wirth. 2003. "Do Crises Promote the Extent of Economic Liberalization?: an Empirical Test." European Journal of Political Economy, 19:3, pp. 565-81.

Presbitero, A. F. 2006. "Institutions and Geography as Sources of Economic Development." Journal of International Development, 18:3, pp. 351-78.

Prichett, L. 1997. "Divergence, Big-Time." Journal of Economic Perspectives, 11:3, pp. 3-17.

Przeworski, A. and F. Limongi. 1993. "Political Regimes and Economic Growth." Journal of Economic Perspectives, 7:3, pp. 51-69.

Quinn, D. P. 2000. "Democracy and International Financial Liberalization." Georgetown University, mimeo.

Rajan, R. G. and L. Zingales. 1998. "Financial Dependence and Growth." American Economic Review, 88:3, pp. 559-86.

Rajan, R. G. and L. Zingales. 2003. "The Great Reversals: the Politics of Financial Development in the 20th Century." Journal of Financial Economics, 69:1, pp. 5-50.

Ravallion, M. 2003. "On Measuring Aggregate 'Social Efficiency'." World Bank Policy Research Department Working Paper, No. 3166.

Rigobon, R. 2003. "Identification through Heteroskedasticity." Review of Economics and Statistics, 85:4 (09), pp. 777-92.

Rigobon, R. and D. Rodrik. 2004. "Rule of Law, Democracy, Openness, and 
Income: Estimating the Interrelationships." CEPR Discussion Papers, No. 4653.

Rodrik, D. 1999. "Democracies Pay Higher Wages." Quarterly Journal of Economics, 114:3, pp. 707-38.

Rodrik, D. 2000. "Institutions for High-Quality Growth: What They Are and How to Acquire Them." Studies in Comparative International Development, 35:3, pp. 3-31.

Rodrik, D. 2005. "Growth Strategies," in Handbook of Economic Growth. Philippe Aghion and Steven Durlauf eds. Amsterdam: Elsevier, pp. 967-1014.

Rodrik, D., A. Subramanian, and F. Trebbi. 2004. "Institutions Rule: The Primacy of Institutions over Geography and Integration in Economic Development." Journal of Economic Growth, 9:2, pp. 131-65.

Roll, R. and J. Talbott. 2002. "The End of Class Warfare: An Examination of Income Disparity." University of California at Los Angeles, Anderson Graduate School of Management Working Paper, No. 1041.

Romer, P. M. 1990. "Endogenous Technological Change." Journal of Political Economy, 98:5, pp. S71-102 Part 2.

Roodman, D. M. 2009. "How to do xtabond2: An introduction to difference and system GMM in Stata." Stata Journal, 9:1 (Mar), pp. 86-136.

Rose, A. K. 2004. "Do We Really Know That the WTO Increases Trade?" The American Economic Review, 94:1, pp. 98-114.

Rose, A. K. 2006. "Size Really Doesn't Matter: In Search of a National Scale Effect." Journal of the Japanese and International Economies, 20:4, pp. 482-507.

Rosenberg, N. and L. Birdzell. 1986. How the West Grew Rich: The Economic Transformation of the Industrial World. New York: Basic Books.

Rudra, N. 2005. "Globalization and the Strengthening of Democracy in the Developing World." American Journal of Political Science, 49:4, pp. 704-30.

Sachs, J. D. 2000. "Tropical Underdevelopment." Centre for International Development at Harvard University, CID Working Paper.

Sachs, J. D. 2003. "Institutions Don't Rule: Direct Effects of Geography on Per Capita Income." NBER Working Paper, No. 9490.

Sachs, J. D. and A. Warner. 1995. "Economic-Reform and the Process of Global Integration." Brookings Papers on Economic Activity, 26:1995-1, pp. $1-118$ 
Sachs, J. D. and A. Warner. 2001. "The Curse of Natural Resources." European Economic Review, 45:4-6, pp. 827-38.

Sargan, J. 1958. "The Estimation of Economic Relationships using Instrumental Variables." Econometrica, 26:3, pp. 393-415.

Scarpetta, S., P. Hemmings, T. Tressel, and J. Woo. 2002. "The Role of Policy and Institutions for Productivity and Firm Dynamics: Evidence from Micro and Industry Data." OECD Economics Department Working Paper, No. 329.

Schmidt, P. and R. C. Sickles. 1984. "Production Frontiers and Panel Data." Journal of Business and Economic Statistics, 2:4, pp. 367-74.

Schumpter, J. 1950. Capitalism, Socialism and Democracy. New York: Harper \& Row.

Scully, G. W. and D. J. Slottje. 1991. "Ranking Economic Liberty Across Countries." Public Choice, 69:2, pp. 121-52.

Singh, H. and K. W. Jun. 1995. "Some New Evidence on Determinants of Foreign Direct Investment in Developing Countries." World Bank Policy Research Working Paper, No. 1531.

Solow, R. M. 1956. "A Contribution to the Theory of Economic Growth." The Quarterly Journal of Economics, 70:1, pp. 65-94.

Stein, E. and C. Daude. 2002. "Institutions, integration and the location of FDI." New Horizons of Foreign Direct Investment, OECD Global Forum on International Investment:Paris: OECD.

Stevenson, R. E. 1980. "Likelihood Functions for Generalized Stochastic Frontier Estimation." Journal of Econometrics, 13:1, pp. 57-66.

Strum, J.-E. and J. d. Haan. 2001. "How Robust is the Relationship Between Economic Freedom and Economic Growth?" Applied Economics, 33:7, pp. 839-44.

Subramanian, A. and S.-J. Wei. 2007. "The WTO promotes trade, strongly but unevenly." Journal of International Economics, 72:1, pp. 151-75.

Sullivan, M. J. 1991. Measuring Global Values. New York: Greenwood.

Sunde, U., M. Cervellati, and P. Fortunato. 2006. "Growth and Endogenous Political Institutions," in Institutions, Development, and Economic Growth. Theo S. Eicher and Cecilia Garcia-Penalosa eds. Cambridge, MA: The MIT Press, pp. 215-48.

Teorell, J., N. Charron, M. Samanni, S. Holmberg, and B. Rothstein. 2009. The Quality of Government Dataset Codebook. University of Gothenburg: The Quality of Government Institute. 
Torstensson, J. 1994. "Property Rights and Economic Growth: An Empirical Study." Kyklos, 47:2, pp. 231-47.

Tybout, J. R. 1992. "Linking Trade and Productivity: New Research Directions." World Bank Economic Review, 6, pp. 189-211.

Ulubasoglu, M. A. and C. Doucouliagos. 2004. "Institutions and Economic Growth: A Systems Approach." mimeo, School of Accounting, Economics and Finance, Deakin University, Melbourne.

UNDP. 2007. Governance Indicators: A Users' Guide. New York: UNDP.

Vandenbussche, J., P. Aghion, and C. Meghir. 2006. "Growth, Distance to Frontier and Composition of Human Capital." Journal of Economic Growth, 11:2, pp. 97-127.

Wacziarg, R. and K. H. Welch. 2003. "Trade Liberalization and Growth: New Evidence." NBER Working Paper, No. 10152.

Wei, S.-J. 2000a. "How Taxing is Corruption on International Investors?" Review of Economics and Statistics, 82:1, pp. 1-11.

Wei, S.-J. 2000b. "Local Corruption and Global Capital Flows." Brookings Papers on Economic Activity, 0:2, pp. 303-46.

Wheeler, D. and A. Mody. 1992. "International Investment Location Decisions: The Case of U.S. Firms." Journal of International Economics, 33:1-2, pp. $57-76$.

Windmeijer, F. 2005. "A Finite Sample Correction for the Variance of Linear Efficient Two-step GMM Estimators." Journal of Econometrics, 126:1, pp. $25-51$.

Wooldridge, J. M. 2000. Introductory Econometrics: A Modern Approach. New York: South-Western College Publishing.

Wooldridge, J. M. 2002. Econometric Analysis of Cross Section and Panel Data. Cambridge, Massachusetts: The MIT Press.

Wu, W. and O. A. Davis. 1999. "The Two Freedoms, Economic Growth, and Development: An Empirical Study." Public Choice, 100:1-2, pp. 39-64. 